Florida International University

FIU Digital Commons

3-26-2019

\title{
Tuning the Coordination Properties of Pyrazoles towards Specific Applications via Judicial Choice of Peripheral Substitution
}

Shambhu Kandel

skand007@fiu.edu

Follow this and additional works at: https://digitalcommons.fiu.edu/etd

Part of the Inorganic Chemistry Commons

\section{Recommended Citation}

Kandel, Shambhu, "Tuning the Coordination Properties of Pyrazoles towards Specific Applications via Judicial Choice of Peripheral Substitution" (2019). FIU Electronic Theses and Dissertations. 4034.

https://digitalcommons.fiu.edu/etd/4034

This work is brought to you for free and open access by the University Graduate School at FIU Digital Commons. It has been accepted for inclusion in FIU Electronic Theses and Dissertations by an authorized administrator of FIU Digital Commons. For more information, please contact dcc@fiu.edu. 


\title{
FLORIDA INTERNATIONAL UNIVERSITY
}

Miami, Florida

\section{TUNING THE COORDINATION PROPERTIES OF PYRAZOLES TOWARDS SPECIFIC APPLICATIONS VIA JUDICIAL CHOICE OF PERIPHERAL SUBSTITUTION}

\author{
A dissertation submitted in partial fulfillment of the \\ requirements for the degree of \\ DOCTOR OF PHILOSOPHY \\ in \\ CHEMISTRY \\ by \\ Shambhu Kandel
}

2019 
To: Dean Michael R. Heithaus

College of Arts, Sciences and Education

This dissertation, written by Shambhu Kandel, and entitled Tuning the Coordination Properties of Pyrazoles towards Specific Applications via Judicial Choice of Peripheral Substitution, having been approved in respect to style and intellectual content, is referred to you for judgment.

We have read this dissertation and recommend that it be approved.

Konstantinos Kavallieratos

Yi Xiao

Yuk-Ching Tse-Dinh

Prem P. Chapagain

Raphael G. Raptis, Major Professor

Date of Defense: March 26, 2019

The dissertation of Shambhu Kandel is approved.

Dean Michael R. Heithaus College of Arts, Sciences and Education

Andrés G. Gil

Vice President for Research and Economic Development and Dean of the University Graduate School

Florida International University, 2019 
(C) Copyright 2019 by Shambhu Kandel

All rights reserved. 


\section{DEDICATION}

My special dedication goes to my late father; Bhanubhakta Kandel, who, despite of many hardships, encouraged me to keep my study high all the time. I also dedicate to my mother, Shushila Kandel, my brother, Bhishma Kandel, my wife Sarita Ghimire Kandel and all the family. I would not be as ambitious or successful without your encouragement. I love you all. 


\section{ACKNOWLEDGMENTS}

I want to express my sincere gratitude to my advisor, Dr. Raphael G. Raptis for his guidance and support. You gave me your hands when I needed to be pulled and always encouraged and motivated me to be a smarter and better person. Not only as a mentor but also as a human being you are an epitome to me. I want to thank my committee members: Dr. Konstantinos Kavallieratos, Dr. Yi Xiao, Dr. Yuk-Ching Tse-Dinh and Dr. Prem P. Chapagain for serving on my committee and providing useful feedback to tackle all of my graduate school hurdles. I would also like to thank graduate coordinator Dr. Watson Lees and office specialist Maggie Autie for their continuous support on reminding the deadlines and making the procedures easier.

I want to thank all of the past and present lab mates, there have been many of you. Dr. Indranil Chakraborty for pushing me into the work and helping in writing manuscripts. Dr. Logesh Mathivathanan for helping me on the X-ray crystallography. Dr. Satish Veerasamy for exploring sensing application of my tripodal ligands. Dr. Alan Rodriguez for being so nice, kind and readily available whenever needed and help me in the research and course work. Thanks to all the past and present graduate students, postdocs and sabbaticals: Dr. Jessica Lopez, Dr. Kaige Shi, Konstantinos Lazarau, David Kreiger, Eduardo Mollinedo, Kelly Rue and Dr. Ievgan Govor. Keep on trucking. Thanks to REU student Kai Chambers, undergraduates Juliana, Pierre and Alejandro for setting the bar too high for a smart and sassy youth. Thank you Govinda Lamichhane and Dr. Janak Sapkota; my nephew, you are my all, a teacher, a friend a motivator, and everything. Thank you Sudip Subedi for helping me the formatting and writing issues.

I want to thank the Department of Chemistry for providing me funding through teaching assistantships and the guidance of Dr. Sandra Stojanovic. I would also like to thank the Graduate and Professional Student Committee and the College of Arts Sciences and Education for awarding me the travel awards for the conference presentation. 
Lastly, I would like to express my deepest gratitude to my parents, my mother Shushila Kandel, my sisters Bhuma Sharma and Kamala Kharal, my brother Bhishma Kandel; you have got the position of my father after he passed away. I thank you, my wife, Sarita Ghimire Kandel for always being supportive and unconditional love, and most importantly, understanding during my time as a Ph.D. student. You took care of two kids without a single stone unturned. Thank you to the rest of my family (there are many of you) for providing me with a wonderful family environment to grow as a person. 


\section{ABSTRACT OF THE DISSERTATION \\ TUNING THE COORDINATION PROPERTIES OF PYRAZOLES TOWARDS SPECIFIC APPLICATIONS VIA JUDICIAL CHOICE OF PERIPHERAL SUBSTITUTION \\ by}

Shambhu Kandel

Florida International University, 2019

Miami, Florida

Professor Raphael G. Raptis, Major Professor

The tunability of pyrazoles make them probably the most versatile ligands, and this is one of the right reasons for its use. Pyrazolyl ligands have intrinsic antibacterial property. Synthesis of pyrazolyl complexes with silver can be of great interest in biological applications. The urgent need to find an alternative of currently used antibiotics has been recognized as a big challenge of the $21^{\text {st }}$ century. Many ideas have been proposed, but the re-emergence of silver medicine could be the most promising alternative to overcome the limitations of these antibiotics. In spite of the popularity of Sonogashira coupling reactions, there is still a room to improve the catalytic system to overcome the existing limitations. N-N donor ligands with palladium metal have shown better catalysis over the conventional ones. This work presents the synthesis of pyrazolyl ligands and their complexes with silver, palladium and mercury and exploring their applications accordingly. The work has been divided into four distinct regions of applications as follows.

Eight new silver pyrazolyl complexes with triphenylphosphine or 1,3,5-triaza-7phosphaadamantane as a co-ligand have been synthesized, characterized with single crystal Xray, spectroscopic techniques and elemental analyses and their antibacterial property against Pseudomonas aeruginosa was investigated with a soft tissue and skin infection model. Water soluble complex was found to be more efficient than silver nitrate. This compound releases $\mathrm{Ag}^{+}$ 
slower than $\mathrm{AgNO}_{3}$ and inhibits the physiological problems associated with the rapid release of $\mathrm{Ag}^{+}$. Five new tripodal (1R) pyrazolyl ligands were synthesized and their application in selective sensing of picric acid (PA) were successfully investigated. They are promising in sensing the picric acid in all physical states. Seven new mercury pyrazolyl complexes with broad versatility in geometry and nuclearity were synthesized. Two of them were used to extract mercury $\left(\mathrm{Hg}^{2+}\right)$ from the mixture of $\mathrm{Ln}^{3+}$ in aqueous solution using chloroform as extractant and found promising. Nine palladium pyrazolyl complexes including three water soluble ones were synthesized. Two of them were used to catalyze the Sonogashira cross coupling reactions. The catalysts worked well in copper free, open air and mild reaction conditions. Reactivity of Pdhexamer was also studied. 
CHAPTER 1 .1

1.1. Introduction.

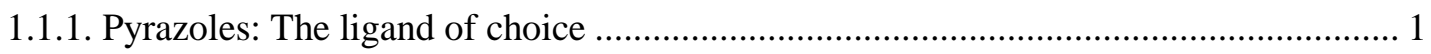

1.1.2. A brief review of silver pyrazolate complexes ......................................................... 3

1.1.3. Sensing of nitro-aromatics using AIEE property ...................................................... 5

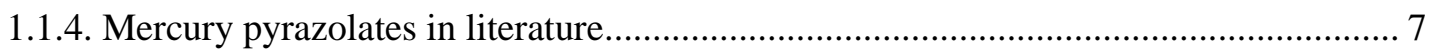

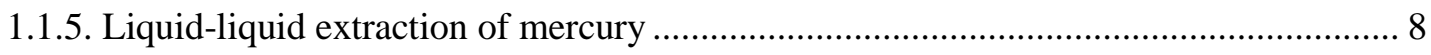

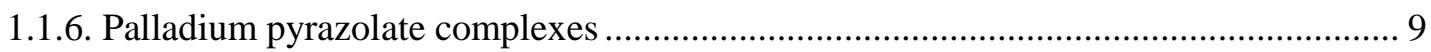

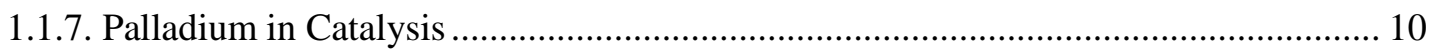

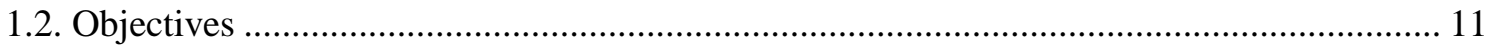

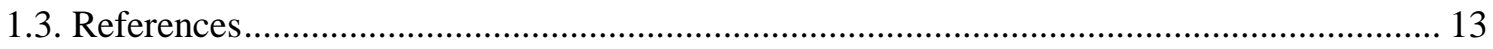

CHAPTER 2 .23 Synthesis and Characterization of family of dinuclear silver(I)pyrazolates for the assessment of

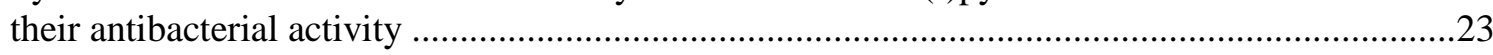



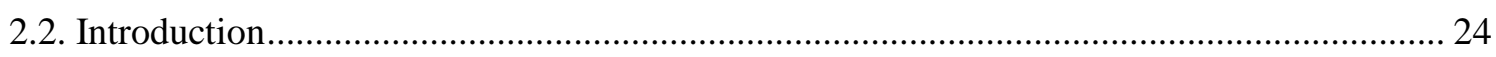

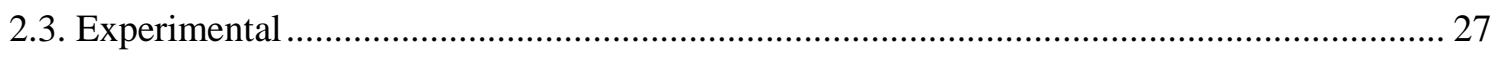

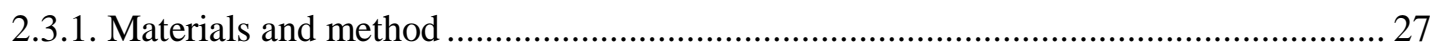

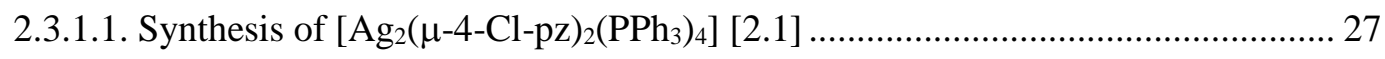

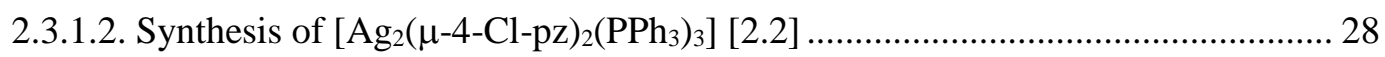

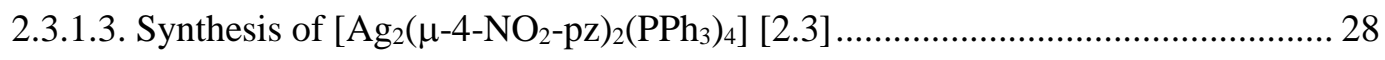

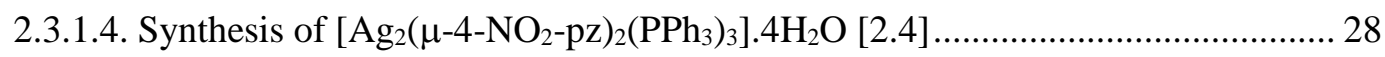

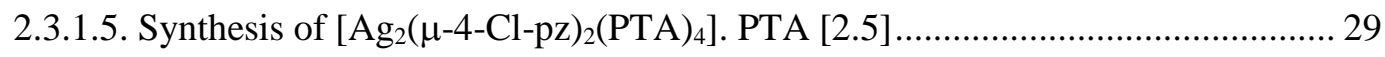

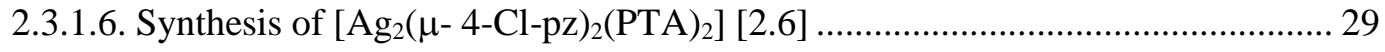

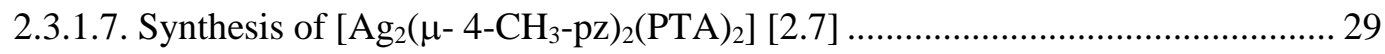

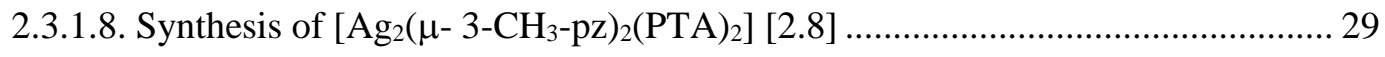



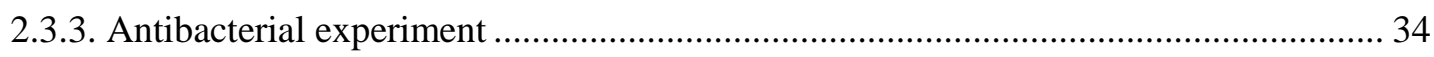

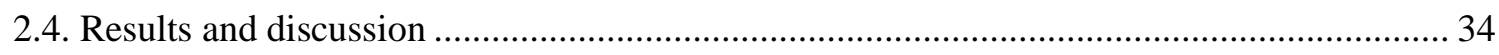

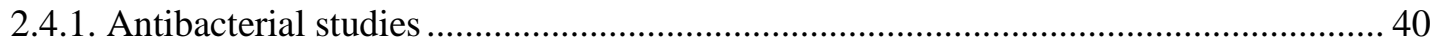




CHAPTER 3

Aggregation Induced Emission Enhancement (AIEE) of Tripodal Pyrazole Derivatives for Sensing of Nitroaromatics; Vapor Phase Detection of Picric Acid ...........................................49

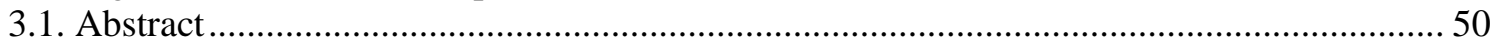

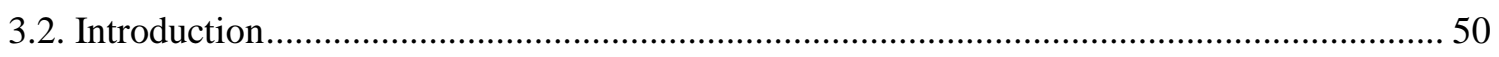

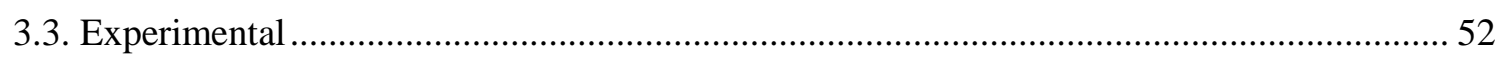

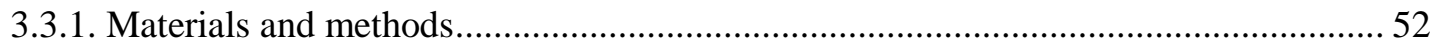

3.3.1.1. Synthesis of Tris-(4-Ph-pz); $\left(\mathrm{C}_{42} \mathrm{H}_{42} \mathrm{~N}_{6}\right)$ [3.1] ............................................. 54

3.3.1.2. Synthesis of Tris-4-(3-Cl-Ph-pz); $\left(\mathrm{C}_{42} \mathrm{H}_{39} \mathrm{~N}_{6} \mathrm{Cl}_{3}\right)[3.3]$................................... 54

3.3.1.3. Synthesis of Tris-4-(4- $\mathrm{NO}_{2}$-phenyl-pz); $\left(\mathrm{C}_{42} \mathrm{H}_{39} \mathrm{~N}_{9} \mathrm{O}_{6}\right)[3.4]$........................... 55

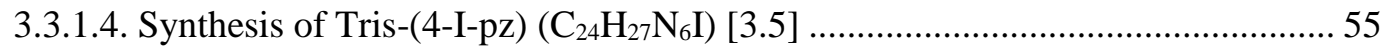

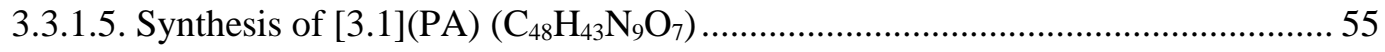

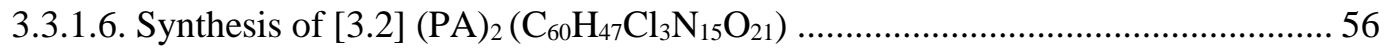

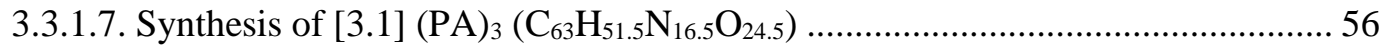

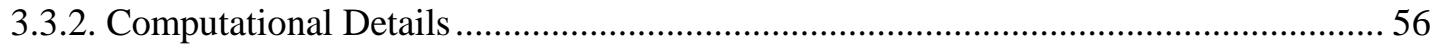

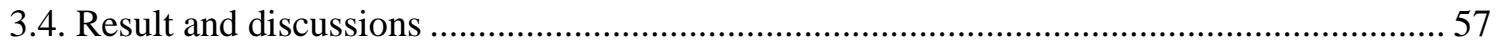

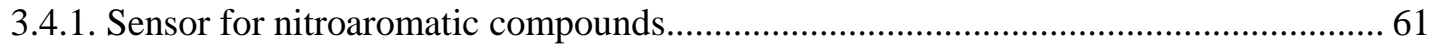

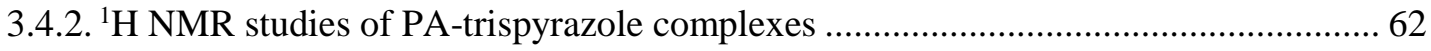

3.4.3. Single crystal X-ray diffraction studies of PA-trispyrazole complexes ...................... 63

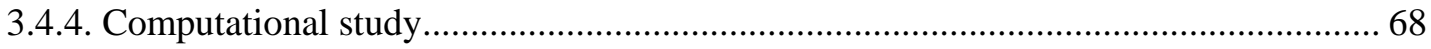

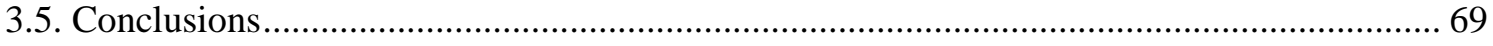

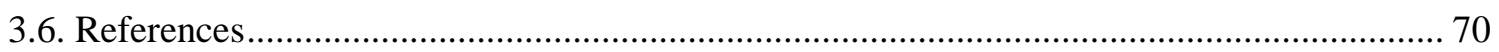

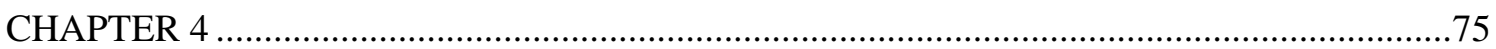

Chemistry of mercury(II)-pyrazolyl complexes; characterization and extraction studies .............75

4.1. Abstract $\quad 75$

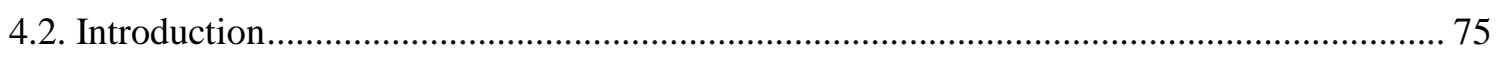

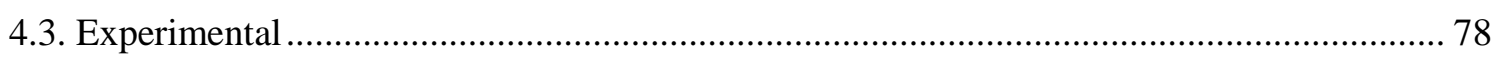

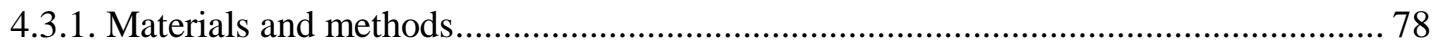

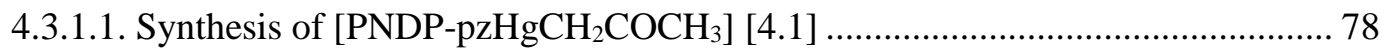

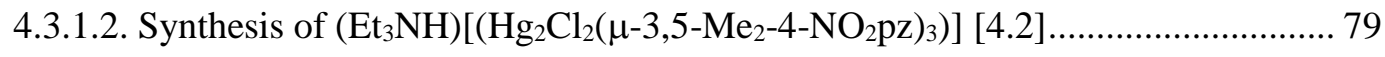

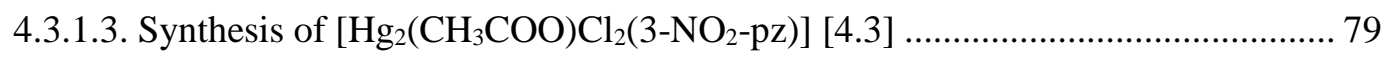

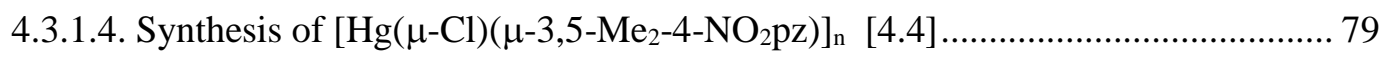

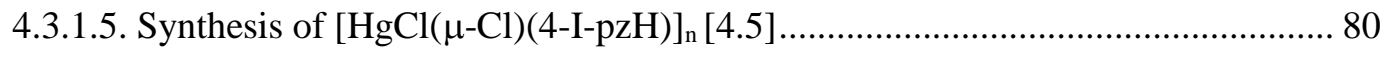




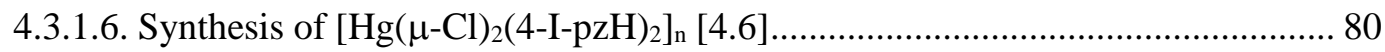

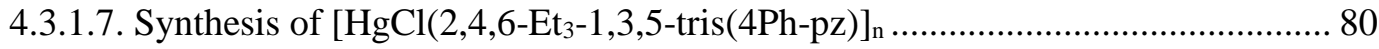

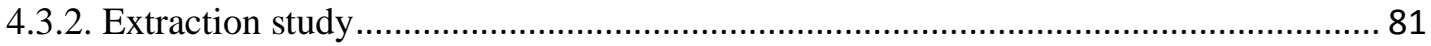

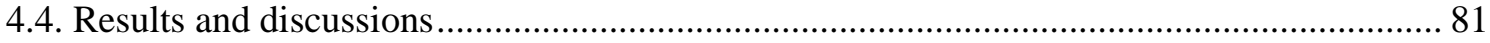

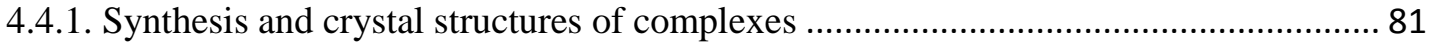

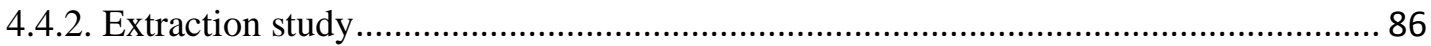

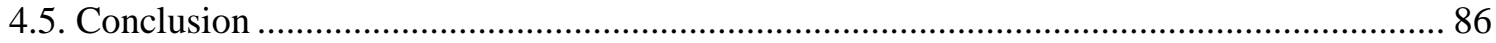

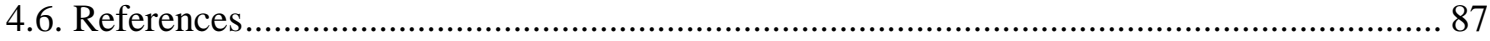

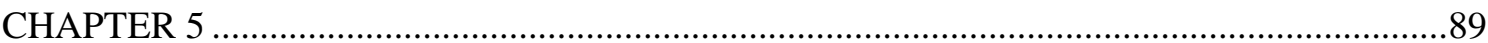

Synthesis and characterization of palladium pyrazolates and their use as a catalyst..................89

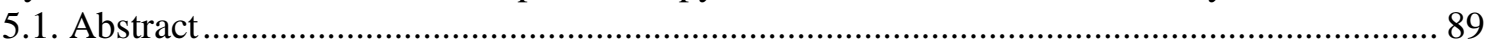

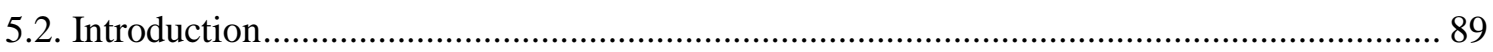

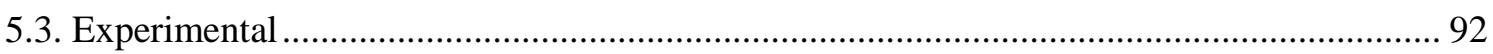

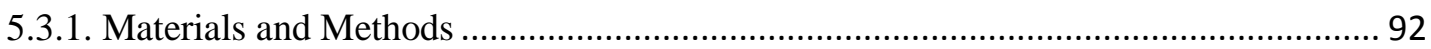

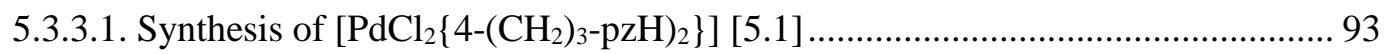

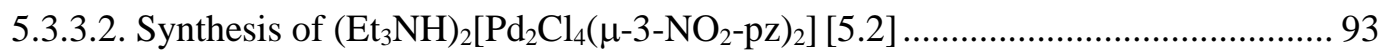

5.3.3.3. Synthesis of $\left(\mathrm{Et}_{3} \mathrm{NH}\right)_{2}\left[\mathrm{Pd}_{2} \mathrm{Cl}_{4}\left(\mu-3,5-\left(\mathrm{CH}_{3}\right)_{2}-4-\mathrm{NO}_{2}-\mathrm{pz}\right)_{2}\right][5.3] \ldots \ldots \ldots \ldots \ldots \ldots \ldots \ldots . . . . . . . . . . . . .93$

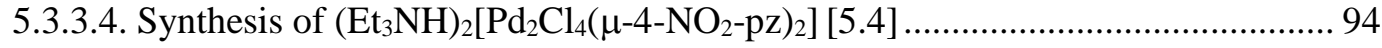

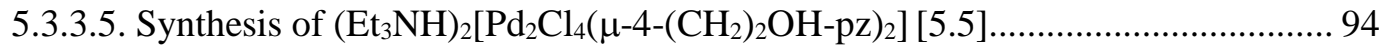

5.3.3.6. Synthesis of $\left(\mathrm{Et}_{3} \mathrm{NH}\right)_{2}\left[\mathrm{Pd}_{3} \mathrm{Cl}_{4}\left(\mu-3,5-\left(\mathrm{CH}_{3}\right)_{2}-4-\mathrm{NO}_{2}-\mathrm{pz}\right)_{4}\right]$ [5.6] ........................ 95

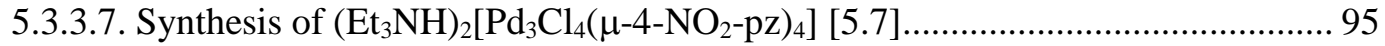



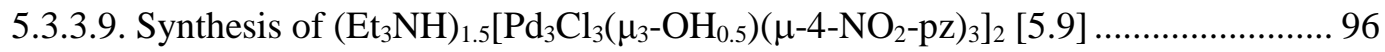

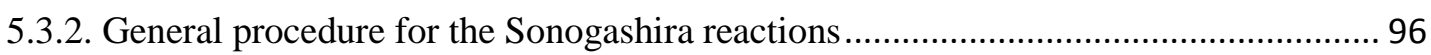

5.3.2.1. Synthesis of diphenylacetylene (1, 1'(1,2-ethynediyl)bis-benzene) (4a)............ 97

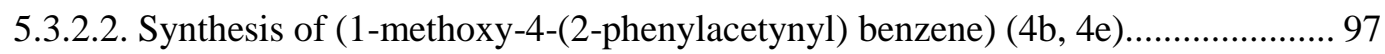

5.3.2.3. Synthesis of (1,3-dimethyl-5-(2-phenylethynylbenzene)) (4c) ......................... 97

5.3.2.4. Synthesis of 1-methyl-4-(2-phenylethynyl)-benzene (4d) ................................ 97

5.3.2.5. Synthesis of $(1,1$ '(1,2-ethynediyl)bis(4-methoxybenzene) (4f) ......................... 97

5.3.2.6. Synthesis of 1-methoxy-4-[2-(4methylphenyl)ethynyl]-benzene (4g) ............... 98

5.3.2.7. Synthesis of 1,3-dimethyl-5-[2-(4-methylphenyl)ethynyl]- Benzene (4h) ......... 98

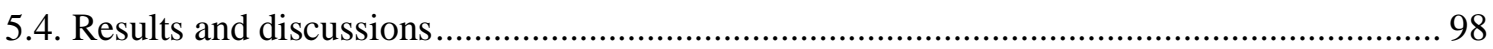

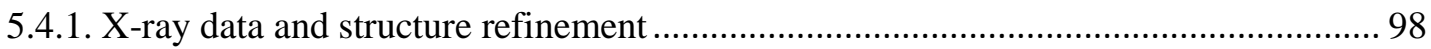




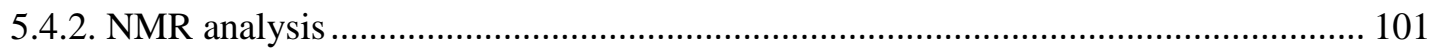

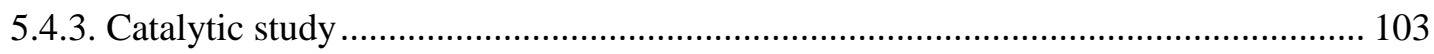

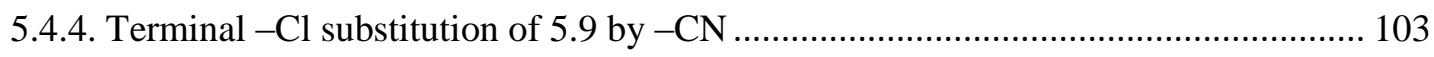

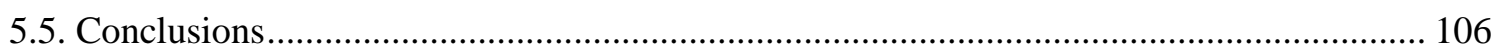

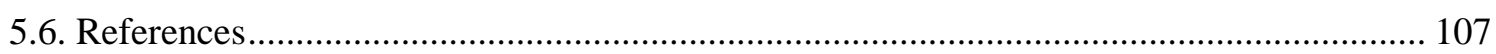

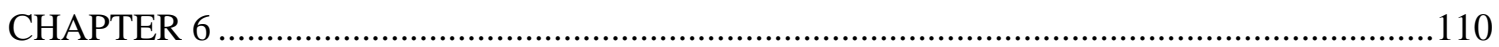

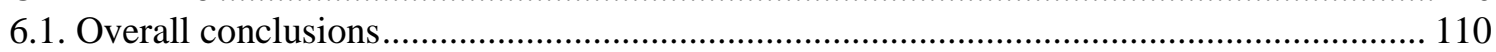

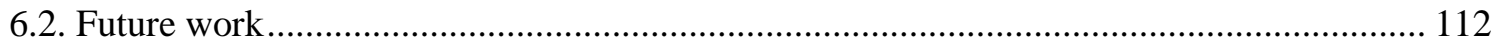

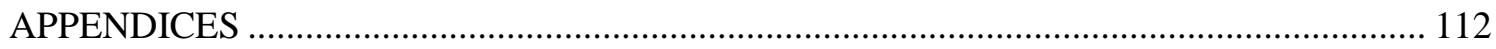

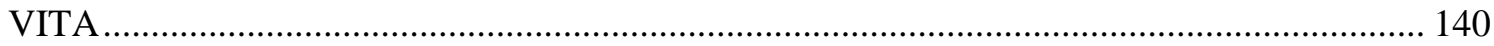


Table 1.1. Structural comparison between Pd-acetate and Pd-pyrazolate trimers

Table 2.1. Crystal data and structure refinement parameters for complexes $2.1-2.5 \ldots \ldots \ldots \ldots \ldots \ldots . . . . . .32$

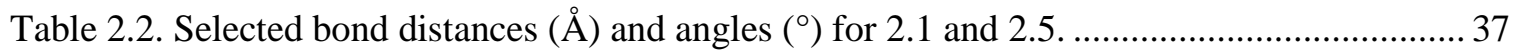

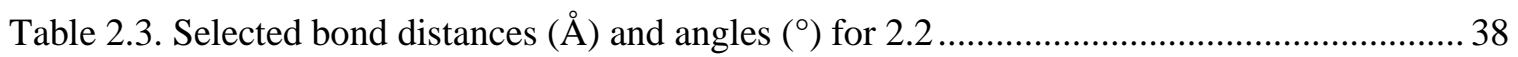

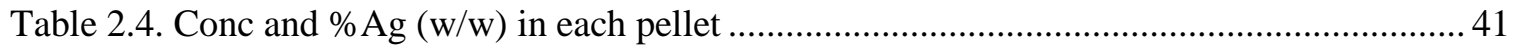

Table 5.1. Crystal data and structure refinement parameters for the complexes ......................... 99

Table 5.2. Crystal data and structure refinement parameters for [5.9] .................................... 100

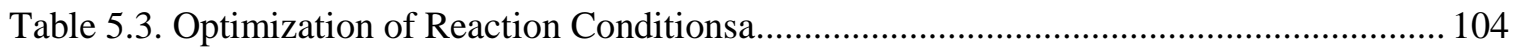

Table 5.4. Sonogashira coupling reactions carried out for this work........................................ 105

Table A2.1. Crystal data and structure refinement parameters for complexes 2.6-2.8 ............... 132

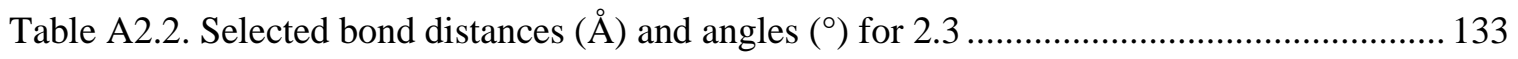



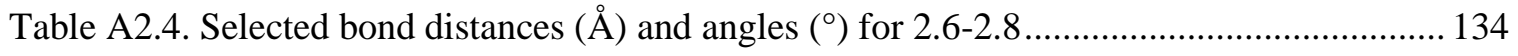

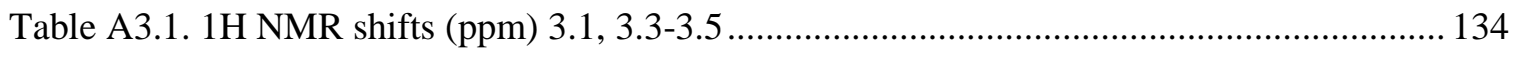

Table A3.2. 1H NMR spectra of ligands (3.1-3.3) and ligands + picric acid in CDCl3............. 135

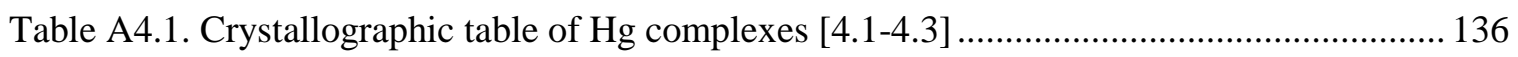

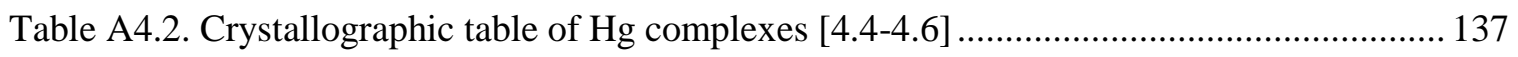

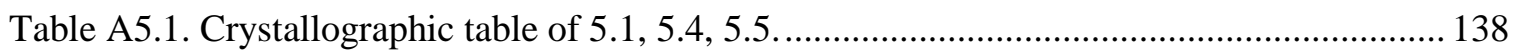

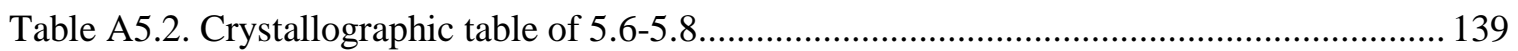




\section{LIST OF FIGURES}

FIGURE

PAGE

Figure 2.1. Comparative ${ }^{31} \mathrm{P}$ NMR spectra for complexes 2.1-2.5. (1 corresponds to 2.1 and so on)

Figure 2.2. Perspective view of the molecular structure of complexes 2.1 (left) and 2.2 (right). The thermal ellipsoids are shown at $35 \%$ probability level (H atoms are omitted and the labeling scheme are shown only for the hetero atom for the sake of clarity). Color code: $\mathrm{C}$, black; $\mathrm{N}$, blue; $\mathrm{Cl}$, green; $\mathrm{P}$, pink and $\mathrm{Ag}$, yellow.

Figure 2.3. Perspective view of the molecular structure of complexes 2.5 (left) and 2.6 (right). The thermal ellipsoids are shown at $35 \%$ probability level (H atoms are omitted and the labeling scheme are shown only for the hetero atom for the sake of clarity). Color code: $\mathrm{C}$, black; $\mathrm{N}$, blue; $\mathrm{Cl}$, green; $\mathrm{P}$, pink and $\mathrm{Ag}$, yellow.

Figure 2.4. P. aeruginosa lawns after $18 \mathrm{~h}$ incubation with pellets of $2 \%(\mathrm{w} / \mathrm{w})$ of a) complex 2.5, b) $\mathrm{AgNO}_{3}$, c) PTA, d) 4-Cl-pzH, e) complex 2.1, f) complex 2.2, g) $\mathrm{PPh}_{3}$, and h) blank plate.

Figure 3.1. Molecular structures of compounds $3.1-3.5$ (1 to 5 respectively). Color code:

black, C; blue, N; red, O; green, Cl; purple, I.................................................................. 58

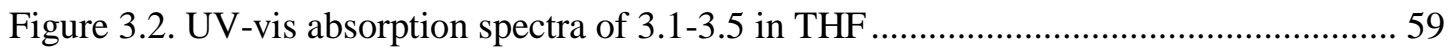

Figure 3.3. (a) UV - visible absorption spectral changes of 3.3 in THF with the addition of water (0 to $90 \%$ ). (b) SEM image of 3.3 in $\mathrm{THF} / \mathrm{H}_{2} \mathrm{O}$ (30:70) mixture.

Figure 3.4. Fluorescence spectral changes of $3.1 \& 3.3(15 \mu \mathrm{M})$ with the addition of water from 0 to $90 \%$ into THF.

Figure 3.5. Emission spectra of $3.1 \& 3.2(15 \mu \mathrm{M})$ in $\mathrm{THF} / \mathrm{H}_{2} \mathrm{O}(20: 80)$ upon addition of PA from 0 to $30 \mu \mathrm{M}$.

Figure 3.6. (a) Stern-Volmer plot for the complex 3.2 with PA (b) SV plot obtained at lower concentration of PA.

Figure 3.7. Partial ${ }^{1} \mathrm{H}-\mathrm{NMR}$ spectra of 3.1 and 3.1-PA. (1 in the figure corresponds to 3.1) 63

Figure 3.8. Crystal structures of [3.1](PA) (top) and [3.1](PA) 3.5. H-atoms omitted for clarity

Figure 3.9. Crystal packing diagram of $3.3(\mathrm{PA})_{2}$ viewed parallel to a-axis. H-atoms are omitted for clarity

Figure 3.10. Fluorescence quenching efficiency of complexes 3.1 and 3.2 with various nitro aromatic compounds. 
Figure 3.11. Change in emission spectra of $3.1 \& 3.2\left(1 \times 10^{-4} \mathrm{M}\right)$ on exposing to the vapors of PA with different time intervals. $(\Delta t=2 \mathrm{mins})\left(\lambda_{\mathrm{ex}}=255 \mathrm{~nm}\right)$.

Figure 3.12. Comparison plot of fluorescence quenching performance for compounds 3.1 and 3.2 with PA vapors upon different exposure of time (0 to $30 \mathrm{~min}$ ).

Figure 3.13. Photographs of compound 3.2 impregnated test strips under various concentrations of PA under illumination of $365 \mathrm{~nm}$ UV lamp blank, $1 \times 10^{-3} \mathrm{M}, 1 \times 10^{-4} \mathrm{M}$, $1 \times 10^{-6} \mathrm{M}$ and, $1 \times 10^{-9} \mathrm{M}$ respectively (left to right)

Figure 3.14. Pictures of compound 3.2 impregnated test strips under diff erent experimental conditions under illumination of $365 \mathrm{~nm}$ UV lamp (i) PA under daylight. (ii) PA under UV light. (iii) After removal of the PA (iv) and (v) Thumb impressions before and after rubbing with PA.

Figure 3.15. Occupied and vacant MOs involved in the bright transition in the complex of trispyrazole with one picric acid molecule.

Figure 4.1. The molecular structure of 4.1 (top), long-range Hg... O interaction forming supramolecular structure (bottom). (H-atoms are omitted for clarity). (Color code: Yellow, Hg; black, C; blue, N; red, O.)

Figure 4.2. The molecular structure of 4.2, showing tetrahedral geometry around $\mathrm{Hg}$ center. (H-atoms are omitted for clarity). Color code: (Yellow, Hg; black, C; blue, N; red, O;

green, Cl.)

Figure 4.3. The molecular structure of 4.3 (H-atoms are omitted for clarity.....

Figure 4.4. The molecular structure of 4.4 (right) and monomeric unit (left). (H-atoms are omitted for clarity). (Yellow, $\mathrm{Hg}$; black, C; blue, N; red, O; green, $\mathrm{Cl}$.).

Figure 4.5. The molecular structure of 4.5 showing tetrahedral geometry around $\mathrm{Hg}$-center. (H-atoms [other than pz (N-H)] are omitted for clarity). (Yellow, Hg; black, C; blue, N; red, O; green, $\mathrm{Cl}$; violet, I.)

Figure 4.6. The molecular structure of 4.6 showing octahedral geometry around $\mathrm{Hg}$-center. (H-atoms [other than pz (N-H)] are omitted for clarity). (Yellow, Hg; black, C; blue, N; red, O; green, $\mathrm{Cl}$; violet, I.)

Figure 4.7. The molecular structure of 4.7 showing tetrahedral geometry around Hg-center. (H-atoms are omitted for clarity). (Yellow, Hg; black, C; blue, N; red, O; green, Cl.)

Figure 4.8. ${ }^{1} \mathrm{H}$ NMR of Monomeric (dinuclear) unit of 4.4. (in MeOD)

Figure 4.9. ${ }^{1} \mathrm{H}$ NMR of 4.4. (in DMSO- $\mathrm{d}_{6}$ )

Figure 5.1. Molecular structure of 5.2 (left) and 5.3 (right). Color code: C, black; N, blue; 
Figure 5.2. The molecular structure of 5.9 (single trimeric unit, left) and (whole hexamer, right). Color code: $\mathrm{C}$, black; $\mathrm{H}$, white; $\mathrm{N}$, blue; $\mathrm{Cl}$, green; $\mathrm{O}$, red; $\mathrm{Pd}$, cyan. (H-atoms are omitted for clarity, bridging $\mathrm{H}$ has been shown).

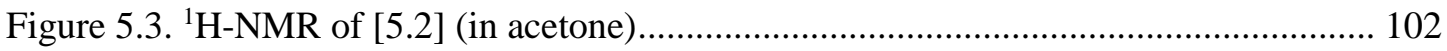

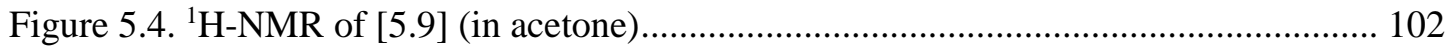

Figure 5.5. [5.9] before adding $\mathrm{AgCN}$ (left) and after adding $\mathrm{AgCN}$ (right)...................... 105

Figure 5.6. IR comparison of [5.9] and after $-\mathrm{Cl}$ substitution by $-\mathrm{CN}$................................. 106

Figure A2.1. Perspective view of the molecular structure of complexes 2.3 (left) and 2.4 (right). The thermal ellipsoids are shown at $35 \%$ probability level (H atoms are omitted, and the labeling scheme are shown only for the hetero atom for the sake of clarity). Color code: C, black; N, blue; O, red; P, pink and Ag, yellow.

Figure A2.2. Perspective view of the molecular structure of complexes 2.7 (left) and 2.8 (right). The thermal ellipsoids are shown at 35\% probability level ( $\mathrm{H}$ atoms are omitted and the labeling scheme are shown only for the hetero atom for the sake of clarity). Color code: $\mathrm{C}$, black; N, blue; $\mathrm{P}$, pink and Ag, yellow.

Figure A3.1. 1H NMR spectrum of compound 3.1, DMSO-d $\mathrm{d}_{6}$. (Top: Expanded aromatic region).

Figure A3.2. ${ }^{1} \mathrm{H}-\mathrm{NMR}$ spectrum of compound 3.3, $\mathrm{CDCl}_{3}$. (Top: Expanded aromatic region).

Figure A3.3. ${ }^{1} \mathrm{H}-\mathrm{NMR}$ spectrum of compound 3.4, $\mathrm{CDCl} 3$. (Top: Expanded aromatic region).

Figure A3.4. ${ }^{1} \mathrm{H}-\mathrm{NMR}$ spectrum of compound $3.5, \mathrm{CDCl}_{3}$

Figure A3.5. IR spectrum of compound 3.1.

Figure A3.6. IR spectrum of compound 3.3.

Figure A3.7. IR spectrum of compound 3.4.

Figure A3.8. IR spectrum of compound 3.5.

Figure A3.9. (a) UV - visible spectra of 3.2 in THF with the addition of water ( 0 to $90 \%)$.

(b) Photographs of 3.3 before (a) and after (b) in THF and THF/ $\mathrm{H}_{2} \mathrm{O}(20: 80)$ mixture.

Figure A3.10. UV - visible spectra for 3.1 in THF with the gradual addition of water from 0 to $90 \%$.

Figure A3.11. DLS data for the aggregates of $3.1(15 \mu \mathrm{M})$ in $\mathrm{THF} / \mathrm{H}_{2} \mathrm{O}(20: 80)$ mixture ... 118

Figure A3.12. DLS data for the aggregates of $3.2(15 \mu \mathrm{M})$ in $\mathrm{THF} / \mathrm{H}_{2} \mathrm{O}(20: 80)$ mixture... 119 
Figure A3.13. DLS data for the aggregates of $3.3(15 \mu \mathrm{M})$ in $\mathrm{THF} / \mathrm{H}_{2} \mathrm{O}(20: 80)$ mixture... 119

Figure A3.14. Fluorescence spectra of $3.2(15 \mu \mathrm{M})$ with the addition of water from 0 to $90 \%$ into THF.

Figure A3.15. Fluorescence spectra of $3.2(15 \mu \mathrm{M})$ in a $\mathrm{THF} / \mathrm{H}_{2} \mathrm{O}$ mixture $(10: 90 \mathrm{v} / \mathrm{v})$ at

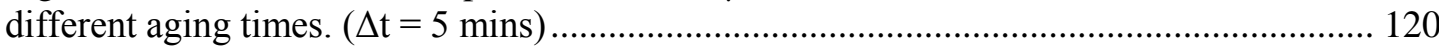

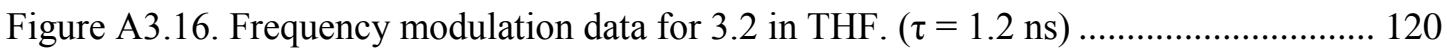

Figure A3.17. Frequency modulation data for 3.2 in $\mathrm{THF} / \mathrm{H}_{2} \mathrm{O}(10: 90)$ mixture. $(\tau=1.8$ ns)

Figure A3.18. Variation of fluorescence intensity of compound $3.1 \& 3.2(15 \mu \mathrm{M})$ in THF/ethylene glycol (EG) mixture. (0, 20, 40, 60, 80 \& 90 volume fraction of EG in THF)

Figure A3.19. Variation of fluorescence intensity of compound 3.3 $(15 \mu \mathrm{M})$ in THF/ ethylene glycol (EG) mixture. (0, 20, 40, 60, 80 \& 90 volume fraction of EG in THF)

Figure A3.20. Absorption spectral changes of $3.1 \& 3.2(15 \mu \mathrm{M})$ in $\mathrm{THF} / \mathrm{H}_{2} \mathrm{O}(20: 80)$ with the addition of PA (0 to $20 \mu \mathrm{M})$

Figure A3.21. Absorption spectral changes of $3.3(15 \mu \mathrm{M})$ in $\mathrm{THF} / \mathrm{H}_{2} \mathrm{O}(20: 80)$ with the addition of PA (0 to $20 \mu \mathrm{M})$

Figure A3.22. Emission spectra of $3.3(15 \mu \mathrm{M})$ in $\mathrm{THF} / \mathrm{H}_{2} \mathrm{O}(20: 80)$ upon addition of PA from 0 to $30 \mu \mathrm{M}$.

Figure A3.23. (a) Stern-Volmer plot for the complex 3.1 with PA (b) SV plot obtain at lower concentration of PA.

Figure A3.24. (a) Stern-Volmer plot for the complex 3.3 with PA (b) SV plot obtain at lower concentration of PA.

Figure A3.25. Photographs taken before (A) Complex 3.2 and 3.2+PA after (B)

Compound 3.2 and $3.2+$ PA...

Figure A3.26. Partial ${ }^{1} \mathrm{H}-\mathrm{NMR}$ spectra of 3.2 and 3.2-PA.

Figure A3.27. Photographs of compound 3.2 impregnated test paper strips upon exposure to the vapors of PA. ( $0 \mathrm{~min}, 5 \mathrm{~min}, 10 \mathrm{~min}$ and $20 \mathrm{~min}$ from left to right respectively........ 126

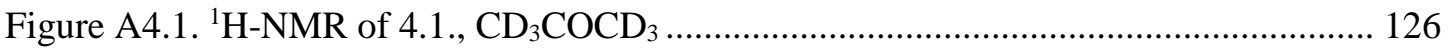

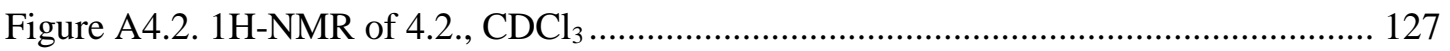

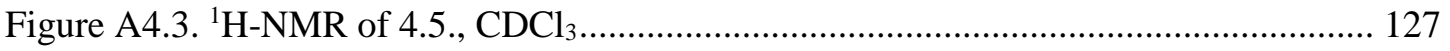

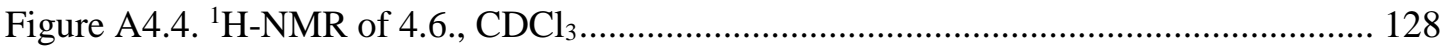


Figure A4.5. 1H-NMR of 4.7., $\mathrm{CDCl}_{3}$

Figure A5.1. Molecular structures of 5.1 (bottom), 5.4 (top right) and 5.5 (top left). Color code: $\mathrm{C}$, black; $\mathrm{H}$, white; $\mathrm{N}$, blue; $\mathrm{Cl}$, green; $\mathrm{O}$, red; $\mathrm{Pd}$, cyan. (H-atoms are omitted for clarity, except for $\mathrm{N}-\mathrm{H}$ in 5.1).

Figure A5.2. Molecular structures of 5.6 (top right), 5.7 (top left) and 5.8 (bottom). Color code: $\mathrm{C}$, black; $\mathrm{H}$, white; $\mathrm{N}$, blue; $\mathrm{Cl}$, green; $\mathrm{O}$, red; $\mathrm{Pd}$, cyan. (H-atoms are omitted for clarity)

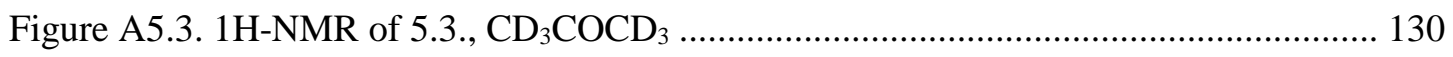

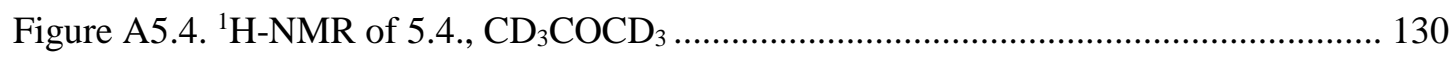

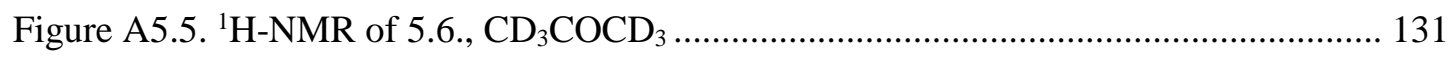

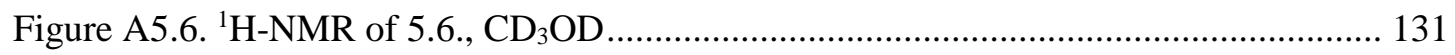




\section{LIST OF SCHEMES}

SCHEME

PAGE

Scheme 1.1. Pyrazole and its substituted derivatives.................................................... 2

Scheme 1.2. The twenty two known coordination modes of pzH and pz-. ............................ 2

Scheme 1.3. Conformational rotamers. Modified and redrawn from Luo et al. ...................... 6

Scheme 1.4. $\mathrm{R}=\mathrm{CH}_{3}, \mathrm{X}=\mathrm{SR}, \mathrm{Y}=\mathrm{H}, \mathrm{R}=\mathrm{H}, \mathrm{X}=\mathrm{CN}, \mathrm{Y}=\mathrm{pz}-\mathrm{R}=\mathrm{Ph}, \mathrm{X}=\mathrm{Et}, \mathrm{Y}=\mathrm{H}$. ..................... 8

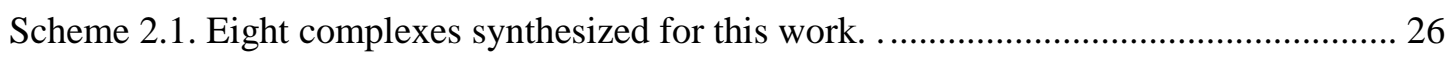

Scheme 3.1. Synthetic scheme of five tripodal pyrazoles $(3.1-3.5)$.................................... 57

Scheme 5.1. Sonogashira cross-coupling compounds synthesized in this study. .................. 92 


\section{ABBREVIATIONS AND ACRONYMS}

ACQ

AIDS

AIE

AIEE

BODIPY

CSD

DFT

DNA

DTA

EDX

ESIPT

FT-IR

HIV

$\mathrm{HNO}_{3}$

HPLC

IDSA

IN

LED

LLW

MDR

$\mathrm{MHz}$

MO

MRSA

NMR aggregation caused quenching

Acquired immunodeficiency syndrome

Aggregation induced emission

Aggregation induced emission enhancement

boron-dipyrromethene

Cambridge structural database

Density functional theory

Deoxyribonucleic acid

Differential thermal analysis

energy-dispersive X-ray

excited-state intramolecular proton transfer

Fourier transform infra-red

Human Immunodeficiency virus

Nitric acid

High performance liquid chromatography

Infectious Disease Society of America

Indazole

Light emitting diode

low-level nuclear waste

multi-drug resistant bacteria

Mega hertz

Molecular orbital

methicillin-resistant Staphylococcus aureus

Nuclear magnetic resonance 


\begin{tabular}{|c|c|}
\hline PA & Picric acid \\
\hline PD & Powder diffraction \\
\hline PET & photoinduced electron transfer \\
\hline PTA & 1, 3, 5-triaza-7-phosphaadamantane \\
\hline $\mathrm{Pz}$ & Pyrazolate \\
\hline $\mathrm{pzH}$ & Pyrazole \\
\hline RIR & Restricted intramolecular rotation \\
\hline ROS & reactive oxygen species \\
\hline SCXRD & Single crystal X-ray diffraction technique \\
\hline SEM & Scanning electron microscopy \\
\hline SRS & Savannah River site \\
\hline SSD & silver sulfadiazine \\
\hline $\mathrm{S}-\mathrm{V}$ & Stern - Volmer \\
\hline TG & Thermogravimetric \\
\hline THF & Tetrahydrofuran \\
\hline TICT & Twisted intermolecular charge transfer \\
\hline TLC & Thin layer chromatography \\
\hline TPE & Tetraphenylethene \\
\hline US & United states \\
\hline $\mathrm{U}$ & Ultra violet \\
\hline
\end{tabular}




\section{CHAPTER 1}

\subsection{Introduction}

\subsubsection{Pyrazoles: The ligand of choice}

Ludwig Knorr synthesized phenazone; the first reported pyrazole compound in $1883 .{ }^{12}$ Pyrazoles given in Scheme 1 are quite versatile ligands and have been studied intensely over the past 40 years as an important family of ligands in coordination chemistry. ${ }^{3}$ Physical and chemical properties, such as acidity/basicity, steric and electronic environment, and solubility, can be tuned easily by varying the substituents on the 3-, 4- and 5-positions of the ring..$^{3-5}$ Pyrazoles can also be utilized to build monopodal to polypodal molecular platforms. ${ }^{6}$ In 2009, Halcrow et al. reported 22 coordination modes (Scheme 1.2) of the pyrazoles and pyrazolide ions. The most common coordination mode for pyrazoles is binding to a metal in the monodentate, $\kappa^{1}$-fashion, through the $\mathrm{N}^{2}$ atom. Deprotonated pyrazolate anions, however, bind the metals as $\kappa^{2}-\mathrm{N}, \mathrm{N}$ ' bridges and most the common coordination modes are the chelating and bridging exo-bidentate $(\mu-\mathrm{pz})$ ones. They are known to be ideal for binding the metals in exo-bidentate fashion maintaining the metal centers in close proximity, i.e., approximately $3 \AA{ }^{7}$ Pyrazoles are $\pi$-excessive five membered heterocycles, i.e. a poorer $\pi$-acceptor, hence good $\pi$-donor for hard metals, unlike six membered $\mathrm{N}$-donor heterocycles, such as bipyridine or terpyridine. However, hardness can be tuned to a desirable extent by substituting various pendant peripheral groups on the ring, making these ligands compatible with very hard to very soft metal acceptors. ${ }^{8}$ 

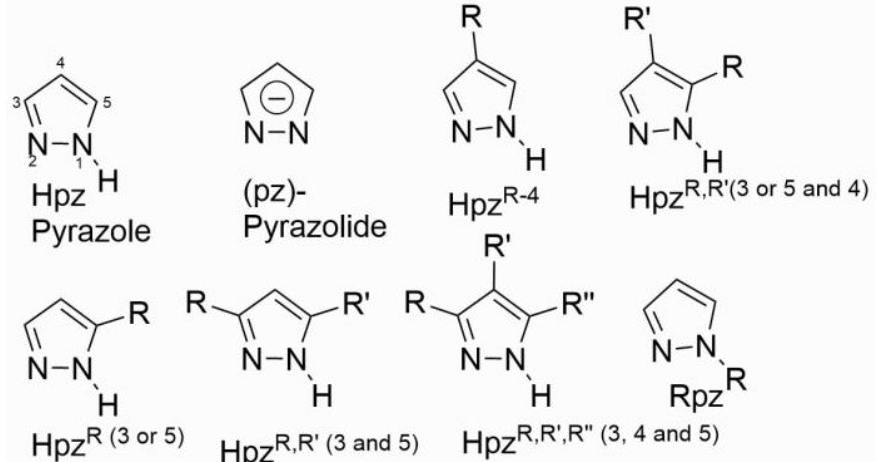<smiles>[R]c1cc([R])n(C)n1</smiles><smiles>[R]c1n[nH]c([R])c1[R]</smiles>

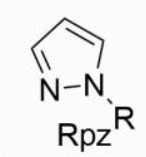

$\mathrm{R}, \mathrm{R}^{\prime}$ and R" may or may not be same

Scheme 1. 1. Pyrazole and its substituted derivatives. Modified and redrawn from Halcrow et al. ${ }^{3}$<smiles></smiles>

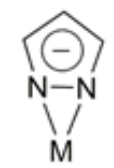<smiles></smiles><smiles>[M][M]1CC=CN1</smiles><smiles>[M]n1cccn1</smiles><smiles></smiles><smiles></smiles><smiles></smiles>
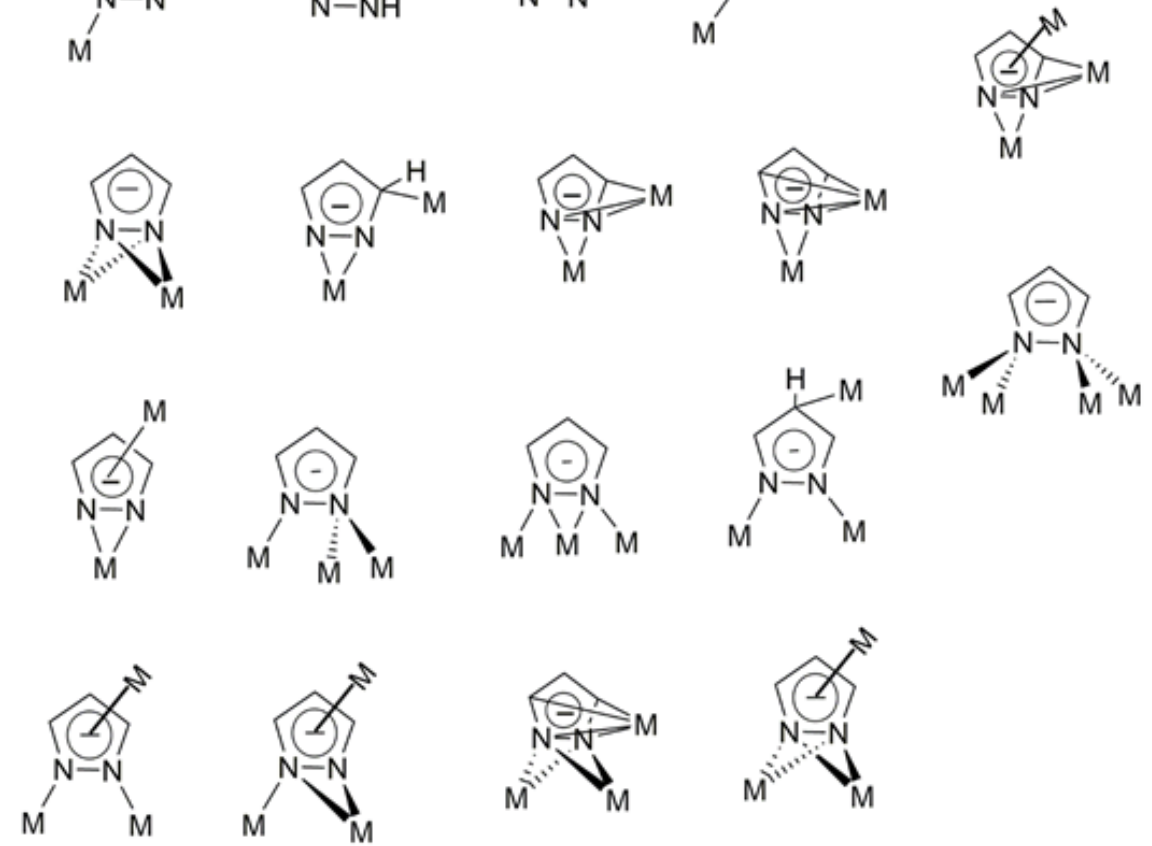

Scheme 1.2. The twenty two known coordination modes of pzH and pz-. Redrawn from Halcrow et al. ${ }^{3}$ 
Some pyrazoles have proven to be biocompatible, which prompted the study of their medicinal (biological) properties. ${ }^{9}$ Pyrazoles have active pharmacophores which make them compounds of medicinal value. They are found to be effective for many health problems, such as inflammation, ${ }^{10}$ cancer, ${ }^{11}$ pain, ${ }^{2}$ microbial ${ }^{12}$ and viral infections. ${ }^{13}$ Pyrazole derivatives are widely used in sensing applications. Recognition of cations such as $\mathrm{Cd}(\mathrm{II}), \mathrm{Zn}(\mathrm{II}), \mathrm{Hg}(\mathrm{II})^{14}$ and nitroaromatics (e.g., picric acid) are some of the most commonly studied areas. Some pyrazoles have AIEE properties, making them good candidates for chemical sensors, biological probes and components for the fabrication of organic LEDs. ${ }^{15}$ Tripodal tris(pyrazolyl) receptors have been used for the selective binding of $\mathrm{NH}_{4}{ }^{+}$and found promising. ${ }^{16-18}$ Tetraaryl pyrazole derivativatives have been successfully used for the sensing of nitroaromatics, because of their AIEE phenomenon. ${ }^{19} 18$ The tunability of the ligands using various pendant substituents make them great extractants for very hard to very soft metal cations. ${ }^{20-22}$ Pyrazole ligands are also proven as useful ligands in catalysis. ${ }^{23}$

\subsubsection{A brief review of silver pyrazolate complexes}

Monomeric, dimeric, trimeric, tetrameric and polymeric silver pyrazolate complexes have been reported in the literature. Polymers are the most common silver pyrazolates, followed by trimers and dimers. Buchner in 1889 synthesized a insoluble silver salt $[\mathrm{Ag}(\mathrm{pz})]_{\mathrm{n}}$, and after that all the derivatives were claimed to be a polymeric. Polymeric silver pyrazolate; $\operatorname{Ag}(\mathrm{pz})_{\mathrm{n}}$ structure was

first determined by powder X-ray diffraction in 1994. ${ }^{74}$ Compounds $\mathrm{Ag}_{2}\left(\mathrm{pz}_{2}\left(\mathrm{pph}_{3}\right)_{2}\right.$ and $\mathrm{Ag}_{2}(\mathrm{pz})_{2}\left(\mathrm{pph}_{3}\right)_{3}$ are the first two silver pyrazolates dimers with $\mathrm{PPh}_{3}$ as a coligand revealed by Cambridge structural database. ${ }^{24 a}$ Omary et al. in 2003 published a paper reporting a silver pyrazolate dimer, $\left[\left(3,5-\left(\mathrm{CF}_{3}\right)_{2}-\mathrm{pz}\right) \mathrm{Ag}(2,4,6 \text {-collidine })\right]_{2}$, the first ever study of the luminescence properties for silver pyrazolates. ${ }^{25}$ Several binary silver pyrazolate complexes with interesting structural features have been reported in the literature in the last two decades, but research on their applications is lacking. ${ }^{26}$ 
The silver pyrazolate trimer, $\left[\left(\mathrm{Ag}\left(\mu-3,5-\mathrm{Ph}_{2}-\mathrm{pz}\right)\right]_{3} .2 \mathrm{THF}\right.$ was the first reported silver trimer and structurally characterized by single crystal X-ray diffraction. ${ }^{27}$ Other groups have reported similar trimeric silver pyrazolate complexes since then. ${ }^{28}$ A trimer $[\mathrm{Ag}(\mathrm{pz})]_{3}$ was though synthesized and characterized by X-ray powder diffraction in $1994 .{ }^{7}$ Rasika Dias in 2000 published a paper reporting silver pyrazolate trimer with $3,5-\left(\mathrm{CF}_{3}\right)_{2}-\mathrm{pz}$ : $\left[\left\{3,5-\left(\mathrm{CF}_{3}\right)_{2}-\mathrm{pz}\right\} \mathrm{xAg}\right]_{3}{ }^{29}$ All the silver pyrazolates published earlier were limited on pz and 3,5-diaryl substituted pyrazolates. Compounds $[\mathrm{Ag}(\mathrm{pzIN})]_{6}$ and $[\mathrm{Ag}(\text { pzbisIN })]_{\mathrm{n}}$ were reported in 2004 along with their magnetic measurements; $;^{30} \mathrm{As} \mathrm{Ag}(\mathrm{I})$ is diamagnetic, the magnetism of these compounds was attributed to the organic radical moieties. A new crystalline form of $\left[\mathrm{Ag}_{3}\left(\mu-3,5-\mathrm{Ph}_{2} \mathrm{pz}\right)_{3}\right]_{2}$ was reported in 2005 showing significant intermolecular argentophilic interaction $[\mathrm{Ag} \ldots \mathrm{Ag}=2.971(1) \AA]$ between two independent trimer units. ${ }^{31}$ Several groups reported their work on the silver pyrazolate trimers (most of them are dimers of trimers with independent trimer units). ${ }^{32-51}$

Group 11 metals exhibit metallophilic interaction; the aurophilic is stronger than the argentophilic interaction, which is easily overcome by the sum of weak dipolar interactions. ${ }^{52}$ Five new silver pyrazolate trimers $\left[\mathrm{Ag}\left(\mu-\mathrm{pz}^{*}\right)\right]_{3}\left(\mathrm{Pz}^{*}=3,5-\mathrm{Ph}_{2}-\mathrm{pz}, 3-\mathrm{Me}-5-\mathrm{Ph}-\mathrm{pz}, 4-\mathrm{Br}-3,5-\mathrm{Ph}_{2}-\mathrm{pz}, 4-\mathrm{Br}-3-{ }^{\mathrm{t}} \mathrm{Bu}-\mathrm{pz}\right.$ and 3-(o-Cl- $\left.\mathrm{C}_{6} \mathrm{H}_{4}\right)-\mathrm{pz}$ were reported in 2012 and the effect of substituents on the supramolecular aggregation were studied. ${ }^{53}$ Among the metals of group 11, silver is most acidic in nature. Addition of electron withdrawing substituents on the pyrazole increases the acidity whereas, electron donating substituents decrease the acidity. ${ }^{54}$ Unlike the compound reported previously, where intermolecular interaction $[(\mathrm{Ag} \ldots \mathrm{Ag}=2.971(1) \AA]$ was observed with the 3,5 diphenylpyrazolato silver trimer, $\left\{\left[\mathrm{Ag}\left(3,5-\mathrm{Ph}_{2}-\mathrm{pz}\right)\right]_{3}\right\}_{2},{ }^{32 \mathrm{~b}}$ they did not observe any intermolecular argentophilic interaction in $\left[\mathrm{Ag}\left(3,5-\mathrm{Ph}_{2}-\mathrm{pz}\right)\right]_{3} \cdot 2 \mathrm{THF}$. Absence of argentophilic interaction might be either because of weakly coordinating solvents, or the solvent enabling $\pi-\pi$ or $\mathrm{C}-\mathrm{H} \ldots \pi$ interactions. ${ }^{53}$ A trigonal prismatic $\mathrm{Ag}_{3} \mathrm{pz}_{3}\left(\mathrm{pz}=\mathrm{C}_{18} \mathrm{H}_{12} \mathrm{~N}_{4} \mathrm{Ph}_{4}\right.$; a bipyrazole ligand) for the first 
time with bipyrazole was synthesized by Duan et al. ${ }^{55}$ In 2014, Chen et al. reported three new silver pyrazolate trimers with $\mathrm{Cl}$, I or $\mathrm{Me}$ in $\mathrm{C}^{4}$ position and $\mathrm{Ph}$ in $\mathrm{C}^{3}$ and $\mathrm{C}^{5}$ position. He depicted the weak $\mathrm{Ag}_{3} \ldots \mathrm{X}\left(\mathrm{Cl}, \mathrm{Br}^{53}, \mathrm{I}\right)$ interactions. ${ }^{56}$

Although polymeric Agpz are the most common in literature followed by trimers, crystal structure of a few tetranuclear silver pyrazolates have been reported. A neutral $\mathrm{Ag}_{4} \mathrm{~N}_{12} ;[\{3,5-$ $\left.\left.\left(\mathrm{CF}_{3}\right)_{2}-\mathrm{pz}\right\}_{4} \mathrm{Ag}_{4}\left(\mathrm{C}_{4} \mathrm{H}_{4} \mathrm{~N}_{2}\right)_{2}\right]$ was reported in $2005 .{ }^{57}$ However, a silver tetramer $\left[\left\{\mathrm{Ag}\left(\mu-3,5-\mathrm{tBu} \mathbf{2}^{-}\right.\right.\right.$ pz) $\}_{4} . \mathrm{CH}_{2} \mathrm{Cl}_{2}$ ] with only pyrazole ligands was first synthesized by G. Yang and R. G. Raptis. ${ }^{58}$ Scheele et al. in 2008 synthesized two complexes including a double crowned complex. ${ }^{59}$ Kiyoshi Fujisawa et al. in 2010 reported the same compound as (Yang and Raptis, 2007). ${ }^{32 a}$

Most of the hexamers reported are dimers of trimers as a result of several weak interactions including argentophilic interaction. ${ }^{30}{ }^{31}$ Because of the poor solubility, the X-ray powder diffraction technique was used for the structural elucidation of polymeric silver pyrazolates. ${ }^{47}$

\subsubsection{Sensing of nitro-aromatics using AIEE property}

Most of the chromophoric organics and polymers have strong emission in dilute solution but weak in thin film form, e.g., formation of aggregation quenches the emission behavior of the chromophore. ${ }^{60}$ Although light emission induced by aggregation is an exceptionally rare phenomenon, existence of light emission was already reported for small organic molecules, ${ }^{61}$ discovery of aggregation induced emission (AIE) and aggregation induced emission enhancement (AIEE) phenomena, however, Tang et al. ${ }^{62}$ and Park et al. ${ }^{63}$ took the sensing of chemicals using a ligand containing AIEE luminogens into a new horizon: Under the UV light, 1-methyl-1,2,3,4,5pentaphenylsilole in a TLC plate with a solvent was faint but, after the solvent evaporated the spot became clearly visible. ${ }^{62}$ The property was different than the property exhibited by many luminophores. The unique and rare phenomena observed were because of co-planarization of the phenyl rings, which in the solution state are twisted. The restricted rotation of the phenyl ring 
favors the enhancement of the photoluminescence property. ${ }^{62}$ The phenomenon was just opposite of "aggregation quenches light emission." A representative image of conformational rotamers in solution and in aggregation is shown in Scheme 1.3.

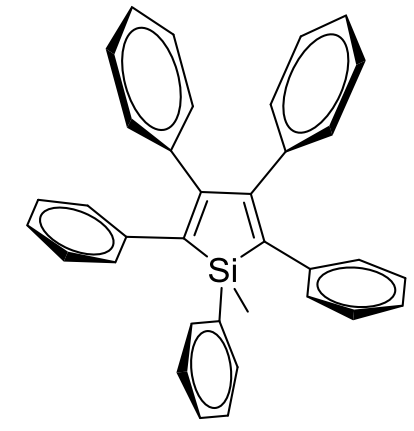

In soltion (twisted)



In aggregation (coplanar)

Scheme 1.3. Conformational rotamers. Modified and redrawn from Luo et al. ${ }^{62}$

After the unusual finding by Tang et al. ${ }^{62}$ several studies have been carried out on sensing using organic molecules containing luminophores having the AIEE property. ${ }^{64}$ Upon aggregation, tetraaryl and triaryl pyrazoles show significant enhancement in their photo emission. ${ }^{64}$ Mukundam et al. in 2013 synthesized the tetraaryl pyrazole polymers for the sensing of picric acid. ${ }^{65}$ Aggregation induces the enhancement on emission spectra as a result of restriction on intramolecular rotation. They also studied the intermolecular rotation restriction phenomenon at various temperatures, and found that AIEE is enhanced when the temperature is lowered. Pyrazole-porphyrin conjugates were studied for sensing of several cations, such as $\mathrm{Ag}(\mathrm{I}), \mathrm{Zn}$ (II), $\mathrm{Hg}(\mathrm{II})$ and $\mathrm{Cd}(\mathrm{II})$ by spectrophotometric and spectrofluorometric titrations in solution and also in gas phase with promising results. ${ }^{18}$ Tripyrazolyl ligands were also found to be effective for selective sensing of $\mathrm{NH}_{4}{ }^{+}$by NMR titration, florescence and X-ray crystallography studies. ${ }^{66}$ 


\subsubsection{Mercury pyrazolates in literature}

The Cambridge Crystallographic Data Center contains the crystal structures of mercury pyrazolates in ten different publications to date. ${ }^{67-76}$ Although a few reports on the synthesis of mercury pyrazolates had been reported earlier, methyl[tetrakis-(pyrazol-1-y1)borato$\left.\mathrm{N}, \mathrm{N}^{\prime}\right]$ mercury(II); [MeH $\mathrm{g}\left(\mathrm{B}(\mathrm{pz})_{4}\right]$ was the first reported crystal structure of mercury pyrazolate in $1987 .{ }^{67}$ The mercury atom is coordinated with the two pyrazolates in the complex in T-shaped coordination geometry with a stronger $\mathrm{Hg}-\mathrm{N}$ bond [2.07(4) $\AA$ ] from one pyrazolate and a weaker $\mathrm{Hg}-\mathrm{N}$ bond [2.65(4) $\AA$ ] from second pyrazolate. Exploring compounds of $\mathrm{Hg}(\mathrm{II})$ and $\mathrm{MeHg}(\mathrm{I})$ with coordination number higher than two has been of great biological importance. ${ }^{68}$ Solution studies, however, are complicated by the lability of mercury compounds. ${ }^{68}$ Aime et al. in 1994 synthesized and crystallized the linear,, 2-coordinate $\operatorname{MeHg}(\mathrm{pz})_{4} \mathrm{~B}$ and the T-shaped 3coordinate $\mathrm{MeSHg}\left(3,5-\mathrm{Me}_{2}-\mathrm{pz}\right)_{3} \mathrm{BH}$ and $\mathrm{EtSHg}\left(3,5-\mathrm{Me}_{2}-\mathrm{pz}\right)_{3} \mathrm{BH}$. Solid state NMR was consistent with the crystal structure, proving that lability is not an issue in the solid state. ${ }^{68}$ Two compounds $[(5-\mathrm{Me})$ thien-2-yl $] \mathrm{Hg}-(\mu-\mathrm{Pz})_{2} \mathrm{~B}(\mathrm{Pz})_{2}$ and $\mathrm{HB}\left[\left(3,5-\mathrm{Me}_{2}-\mathrm{pz}\right)_{3}\right] \mathrm{HgCN}$ were synthesized and X-ray data were reported by Lobbia et al. in 1996 and $1997 .{ }^{370}$ Unlike previously reported mercury pyrazolates (which were either T-shaped or linear), $\mathrm{HB}\left[\left(3,5-\mathrm{Me}_{2}-\mathrm{pz}\right)_{3}\right] \mathrm{HgCN}$ has distorted tetrahedral geometry, but with one of the bonds significantly weaker than the rest. Lobbia et al. in 1998 synthesized and crystallized $\left[\mathrm{HB}\left(3,5-\mathrm{ph}_{2}-\mathrm{pz}_{3} \mathrm{HgC}_{2} \mathrm{H}_{5}\right.\right.$, the first reported complex with true and rigid tetrahedral geometry. ${ }^{71}$ Mercury complexes with high coordination numbers are always desired for the activation and cleavage of $\mathrm{Hg}-\mathrm{C}$ bonds in both bacterial degradation ${ }^{77}$ and other reactions, such as symmetrization of the aryl mercury salts. ${ }^{78}$ Masciocchi et al. in 1999 synthesized two mercury pyrazolate polymers, $\left[\mathrm{Hg}(\mathrm{pz})\left(\mathrm{NO}_{3}\right)\right]_{\mathrm{n}}$ and $\left[\mathrm{Hg}(\mathrm{pz})_{2}\right]_{\mathrm{n}}$, and elucidated the structure with powder X-ray diffraction; their poor solubility in various solvents did not allow the growth of single crystal for the single crystals. Unsubstituted pyrazole with $\mathrm{Hg}\left(\mathrm{NO}_{3}\right)_{2}$ gave the deprotonated polymer without any deprotonating agents. However, addition of 
$\mathrm{Et}_{3} \mathrm{~N}$ on the reaction medium yielded a $\mathrm{Hg}(\mathrm{pz})_{2}$ monomer. ${ }^{72}$ Masciocchi in 2006 synthesized the first C-mercuriated pyrazole: ${ }^{73}\left[\{\mathrm{Hg}(\mathrm{ac})(\mu-\kappa C: \kappa N-\mathrm{Hdmpz})\}_{n}\right]$ along with the two conventional coordination compounds $\left[\left\{\mathrm{Hg}_{3}(\mu-\mathrm{ac})_{3}(\mu-\mathrm{pz})_{3}\right\}_{\mathrm{n}}\right]$ and $\left[\left\{\mathrm{Hg}_{3}(\mu-\mathrm{ac})_{3}(\mu-\mathrm{dmpz})_{3}\right\}_{\mathrm{n}}\right]$. Kiyoshi Fujisawa in 2006 reported the crystal structure of $\left[\mathrm{Hg}(\mathrm{Cl})\left\{\mathrm{HB}(3,5-\mathrm{iPr} 2-\mathrm{pz})_{3}\right\}\right]$ with tetrahedral geometry. ${ }^{74}$ Hitzbleck et al. in 2007 reported a trinuclear $\mathrm{Hg}$ complex; $\left[\mathrm{Hg}_{3}\left(i \mathrm{Pr}_{2}-\mathrm{pz}\right)_{4}\left(\mathrm{C}_{6} \mathrm{~F}_{5}\right)_{2}\right]$ with two $\mathrm{Hg}$ in a trigonal planar and one mercury in tetrahedral coordination mode. ${ }^{75}$ In 2018 N. Mosca et al. synthesized $\mathrm{Hg}\left(\mathrm{Me}_{2} \mathrm{BPZ}\right)$ and characterized it by powder diffraction. ${ }^{76}$ The metal center in the compound $\mathrm{Hg}\left(\mathrm{Me}_{2} \mathrm{BPZ}\right)$ has a see-saw (4 coordinate) coordination geometry. The majority of mercury pyrazolylborates are represented by Scheme 1.4.

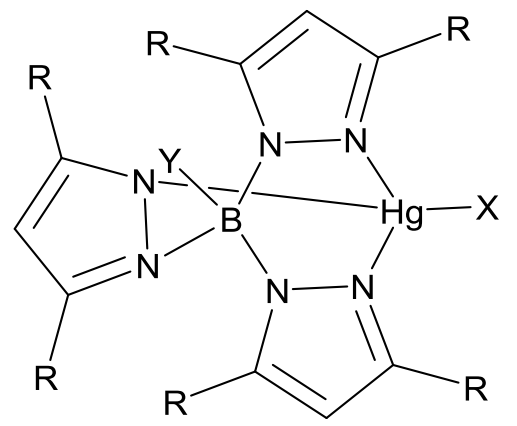

Scheme 1.4. $\mathrm{R}=\mathrm{CH}_{3}, \mathrm{X}=\mathrm{SR}, \mathrm{Y}=\mathrm{H}^{68}, \mathrm{R}=\mathrm{H}, \mathrm{X}=\mathrm{CN}, \mathrm{Y}=\mathrm{pz}^{-70}, \mathrm{R}=\mathrm{Ph}, \mathrm{X}=\mathrm{Et}, \mathrm{Y}=\mathrm{H}^{71}$

\subsubsection{Liquid-liquid extraction of mercury}

Liquid-liquid extraction, it is one of the most convenient techniques in separation chemistry. Mercury salts along with the interfering metals ions have high preference in aqueous phase and the highly lipophilic, soft organic ligands extract mercury out of aqueous solution. Garcia et al. designed a series of dithiophosphate compounds $\left(\mathrm{CH}_{3}\right)\left(\mathrm{CH}_{2}\right)_{\mathrm{n}} \mathrm{S}_{2} \mathrm{P}\left(\mathrm{OC}_{6} \mathrm{H}_{4}\right)_{2}$ ( $\mathrm{n}=0$ to 4 ) and extracted $\mathrm{Hg}(\mathrm{II})$ selectively in toluene from an aqueous mixture of $\mathrm{Ag}(\mathrm{I}), \mathrm{Cd}(\mathrm{II}), \mathrm{Pb}(\mathrm{II})$ and Bi(III) nitrates. ${ }^{79}$ A dithiophosphate with a long alkyl chain had better extracting ability than dithiophosphates with shorter chains. Mane et al. used 2-octylaminopyridine to extract $\mathrm{Hg}$ (II) in 
chloroform from a mixture of $\mathrm{Cd}(\mathrm{II}), \mathrm{Pb}(\mathrm{II}), \mathrm{Zn}(\mathrm{II}), \mathrm{Sb}(\mathrm{III}), \mathrm{Sn}(\mathrm{IV}), \mathrm{Tl}(\mathrm{I})$, and $\mathrm{Cr}(\mathrm{VI}) .{ }^{80}$ They studied the extraction in various conditions, such as $\mathrm{pH}$, concentration, etc., and proved that extraction was more eficient in alkaline conditions ( $\mathrm{pH}$ range 8.3 to 10). Cyanex 302 was used for the extraction of mercury in highly acidic medium. ${ }^{81}$ Several other works in the literature have been reported for the extraction of mercury.

\subsubsection{Palladium pyrazolate complexes}

Mononuclear and polynuclear palladium pyrazolyl complexes have been reported with the majority being binuclear ones. ${ }^{82-84}$ Monomers usually are obtained with the protonated pyrazoles. ${ }^{85}$ However, addition base deprotonates the $1 \mathrm{H}$ of pyrazoles resulting in higher nuclearity pyrazolyl complexes. The design of binuclear metal complexes is of research interest from the standpoint of catalysis, ${ }^{86}$ multi electron transfer reactions, ${ }^{87,} 88$ and metal-metal interactions. ${ }^{89}$ Pons et. al. synthesized first binuclear palladium pyrazolate with a $\operatorname{Pd}_{2}(\mathrm{pz})_{4}$ environment. ${ }^{90}$ Baran et al. reported a trinuclear palladium pyrazolate; $\left[\mathrm{Pd}(\mu-3-\mathrm{Ph}-\mathrm{pz})_{2}\right]_{3}{ }^{84}$ They synthesized the compound; $\left[\mathrm{Pd}(\mu-3-\mathrm{Ph}-\mathrm{pz})_{2}\right]_{3}$ using two different methods and it was the first $\mathrm{Pd}$ trimer reported in the literature. Umakoshi et. al. synthesized two trinuclear palladium pyrazolates; $\left[\mathrm{Pd}_{3}(\mu-\mathrm{pz})_{6}\right]$ and $\mathrm{Pd}_{3}(\mu-4-\mathrm{Me}-\mathrm{pz})_{6}$, a dinuclear complex; $\left[\mathrm{Pd}_{2}\left(\mu-3-{ }^{-} \mathrm{Bu}-\mathrm{pz}\right)_{2}\left(3-{ }^{\mathrm{t}} \mathrm{Bu}-\right.\right.$ $\left.\mathrm{pz})_{2}\left(3-{ }^{\mathrm{t}} \mathrm{Bu}-\mathrm{pzH}\right)_{2}\right]$, a mononuclear complex $\left[\mathrm{Pd}(\mathrm{pzH})_{4} \mathrm{Cl}_{2}\right]$ and a heteronuclear complex; $\left[\mathrm{Pd}_{2} \mathrm{Ag}_{2}(\mu-3-\mathrm{tBu}-\mathrm{pz})_{6}\right] .{ }^{82} \mathrm{~A}$ set of polynuclear complexes, i.e., $\left[\mathrm{Pd}(\mu-\mathrm{pz})_{2}\right]_{\mathrm{n}},\left[\operatorname{Pd}(\mu-\mathrm{Me}-\mathrm{pz})_{2}\right]_{\mathrm{n}}$, $\left[\operatorname{Pd}\left(\mu-\mathrm{Me}_{2}-\mathrm{pz}\right)_{2}\right]_{\mathrm{n}}$ and $\left[\mathrm{Pd}(\mu-\mathrm{I}-\mathrm{pz})_{2}\right]_{\mathrm{n}}$ were characterized by infrared spectroscopy ${ }^{83}$ Their thermal behaviors were studied by TG and DTA and demonstrated that substitution in 4-position does not affect the stability but, substitutions in the 3- and 5-positions reduce the stability of polymeric chain. Decomposition ultimately leads to metallic palladium, identified by X-ray powder diffraction. 


\subsubsection{Palladium in Catalysis}

Catalysis is one of the most important applications of metal complexes. The organic ligands of poly-nuclear complexes give a variety of chemistry and they are essential for the reactions that require milder conditions. ${ }^{91}$ Sonogashira and Mizoroki-Heck couplings ${ }^{92}{ }^{93}$ are widely studied palladium-catalyzed reactions. Investigations have shown that catalytic activity of water soluble palladium compounds is superior or comparable to that of water insoluble ones. ${ }^{94}$

Palladium carboxylate, $\left[\mathrm{Pd}(\mu-\mathrm{OAc})_{2}\right]_{3}$, is one of the earliest examples of a catalyst used in $\mathrm{C}-\mathrm{H}$ activation of benzene. ${ }^{95}$ Palladium catalysts cleave terminal and internal amide bonds near histidine and methionine residues in peptides and proteins, unlike that of $\mathrm{Co}(\mathrm{III})$ complexes that cleave only the N-terminal amino acids. ${ }^{96}$ Binuclear complexes with stable bridging and relatively labile terminal ligands are expected to have better catalytic applications than mononuclear ones. ${ }^{97}$ In spite of substantial work already accomplished in cross coupling reactions, there is still room for improvement. ${ }^{98}$ The crystallographic details of palladium acetate trimer, $\left[\mathrm{Pd}(\mu-\mathrm{OAc})_{2}\right]_{3}$, were first investigated by Skapski et al. ${ }^{99}$ and comparative studies of $\left[\mathrm{Pd}(\mu-\mathrm{OAc})_{2}\right]_{3}$ with $\left[\mathrm{Pd}_{3}(\mu-\mathrm{pz})_{6}\right]$, $\left[\mathrm{Pd}_{3}(\mu-4-\mathrm{Me}-\mathrm{pz})_{6}\right]^{82}$ and $\left[\mathrm{Pd}_{3}(\mu-3-\mathrm{Ph}-\mathrm{pz})_{6}\right]^{84}$ have shown that they are structurally parallel. Table 1.1 gives summarizes a structural comparisons among palladium acetate and three palladium pyrazolate trimers. Palladium pyrazolates are expected to be less labile in the solution than the corresponding carboxylates.

Table 1.1. Structural comparison between Pd-acetate and Pd-pyrazolate trimers. Interatomic distances and angles are averages.

\begin{tabular}{lllcl}
\hline Compounds & {$\left[\mathbf{P d}_{\mathbf{3}}(\boldsymbol{\mu - O A c})_{\mathbf{6}}\right]^{\mathbf{9 9}}$} & $\begin{array}{c}{\left[\mathbf{P d}_{\mathbf{3}}(\boldsymbol{\mu}-\right.} \\
\left.\mathbf{p z})_{\mathbf{6}}\right]^{\mathbf{8 2}}\end{array}$ & $\begin{array}{c}{\left[\mathbf{P d}_{\mathbf{3}}(\boldsymbol{\mu - 4}-\mathbf{M e}-\mathbf{M e}\right.} \\
\left.\mathbf{p z})_{\mathbf{6}}\right]^{\mathbf{8 2}}\end{array}$ & $\begin{array}{c}{\left[\mathbf{P d}_{\mathbf{3}}(\boldsymbol{\mu}-\mathbf{3}-\mathbf{P h}-\right.} \\
\left.\mathbf{p z})_{\mathbf{6}}\right]^{\mathbf{8 4}}\end{array}$ \\
\hline $\mathrm{Pd}-\mathrm{Pd}(\AA)$ & 3.140 & 3.047 & 3.054 & 3.010 \\
$\mathrm{Pd}-\mathrm{O} / \mathrm{N}(\AA)$ & 1.99 & 2.017 & 2.018 & 2.002 \\
$\mathrm{M}-\mathrm{M}-\mathrm{O} / \mathrm{N}\left({ }^{\circ}\right)$ & 76.3 & 65.18 & 65.19 & 65.01 \\
$\mathrm{M}-\mathrm{N}-\mathrm{N}\left({ }^{\circ}\right)$ & $129.6(\mathrm{M}-\mathrm{O}-\mathrm{C})$ & 114.8 & 114.8 & 114.9 \\
\hline
\end{tabular}


Although palladium acetate is a widely used homogenous catalyst, it is insoluble in water, which limits its application in green chemistry. ${ }^{100}$ The structural similariry of Pd-pyrazolyl complexes with well estabilished Pd-acetate catalysts makes persuing the former system in catalytic studies a worthwhile endeavor.

\subsection{Objectives}

Considering the fascinating amenability through suitable functionalization of 3-, 4- and 5positions of the pyrazolyl ligand, we have undertaken the synthesis of their silver(I), palladium(II) and mercury(II) complexes aiming towards diverse applications. ${ }^{101}$ Pyrazole and its derivatives have been employed to synthesize a wide range of transition metal complexes that can be "fine tuned" with regard to their steric and electronic properties through suitable derivatization of the ligand. Silver, palladium and mercury are relatively week to moderate Lewis acids. Pyrazole(s) can bind these metal centers either in a monodentate or in bridging bidentate fashion. In case of mercury(II), the pyrazole derivatives are employed with an objective to serve as extractants of $\mathrm{Hg}(\mathrm{II})$ embedded within mixed alkaline nuclear wastes. The idea was to extract the $\mathrm{Hg}$ (II) from aqueous to the organic phase through complexation. Along this line, indeed various mercury(II) pyrazole/pyrazolato complexes of varied nuclearity have been isolated and characterized (including X-ray structural studies). The steric and electronic nature of the substituents of these pyrazole derivatives significantly influenced the nature of the complexes isolated. In addition, initial assessment shows selective extraction of mercury(II) from the mixture

of lanthanides; . In a step further, design and synthesis of a fluorescent tripodal pyrazole derivative presents the opportunity of its utilization in sensing applications. 
Manipulation of solubility was another reason for the choice of pyrazole. ${ }^{102}$ Our initial objective was to synthesize water-soluble pyrazolate complexes for biological applications. We have carried out the project aiming to accentuate the therapeutic application of silver pyrazolates and demonstrate that silver(I)-based therapeutic agent might prove to be a viable alternative to currently used antibiotics, many of which have become ineffective because of the emergence of severe multidrug resistant (MDR) pathogens. The well-known pharmacokinetic profile and biocompatibility of pyrazoles make them excellent candidates to achieve the goal. ${ }^{103}$ In this endeavor we have synthesized a new family of $\operatorname{Ag}(\mathrm{I})$ pyrazolate dimers (both hydrophilic and lipophilic ones) that exhibit significant growth inhibition towards colonies of a notorious nosocomial pathogen, $P$. aeruginosa (prevalent with burn wound infections), with the aid of a soft tissue and skin infection (SSTI) model.

On another front, we attempted to synthesize water-soluble palladium pyrazolato complexes for green catalysis. New water-soluble palladium(II) complexes have been synthesized and structurally characterized. These Pd-pyrazolate systems are expected to be potent for catalytic applications. For example, two of these Pd(II) complexes demonstrated excellent catalytic efficiency for Sonogashira cross-coupling reactions, circumventing the limitation of commercially used Sonogashira catalysts. ${ }^{104}$ Although beyond the scope of the current research, it is anticipated that pyrazolyl ligands might be used in the future for chelation therapy, replacing the currently used sulfur-containing ligands, ${ }^{105}$ which cause adverse biological reactions.

Finally, considering the efficient sensing characteristics, new tripodal pyrazole-based platforms were designed, and their aggregation induced emission enhancement (AIEE) property was exploited with regard to their use as sensors for explosives (picric acid) in both solution and solid states. 
In summary, new $\mathrm{Hg}(\mathrm{II}), \mathrm{Ag}(\mathrm{I})$ and $\mathrm{Pd}(\mathrm{II})$ complexes incorporating pyrazoles have been synthesized and characterized. Apart from basic research interests, the chemistry extends to broader areas of applications of interest.

\subsection{References}

1. Eicher, T.; Hauptmann, S.; Speicher, A., Five- Membered Heterocycles: Sections 5.1-5.21. The Chemistry of Heterocycles: Structure, Reactions, Syntheses, and Applications, Second Edition 2003, 52-121.

2. Alam, M. J.; Alam, O.; Alam, P.; Naim, M. J., A review on pyrazole chemical entity and biological activity. Int. J. Pharm. Sci. Res 2015, 6, 1433-1442.

3. Halcrow, M. A., Pyrazoles and pyrazolides-flexible synthons in self-assembly. Dalton Transactions 2009, (12), 2059-2073.

4. Pérez, J.; Riera, L., Stable metal-organic complexes as anion hosts. Chemical Society Reviews 2008, 37 (12), 2658-2667.

5. Burini, A.; Mohamed, A. A.; Fackler, J. P., CYCLIC TRINUCLEAR GOLD (I) COMPOUNDS: SYNTHESIS, STRUCTURES AND SUPRAMOLECULAR ACID-BASE $\pi$-STACKS. Comments on Inorganic Chemistry 2003, 24 (5-6), 253-280.

6. Panak, P. J.; Geist, A., Complexation and extraction of trivalent actinides and lanthanides by triazinylpyridine N-donor ligands. Chemical reviews 2013, 113 (2), 1199-1236.

7. Masciocchi, N.; Moret, M.; Cairati, P.; Sironi, A.; Ardizzoia, G. A.; La Monica, G., The multiphase nature of the $\mathrm{Cu}(\mathrm{pz})$ and $\mathrm{Ag}(\mathrm{pz})(\mathrm{Hpz}=$ pyrazole) systems: selective syntheses and ab-initio X-ray powder diffraction structural characterization of copper (I) and silver (I) pyrazolates. Journal of the American Chemical Society 1994, 116 (17), 7668-7676.

8. Mukherjee, R., Coordination chemistry with pyrazole-based chelating ligands: molecular structural aspects. Coordination Chemistry Reviews 2000, 203 (1), 151-218.

9. Karrouchi, K.; Radi, S.; Ramli, Y.; Taoufik, J.; Mabkhot, Y. N.; Al-aizari, F. A., Synthesis and Pharmacological Activities of Pyrazole Derivatives: A Review. Molecules 2018, 23 (1), 134.

10. Hall, A.; Billinton, A.; Brown, S. H.; Clayton, N. M.; Chowdhury, A.; Giblin, G. M.; Goldsmith, P.; Hayhow, T. G.; Hurst, D. N.; Kilford, I. R., Non-acidic pyrazole EP 1 receptor antagonists with in vivo analgesic efficacy. Bioorganic \& medicinal chemistry letters 2008, 18 (11), 3392-3399.

11. Xia, Y.; Dong, Z.-W.; Zhao, B.-X.; Ge, X.; Meng, N.; Shin, D.-S.; Miao, J.-Y., Synthesis and structure-activity relationships of novel 1-arylmethyl-3-aryl-1H-pyrazole-5carbohydrazide derivatives as potential agents against A549 lung cancer cells. Bioorganic \& medicinal chemistry 2007, 15 (22), 6893-6899. 
12. Radi, S.; Salhi, S.; Radi, A., Synthesis and preliminary biological activity of some new pyrazole derivatives as acyclonucleoside analogues. Letters in Drug Design \& Discovery 2010, 7 (1), 27-30.

13. Rashad, A. E.; Hegab, M. I.; Abdel-Megeid, R. E.; Micky, J. A.; Abdel-Megeid, F. M., Synthesis and antiviral evaluation of some new pyrazole and fused pyrazolopyrimidine derivatives. Bioorganic \& medicinal chemistry 2008, 16 (15), 7102-7106.

14. Ramdani, A., Liquid-liquid extraction of copper (II), cadmium (II) and lead (II) using tripodal N-donor pyrazole ligands. Arkivoc 2006, 11, 59-65.

15. Mukundam, V.; Dhanunjayarao, K.; Mamidala, R.; Venkatasubbaiah, K., Synthesis, characterization and aggregation induced enhanced emission properties of tetraaryl pyrazole decorated cyclophosphazenes. Journal of Materials Chemistry C 2016, 4 (16), 3523-3530.

16. Mazik, M.; Wilhelm, S.; Koch, N.; Schulze, M., Crystalline ammonium complexes of trimethyl- and triethylbenzene- based tripodal compounds bearing pyrazole and indazole groups. European Journal of Organic Chemistry.

17. Rachuri, Y.; Parmar, B.; Bisht, K. K.; Suresh, E., Mixed ligand two dimensional Cd (II)/Ni (II) metal organic frameworks containing dicarboxylate and tripodal N-donor ligands: $\mathrm{Cd}$ (II) MOF is an efficient luminescent sensor for detection of picric acid in aqueous media. Dalton Transactions 2016, 45 (18), 7881-7892.

18. Moura, N. M.; Núñez, C.; Santos, S. M.; Faustino, M. A. F.; Cavaleiro, J. A.; Neves, M. G. a. P.; Capelo, J. L.; Lodeiro, C., Synthesis, spectroscopy studies, and theoretical calculations of new fluorescent probes based on pyrazole containing porphyrins for $\mathrm{Zn}$ (II), Cd (II), and $\mathrm{Hg}$ (II) optical detection. Inorganic chemistry 2014, 53 (12), 6149-6158.

19. Ciupa, A.; Mahon, M. F.; Paul, A.; Caggiano, L., Simple pyrazoline and pyrazole "turn on" fluorescent sensors selective for $\mathrm{Cd} 2+$ and $\mathrm{Zn} \mathrm{2+}$ in MeCN. Organic \& biomolecular chemistry 2012, 10 (44), 8753-8757.

20. Lin, C.; Wang, H.; Wang, Y.; Cheng, Z., Selective solid-phase extraction of trace thorium (IV) using surface-grafted Th (IV)-imprinted polymers with pyrazole derivative. Talanta 2010, 81 (1-2), 30-36.

21. Arichi, J.; Goetz-Grandmont, G.; Brunette, J. P., Solvent extraction of europium (III) from nitrate medium with 4-acyl-isoxazol-5-ones and 4-acyl-5-hydroxy-pyrazoles. Effect of salts and diluents. Hydrometallurgy 2006, 82 (1-2), 100-109.

22. Radi, S.; Ramdani, A.; Lekchiri, Y.; Morcellet, M.; Crini, G.; Janus, L.; Bacquet, M., Immobilization of pyrazole compounds on silica gels and their preliminary use in metal ion extraction. New Journal of Chemistry 2003, 27 (8), 1224-1227.

23. Chandrasekhar, V.; Athimoolam, A.; Krishnan, V.; Azhakar, R.; Madhavaiah, C.; Verma, S., A Copper- Metalated, Hybrid Inorganic-Organic Polymer as an Oxidative Nuclease. European journal of inorganic chemistry 2005, 2005 (8), 1482-1486. 
24. (a) Ardizzoia, G. A.; La Monica, G.; Maspero, A.; Moret, M.; Masciocchi, N., Silver (I) pyrazolates. Synthesis and X-ray and 31P-NMR characterization of triphenylphosphine complexes and their reactivity toward heterocumulenes. Inorganic chemistry 1997, 36 (11), 2321-2328; (b) Jayaratna, N. B.; Olmstead, M. M.; Kharisov, B. I.; Dias, H. R., Coinage Metal Pyrazolates $[(3,5-(\mathrm{CF} 3) 2 \mathrm{Pz}) \mathrm{M}] 3(\mathrm{M}=\mathrm{Au}, \mathrm{Ag}, \mathrm{Cu})$ as Buckycatchers. Inorganic chemistry 2016, 55 (17), 8277-8280.

25. Omary, M. A.; Rawashdeh-Omary, M. A.; Diyabalanage, H. V.; Dias, H. R., Blue Phosphors of Dinuclear and Mononuclear Copper (I) and Silver (I) Complexes of 3, 5-Bis (trifluoromethyl) pyrazolate and the Related Bis (pyrazolyl) borate. Inorganic chemistry 2003, 42 (26), 8612-8614.

26. Bertolotti, F.; Maspero, A.; Cervellino, A.; Guagliardi, A.; Masciocchi, N., Bending by faulting: a multiple scale study of copper and silver nitropyrazolates. Crystal growth \& design 2014, 14 (6), 2913-2922.

27. Raptis, R. G.; Fackler Jr, J. P., Structure of tris (. mu.-3, 5-diphenylpyrazolato-N, N') tricopper (I). Structural comparisons with the silver (I) and gold (I) pyrazolate trimers. Inorganic Chemistry 1988, 27 (23), 4179-4182.

28. Meyer, F.; Jacobi, A.; Zsolnai, L., Pyrazolate- Based Oligonuclear Copper and Silver Complexes with N/S Coordination Spheres. Chemische Berichte 1997, 130 (10), 1441-1447.

29. Dias, H. R.; Polach, S. A.; Wang, Z., Coinage metal complexes of 3, 5-bis (trifluoromethyl) pyrazolate ligand: Synthesis and characterization of $\{[3,5-(\mathrm{CF} 3) 2 \mathrm{Pz}] \mathrm{Cu}\} 3$ and $\{[3,5-$ (CF3) 2Pz] Ag 3 3. Journal of Fluorine Chemistry 2000, 103 (2), 163-169.

30. Yamada, S.; Ishida, T.; Nogami, T., Supramolecular triangular and linear arrays of metalradical solids using pyrazolato-silver (i) motifs. Dalton Transactions 2004, (6), 898-903.

31. Mohamed, A. A.; Pérez, L. M.; Fackler, J. P., Unsupported intermolecular argentophilic interaction in the dimer of trinuclear silver (I) 3, 5-diphenylpyrazolates. Inorganica chimica acta 2005, 358 (5), 1657-1662.

32. (a) Fujisawa, K.; Ishikawa, Y.; Miyashita, Y.; Okamoto, K.-i., Pyrazolate-bridged group 11 metal (I) complexes: Substituent effects on the supramolecular structures and physicochemical properties. Inorganica Chimica Acta 2010, 363 (12), 2977-2989; (b) Omary, M. A.; Rawashdeh-Omary, M. A.; Gonser, M. A.; Elbjeirami, O.; Grimes, T.; Cundari, T. R.; Diyabalanage, H. V.; Gamage, C. S. P.; Dias, H. R., Metal Effect on the Supramolecular Structure, Photophysics, and Acid- Base Character of Trinuclear Pyrazolato Coinage Metal Complexes. Inorganic chemistry 2005, 44 (23), 8200-8210.

33. Dias, H. R.; Diyabalanage, H. V., Trimeric silver (I) pyrazolates with isopropyl, bromo, and nitro substituents: Synthesis and characterization of $\{[3,5-(\mathrm{i}-\mathrm{Pr}) 2 \mathrm{Pz}] \mathrm{Ag}\} 3,\{[3,5-(\mathrm{i}-\mathrm{Pr}) 2$, 4-(Br) Pz $] \mathrm{Ag}\}$ 3, and \{[3, 5-(i-Pr) 2, 4-(NO 2) Pz] Ag $\}$. Polyhedron 2006, 25 (7), 16551661 .

34. Li, R., Bis \{tris [ $\mu-2-(1 \mathrm{H}-$ pyrazol-3-yl- $\mathrm{kN} 1: \kappa \mathrm{N} 2)$ pyridinato- $\mathrm{kN}]$ trisilver $(\mathrm{I})\}(2 \mathrm{Ag}-\mathrm{Ag})$. Acta Crystallographica Section E: Structure Reports Online 2007, 63 (6), m1640-m1640. 
35. Rasika Dias, H.; Palehepitiya Gamage, C. S., Arene- Sandwiched Silver (I) Pyrazolates. Angewandte Chemie International Edition 2007, 46 (13), 2192-2194.

36. (a) Zhang, J. P.; Horike, S.; Kitagawa, S., A flexible porous coordination polymer functionalized by unsaturated metal clusters. Angewandte Chemie International Edition 2007, 46 (6), 889-892; (b) Dias, H. R.; Gamage, C. S. P.; Keltner, J.; Diyabalanage, H. V.; Omari, I.; Eyobo, Y.; Dias, N. R.; Roehr, N.; McKinney, L.; Poth, T., Trinuclear silver (I) complexes of fluorinated pyrazolates. Inorganic chemistry 2007, 46 (8), 2979-2987.

37. Zhang, J.-P.; Kitagawa, S., Supramolecular isomerism, framework flexibility, unsaturated metal center, and porous property of ag (i)/cu (i) 3, 3', 5, 5 '-tetrametyl-4, 4 '-bipyrazolate. Journal of the American Chemical Society 2008, 130 (3), 907-917.

38. Omary, M. A.; Elbjeirami, O.; Gamage, C. S. P.; Sherman, K. M.; Dias, H. R., Sensitization of naphthalene monomer phosphorescence in a sandwich adduct with an electron-poor trinuclear silver (I) pyrazolate complex. Inorganic chemistry 2009, 48 (5), 1784-1786.

39. Tsupreva, V. N.; Titov, A. A.; Filippov, O. A.; Bilyachenko, A. N.; Smol'yakov, A. F.; Dolgushin, F. M.; Agapkin, D. V.; Godovikov, I. A.; Epstein, L. M.; Shubina, E. S., Peculiarities of the Complexation of Copper and Silver Adducts of a 3, 5-Bis (trifluoromethyl) pyrazolate Ligand with Organoiron Compounds. Inorganic chemistry 2011, 50 (8), 3325-3331.

40. Yang, C.; Elbjeirami, O.; Gamage, C. S. P.; Dias, H. R.; Omary, M. A., Luminescence enhancement and tuning via multiple cooperative supramolecular interactions in an ionpaired multinuclear complex. Chemical Communications 2011, 47 (26), 7434-7436.

41. Jahnke, A. C.; Pröpper, K.; Bronner, C.; Teichgräber, J. r.; Dechert, S.; John, M.; Wenger, O. S.; Meyer, F., A new dimension in cyclic coinage metal pyrazolates: decoration with a second ring of coinage metals supported by inter-ring metallophilic interactions. Journal of the American Chemical Society 2012, 134 (6), 2938-2941.

42. Titov, A. A.; Filippov, O.; Bilyachenko, A. N.; Smol'yakov, A. F.; Dolgushin, F. M.; Belsky, V. K.; Godovikov, I. A.; Epstein, L. M.; Shubina, E. S., Complexes of Trinuclear Macrocyclic Copper (I) and Silver (I) 3, 5- Bis (Trifluoromethyl) Pyrazolates with Ketones. European Journal of Inorganic Chemistry 2012, 2012 (33), 5554-5561.

43. Soria, L.; Cano, M.; Campo, J. A.; Torres, M. R.; Lodeiro, C., Silver compounds based on $\mathrm{N}, \mathrm{N}, \mathrm{N}$-tridentate pyridylpyrazolate ligands. An opportunity to build cyclic trimetallic and oligomeric luminescent liquid crystals. Polyhedron 2017, 125, 141-150.

44. Titov, A. A.; Smol'yakov, A. F.; Filippov, O. A.; Godovikov, I. A.; Muratov, D. A.; Dolgushin, F. M.; Epstein, L. M.; Shubina, E. S., Supramolecular Design of the Trinuclear Silver (I) and Copper (I) Metal Pyrazolates Complexes with Ruthenium Sandwich Compounds via Intermolecular Metal- $\pi$ Interactions. Crystal Growth \& Design 2017, 17 (12), 6770-6779.

45. Tian, A.-X.; Ning, Y.-l.; Ying, J.; Hou, X.; Li, T.-j.; Wang, X.-1., Three multi-nuclear clusters and one infinite chain induced by a pendant 4-butyl-1 H-pyrazole ligand for modification of Keggin anions. Dalton Transactions 2015, 44 (1), 386-394. 
46. Titov, A. A.; Filippov, O. A.; Guseva, E. A.; Smol'yakov, A. F.; Dolgushin, F. M.; Epstein, L. M.; Belsky, V. K.; Shubina, E. S., Role of basic sites of substituted ferrocenes in interaction with the trinuclear 3, 5-bis (trifluoromethyl) pyrazolates: thermodynamics and structure of complexes. RSC Advances 2014, 4 (16), 8350-8359.

47. Morishima, Y.; Young, D. J.; Fujisawa, K., Structure and photoluminescence of silver (I) trinuclear halopyrazolato complexes. Dalton Transactions 2014, 43 (42), 15915-15928.

48. Veronelli, M.; Kindermann, N.; Dechert, S.; Meyer, S.; Meyer, F., Crowning of Coinage Metal Pyrazolates: Double-Decker Homo-and Heteronuclear Complexes with Synergic Emissive Properties. Inorganic chemistry 2014, 53 (4), 2333-2341.

49. Galassi, R.; Ricci, S.; Burini, A.; Macchioni, A.; Rocchigiani, L.; Marmottini, F.; Tekarli, S. M.; Nesterov, V. N.; Omary, M. A., Solventless supramolecular chemistry via vapor diffusion of volatile small molecules upon a new trinuclear silver (I)-nitrated pyrazolate macrometallocyclic solid: An experimental/theoretical investigation of the dipole/quadrupole chemisorption phenomena. Inorganic chemistry 2013, 52 (24), 1412414137.

50. Titov, A.; Guseva, E.; Smol'yakov, A.; Dolgushin, F.; Filippov, O.; Golub, I.; Krylova, A.; Babakhina, G.; Epstein, L.; Shubina, E., Complexation of Trimeric Copper (I) and Silver (I) 3, 5-bis (trifluoromethyl) pyrazolates with Amine-Borane. Russian Chemical Bulletin 2013, $62(8), 1829-1834$.

51. Hettiarachchi, C. V.; Rawashdeh-Omary, M. A.; Korir, D.; Kohistani, J.; Yousufuddin, M.; Dias, H. R., Trinuclear Copper (I) and Silver (I) Adducts of 4-Chloro-3, 5-bis (trifluoromethyl) pyrazolate and 4-Bromo-3, 5-bis (trifluoromethyl) pyrazolate. Inorganic chemistry 2013, 52 (23), 13576-13583.

52. Murray, H.; Raptis, R. G.; Fackler Jr, J. P., Syntheses and X-ray structures of group 11 pyrazole and pyrazolate complexes. X-ray crystal structures of bis (3, 5-diphenylpyrazole) copper (II) dibromide, tris (. mu.-3, 5-diphenylpyrazolato-N, N') trisilver (I)-2tetrahydrofuran, tris (. mu.-3, 5-diphenylpyrazolato-N, $\mathrm{N}^{\prime}$ ) trigold (I), and hexakis (. mu.-3, 5-diphenylpyrazolato-N, N') hexagold (I). Inorganic Chemistry 1988, 27 (1), 26-33.

53. Yang, G.; Baran, P.; Martínez, A. R.; Raptis, R. G., Substituent Effects on the Supramolecular Aggregation of AgI-Pyrazolato Trimers. Crystal Growth \& Design 2012, 13 (1), 264-269.

54. Tekarli, S. M.; Cundari, T. R.; Omary, M. A., Rational design of macrometallocyclic trinuclear complexes with superior $\pi$-acidity and $\pi$-basicity. Journal of the American Chemical Society 2008, 130 (5), 1669-1675.

55. Duan, P.-C.; Wang, Z.-Y.; Chen, J.-H.; Yang, G.; Raptis, R. G., Trigonal prismatic Cu (i) and $\mathrm{Ag}$ (i) pyrazolato nanocage hosts: encapsulation of $\mathrm{S} 8$ and hydrocarbon guests. Dalton Transactions 2013, 42 (42), 14951-14954.

56. Chen, J.-H.; Liu, Y.-M.; Zhang, J.-X.; Zhu, Y.-Y.; Tang, M.-S.; Ng, S. W.; Yang, G., Halogen-involving weak interactions manifested in the crystal structures of silver (I) or gold 
(I) 4-halogenated-3, 5-diphenylpyrazolato trimers. CrystEngComm 2014, 16 (23), 49874998.

57. Dias, H. R.; Diyabalanage, H. V.; Gamage, C. S. P., Neutral Cu 4 N 12 and Ag 4 N 12 metallacycles with a para-cyclophane framework assembled from copper (i) and silver (i) pyrazolates and pyridazine. Chemical Communications 2005, (12), 1619-1621.

58. Yang, G.; Raptis, R. G., Synthesis and crystal structure of tetrameric silver (I) 3, 5-di-tertbutyl-pyrazolate. Inorganica chimica acta 2007, 360 (7), 2503-2506.

59. Scheele, U. J.; Georgiou, M.; John, M.; Dechert, S.; Meyer, F., Combining pyrazolate and $\mathrm{N}$-heterocyclic carbene coordination motifs: synthesis and characterization of a doublecrowned silver complex. Organometallics 2008, 27 (19), 5146-5151.

60. Friend, R.; Gymer, R.; Holmes, A.; Burroughes, J.; Marks, R.; Taliani, C.; Bradley, D.; Dos Santos, D.; Bredas, J.; Lögdlund, M., Electroluminescence in conjugated polymers. Nature 1999, 397 (6715), 121.

61. Deans, R.; Kim, J.; Machacek, M. R.; Swager, T. M., A poly (p-phenyleneethynylene) with a highly emissive aggregated phase. Journal of the American Chemical Society 2000, 122 (35), 8565-8566.

62. Luo, J.; Xie, Z.; Lam, J. W.; Cheng, L.; Chen, H.; Qiu, C.; Kwok, H. S.; Zhan, X.; Liu, Y.; Zhu, D., Aggregation-induced emission of 1-methyl-1, 2, 3, 4, 5-pentaphenylsilole. Chemical communications 2001, (18), 1740-1741.

63. An, B.-K.; Kwon, S.-K.; Jung, S.-D.; Park, S. Y., Enhanced emission and its switching in fluorescent organic nanoparticles. Journal of the American Chemical Society 2002, 124 (48), $14410-14415$.

64. Mukherjee, S.; Salini, P.; Srinivasan, A.; Peruncheralathan, S., AIEE phenomenon: tetraaryl vs. triaryl pyrazoles. Chemical Communications 2015, 51 (96), 17148-17151.

65. Mukundam, V.; Kumar, A.; Dhanunjayarao, K.; Ravi, A.; Peruncheralathan, S.; Venkatasubbaiah, K., Tetraaryl pyrazole polymers: versatile synthesis, aggregation induced emission enhancement and detection of explosives. Polymer Chemistry 2015, 6 (44), 77647770 .

66. Jonah, T. M.; Mathivathanan, L.; Morozov, A. N.; Mebel, A. M.; Raptis, R. G.; Kavallieratos, K., Remarkably selective NH 4+ binding and fluorescence sensing by tripodal tris (pyrazolyl) receptors derived from 1, 3, 5-triethylbenzene: structural and theoretical insights on the role of ion pairing. New Journal of Chemistry 2017, 41 (24), 14835-14838.

67. Canty, A.; Skelton, B.; White, A., Crystal Structure of Methyl [tetrakis (pyrazol-1-yl) borato-N, N'] mercury (II). Australian journal of chemistry 1987, 40 (9), 1609-1611.

68. Aime, S.; Digilio, G.; Gobetto, R.; Cecchi, P.; Lobbia, G. G.; Camalli, M., Solution and solid-state NMR studies of MeHg II and RSHg II (R= Me, Et) complexes with pyrazolylcontaining ligands. Polyhedron 1994, 13 (18), 2695-2702. 
69. Lobbia, G. G.; Cecchi, P.; Giordano, F.; Santini, C., Metal polypyrazolylborates. X. Thienylmercury (II) derivatives: the X-ray crystal structure of [(5-Me) Thien-2-yl] Hg-(v$\mathrm{Pz}$ ) 2B (Pz) 2. Journal of organometallic chemistry 1996, 515 (1-2), 213-220.

70. Lobbia, G. G.; Cecchi, P.; Gobetto, R.; Digilio, G.; Spagna, R.; Camalli, M., Metal polypyrazolylborates XIII. Solution and solid state NMR study of cyano-mercury (II) polypyrazolylborates. X-ray crystal structure of [HB (3, 5-Me 2 pz) 3] $\mathrm{HgCN}$. Journal of organometallic chemistry 1997, 539 (1), 9-17.

71. Lobbia, G. G.; Santini, C.; Giordano, F.; Cecchi, P.; Coacci, K., Metal polypyrazolylborates: XIV. Organomercury (II) complexes with hydridotris (3, 5-diphenyl-1H-pyrazolyl) borate and hydridotris (4-bromo-1H-pyrazolyl) borate. The X-ray crystal structure of [HB (3, 5$\mathrm{Ph} 2 \mathrm{pz}$ ) 3] HgC2H5. Journal of organometallic chemistry 1998, 552 (1), 31-38.

72. Masciocchi, N.; Ardizzoia, G. A.; Maspero, A.; LaMonica, G.; Sironi, A., Metal pyrazolato complexes. Synthesis, characterization, and X-ray powder diffraction studies of group 12 coordination polymers. Inorganic chemistry 1999, 38 (16), 3657-3664.

73. Masciocchi, N.; Galli, S.; Alberti, E.; Sironi, A.; Di Nicola, C.; Pettinari, C.; Pandolfo, L., Synthesis, solid-state NMR, and X-ray powder diffraction characterization of group 12 coordination polymers, including the first example of a $\mathrm{C}$-mercuriated pyrazole. Inorganic chemistry 2006, 45 (22), 9064-9074.

74. Fujisawa, K.; Matsunaga, Y.; Ibi, N.; Amir, N.; Miyashita, Y.; Okamoto, K.-i., Bond Length Contraction in Zinc-Triad Complexes Ligated by Hydrotris (pyrazolyl) borate: $[\mathrm{M}(\mathrm{Cl})\{\mathrm{HB}$ (3, 5-i Pr2pz) 3$\}](M=$ ZnII, CdII, and HgII). Bulletin of the Chemical Society of Japan 2006, 79 (12), 1894-1896.

75. Hitzbleck, J.; Deacon, G. B.; Ruhlandt- Senge, K., Structural Trends in Alkaline Earth and Rare Earth Metal 3, 5- Diisopropylpyrazolates. European journal of inorganic chemistry 2007, 2007 (4), 592-601.

76. Mosca, N.; Vismara, R.; Fernandes, J. A.; Pettinari, C.; Galli, S., The Hg(3,3'-dimethyl$1 \mathrm{H}, 1 \mathrm{H}^{\prime}-4,4^{\prime}$-bipyrazolate) coordination polymer: Synthesis, crystal structure and thermal behavior. Inorganica Chimica Acta 2018, 470, 423-427.

77. Wright, J. G.; Natan, M. J.; MacDonnel, F. M.; Ralston, D. M.; O'Halloran, T. V., Mercury (II) - Thiolate Chemistry and the Mechanism of the Heavy Metal Biosensor MerR. Progress in Inorganic Chemistry: Bioinorganic Chemistry, Volume 38 1990, 323-412.

78. Moore, M. J.; Distefano, M. D.; Zydowsky, L. D.; Cummings, R. T.; Walsh, C. T., Organomercurial lyase and mercuric ion reductase: nature's mercury detoxification catalysts. Accounts of chemical research 1990, 23 (9), 301-308.

79. Pérez-García, F.; Galán-Vidal, C. A.; Alvarado-Rodríguez, J. G.; Páez-Hernández, M. E.; Andrade-López, N.; Ramírez Silva, M. T., Selective Liquid-Liquid Extraction of Mercury (II) from Aqueous Solution by N-Alkyldithiophosphate Compounds $\mathrm{CH} 3(\mathrm{CH} 2) \mathrm{nS} 2 \mathrm{P}$ (OC6H4) 2 (n= 0 to 4). Separation Science and Technology 2013, 48 (5), 736-740. 
80. Mane, C. P.; Mahamuni, S. V.; Gaikwad, A. P.; Shejwal, R. V.; Kolekar, S. S.; Anuse, M. A., Extraction and separation of mercury (II) from succinate media with high molecular weight amine as an extractant. Journal of Saudi Chemical Society 2015, 19 (1), 46-53.

81. Fábrega, F.; Guimarães, A.; Resende, G.; Mansur, M., Solvent extraction of mercury (II) from aqueous chloride solutions using Cyanex 302. Mineral Processing and Extractive Metallurgy 2017, 126 (4), 193-198.

82. Umakoshi, K.; Yamauchi, Y.; Nakamiya, K.; Kojima, T.; Yamasaki, M.; Kawano, H.; Onishi, M., Pyrazolato-bridged polynuclear palladium and platinum complexes. Synthesis, structure, and reactivity. Inorganic chemistry 2003, 42 (12), 3907-3916.

83. Netto, A. V. d. G.; Frem, R. C.; Mauro, A. E.; Crespi, M. S.; Zorel Jr, H., Synthesis, spectral and thermal studies on pyrazolatebridged palladium (II) coordination polymers. Journal of Thermal Analysis and Calorimetry 2007, 87 (3), 789-792.

84. Baran, P.; Marrero, C. M.; Pérez, S.; Raptis, R. G., Stepwise, ring-closure synthesis and characterization of a homoleptic palladium (II)-pyrazolato cyclic trimer. Chemical Communications 2002, (9), 1012-1013.

85. Perez, J. A.; Pons, J.; Solans, X.; Font-Bardia, M.; Ros, J., Synthesis and characterisation of palladium (II) and platinum (II) compounds containing pyrazole-derived ligands: crystal structure of [ $\mathrm{PdCl} 2$ (HL 1)](HL 1= 3-phenyl-5-(2-pyridyl) pyrazole). Inorganica chimica acta 2005,358 (3), 617-622.

86. Claver, C.; Kalck, P.; Ridmy, M.; Thorez, A.; Oro, L. A.; Pinillos, M. T.; Apreda, M. C.; Cano, F. H.; Foces-Foces, C., Synthesis and hydroformylation reaction of dinuclear rhodium (I) complexes with mixed bridging ligands. X-ray structure of [Rh $2(\mu-\mathrm{pz})(\mu-\mathrm{SBu} t)(\mathrm{CO}) 2$ $\{\mathrm{P}(\mathrm{OMe}) 3\} 2$ ]. Journal of the Chemical Society, Dalton Transactions 1988, (6), 15231528.

87. Garc, M., a, AM Lo pez, MA Esteruelas, FJ Lahoz and LA Oro. J. Chem. Soc., Dalton T rans 1990, 3465.

88. Van Veggel, F. C.; Harkema, S.; Bos, M.; Verboom, W.; Van Staveren, C. J.; Gerritsma, G. J.; Reinhoudt, D. N., Metallomacrocycles: synthesis, X-ray structure, electrochemistry, and ESR spectroscopy of mononuclear and heterodinuclear complexes. Inorganic Chemistry 1989, 28 (6), 1133-1148.

89. Yersin, H.; Vogler, A., Photochemistry and photophysics of coordination compounds. Springer: 1987.

90. Pons, J.; Chadghan, A.; Casabo, J.; Alvarez-Larena, A.; Piniella, J. F.; Ros, J., Synthesis and structural characterisation of new binuclear Pd (II) complexes with both bridging and terminal pyrazolate ligands. Inorganic Chemistry Communications 2000, 3 (6), 296-299.

91. Lee, J.; Farha, O. K.; Roberts, J.; Scheidt, K. A.; Nguyen, S. T.; Hupp, J. T., Metal-organic framework materials as catalysts. Chemical Society Reviews 2009, 38 (5), 1450-1459. 
92. Li, F.; Hor, T., Benzimidazolium- Pyrazole- Palladium (II) Complexes: New and Efficient Catalysts for Suzuki, Heck and Sonogashira Reactions. Advanced Synthesis \& Catalysis 2008, 350 (14- 15), 2391-2400.

93. Sonogashira, K., Development of $\mathrm{Pd}-\mathrm{Cu}$ catalyzed cross-coupling of terminal acetylenes with sp 2-carbon halides. Journal of Organometallic Chemistry 2002, 653 (1), 46-49.

94. Godoy, F.; Segarra, C.; Poyatos, M.; Peris, E., Palladium Catalysts with SulfonateFunctionalized-NHC Ligands for Suzuki- Miyaura Cross-Coupling Reactions in Water. Organometallics 2011, 30 (4), 684-688.

95. Moritanl, I.; Fujiwara, Y., Aromatic substitution of styrene-palladium chloride complex. Tetrahedron Letters 1967, 8 (12), 1119-1122.

96. (a) Suh, J.; Lee, S. H.; Zoh, K. D., A novel host containing both binding site and nucleophile prepared by attachment of. beta.-cyclodextrin to poly (ethylenimine). Journal of the American Chemical Society 1992, 114 (20), 7916-7917; (b) Jessop, P. G.; Hsiao, Y.; Ikariya, T.; Noyori, R., Catalytic production of dimethylformamide from supercritical carbon dioxide. Journal of the American Chemical Society 1994, 116 (19), 8851-8852.

97. Karet, G. B.; Kostic, N. M., Rapid, catalytic hydrolysis of methionine-containing dipeptides by a dinuclear palladium (II) complex having thiolate bridging ligands. Inorganic Chemistry 1998, 37 (5), 1021-1027.

98. Chen, X.; Engle, K. M.; Wang, D. H.; Yu, J. Q., Palladium (II)- Catalyzed C $\square$ H Activation/C $\square \mathrm{C}$ Cross- Coupling Reactions: Versatility and Practicality. Angewandte Chemie International Edition 2009, 48 (28), 5094-5115.

99. Skapski, A.; Smart, M., The crystal structure of trimeric palladium (II) acetate. Journal of the Chemical Society D: Chemical Communications 1970, (11), 658b-659.

100. Herrmann, W. A.; Kohlpaintner, C. W., Water- Soluble Ligands, Metal Complexes, and Catalysts: Synergism of Homogeneous and Heterogeneous Catalysis. Angewandte Chemie International Edition in English 1993, 32 (11), 1524-1544.

101. Yu, S. Y.; Lu, H. L., From Metal- Metal Bonding to Supra- Metal- Metal Bonding Directed Self- Assembly: Supramolecular Architectures of Group 10 and 11 Metals with Ligands from Mono- to Poly- pyrazoles. Israel Journal of Chemistry 2018.

102. (a) Harbindu, A.; Seetharaman, J.; Atkins, J. M.; Rane, D.; Sivaswamy, V., Water-Soluble Pyrazole Derivatives as Corrosion Inhibitors. Google Patents: 2016; (b) Henkelis, J. J.; Kilner, C. A.; Halcrow, M. A., New insights into the aggregation of silver pyrazolides using sterically hindered bidentate pyrazole ligands. Chemical Communications 2011, 47 (18), 5187-5189; (c) Halcrow, M. A., Pyrazoles and pyrazolides-flexible synthons in selfassembly. Dalton Transactions 2009, (12), 2059-2073.

103. Karrouchi, K.; Radi, S.; Ramli, Y.; Taoufik, J.; Mabkhot, Y.; Al-aizari, F., Synthesis and pharmacological activities of pyrazole derivatives: A review. Molecules 2018, 23 (1), 134. 
104. Chinchilla, R.; Nájera, C., The Sonogashira reaction: a booming methodology in synthetic organic chemistry. Chemical reviews 2007, 107 (3), 874-922.

105. Andersen, O., Principles and recent developments in chelation treatment of metal intoxication. Chemical Reviews 1999, 99 (9), 2683-2710. 


\section{CHAPTER 2}

Synthesis and Characterization of family of dinuclear silver(I)pyrazolates for the assessment of their antibacterial activity

Reproduced in part with permission from Polyhedron, 154, (2018), 390-397

Copyright (C) 2018

Elsevier

Shambhu Kandel ${ }^{a}$, Jenny Stenger-Smith ${ }^{b}$ Indranil Chakraborty ${ }^{a^{*}}$, Raphael G. Raptis ${ }^{a^{*}}$

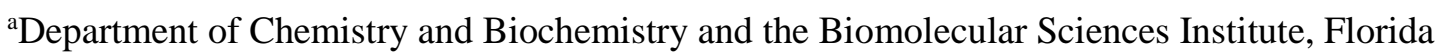
International University, Miami, FL 33199, United States

${ }^{\mathrm{b}}$ Department of Chemistry and Biochemistry, University of California Santa Cruz, Santa Cruz, CA 95064, United States






\subsection{Abstract}

Eight new dinuclear silver(I) complexes, namely $\left[\mathrm{Ag}_{2}(\mu-4-\mathrm{Cl}-\mathrm{pz})_{2}\left(\mathrm{PPh}_{3}\right)_{4}\right][\mathbf{2 . 1}],\left[\mathrm{Ag}_{2}(\mu-4-\mathrm{Cl}\right.$ $\left.\mathrm{pz})_{2}\left(\mathrm{PPh}_{3}\right)_{3}\right]\left[\right.$ 2.2], $\left[\mathrm{Ag}_{2}\left(\mu-4-\mathrm{NO}_{2}-\mathrm{pz}\right)_{2}\left(\mathrm{PPh}_{3}\right)_{4}\right]$ [2.3], $\left[\mathrm{Ag}_{2}\left(\mu-4-\mathrm{NO}_{2}-\mathrm{pz}\right)_{2}\left(\mathrm{PPh}_{3}\right)_{3}\right]$ [2.4], $\left[\mathrm{Ag}_{2}(\mu-4-\right.$ $\left.\mathrm{Cl}-\mathrm{pz})_{2}(\mathrm{PTA})_{4}\right]\left[\right.$ 2.5], $\left[\mathrm{Ag}_{2}(\mu-4-\mathrm{Cl}-\mathrm{pz})_{2}(\mathrm{PTA})_{2}\right] \quad[\mathbf{2 . 6}], \quad\left[\mathrm{Ag}_{2}\left(\mu-4-\mathrm{CH}_{3}-\mathrm{pz}\right)_{2}(\mathrm{PTA})_{2}\right]$ [2.7] and $\left[\mathrm{Ag}_{2}\left(\mu-3-\mathrm{CH}_{3}-\mathrm{pz}\right)_{2}(\mathrm{PTA})_{2}\right][\mathbf{2 . 8}]$ (where $\mathrm{pz}=$ pyrazolate and $\mathrm{PTA}=1, \quad 3$, 5triazaphosphaadamantane) have been synthesized and structurally characterized. The coordination geometry of both silver centers in complexes 2.1, 2.3 and 2.5 is distorted tetrahedral, while in case of complexes $\mathbf{2 . 2}$ and $\mathbf{2 . 4}$, one of the Ag centers resides in a trigonal planar environment. The coordination geometry on both silver centers in complexes $\mathbf{2 . 6}, \mathbf{2 . 7}$ and $\mathbf{2 . 8}$ is trigonal planar. The two $\mu$-pyrazolates act as bridges between two Ag atoms. Complexes 2.5-2.8 are water soluble. Complex 2.5 exhibits strong antimicrobial actions against a Gram-negative nosocomial pathogen Pseudomonas aeruginosa. The zone of bacterial clearance by complex $\mathbf{2 . 5}$ in soft tissue and skin infection (SSTI) model is found to be superior to that by silver nitrate. The biological activities of other water-soluble complexes (2.6-2.8) are under study.

\subsection{Introduction}

Antibiotic resistance is currently an alarming issue ${ }^{1}$ and several health organizations throughout the World have already declared bacterial resistance towards antibiotics as "catastrophic". ${ }^{2}$ The Infectious Disease Society of America (IDSA) has expressed significant concern on antibacterial resistance, in particular regarding the multi-drug resistant bacteria (MDR), which have been singled out as an imminent threat to US public health. ${ }^{1}$ Among the Gram-positive variety, methicillin-resistant Staphylococcus aureus (MRSA) is annually responsible for more loss of life in US than the infectious HIV/AIDS disease. ${ }^{1,3}$ Gram-negative strains have also started showing resistance towards a range of antimicrobials. The notorious Gram-negative hospital infections are mostly caused by Klebsiella pneumonia, Pseudomonas aeruginosa, and Acinetobacter 
baumannii. ${ }^{4}$ These circumstances have prompted the research community in recent years to focus on developing alternative chemotherapeutics to combat antibacterial resistance.

Ionic or bioactive silver $\left(\mathrm{Ag}^{+}\right)$has been historically found to be a quite effective antimicrobial against a broad range of microorganisms. ${ }^{5}$ At controlled concentrations, ionic Ag has been widely used in various commercially available healthcare products and also as antibacterial agent. ${ }^{5 c}$ Silver is also known as "oligodynamic" because of its ability to exert its antimicrobial actions even at very low concentrations. ${ }^{6}$ In addition, $\mathrm{Ag}^{+}$ions interact with bacteria by several different mechanisms, making difficult for the pathogens to develop resistance. ${ }^{7}$ In bacteria, $\mathrm{Ag}^{+}$interacts with the nucleophilic amino acid residues, ${ }^{8}$ inhibits the function of oxidative enzymes, ${ }^{8}$ promotes generation of reactive oxygen species $(\mathrm{ROS})^{8}$ and interferes with DNA replication. ${ }^{9}$ These observations have led to silver-based antimicrobials, particularly effective against burn wound infections. ${ }^{10}$ Silver nitrate and silver sulfadiazine (SSD) are used extensively as topical antimicrobials for severe burn wounds. ${ }^{11}$ Slow and sustainable delivery of $\mathrm{Ag}^{+}$ions under a physiological milieu by dissociation of the topically applied compound is crucial to its exerting effective antibacterial action, ensuring also that the Ag-based antimicrobial is not being over used, which might cause other undesirable side effects. Appropriately designed $\operatorname{Ag}(\mathrm{I})$ coordination complexes can meet these requirements. ${ }^{12}$

Our group has previously studied some silver pyrazolate and triazolate materials with regard to their porosity, structural and supramolecular chemistry. ${ }^{13}$ This has prompted us to extend our work to new $\operatorname{Ag}(\mathrm{I})$ pyrazolates and assess their antibacterial efficacy (if any), towards a Gramnegative strain, abundant in the sites of burn wound infections. Pyrazoles themselves have been reported to exhibit a wide range of biological activities, including antimicrobial, anti-fungal, antiinflammatory, anti-convulsant, anticancer, and neuroprotective. ${ }^{14}$ Several pyrazole derivatives have already found their place in some clinically approved non-steroidal anti-inflammatory drugs 
(NSAIDs). ${ }^{14}$ The pyrazole 3, 4, 5-positions are amenable to functionalization, offering the opportunity to "fine tune" the chemical properties of their metal complexes. Herein, we report the synthesis and structural characterization of eight pyrazolate-bridged dimeric $\mathrm{Ag}(\mathrm{I})$ complexes, namely, $\quad\left[\mathrm{Ag}_{2}(\mu-4-\mathrm{Cl}-\mathrm{pz})_{2}\left(\mathrm{PPh}_{3}\right)_{4}\right] \quad(\mathbf{2 . 1}), \quad\left[\mathrm{Ag}_{2}(\mu-4-\mathrm{Cl} \quad \mathrm{pz})_{2}\left(\mathrm{PPh}_{3}\right)_{3}\right] \quad$ (2.2) $\quad\left[\mathrm{Ag}_{2}\left(\mu-4-\mathrm{NO}_{2}-\right.\right.$ $\left.\mathrm{pz})_{2}\left(\mathrm{PPh}_{3}\right)_{4}\right]$ (2.3), $\left[\mathrm{Ag}_{2}\left(\mu-4-\mathrm{NO}_{2}-\mathrm{pz}\right)_{2}\left(\mathrm{PPh}_{3}\right)_{3}\right]$ (2.4), $\left[\mathrm{Ag}_{2}(\mu-4-\mathrm{Cl}-\mathrm{pz})_{2}(\mathrm{PTA})_{4}\right]$ (2.5), $\left[\mathrm{Ag}_{2}(\mu-4-\mathrm{Cl}\right.$ pz $\left.)_{2}(\mathrm{PTA})_{2}\right]$ (2.6), $\left[\mathrm{Ag}_{2}\left(\mu-4-\mathrm{CH}_{3}-\mathrm{pz}\right)_{2}(\mathrm{PTA})_{2}\right]\left(\right.$ 2.7) and $\left[\mathrm{Ag}_{2}\left(\mu-3-\mathrm{CH}_{3}-\mathrm{pz}\right)_{2}(\mathrm{PTA})_{2}\right]$ (2.8) (where $\mathrm{pz}=$ pyrazolate and PTA $=1,3,5$-triazaphosphaadamantane) (Scheme 2.1), along with a preliminary report of antibacterial properties of 2.1, 2.2 and 2.5 against the Gram-negative bacterial strain $P$. aeuroginosa. Complexes 2.1-2.4 are soluble in organic solvents but barely soluble in aqueous media. To circumvent this limitation, 1, 3, 5-triazaphosphaadamantane (PTA) has been employed as a co-ligand to synthesize the highly water-soluble complexes $\mathbf{2 . 5 - 2 . 8}$. By virtue of its ability to H-bond strongly with water molecules through the bridgehead $\mathrm{N}$ atoms, PTA has gained considerable attention as an auxiliary ligand for various catalytic reactions. ${ }^{15}$ Due to its biocompatibility and minimal intrinsic toxicity, ${ }^{16}$ PTA has also been utilized in the development of transition metal-based anticancer agents with excellent antiangiogenic and antimetastatic properties. ${ }^{17}$
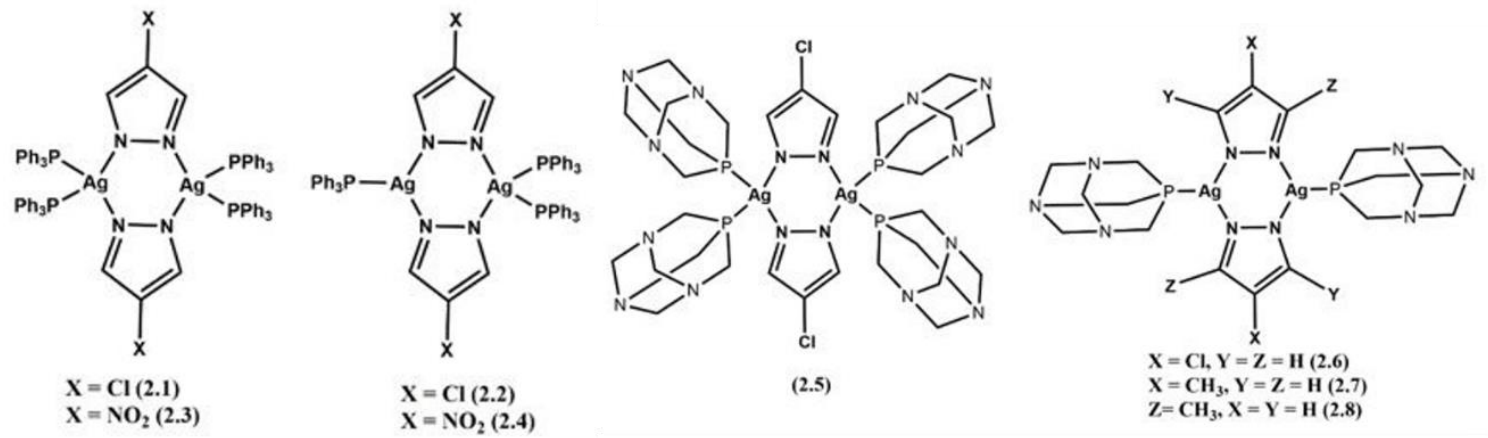

Scheme 2.1. Eight complexes synthesized for this work. 


\subsection{Experimental}

\subsubsection{Materials and method}

Reagent grade chemicals were purchased from Aldrich Chemical Co, Alfa Aesar, Fisher scientific and Acros Organics. THF was distilled over Na/benzophenone and $\mathrm{CH}_{2} \mathrm{Cl}_{2}$ was distilled over $\mathrm{CaCl}_{2} / \mathrm{CaH}_{2}$ prior to use. NMR spectra were recorded on $400 \mathrm{MHz}$ or $500 \mathrm{MHz}$ Bruker Avance spectrometers. FT-IR spectra were recorded with a Perkin Elmer Spectrum 100 FT-IR Spectrometer. Elemental analyses (CHN) were performed by Galbraith Laboratories, Inc. at Knoxville, TN.

\subsubsection{Synthesis of $\left[\mathrm{Ag}_{2}(\mu-4-\mathrm{Cl}-\mathrm{pz})_{2}\left(\mathrm{PPh}_{3}\right)_{4}\right][2.1]$}

$10.3 \mathrm{mg}(0.101 \mathrm{mmol}) 4-\mathrm{Cl}-\mathrm{pzH}$ and $22.9 \mathrm{mg}(0.10 \mathrm{mmol}) \mathrm{Ag}(\mathrm{PhCOO})$ were added to $5 \mathrm{~mL}$ THF and the reaction mixture was stirred at room temperature for $12 \mathrm{~h}$. After this time, the mixture was filtered and the insoluble polymeric $[\mathrm{Ag}(4-\mathrm{Cl}-\mathrm{pz})]_{\mathrm{n}}$ was collected by filtration and was thoroughly washed with $\mathrm{CH}_{2} \mathrm{Cl}_{2}$ to remove any unreacted starting materials. The solid was then dried under vacuum (Yield, $19.5 \mathrm{mg}$ (93\%), based on $\mathrm{Ag}(\mathrm{PhCOO})$ as a limiting reagent). Subsequently, $19.5 \mathrm{mg}(0.093 \mathrm{mmol})$ of the dry solid was suspended in $5 \mathrm{~mL} \mathrm{CH}_{2} \mathrm{Cl}_{2}, 131 \mathrm{mg}$ $\mathrm{PPh}_{3}(0.50 \mathrm{mmol})$ was added and the reaction mixture was stirred at room temperature for $20 \mathrm{~min}$ resulting in a clear colorless solution. The solvent was removed under reduced pressure and the resulting solid was thoroughly washed with hexanes to eliminate any excess $\mathrm{PPh}_{3}$. Finally the solid material was dissolved in $\mathrm{CH}_{2} \mathrm{Cl}_{2}$ and carefully layered with hexanes. X-ray quality blockshaped colorless crystals of 2.1. Yield: $60 \mathrm{mg}(88 \%)$. Anal. Calcd for $\mathrm{C}_{78} \mathrm{H}_{64} \mathrm{~N}_{4} \mathrm{Cl}_{2} \mathrm{P}_{4} \mathrm{Ag}_{2}(1467.93$ g mol-1): C, 62.82; H, 4.39; N, 3.82. Found: C, 62.73; H, 4.60; N, 3.51. IR ( $\left.\mathrm{v}_{\max }, \mathrm{cm}^{-1}\right)$ : 3046(w), 1477(m), 1432(s), 1268(w), 1174(w), 1093(m), 1024(m), 952(m), 815(w), 742(s), 692(s), 615(w). ${ }^{1} \mathrm{H}$ NMR (400 MHz, $\left.\mathrm{CDCl}_{3}\right) \delta(\mathrm{ppm}): 7.55$ (s, 4H, -CH/pz), 7.69-7.32 (m, 60H, -CH/PPh $) .{ }^{31} \mathrm{P}$ $\operatorname{NMR}\left(12.35 \mathrm{MHz}, \mathrm{CDCl}_{3}, \mathrm{ppm}\right)$ : -30.03 $\left(\mathrm{PPh}_{3}\right.$ at $-5.89 \mathrm{ppm}$ as reference). 


\subsubsection{Synthesis of $\left[\mathrm{Ag}_{2}(\mu-4-\mathrm{Cl}-\mathrm{pz})_{2}\left(\mathrm{PPh}_{3}\right)_{3}\right][2.2]$}

This complex was synthesized in the same way as complex 2.1, except 1.5 equivalents of $\mathrm{PPh}_{3}$ was used in this reaction. The solid obtained from the colorless reaction solution was washed thoroughly with hexanes and dried under vacuum. Next, this solid was dissolved in $\mathrm{CH}_{2} \mathrm{Cl}_{2}$ and layered with hexanes. Single crystals (as colorless blocks) of complex 2.2 were obtained after one week. Yield: $52 \mathrm{mg}$ (92\%). Anal. Calcd for $\mathrm{C}_{60} \mathrm{H}_{49} \mathrm{~N}_{4} \mathrm{Cl}_{2} \mathrm{P}_{3} \mathrm{Ag}_{2}$ (1205.64 g mol-1): C, 59.77; H, 4.10; N, 4.65. Found: C, 59.29; H, 3.99; N, 4.56. IR ( $\left.\mathrm{v}_{\max }, \mathrm{cm}^{-1}\right)$ 3048(w), 1477(m), 1432(s), 1268(w), 1174(w), 1093(m), 1024(m), 952(m), 817(w), 744(s), 692(s), 615(w). ${ }^{1} \mathrm{H}$ NMR (400 $\left.\mathrm{MHz}, \mathrm{CDCl}_{3}\right) \delta(\mathrm{ppm}): 7.41(\mathrm{~s}, 4 \mathrm{H},-\mathrm{CH} / \mathrm{pz}), 7.39-7.27\left(\mathrm{~m}, 45 \mathrm{H},-\mathrm{CH} / \mathrm{PPh}_{3}\right) .{ }^{31} \mathrm{P} \mathrm{NMR}\left(\mathrm{CDCl}_{3}\right.$, ppm): -27.82 $\left(\mathrm{PPh}_{3}\right.$ as reference).

\subsubsection{Synthesis of $\left[\mathrm{Ag}_{2}\left(\mu-4-\mathrm{NO}_{2}-\mathrm{pz}\right)_{2}\left(\mathrm{PPh}_{3}\right)_{4}\right][2.3]$}

This complex was prepared by the same procedure as 2.1, using $\left[\mathrm{Ag}\left(4-\mathrm{NO}_{2}-\mathrm{pz}\right)\right]_{\mathrm{n}}$ polymeric precursor (this polymer was obtained from the reaction of $\mathrm{Ag}(\mathrm{PhCOO})$ and 4- $\mathrm{NO}_{2}-\mathrm{pzH}$ following the same reaction conditions employed to isolate $[\mathrm{Ag}(4-\mathrm{Cl}-\mathrm{pz})]_{\mathrm{n}}$ polymer) and excess $\mathrm{PPh}_{3}$. Yield: 58 mg (88\%). Anal. Calcd for $\mathrm{C}_{78} \mathrm{H}_{64} \mathrm{~N}_{6} \mathrm{O}_{4} \mathrm{P}_{4} \mathrm{Ag}_{2}$ (1489.04 g mol-1): C, 62.92; H, 4.33; N, 5.64. Found: C, 61.90; H, 4.28; N, 5.66. IR ( $\left.\mathrm{v}_{\max }, \mathrm{cm}^{-1}\right): 3050(\mathrm{w}), 1496(\mathrm{~m}), 1475(\mathrm{~s}), 1430(\mathrm{~m})$, 1392(s), 1259(s), 1147(m), 1089(m), 1002(m), 852(w), 811(w), 742(s), 690(s), 601(s); ). ${ }^{1} \mathrm{H}$ NMR (400 MHz, $\left.\mathrm{CDCl}_{3}\right) \delta(\mathrm{ppm}): 7.91$ (s, 4H, -CH/pz),7.70-7.24 (m, 60H, -CH/PPh $) .{ }^{31} \mathrm{P} \mathrm{NMR}$ $\left(\mathrm{CDCl}_{3}, \mathrm{ppm}\right):-29.40\left(\mathrm{PPh}_{3}\right.$ as reference).

\subsubsection{Synthesis of $\left[\operatorname{Ag}_{2}\left(\mu-4-\mathrm{NO}_{2}-\mathrm{pz}\right)_{2}\left(\mathrm{PPh}_{3}\right)_{3}\right] .4 \mathrm{H}_{2} \mathrm{O}[2.4]$}

This complex was prepared by the same procedure as 2.2, using $\left[\mathrm{Ag}\left(4-\mathrm{NO}_{2}-\mathrm{pz}\right)\right]_{\mathrm{n}}$ polymeric precursor and 1.5 equivalent of $\mathrm{PPh}_{3}$. Yield: $52 \mathrm{mg}$ (94\%). Anal. Calcd for $\mathrm{C}_{60} \mathrm{H}_{49} \mathrm{~N}_{6} \mathrm{O}_{4} \mathrm{P}_{3} \mathrm{Ag}_{2}$ (1298.70 g mol-1): C, 55.44; H, 4.39; N, 6.46. Found: C, 56.22; H, 4.29; N, 6.28. IR ( $\left.\mathrm{v}_{\max }, \mathrm{cm}^{-1}\right)$ : 3050(w), 1479(s), 1432(m), 1396(s), 1263(s), 1151(m), 1093(m), 1002(m), 854(w), 811(m), 
742(s), 692(s), 603(s). ${ }^{1} \mathrm{H}$ NMR (400 MHz, $\left.\mathrm{CDCl}_{3}\right) \delta(\mathrm{ppm}): 7.81(\mathrm{~s}, 4 \mathrm{H},-\mathrm{CH} / \mathrm{pz}), 7.38-7.22(\mathrm{~m}$, 45H, $\left.-\mathrm{CH} / \mathrm{PPh}_{3}\right) .{ }^{31} \mathrm{P} \mathrm{NMR}\left(\mathrm{CDCl}_{3}, \mathrm{ppm}\right):-27.31\left(\mathrm{PPh}_{3}\right.$ as reference).

\subsubsection{Synthesis of $\left[\operatorname{Ag}_{2}(\mu-4-\mathrm{Cl}-\mathrm{pz})_{2}(\mathrm{PTA})_{4}\right]$. PTA [2.5]}

This complex was prepared by the same procedure as 2.1, using $[\mathrm{Ag}(4-\mathrm{Cl}-\mathrm{pz})]_{\mathrm{n}}$ polymeric precursor and 4 equivalents of PTA. Yield: $25 \mathrm{mg}$ (51\%). Anal. Calcd. for $\mathrm{C}_{36} \mathrm{H}_{64} \mathrm{~N}_{19} \mathrm{Cl}_{2} \mathrm{P}_{5} \mathrm{Ag}_{2}$ (1787.17 g mol-1): C, 35.90; H, 5.36; N, 22.09. Found: C, 36.51; H, 6.04; N, 21.10. IR ( $\mathrm{vmax}_{\max } \mathrm{cm}^{-}$ $\left.{ }^{1}\right)$ : 3197(s), 2944(w), 2906(w), 2275(w), 1637(w), 1448(m), 1411(s), 1295(s), 1241(s), 1105(m), 1037(s), 1012(s), 970(s), 948(m), 900(s), 794(m). ${ }^{1} \mathrm{H}$ NMR (400 MHz, D $\left.2 \mathrm{O}\right) \delta(\mathrm{ppm}): 7.67$ (s, 4H, -CH/pz), 7.32 - $7.23\left(\mathrm{~m}, 48 \mathrm{H},-\mathrm{CH} / \mathrm{PPh}_{3}\right) .{ }^{31} \mathrm{P}$ NMR $\left(\mathrm{D}_{2} \mathrm{O}, \mathrm{ppm}\right):-178.31$ (PTA at $-98.51 \mathrm{ppm}$ as reference).

\subsubsection{Synthesis of $\left[\mathrm{Ag}_{2}(\mu-4-\mathrm{Cl}-\mathrm{pz})_{2}(\mathrm{PTA})_{2}\right][2.6]$}

This complex was prepared by the same procedure as 2.1, using $[\mathrm{Ag}(4-\mathrm{Cl}-\mathrm{pz})]_{\mathrm{n}}$ polymeric precursor and 2 equivalents of PTA. X-ray quality crystals were obtained by the slow evaporation of reaction solution.

\subsubsection{Synthesis of $\left[\mathrm{Ag}_{2}\left(\mu-4-\mathrm{CH}_{3}-\mathrm{pz}\right)_{2}(\mathrm{PTA})_{2}\right][2.7]$}

This complex was prepared by the same procedure as 2.1, using $\left[\mathrm{Ag}\left(4-\mathrm{CH}_{3}-\mathrm{pz}\right)\right]_{\mathrm{n}}$ polymeric precursor and 1 equivalent of PTA. X-ray quality crystals were obtained by the slow evaporation of reaction solution.

\subsubsection{Synthesis of $\left[\mathrm{Ag}_{2}\left(\mu-3-\mathrm{CH}_{3}-\mathrm{pz}\right)_{2}(\mathrm{PTA})_{2}\right][2.8]$}

This complex was prepared by the same procedure as 2.1, using $\left[\mathrm{Ag}\left(3-\mathrm{CH}_{3}-\mathrm{pz}\right)\right]_{\mathrm{n}}$ polymeric precursor and 1 equivalent of PTA. X-ray quality crystals were obtained by the slow evaporation of reaction solution. 


\subsubsection{X-ray data collection and structure refinement}

Colorless block-shaped crystals of all complexes (2.1-2.8) were obtained by recrystallization through diffusion of hexanes into their dichloromethane $\left(\mathrm{CH}_{2} \mathrm{Cl}_{2}\right)$ solutions and/or slow evaporation of the reaction solution. In all cases a suitable crystal was selected and mounted on a Bruker D8 Quest diffractometer equipped with PHOTON 100 detector operating at $\mathrm{T}=298 \mathrm{~K}$. Data were collected with $\omega$ shutter less scan technique using graphite monochromated Mo-K $\alpha$ radiation $(\lambda=0.71073 \AA)$. The total number of runs and images for data collection was based on strategy calculation from the program APEX3 (Bruker). Resolution of $\theta>26^{\circ}$ was achieved in all cases. Cell parameters were retrieved using the SAINT (Bruker) software and refined using SAINT (Bruker). Data reduction was performed using the SAINT (Bruker) software, which corrects for Lorentz and polarization effects. The final completeness is $95.3 \%(\mathbf{2 . 1}), 99.7 \%(\mathbf{2 . 2}), 99.6 \%$ for (2.3), $99.4 \%(\mathbf{2 . 4}) 99.2 \%(\mathbf{2 . 5}), 99.7 \%(\mathbf{2 . 6}), 99.7 \%(\mathbf{2 . 7})$ and $99.2 \%(\mathbf{2 . 8})$. Multi-scan absorption corrections were performed on all data sets using SADABS 2016/2. The minimum and maximum transmissions for $\mathbf{2 . 1}$ are 0.685 and 0.746 , for $\mathbf{2 . 2}$ are 0.695 and 0.745 , for 2.3 are 0.646 and 0.745, for $\mathbf{2 . 4}$ are 0.685 and 0.745 and for $\mathbf{2 . 5}$ are 0.646 and 0.745 for $\mathbf{2 . 6}$ are 0.399 and 0.745 , for 2.7 are 0.685 and 0.745 and for $\mathbf{2 . 8}$ are 0.643 and 0.745 respectively. The structures for complexes 2.1-2.4 were solved in the space group $P-1$ (No. 2), for complexes 2.5 and 2.6 in $C 2 / c$ (No. 15) and for complexes 2.7 and 2.8 by $P 2_{l} / n$ (No. 11) by intrinsic phasing using the ShelXT (Sheldrick, 2015) ${ }^{18}$ structure solution program and refined by full matrix least square procedure on $\mathrm{F}^{2}$ using version $2016 / 6$ of ShelXL. ${ }^{19}$ The non-hydrogen atoms were refined anisotropically in all cases. Hydrogen atom positions were calculated geometrically and refined using the riding model. For structures of complexes $2.1,2.3,2.5,2.6,2.7$ and 2.8 only half of the molecule is present in the asymmetric unit, with the other half consisting of symmetry equivalent atoms. To alleviate the complications related to solvent accessible voids within the extended lattice of complex 2.2, the SQUEEZE operation (included in the PLATON program) was performed with 
the raw data set and the structure was refined form the data obtained upon SQUEEZE operation. ${ }^{20}$ For the complex 2.6, solvent accessible voids were masked in Olex 2 by solvent mask operation. ${ }^{21}$ Despite of several attempts, in case of $\mathbf{2 . 4}$, an accurate position of the hydrogen atoms for the lattice water molecules was not achieved. Therefore, no hydrogen is added on those oxygen atoms. All calculations and molecular graphics were preformed using either SHELXTL 2014 or Olex $2^{21}$ programs. Crystal data and structure refinement parameters for compounds $\mathbf{2 . 1}-\mathbf{2 . 5}$ are listed in Table 2.1 and 2.6-2.8 are listed in appendices Table A2.1. CCDC 1825643 (complex 2.1), CCDC 1825644 (complex 2.2), CCDC 1825646 (complex 2.3), CCDC 1825647 (complex 2.4) and CCDC 1825645 (complex 2.5 ) contain the supplementary crystallographic data for this paper. Complexes 2.6, 2.7 and $\mathbf{2 . 8}$ have not been deposited yet. 
Table 2.1. Crystal data and structure refinement parameters for complexes 2.1-2.5

\begin{tabular}{|c|c|c|c|c|c|}
\hline Formula & $\mathrm{C}_{78} \mathrm{H}_{64} \mathrm{Ag}_{2} \mathrm{~N}_{4} \mathrm{Cl}_{2} \mathrm{P}_{4}$ & $\mathrm{C}_{60} \mathrm{H}_{49} \mathrm{Ag}_{2} \mathrm{~N}_{4} \mathrm{Cl}_{2} \mathrm{P}_{3}$ & $\mathrm{C}_{78} \mathrm{H}_{64} \mathrm{Ag}_{2} \mathrm{~N}_{6} \mathrm{O}_{4} \mathrm{P}_{4}$ & $\mathrm{C}_{60} \mathrm{H}_{57} \mathrm{Ag}_{2} \mathrm{~N}_{6} \mathrm{O}_{8} \mathrm{P}_{3}$ & $\mathrm{C}_{30} \mathrm{H}_{52} \mathrm{Ag}_{2} \mathrm{~N}_{16} \mathrm{Cl}_{2} \mathrm{P}_{4}$ \\
\hline$D_{\text {calc. }} / \mathrm{g} \mathrm{cm}^{-3}$ & 1.434 & 1.335 & 1.443 & 1.374 & 1.722 \\
\hline$\mu / \mathrm{mm}^{-1}$ & 0.80 & 0.86 & 0.72 & 0.76 & 1.31 \\
\hline Formula Weight & 1467.85 & 1205.58 & 1488.97 & 1298.70 & 1047.39 \\
\hline Color & Colorless & Colorless & Colorless & Colorless & Colorless \\
\hline Shape & Block & Block & Block & Block & Block \\
\hline$T / \mathrm{K}$ & $298(2)$ & $298(2)$ & $298(2)$ & $298(2)$ & $298(2)$ \\
\hline Crystal System & Triclinic & Triclinic & Triclinic & Triclinic & Monoclinic \\
\hline Space Group & $P-1$ & $P-1$ & $P-1$ & $P-1$ & $C 2 / c$ \\
\hline$a / \AA ̊$ & $12.3970(7)$ & $11.9900(6)$ & $12.4684(8)$ & $12.0477(6)$ & $22.3522(18)$ \\
\hline$b / \AA$ & $12.6513(7)$ & $13.4064(7)$ & $12.7646(9)$ & $13.9333(6)$ & $7.6984(6)$ \\
\hline$c / \AA ̊$ & $13.4150(7)$ & $20.5531(11)$ & $13.4383(10)$ & $20.1754(10)$ & $25.899(2)$ \\
\hline$\alpha /^{\circ}$ & $97.372(2)$ & $93.164(2)$ & $98.117(2)$ & $81.223(1)$ & 90 \\
\hline$\beta l^{\circ}$ & $116.099(1)$ & $93.563(2)$ & $116.230(2)$ & $84.884(1)$ & $114.962(1)$ \\
\hline$y^{\circ}$ & $108.552(2)$ & $114.083(1)$ & $108.435(2)$ & $68.853(1)$ & 90 \\
\hline $\mathrm{V} / \AA^{3}$ & 1700.01(16) & 2998.6(3) & $1714.0(2)$ & $3119.5(3)$ & $4040.2(6)$ \\
\hline$Z$ & 1 & 2 & 1 & 2 & 4 \\
\hline Wavelength/Å & 0.71073 & 0.71073 & 0.71073 & 0.71073 & 0.71073 \\
\hline Radiation type & Mo-K $\alpha$ & Mo-K $\alpha$ & Mo-K $\alpha$ & Mo-K $\alpha$ & Mo-K $\alpha$ \\
\hline
\end{tabular}


Table 2.1. Crystal data and structure refinement parameters for complexes 2.1-2.5 (Continued)

\begin{tabular}{|c|c|c|c|c|c|}
\hline Formula & $\mathrm{C}_{78} \mathrm{H}_{64} \mathrm{Ag}_{2} \mathrm{~N}_{4} \mathrm{Cl}_{2} \mathrm{P}_{4}$ & $\mathrm{C}_{60} \mathrm{H}_{49} \mathrm{Ag}_{2} \mathrm{~N}_{4} \mathrm{Cl}_{2} \mathrm{P}_{3}$ & $\mathrm{C}_{78} \mathrm{H}_{64} \mathrm{Ag}_{2} \mathrm{~N}_{6} \mathrm{O}_{4} \mathrm{P}_{4}$ & $\mathrm{C}_{60} \mathrm{H}_{57} \mathrm{Ag}_{2} \mathrm{~N}_{6} \mathrm{O}_{8} \mathrm{P}_{3}$ & $\mathrm{C}_{30} \mathrm{H}_{52} \mathrm{Ag}_{2} \mathrm{~N}_{16} \mathrm{Cl}_{2} \mathrm{P}_{4}$ \\
\hline $2 \theta \mathrm{min} /{ }^{\circ}$ & 6.00 & 6.00 & 5.80 & 5.80 & 6.20 \\
\hline $2 \theta \max /{ }^{\circ}$ & 56.60 & 52.80 & 53.00 & 52.60 & 52.80 \\
\hline Measured Refl. & 28423 & 55827 & 31251 & 57586 & 38314 \\
\hline Independent Refl. & 8045 & 12266 & 7051 & 12623 & 4113 \\
\hline Reflections Used & 6244 & 8456 & 5461 & 10176 & 3876 \\
\hline Rint & 0.032 & 0.043 & 0.051 & 0.024 & 0.019 \\
\hline Parameters & 406 & 622 & 424 & 712 & 244 \\
\hline${ }^{\mathrm{a}} \mathrm{GOF}$ & 1.050 & 1.040 & 1.070 & 1.040 & 1.190 \\
\hline${ }^{c} \mathrm{wR}_{2}$ & 0.083 & 0.107 & 0.154 & 0.129 & 0.073 \\
\hline${ }^{b} \mathrm{R}_{1}$ & 0.037 & 0.045 & 0.058 & 0.039 & 0.029 \\
\hline
\end{tabular}

$\mathrm{aGOF}=[\Sigma[\omega(\mathrm{Fo} 2-\mathrm{Fc} 2) 2] /(\mathrm{No}-\mathrm{Nv})] 1 / 2(\mathrm{No}=$ number of observations, $\mathrm{Nv}=$ number of variables $)$.

${ }^{\mathrm{b}} \mathrm{R}_{1}=\Sigma|| \mathrm{F}_{\mathrm{o}}|-| \mathrm{F}_{\mathrm{c}}|| / \Sigma\left|\mathrm{F}_{\mathrm{o}}\right| \cdot{ }^{\mathrm{c}} \mathrm{WR}_{2}=\left[\left(\Sigma \omega\left(\mathrm{F}_{\mathrm{o}}^{2}-\mathrm{F}_{\mathrm{c}}^{2}\right)^{2} / \Sigma\left|\mathrm{F}_{\mathrm{o}}\right|^{2}\right)\right]^{1 / 2}$ 


\subsubsection{Antibacterial experiment}

A skin and soft tissue infection (SSTI) model was used to study the antibacterial properties of three silver complexes. In this model, two layers of agar were employed to mimic a tissue infection with a nutrient rich bottom and the soft-top layer to allow for even dispersal of bacteria. The top soft agar acts like the skin and as bacteria grow they migrate towards the bottom nutrient layer mimicking an infected tissue. Frozen samples of Pseudomonas Aeruginosa were thawed and streaked on an agar plate. A single colony was selected and grown in Luria Broth (LB) for 18 h. The suspension was diluted with LB until an $A_{600}$ (absorbance) of 0.5 was reached. The soft agar bacterial suspension was prepared by adding $120 \mu \mathrm{L}$ of the above solution to $100 \mathrm{~mL} 0.8 \%$ (w/v) agar with $1 \% \mathrm{NaCl}$, which had been autoclaved and cooled to $45^{\circ} \mathrm{C}$ before addition. The suspension was gently vortexed and $8 \mathrm{~mL}$ was spread evenly on the surface of $20 \mathrm{~mL}$ of a $1.5 \%$ (w/v) TSB agar plate $\left(100 \times 15 \mathrm{~mm}^{2}\right)$ and allowed to solidify. The plates were incubated for $2 \mathrm{~h}$ at $37^{\circ} \mathrm{C}$ in order for the bacteria to reach $\log$ phase before bactericidal experiments were performed.

\subsection{Results and discussion}

In most cases the solution structure of coordination complexes with substitutionally labile ligands (like $\mathrm{PPh}_{3}$ and PTA in the present case) is different from the solid-state structure. Therefore, we have chosen to perform ${ }^{31} \mathrm{P}$ NMR studies with complexes $\mathbf{2 . 1 - 2 . 5}$, to gain an insight on possible solution characteristics of these complexes. Due to difference in solubility, ${ }^{31} \mathrm{P}$ NMR spectroscopy for complexes 2.1-2.4 was performed in $\mathrm{CDCl}_{3}$ solutions, while the same for complex 2.5 was carried out in $\mathrm{D}_{2} \mathrm{O}$ (due to poor solubility in $\mathrm{CDCl}_{3}$ or $\mathrm{CD}_{2} \mathrm{Cl}_{2}$ ). For the former complexes $\mathrm{PPh}_{3}$ was used as standard and PTA has been employed for the latter one. The substantial kinetic lability of the phosphine ligands often leads to rapid ligand exchange in solution at ambient temperature at the NMR time scale. Indeed, ${ }^{31} \mathrm{P}$ NMR spectra recorded in the $275-295 \mathrm{~K}$ temperature range for the complexes uniformly reveal one resonance indicating the 
fluxional behavior in solution resulting in convergence of the two magnetically inequivalent $\mathrm{PPh}_{3}$ ligands for complexes $\mathbf{2 . 2}$ and 2.4. The comparative ${ }^{31} \mathrm{P}$ NMR spectra are shown in Figure 2.1 and the chemical shift values are listed in the experimental section. The room temperature ${ }^{1} \mathrm{H}$ NMR spectra of 2.2 and 2.4 also show a single resonance for the pyrazole $\mathrm{H}^{3}$ and $\mathrm{H}^{5}$ protons, in agreement with the ${ }^{31} \mathrm{P}$ NMR results.

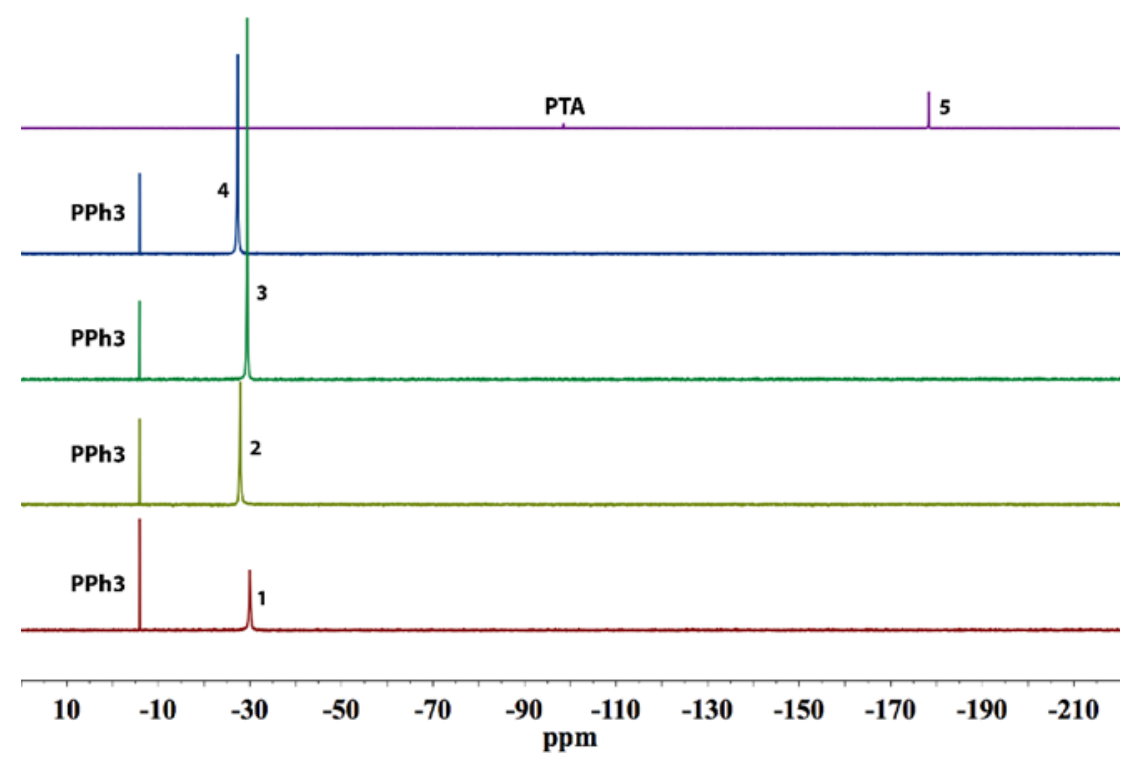

Figure 2.1. Comparative ${ }^{31} \mathrm{P}$ NMR spectra for complexes 2.1-2.5. (1 corresponds to 2.1 and so on)

Single crystal X-ray crystallographic analyses reveal the molecular structures for all complexes (2.1-2.8). Among them the perspective view for three structures $(2.1,2.2,2.5$ and 2.6) are depicted in Figures 2.2 and 2.3 and selected metric parameters are listed in Tables 2.2 and 2.3. The X-ray structures and the metric parameters for complexes $2.3,2.4,2.7$ and 2.8 are provided in the Appendices as Figures A2.1, A2.2 and Tables A2.2, A2.3 for $\mathbf{2 . 3}$ and 2.4 and A2.4 for 2.6, 2.7, and $\mathbf{2 . 8}$ respectively. 

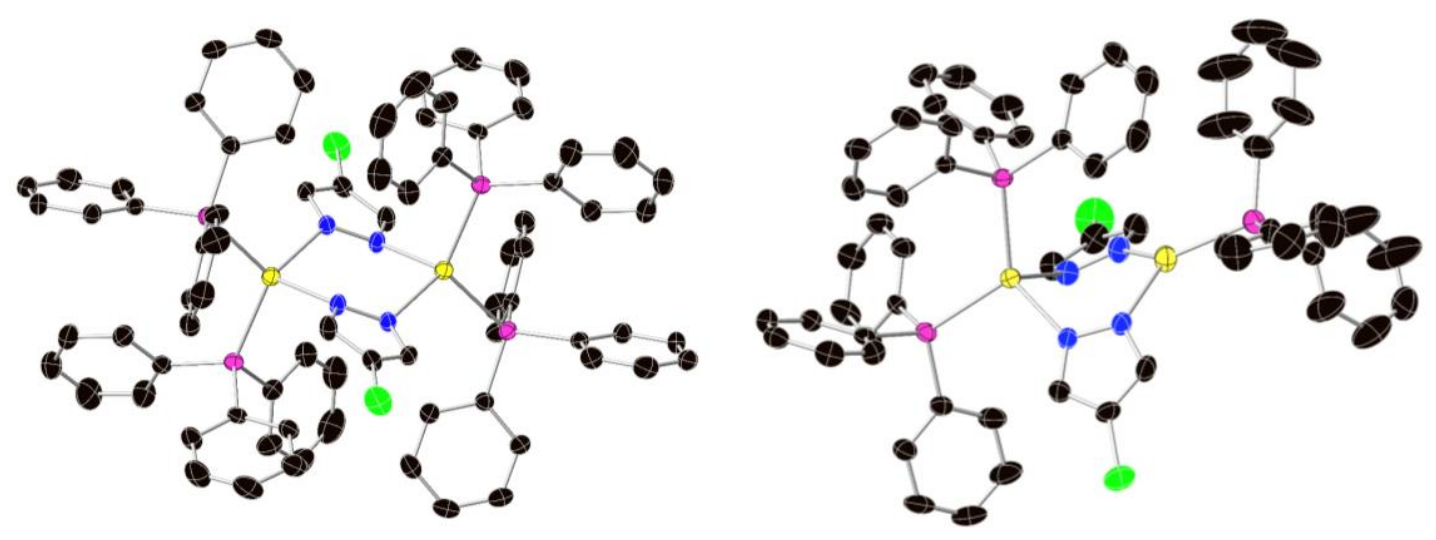

Figure 2.2. Perspective view of the molecular structure of complexes $\mathbf{2 . 1}$ (left) and $\mathbf{2 . 2}$ (right). The thermal ellipsoids are shown at $35 \%$ probability level $(\mathrm{H}$ atoms are omitted and the labeling scheme are shown only for the hetero atom for the sake of clarity). Color code: C, black; N, blue; $\mathrm{Cl}$, green; $\mathrm{P}$, pink and Ag, yellow.
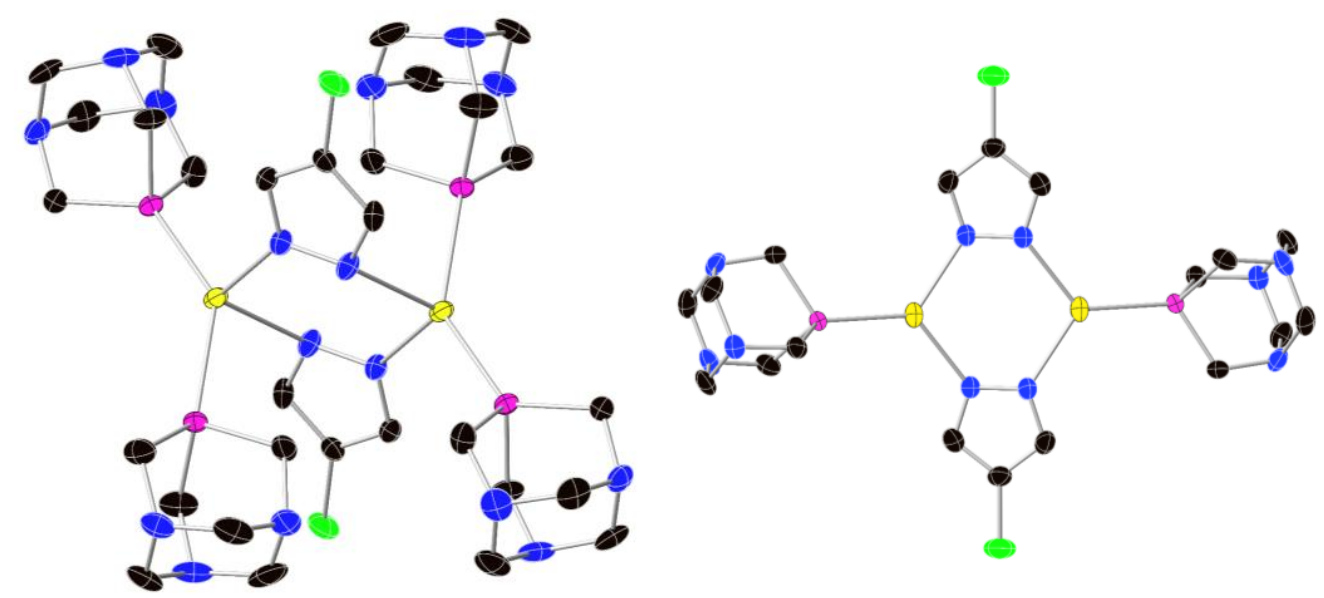

Figure 2.3. Perspective view of the molecular structure of complexes 2.5 (left) and $\mathbf{2 . 6}$ (right). The thermal ellipsoids are shown at $35 \%$ probability level $(\mathrm{H}$ atoms are omitted and the labeling scheme are shown only for the hetero atom for the sake of clarity). Color code: C, black; N, blue; $\mathrm{Cl}$, green; $\mathrm{P}$, pink and $\mathrm{Ag}$, yellow.

X-ray structures of complexes $\mathbf{2 . 1}, \mathbf{2 . 3}, \mathbf{2 . 5}, \mathbf{2 . 6}, \mathbf{2 . 7}$ and 2.8 (Figs 2.2(left), A1 (left), 2.3 (left), 2.3 (right), A2.2 (left) and A2.2 (right) respectively) reveal that in all six cases the two $\mathrm{Ag}(\mathrm{I})$ centers are equivalent and each metal center for 2.1, 2.3 and 2.5 resides in a distorted tetrahedral coordination environment. To assess the distortion from the ideal tetrahedral geometry around the Ag centers, a simple index $(\tau 4)$ developed by Houser and co-workers ${ }^{22}$ have been calculated for 
2.1 and 2.5. Simple index is unity for a perfect tetrahedron and zero for square planar geometry. The $\tau 4$ values for $\mathbf{2 . 1}$ and $\mathbf{2 . 5}$ are 0.89 and 0.78 respectively suggesting the coordination environment around the Ag centers is distorted tetrahedral in these complexes. Two $\mu$-pyrazolates bridge the $\operatorname{Ag}(\mathrm{I})$ centers and the other two coordination sites of each $\operatorname{Ag}(\mathrm{I})$ center are occupied by two $\mathrm{PPh}_{3}$ ligands. The two Ag atoms along with four N atoms (Ag1, Ag1a, N1, N2, N1a, N2a) of the bridging pyrazolates form a centrosymmetric six-membered ring in a chair conformation, with one Ag-atom on either side of the planes defined by the pz rings and at a Ag...Ag distance of 4.209(4) $\AA$ (2.1) and 4.205(3) $\AA$ (2.5). This twisted metallacyclic conformation is rare in literature, but not unprecedented. ${ }^{23}$ Although 2.1 and 2.5 are structurally similar, careful scrutiny of the metric parameters reveals certain differences (Table 2.1): The average $\mathrm{Ag}-\mathrm{N}$ bond length in 2.1, 2.319(2) $\AA$, is shorter than that in 2.5 (2.367(3) $\AA$ ); The $\mathrm{P}-\mathrm{Ag}-\mathrm{P}$ angle in 2.1, 118.82(2) is noticeably more acute than the corresponding $140.43(3)^{\circ}$ angle in $\mathbf{2 . 5}$ and the same applies to the $\mathrm{N}-\mathrm{Ag}-\mathrm{N}$ bond angles, $98.00(7)^{\circ}(\mathbf{2 . 1})$ and $103.37(9)^{\circ}(\mathbf{2 . 5})$, the differences attributed to the steric bulk of PTA compared to $\mathrm{PPh}_{3}$. Consequently, the average $\mathrm{N} 1-\mathrm{Ag} 1-\mathrm{P} 1$ angle in $\mathbf{2 . 1}$ $109.32(6)^{\circ}$ is more obtuse than in $2.5101 .80(7)^{\circ}$. The average $\mathrm{Ag} 1-\mathrm{P} 1$ bond lengths for these two complexes, 2.4921(7) $\AA$ (2.1) and 2.4972(8) $\AA$ (2.5), respectively, are indistinguishable.

Table 2.2. Selected bond distances $(\AA)$ and angles $\left(^{\circ}\right)$ for $\mathbf{2 . 1}$ and $\mathbf{2 . 5}$.

\begin{tabular}{lcc}
\hline & Complex 2.1 & Complex 2.5 \\
\hline Ag1-P1 & $2.5003(7)$ & $2.5345(8)$ \\
Ag1-P2 & $2.4838(7)$ & $2.4598(7)$ \\
Ag1-N1 & $2.285(2)$ & $2.336(2)$ \\
Ag1-N2a & $2.353(2)$ & $2.398(3)$ \\
P2-Ag1-P1 & $118.82(2)$ & $140.43(3)$ \\
N1-Ag1-P2 & $110.20(6)$ & $109.52(7)$ \\
\hline
\end{tabular}




\begin{tabular}{lcc}
\hline & Complex 2.1 & Complex 2.5 \\
\hline $\mathrm{N} 1-\mathrm{Ag} 1-\mathrm{P} 1$ & $115.09(6)$ & $100.00(7)$ \\
$\mathrm{N} 1-\mathrm{Ag} 1-\mathrm{N} 2 \mathrm{a}$ & $98.00(7)$ & $103.37(9)$ \\
$\mathrm{N} 2 \mathrm{a}-\mathrm{Ag} 1-\mathrm{P} 2$ & $105.32(6)$ & $105.46(7)$ \\
$\mathrm{N} 2-\mathrm{Ag} 1-\mathrm{P} 1$ & $106.68(6)$ & $92.23(7)$ \\
\hline
\end{tabular}

The a-labeled atoms are generated by the $-\mathrm{x}+1,-\mathrm{y},-\mathrm{z}+1$ symmetry operation

The crystal structure of $\mathbf{2 . 2}$ reveals an unsymmetrical dinuclear complex (Fig. 2.2). In this case, the coordination geometry of one $\operatorname{Ag}(\mathrm{I})$ center is distorted tetrahedral, whereas that of the other $\mathrm{Ag}(\mathrm{I})$ center is approximately triangular planar.

Table 2.3. Selected bond distances $(\AA)$ and angles $\left(^{\circ}\right)$ for $\mathbf{2 . 2}$

\begin{tabular}{llll}
\hline & & \multicolumn{3}{c}{ Complex 2.2 } \\
\hline Ag1-P1 & $2.4852(9)$ & $\mathrm{Ag} 2-\mathrm{P} 3$ & $2.3735(11)$ \\
$\mathrm{Ag} 1-\mathrm{P} 2$ & $2.4751(9)$ & $\mathrm{Ag} 2-\mathrm{N} 4$ & $2.204(3)$ \\
$\mathrm{Ag} 1-\mathrm{N} 1$ & $2.260(3)$ & $\mathrm{Ag} 2-\mathrm{N} 2$ & $2.246(3)$ \\
$\mathrm{Ag} 1-\mathrm{N} 3$ & $2.361(3)$ & & $130.82(9)$ \\
$\mathrm{P} 2-\mathrm{Ag} 1-\mathrm{P} 1$ & $121.03(3)$ & $\mathrm{N} 4-\mathrm{Ag} 2-\mathrm{P} 3$ & $108.63(12)$ \\
$\mathrm{N} 1-\mathrm{Ag} 1-\mathrm{P} 2$ & $121.43(8)$ & $\mathrm{N} 4-\mathrm{Ag} 2-\mathrm{N} 2$ & $120.06(8)$ \\
$\mathrm{N} 1-\mathrm{Ag} 1-\mathrm{P} 1$ & $107.29(8)$ & $\mathrm{N} 2-\mathrm{Ag} 2-\mathrm{P} 3$ & \\
$\mathrm{~N} 1-\mathrm{Ag} 1-\mathrm{N} 3$ & $95.28(11)$ & & \\
$\mathrm{N} 3-\mathrm{Ag} 1-\mathrm{P} 2$ & $102.40(8)$ & & \\
$\mathrm{N} 3-\mathrm{Ag} 1-\mathrm{P} 1$ & $104.14(8)$ & & \\
\hline
\end{tabular}


In 2.2, the average $\mathrm{Ag}-\mathrm{N}$ bond length of 2.311(3) $\AA$ at the tetrahedral site is comparable to the corresponding distance in $\mathbf{2 . 1}$, while that of the trigonal planar site, 2.225(3) $\AA$, is considerably shorter. The P1-Ag1-P2 angle (tetrahedral site) of 121.03(3) ${ }^{\circ}$, and the N1-Ag1-N3 angle of 2.2 $\left(95.28(11)^{\circ}\right)$ are comparable to the corresponding values in complex 2.1. However, the $\mathrm{N} 4-\mathrm{Ag} 2-\mathrm{N} 2$ angle is noticeably larger $108.63(12)^{\circ}$, consistent with the planar coordination sphere around Ag2 center. A structurally similar complex as $\mathbf{2 . 2}$ derived from unsubstituted pyrazole, namely, $\left[\mathrm{Ag}_{2}(\mu-\mathrm{pz})_{2}\left(\mathrm{PPh}_{3}\right)_{3}\right]$ has been reported earlier. ${ }^{24}$ In this case the $\mathrm{Ag}-\mathrm{N}$ bond length at the tetrahedral and the triangular planar sites are 2.309(2) and 2.206(2) A, respectively, comparable to the values observed in complex 2.2. The bond angles for both tetrahedral and the planar sites in $\left[\mathrm{Ag}_{2}(\mu-\mathrm{pz})_{2}\left(\mathrm{PPh}_{3}\right)_{3}\right]$ and complex 2.2 are rather similar. The $\mathrm{Ag} \ldots \mathrm{Ag}$ distance in 2.2 is $3.707(3) \AA$ almost identical with that in $\left[\mathrm{Ag}_{2}(\mu-\mathrm{pz})_{2}\left(\mathrm{PPh}_{3}\right)_{3}\right](3.706(1) \AA)$.

Complex 2.3 (Fig A1 (left)) is structurally quite similar to complex 2.1 (Fig 2 (left)). The two Ag atoms in this structure also form a twisted metallacycle as observed for 2.1. In this case the Ag...Ag distance is 4.305(4) $\AA$. The average $\mathrm{Ag}-\mathrm{N}$ bond length in $\mathbf{2 . 3}, 2.343(4) \AA$ is similar to that in $\mathbf{2 . 1}(2.319(2) \AA)$. The $\mathrm{P}-\mathrm{Ag}-\mathrm{P}$ angle in $\mathbf{2 . 3}, \mathbf{1 2 0 . 7 5 ( 4 )}$ is consistent with that found in $\mathbf{2 . 1}$ $\left(118.82(2)^{\circ}\right)$. The two Ag atoms in $\mathbf{2 . 4}$ (Fig A1 (right)) exhibit same coordination geometry as in complex 2.2 (Fig 2(right)). In 2.4, the average $\mathrm{Ag}-\mathrm{N}$ bond length of 2.364(3) $\AA$ at the tetrahedral site, slightly longer than the corresponding distance in $\mathbf{2 . 2}$, while that of the trigonal planar site, 2.233(3) $\AA$, is very similar. The $\mathrm{P} 1-\mathrm{Ag} 1-\mathrm{P} 2$ angle (tetrahedral site) is $24.62(3)^{\mathrm{o}}$ and the $\mathrm{N} 1-\mathrm{Ag} 1-\mathrm{N} 4$ angle in $\mathbf{2 . 4}\left(97.24(11)^{\circ}\right)$ are comparable to the corresponding values in complex 2.2. Ag1-P1 bond distances of complexes 2.6, 2.7 and $\mathbf{2 . 8}$ are quite similar i.e. 2.3630 (12), 2.3618 (19) and 2.3654 (13) respectively (Table A4). In all three cases both silver metals have distorted trigonal planar geometry with N1-Ag-N2 angles 107.47(13) for 2.6, 108.3(2) for 2.7 and 108.48(12) for $\mathbf{2 . 8 .}$ 


\subsubsection{Antibacterial studies}

Blank $\mathrm{KBr}$ pellets (typically utilized for recording IR spectra) and $\mathrm{KBr}$ pellets with $2 \%$ (w/w) of three complexes (2.1, 2.2 and 2.5), each weighing between 34 and $46 \mathrm{mg}$, were evenly mulled and pressed with a two-ton load. Three blanks, containing PTA, or 4-Cl-pzH, or $\mathrm{PPh}_{3}$, were also prepared in the same manner. Pellets were carefully placed on the plates (see Experimental section for preparation) after $2 \mathrm{~h}$ of incubation at $37{ }^{\circ} \mathrm{C}$. Visible circular zones of bacterial clearing (zone of inhibition) around complex 2.5 and $\mathrm{AgNO}_{3}$ pellets were observed after incubation at $37{ }^{\circ} \mathrm{C}$ for $18 \mathrm{~h}$ (Figure 2.4). Complex 2.5 and $\mathrm{AgNO}_{3}$ pellets revealed comparable bacterial clearance even though the $\mathrm{KBr}$ pellet with complex 2.5 contained less silver per weight than the $\mathrm{AgNO}_{3}$ pellet. This superior growth inhibitory performance of $\mathbf{2 . 5}$ could in part be due to marginal antibacterial effects of ligands (PTA and 4-Cl-pzH), which showed much smaller but still visible zones of bacterial growth inhibition. The plates containing complexes $\mathbf{2 . 1}$ and $\mathbf{2 . 2}$ exhibited minimal bacterial clearance while $\mathrm{PPh}_{3}$ and $\mathrm{KBr}$ (bottom row) showed no zone of inhibition. Also the $\%$ of $\mathrm{Ag}(\mathrm{w} / \mathrm{w})$ and concentration of bio-active silver in plates a), b), e) and f) are listed in Table 2.4.

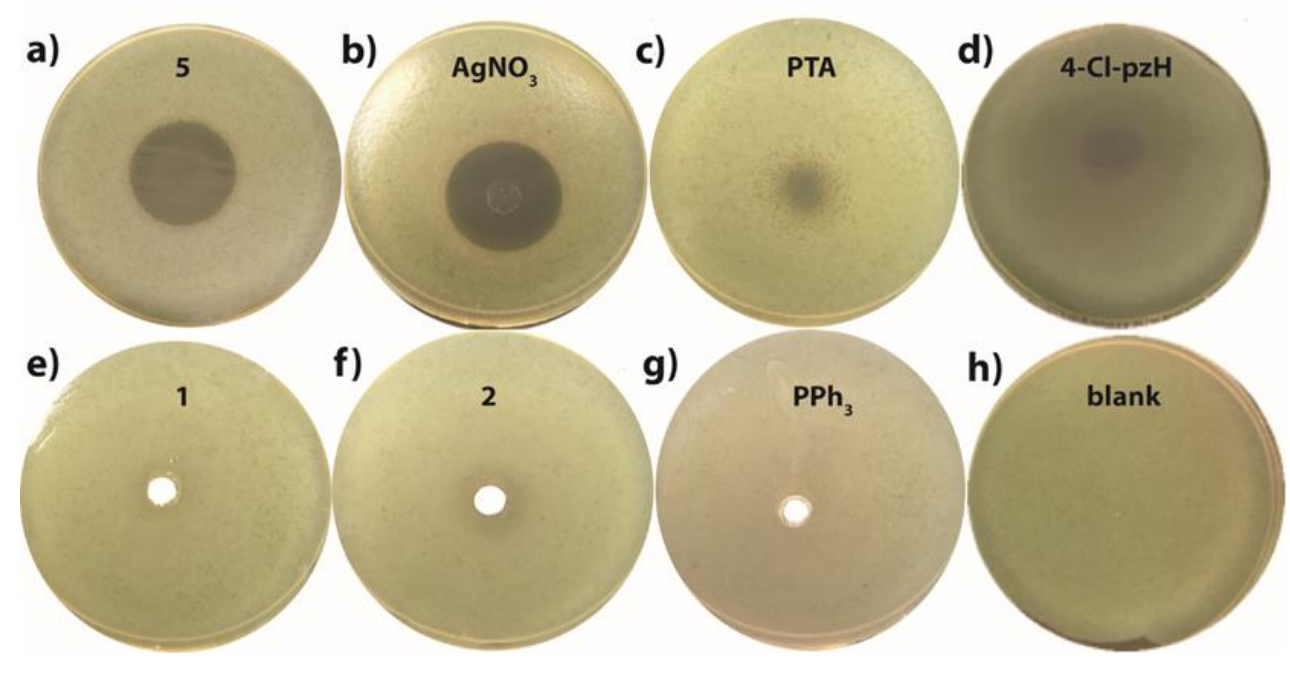

Figure 2.4. P. aeruginosa lawns after $18 \mathrm{~h}$ incubation with pellets of $2 \%(\mathrm{w} / \mathrm{w})$ of a) complex $\mathbf{2 . 5}$, b) $\mathrm{AgNO}_{3}$, c) PTA, d) 4-Cl-pzH, e) complex 2.1, f) complex 2.2, g) $\mathrm{PPh}_{3}$, and h) blank plate. 
The antibacterial efficacy is highly dependent on efficient cellular uptake of the compound. A slightly electronegative surface potential of bacterial cell walls allow cationic complexes to penetrate relatively easily compared to their neutral analogues. ${ }^{25}$ In the present study all silver(I) complexes are neutral and thereby are lacking this advantage, as can be seen from the marginal antibacterial effects of complexes $\mathbf{2 . 1}$ and 2.2 (Figure 2.4). However exceptional growth inhibition of P. aeruginosa by complex 2.5 can be attributed to enhanced cellular uptake of this complex facilitated by the PTA moieties due to their optimal lipophilicity. The bridgehead N atoms of the PTA moiety become protonated under certain physiological conditions ${ }^{15}$ and can thereby contribute towards facile cellular uptake and thereafter retention of its complexes. In fact, the adamantane motif has been widely used in various pharmaceuticals as a "lipophilic bullet" and these drugs are generally very effective due to rapid internalization by a variety of cells and tissues. ${ }^{26}$ Although a few silver complexes containing the PTA moiety have shown promise as antibacterial agents, they are relatively sparse. ${ }^{27}$ It is interesting to note that the majority of $\mathrm{Ag}$ PTA compounds are polymeric and their bridgehead $\mathrm{N}$ atoms also engage in bonding with silver. ${ }^{26-27}$ Our present report describes a new discrete dinuclear silver pyrazolate complex, where PTA is directly coordinated to $\operatorname{Ag}(\mathrm{I})$ centers and no further polymeric growth through the $\mathrm{N}$ atoms of the PTA moiety has been realized.

Table 2.4. Concentration and $\% \mathrm{Ag}(\mathrm{w} / \mathrm{w})$ in each pellet.

\begin{tabular}{ccc}
\hline Sample & Conc. of Ag in the pellet (M) & \% Ag in the pellet (w/w) \\
\hline $\mathbf{2 . 1}$ & $1.03548 \times 10^{-6}$ & 0.29394 \\
$\mathbf{2 . 2}$ & $1.26075 \times 10^{-6}$ & 0.35789 \\
$\mathbf{2 . 5}$ & $1.45127 \times 10^{-6}$ & 0.41197 \\
$\mathrm{AgNO}_{3}$ & $4.47401 \times 10^{-6}$ & 1.27003 \\
\hline
\end{tabular}


A previously developed soft tissue infection (SSTI) model has been utilized for the present antibacterial studies. ${ }^{28}$ This model mimics the skin in which steady penetration of bacteria to the deeper layer has been achieved using a two-layer agar system that has a soft, evenly dispersed bacterial lawn on the top and a nutrient-rich bottom layer. The gradient causes the bacteria to slowly travel from the slender top layer to the nutrient-rich bottom layer, much alike what would occur in a typical skin infection.

Three complexes (2.1, 2.2 and 2.5) along with 4-Cl-pzH and two the phosphine ligands $\left(\mathrm{PPh}_{3}\right.$ and PTA) have been assessed for their bactericidal efficacy against a Gram-negative aerobic gammaproteobacterium namely, $P$. aeruginosa. This bacterium is one of the most notorious contributors to the nosocomial infections around the World. ${ }^{29}$ During pre-penicillin G era, Staphylococcus aureus used to be the most common pathogen responsible in burn wound infections. Although this Gram-positive bacterium still remains one of the sources for such infections, in recent times P. aeruginosa has been recognized as major cause of burn wound infections in hospitals. ${ }^{30}$ Apart from P. aeruginosa, fatal burn wound sepsis can also be instigated through infections caused by $\mathrm{S}$. aureus and A. Baumannii. ${ }^{31}$ However, a very recent study revealed that P. aeruginosa infections have the most severe consequences towards burn injuries and often lead to mortality. ${ }^{32}$ In the same study, the effect of the burn wound exudates from a group of patients has been investigated on virulence of several pathogens (including S. aureus and A. Baumannii). Interestingly among all the pathogens, $P$. aeruginosa exclusively exhibits normal proliferation within these exudates. In contrast, kinetic studies clearly delineated growth inhibitory effect of the burn wound exudates for other pathogens. ${ }^{32}$ Development of therapeutics to combat this nosocomial pathogen deserves urgent attention as with time these microorganisms have developed increasing resistance to antibiotics, particularly in immunocompromised and cystic fibrosis patients. ${ }^{29}$ 
Silver nitrate and silver sulfadiazine (SSD) are two widely used topical antimicrobial agents for burn wound infections. However, these topical therapeutics suffer from serious limitations: Rapid reaction of silver nitrate with biological chloride ions forms insoluble silver chloride and thereby requires continuous administration with the occlusive dressings. Also, although dissociation of silver ions from of SSD is slower compared to that in silver nitrate, poor dermal penetration of this topical agent limits its efficacy on severe burn wound sites. Moreover, a nephrotic syndrome is prevalent within patients receiving this topical therapy, due to an allergenic reaction associated with the sulfadiazine component. ${ }^{29}, 33$ These considerations encouraged us to assess the effectiveness of the silver pyrazolate complexes as alternative topical therapeutics against P. aeruginosa infections utilizing a SSTI model. The lability of Ag-P bonds, as discussed in detail earlier by other research groups, ${ }^{24}$ is also evident from the NMR spectroscopic behavior of the present $\operatorname{Ag}(\mathrm{I})$ complexes. Such lability induces the release of bioactive Ag to the wound sites and is believed to be a contributing factor towards the antibacterial activity of complexes 2.1, 2.2 and 2.5 in the present work.

\subsection{Conclusions}

In conclusion eight dinuclear silver(I) complexes (2.1-2.8) derived from two 3 and 4-subsitutued pyrazole ligands have been synthesized and structurally characterized. The highly water-soluble complex 2.5 incorporating a PTA coligand has shown excellent antibacterial activity in SSTI model against $P$. aeruginosa. Antibacterial sctivity of 2.6-2.8 is under study. The zone of inhibition (could be either bactericidal or bacteriostatic) in the bacterial culture caused by application of complex 2.5 is superior to that for $\mathrm{AgNO}_{3}$. The 4-Cl-pzH ligand shows marginal growth inhibition, in line with the known antimicrobial properties of pyrazoles. The relatively lower efficacy of the two organosoluble complexes (2.1 and 2.2) is tentatively attributed to inferior cellular uptake (considering all these complexes are neutral in charge). The highly 
lipophilic nature of the PTA motif (in case of 2.5) overwhelms the disadvantage of its complex being neutral, which is considered unfavorable towards cellular internalization compared to a positively charged analogue. Silver-based nanoscale antibacterial agents have also been projected as new generation chemotherapeutics to combat antibiotic resistance. However, the toxicity profile of these nanomaterials towards human health and environment is debatable and extensive in vitro and in vivo studies are warranted to understand their transport and fate. ${ }^{34}$ Therefore, the urge for the development of discrete molecular Ag-based antibacterial agents remains highly relevant in treating most notorious classes of pathogens that are becoming resistant to a variety of antibiotics. Though there have been persistent efforts within the related research community to develop $\operatorname{Ag}(\mathrm{I})$-based antimicrobial agents, such studies with $\operatorname{Ag}(\mathrm{I})$ pyrazolate complexes is relatively sparse. The majority of the biomedical studies have, so far, involved either $\mathrm{Ag}(\mathrm{I})$-based coordination polymer/MOF or hybrid materials. ${ }^{35}$ In one of such studies $\mathrm{Ag}(\mathrm{I})$ bipyrazole-based coordination polymers were employed to assess the antibacterial activity against E.Coli, P. aeruginosa and S. sureus. ${ }^{35}$

In the present case, we have described a rare experimental venture of assessing the antimicrobial potency of a class of discrete $\operatorname{Ag}(\mathrm{I})$ pyrazolate complexes. Complex 2.5 is particularly highlighted in our antibacterial experiments due to the biocompatible nature of its constituents. Further antibacterial study of $\mathbf{2 . 5}$ and other water-soluble complexes is in progress. Several pyrazole-based NSAIDs are already approved for clinical use and PTA has been part of several Ru-based anticancer agents. ${ }^{14}$

\subsection{References}

1. Golkar, Z.; Bagasra, O.; Pace, D. G., Bacteriophage therapy: a potential solution for the antibiotic resistance crisis. The Journal of Infection in Developing Countries 2014, 8 (02), 129-136. 
2. (a) Viswanathan, V., Off-label abuse of antibiotics by bacteria. Taylor \& Francis: 2014; (b) Michael, C. A.; Dominey-Howes, D.; Labbate, M., The antimicrobial resistance crisis: causes, consequences, and management. Frontiers in public health 2014, 2, 145.

3. Gross, M., Phage therapies for plants and people. Elsevier: 2014.

4. Rossolini, G. M.; Arena, F.; Pecile, P.; Pollini, S., Update on the antibiotic resistance crisis. Current opinion in pharmacology 2014, 18, 56-60.

5. (a) Johnson, N. A.; Southerland, M. R.; Youngs, W. J., Recent developments in the medicinal applications of silver-NHC complexes and imidazolium salts. Molecules 2017, 22 (8), 1263; (b) Azócar, M. I.; Gómez, G.; Levín, P.; Paez, M.; Muñoz, H.; Dinamarca, N., Antibacterial behavior of carboxylate silver (I) complexes. Journal of Coordination Chemistry 2014, 67 (23-24), 3840-3853; (c) Chernousova, S.; Epple, M., Silver as antibacterial agent: ion, nanoparticle, and metal. Angewandte Chemie International Edition 2013, 52 (6), 1636-1653.

6. (a) Clement, J. L.; Jarrett, P. S., Antibacterial silver. Metal-based drugs 1994, 1 (5-6), 467482; (b) Russell, A.; Hugo, W., 7 antimicrobial activity and action of silver. In Progress in medicinal chemistry, Elsevier: 1994; Vol. 31, pp 351-370.

7. Jung, W. K.; Koo, H. C.; Kim, K. W.; Shin, S.; Kim, S. H.; Park, Y. H., Antibacterial activity and mechanism of action of the silver ion in Staphylococcus aureus and Escherichia coli. Applied and environmental microbiology 2008, 74 (7), 2171-2178.

8. Park, H.-J.; Kim, J. Y.; Kim, J.; Lee, J.-H.; Hahn, J.-S.; Gu, M. B.; Yoon, J., Silver-ionmediated reactive oxygen species generation affecting bactericidal activity. Water research 2009, 43 (4), 1027-1032.

9. Feng, Q. L.; Wu, J.; Chen, G.; Cui, F.; Kim, T.; Kim, J., A mechanistic study of the antibacterial effect of silver ions on Escherichia coli and Staphylococcus aureus. Journal of biomedical materials research 2000, 52 (4), 662-668.

10. (a) Aziz, Z.; Abu, S.; Chong, N., A systematic review of silver-containing dressings and topical silver agents (used with dressings) for burn wounds. Burns 2012, 38 (3), 307-318; (b) Atiyeh, B. S.; Costagliola, M.; Hayek, S. N.; Dibo, S. A., Effect of silver on burn wound infection control and healing: review of the literature. burns 2007, 33 (2), 139-148.

11. (a) Politano, A. D.; Campbell, K. T.; Rosenberger, L. H.; Sawyer, R. G., Use of silver in the prevention and treatment of infections: silver review. Surgical infections 2013, 14 (1), 8-20; (b) Dai, T.; Huang, Y.-Y.; K Sharma, S.; T Hashmi, J.; B Kurup, D.; R Hamblin, M., Topical antimicrobials for burn wound infections. Recent patents on anti-infective drug discovery 2010, 5 (2), 124-151.

12. Gouma, E.; Batistatou, A.; Verginadis, I. I.; Simos, Y. V.; Kyros, L.; Hadjikakou, S. K.; Karkabounas, S. C.; Evangelou, A. M.; Ragos, V. N.; Peschos, D., The Healing Effect of Four Different Silver Complexes on Full-thickness Skin Burns in a Rat Model. In Vivo 2015, $29(1), 55-63$. 
13. (a) Yang, G.; Santana, J. A.; Rivera-Ramos, M. E.; García-Ricard, O.; Saavedra-Arias, J. J.; Ishikawa, Y.; Hernández-Maldonado, A. J.; Raptis, R. G., A combined experimental and theoretical study of gas sorption on nanoporous silver triazolato metal-organic frameworks. Microporous and Mesoporous Materials 2014, 183, 62-68; (b) Yang, G.; Baran, P.; Martínez, A. R.; Raptis, R. G., Substituent Effects on the Supramolecular Aggregation of AgI-Pyrazolato Trimers. Crystal Growth \& Design 2012, 13 (1), 264-269; (c) Yang, G.; Raptis, R. G., Synthesis and crystal structure of tetrameric silver (I) 3, 5-di-tert-butylpyrazolate. Inorganica chimica acta 2007, 360 (7), 2503-2506; (d) Yang, G.; Raptis, R. G., A robust, porous, cationic silver (i) 3, 5-diphenyl-1, 2, 4-triazolate framework with a uninodal 49.66 net. Chemical communications 2004, (18), 2058-2059.

14. Naim, M. J.; Alam, O.; Farah Nawaz, M.; Alam, J.; Alam, P., Current status of pyrazole and its biological activities. Journal of pharmacy \& bioallied sciences 2016, 8 (1), 2.

15. Phillips, A. D.; Gonsalvi, L.; Romerosa, A.; Vizza, F.; Peruzzini, M., Coordination chemistry of 1, 3, 5-triaza-7-phosphaadamantane (PTA): transition metal complexes and related catalytic, medicinal and photoluminescent applications. Coordination chemistry reviews 2004, 248 (11-12), 955-993.

16. Atrián-Blasco, E.; Cerrada, E.; Conte-Daban, A.; Testemale, D.; Faller, P.; Laguna, M.; Hureau, C., Copper (i) targeting in the Alzheimer's disease context: a first example using the biocompatible PTA ligand. Metallomics 2015, 7 (8), 1229-1232.

17. (a) Guerriero, A.; Oberhauser, W.; Riedel, T.; Peruzzini, M.; Dyson, P. J.; Gonsalvi, L., New Class of Half-Sandwich Ruthenium (II) Arene Complexes Bearing the Water-Soluble CAP Ligand as an in Vitro Anticancer Agent. Inorganic chemistry 2017, 56 (10), 5514-5518; (b) Guerrero, E.; Miranda, S.; Lüttenberg, S.; Fröhlich, N.; Koenen, J.-M.; Mohr, F.; Cerrada, E.; Laguna, M.; Mendía, A. n., Trans-thionate derivatives of Pt (II) and Pd (II) with watersoluble phosphane PTA and DAPTA ligands: antiproliferative activity against human ovarian cancer cell lines. Inorganic chemistry 2013, 52 (11), 6635-6647; (c) NowakSliwinska, P.; van Beijnum, J. R.; Casini, A.; Nazarov, A. A.; Wagnieres, G.; van den Bergh, H.; Dyson, P. J.; Griffioen, A. W., Organometallic ruthenium (II) arene compounds with antiangiogenic activity. Journal of medicinal chemistry 2011, 54 (11), 3895-3902; (d) Vergara, E.; Cerrada, E.; Casini, A.; Zava, O.; Laguna, M.; Dyson, P. J., Antiproliferative activity of gold (i) alkyne complexes containing water-soluble phosphane ligands. Organometallics 2010, 29 (11), 2596-2603; (e) Porchia, M.; Benetollo, F.; Refosco, F.; Tisato, F.; Marzano, C.; Gandin, V., Synthesis and structural characterization of copper (I) complexes bearing N-methyl-1, 3, 5-triaza-7-phosphaadamantane (mPTA): Cytotoxic activity evaluation of a series of water soluble $\mathrm{Cu}$ (I) derivatives containing PTA, PTAH and mPTA ligands. Journal of inorganic biochemistry 2009, 103 (12), 1644-1651.

18. Sheldrick, G. M., SHELXT-Integrated space-group and crystal-structure determination. Acta Crystallographica Section A: Foundations and Advances 2015, 71 (1), 3-8.

19. Sheldrick, G. M., Crystal structure refinement with SHELXL. Acta Crystallographica Section C: Structural Chemistry 2015, 71 (1), 3-8.

20. Spek, A. L., Single-crystal structure validation with the program PLATON. Journal of Applied Crystallography 2003, 36 (1), 7-13. 
21. Dolomanov, O. V.; Bourhis, L. J.; Gildea, R. J.; Howard, J. A.; Puschmann, H., OLEX2: a complete structure solution, refinement and analysis program. Journal of Applied Crystallography 2009, 42 (2), 339-341.

22. Yang, L.; Powell, D. R.; Houser, R. P., Structural variation in copper (I) complexes with pyridylmethylamide ligands: structural analysis with a new four-coordinate geometry index, $\tau$ 4. Dalton Transactions 2007, (9), 955-964.

23. (a) Ardizzoia, G. A.; Cenini, S.; La Monica, G.; Masciocchi, N.; Moret, M., Synthesis, Xray structure, and catalytic properties of the unprecedented tetranuclear copper (I) species [Cu (dppz)] 4 (Hdppz= 3, 4-diphenylpyrazole). Inorganic Chemistry 1994, 33 (7), 14581463; (b) Fieselmann, B. F.; Hendrickson, D. N.; Stucky, G. D., Synthesis, electron paramagnetic resonance, and magnetic studies of binuclear bis (. eta. 5-cyclopentadienyl) titanium (III) compounds with bridging pyrazolate, biimidazolate, and bibenzimidazolate anions. Inorganic Chemistry 1978, 17 (8), 2078-2084.

24. Ardizzoia, G. A.; La Monica, G.; Maspero, A.; Moret, M.; Masciocchi, N., Silver (I) pyrazolates. Synthesis and X-ray and 31P-NMR characterization of triphenylphosphine complexes and their reactivity toward heterocumulenes. Inorganic chemistry 1997, 36 (11), 2321-2328.

25. van Rijt, S. H.; Sadler, P. J., Current applications and future potential for bioinorganic chemistry in the development of anticancer drugs. Drug discovery today 2009, 14 (23-24), 1089-1097.

26. Wanka, L.; Iqbal, K.; Schreiner, P. R., The lipophilic bullet hits the targets: medicinal chemistry of adamantane derivatives. Chemical reviews 2013, 113 (5), 3516-3604.

27. (a) Jaros, S. W.; Guedes da Silva, M. F. t. C.; Król, J.; Conceição Oliveira, M.; Smoleński, P.; Pombeiro, A. J.; Kirillov, A. M., Bioactive silver-organic networks assembled from 1, 3, 5-triaza-7-phosphaadamantane and flexible cyclohexanecarboxylate blocks. Inorganic chemistry 2016, 55 (4), 1486-1496; (b) Smoleński, P.; Jaros, S. W.; Pettinari, C.; Lupidi, G.; Quassinti, L.; Bramucci, M.; Vitali, L. A.; Petrelli, D.; Kochel, A.; Kirillov, A. M., New water-soluble polypyridine silver (I) derivatives of 1, 3, 5-triaza-7-phosphaadamantane (PTA) with significant antimicrobial and antiproliferative activities. Dalton Transactions 2013, 42 (18), 6572-6581; (c) Kirillov, A. M.; Wieczorek, S. W.; Lis, A.; Guedes da Silva, M. F. C.; Florek, M.; Król, J.; Staroniewicz, Z.; Smolenski, P.; Pombeiro, A. J., 1, 3, 5Triaza-7-phosphaadamantane-7-oxide (PTA $\square$ ): New Diamondoid Building Block for Design of Three-Dimensional Metal-Organic Frameworks. Crystal Growth \& Design 2011, 11 (7), 2711-2716; (d) Jimenez, J.; Chakraborty, I.; Del Cid, A. M.; Mascharak, P. K., Fiveand Six-Coordinated Silver (I) Complexes Derived from 2, 6-(Pyridyl) iminodiadamantanes: Sustained Release of Bioactive Silver toward Bacterial Eradication. Inorganic chemistry 2017, 56 (9), 4784-4787.

28. Heilman, B. J.; St. John, J.; Oliver, S. R.; Mascharak, P. K., Light-triggered eradication of acinetobacter baumannii by means of NO delivery from a porous material with an entrapped metal nitrosyl. Journal of the American Chemical Society 2012, 134 (28), 11573-11582.

29. Mesaros, N.; Nordmann, P.; Plésiat, P.; Roussel-Delvallez, M.; Van Eldere, J.; Glupczynski, Y.; Van Laethem, Y.; Jacobs, F.; Lebecque, P.; Malfroot, A., Pseudomonas aeruginosa: 
resistance and therapeutic options at the turn of the new millennium. Clinical microbiology and infection 2007, 13 (6), 560-578.

30. Rennie, R. P.; Jones, R. N.; Mutnick, A. H.; Group, S. P. S., Occurrence and antimicrobial susceptibility patterns of pathogens isolated from skin and soft tissue infections: report from the SENTRY Antimicrobial Surveillance Program (United States and Canada, 2000). Diagnostic microbiology and infectious disease 2003, 45 (4), 287-293.

31. Branski, L. K.; Al-Mousawi, A.; Rivero, H.; Jeschke, M. G.; Sanford, A. P.; Herndon, D. N., Emerging infections in burns. Surgical infections 2009, 10 (5), 389-397.

32. Gonzalez, M. R.; Fleuchot, B.; Lauciello, L.; Jafari, P.; Applegate, L. A.; Raffoul, W.; Que, Y.-A.; Perron, K., Effect of human burn wound exudate on Pseudomonas aeruginosa virulence. mSphere 2016, 1 (2), e00111-15.

33. Fuller, F. W., The side effects of silver sulfadiazine. Journal of burn care \& research 2009, 30 (3), 464-470.

34. Marambio-Jones, C.; Hoek, E. M., A review of the antibacterial effects of silver nanomaterials and potential implications for human health and the environment. Journal of Nanoparticle Research 2010, 12 (5), 1531-1551.

35. Pettinari, C.; Marchetti, F.; Mosca, N.; Tosi, G.; Drozdov, A., Application of metal- organic frameworks. Polymer International 2017, 66 (6), 731-744. 


\section{CHAPTER 3}

Aggregation Induced Emission Enhancement (AIEE) of Tripodal Pyrazole Derivatives for Sensing of Nitroaromatics; Vapor Phase Detection of Picric Acid

This chapter has been accepted "S. Kandel et al. / New J. Chem., 2019"

DOI: $10.1039 / \mathrm{C} 9 \mathrm{NJ} 00166 \mathrm{~B}$

Copyright (C) 2019

Royal Society of Chemistry

Shambhu Kandel ${ }^{a}$, Veerasamy Sathish ${ }^{a, b}$, Logesh Mathivathanan $^{a}$, Alexander N. Morozov ${ }^{a}$, Alexander M. Mebel $^{a}$, Raphael G. Raptis ${ }^{a^{*}}$

${ }^{a}$ Department of Chemistry and Biochemistry and Biomolecular Sciences Institute,

Florida International University, 11200 SW 8th St, Miami, FL 33199, USA

${ }^{\mathrm{b}}$ Department of Chemistry, Bannari Amman Institute of Technology, Sathyamangalam 638401 , India 


\subsection{Abstract}

Five pyrazole-based tripodal ligands, compounds 3.1 $-\mathbf{3 . 5}$, based on a 1,3,5-triethylbenzene scaffold, show aggregation-induced emission enhancement (AIEE) and their application as fluorescent probes for nitroaromatics has been investigated. All five compounds are weakly fluorescent in THF, but their fluorescence intensity increases with the addition of a poor solvent (water), causing nanoaggregation, as confirmed by changes in UV-vis and emission spectra, and light scattering techniques. The nanoaggregates exhibit time-dependent emission characteristics and can serve as sensors for the detection of nitroaromatic compounds. The selective detection of picric acid (PA) over other nitroaromatic compounds by 3.1-3.3 is attributed to the photoinduced electron transfer from the trispyrazole to the quencher, as confirmed by TD-DFT calculations. Furthermore, these compounds were tested towards sensing of PA in the vapor and solid phases by means of changes in emission spectra observable by naked eye. The supramolecular assemblies of 3.1 and 3.3 with PA have been structurally characterized by X-ray crystallography.

\subsection{Introduction}

Materials displaying aggregation induced emission (AIE; an intense emission in the aggregated or solid state, but weak or no luminescence in solution) $)^{1}$, or aggregation induced emission enhancement (AIEE; emission of a chromophoric material enhanced by aggregate formation) ${ }^{2}$ have attracted much interest over the past decade because of their applications in optoelectronics ${ }^{3}$, fluorescent probes $^{4}$, and biosensors ${ }^{5}$. Both phenomena are opposite to the phenomenon of aggregation caused quenching (ACQ) of common organic chromophores, the result of high concentration or $\pi-\pi$ stacking interaction, which limits their application potential ${ }^{6}$. Since the recognition of AIE in 2001 by Tang and co-workers, researchers have been pursuing the development and applications of materials with AIE characteristics ${ }^{7}$. Up to date, numerous AIE/AIEE active organic compounds, such as siloles ${ }^{8}$, tetraphenylethene (TPE) derivatives ${ }^{9}$, 
naphthalimide $^{10}$, carbazole $^{11}$, boron-dipyrromethene (BODIPY) derivatives ${ }^{12}$, pyrene ${ }^{13}$, Schiffbase $^{14}$ and triphenylamine-based compounds have been documented ${ }^{15}$. Several mechanisms have been proposed for the AIE phenomenon, such as restriction of intramolecular rotations (RIR) ${ }^{16}$, twisted intermolecular charge transfer $(\text { TICT })^{17}$, J-aggregate formation ${ }^{18}$, excited-state intramolecular proton transfer $(\mathrm{ESIPT})^{19}$, photoinduced electron transfer $(\mathrm{PET})^{20}$ and $\mathrm{C}=\mathrm{N}$ isomerization ${ }^{21}$. Concurrently with the above developments, much attention has been focused on the sensing of explosives, which besides presenting safety and security risks, are also potent environmental contaminants ${ }^{22}$, being highly toxic and/or mutagenic to humans and other $\operatorname{organisms}^{23}$. Nitrotoluenes, such as 2-nitrotoluene, 4-nitrotoluene, dinitrotoluenes and trinitrotoluenes, are examples of microorganism secondary metabolites released in the environment. However, industrial chemicals, such as dyes, explosives, solvents and insecticides, contribute the majority of nitroaromatic environmental contaminants ${ }^{24}$.

The latter (industrial chemicals) are recalcitrant contaminants that persist in the environment even after biological treatment. Therefore, the development of efficient sensors to detect nitroaromatics at low concentrations is highly desirable in order to prevent terrorist threats, as well as detect environmental pollution ${ }^{25}$. Among the various analytical techniques, fluorescence sensing offers high sensitivity, simplicity, low background noise, low cost, as well as on-site workability ${ }^{26}$. In addition, AIE exhibiting materials offer more diffusion channels for the exciton to migrate and, therefore, be faster annihilated by the nitro explosives ${ }^{27}$. Taking advantage of these effects, emission signals promoted by AIEE dyes in the presence of nitro explosives offer a promising platform for the development of an optical sensor ${ }^{28}$. Tripodal receptors can form complexes with cations and anions, where the size of cavity, flexibility and hardness of donor atoms are the main factors determining their binding selectivity ${ }^{29}$, which can be further fine-tuned by chemical modification of pendant arms, e.g., shape, size, chain length, donor atoms ${ }^{30}$. The design and development of tripodal ligands to selectively recognize a specific analyte has encouraged 
considerable research activity, becoming a significant field of supramolecular chemistry ${ }^{31}$. Along these lines, we herein report five tripodal trispyrazole compounds, 3.1- 3.5, having AIEE properties, along with the study of their properties as fluorescence sensors for nitroaromatic compounds. Picric acid (PA) is a primary constituent of explosives in landmines and serves as model compound for studies of explosives ${ }^{21,32}$. To the best of our knowledge, this is the first report on tripodal pyrazole-based compounds exhibiting AIEE properties and their use in the detection of PA in the solid, liquid and vapor phases.

Caution! Picric acid, a polynitroaromatic compound, is a powerful explosive. It must be handled with care, and in small quantities.

\subsection{Experimental}

\subsubsection{Materials and methods}

All chemicals were purchased from Sigma-Aldrich, Alfa Aesar or Fisher Scientific Co., and used as received. Reagent grade solvents were used without further purification. 1,3,5tris(bromomethyl)-2,4,6-triethylbenzene ${ }^{33}$ and 4-phenyl-1H-pyrazole ${ }^{34}$ were synthesized by literature procedures. 4- (3- chlorophenyl)- $1 H$ - Pyrazole and 4- (4- nitrophenyl)- $1 H$ - Pyrazole were synthesized similarly to 4 -phenyl- $1 H$-pyrazole ${ }^{34}$ but, using the 3 -chloro-phenylacetic acid and 4-nitro-phenylacetic acid, respectively. The ${ }^{1} \mathrm{H}-\mathrm{NMR}$ spectra were recorded on a $400 \mathrm{MHz}$ Bruker Avance spectrometer. FT-IR spectra were recorded with an Agilent Cary 600 FTIR. Elemental analyses were carried out by Galbraith Laboratories, Inc., Knoxville, TN, USA.

Electronic absorption spectra were recorded on an Agilent Cary 5000 UV-vis-NIR spectrophotometer using $1 \mathrm{~cm}$ path length cuvette. Emission spectral studies of solutions and fluorescent test strips were carried out using an Agilent fluorometer using an excitation and emission bandwidth of $2.5 \mathrm{~nm}$. The fluorescent test strips were prepared by dip coating of trispyrazole compounds, followed by air drying. The morphology of the nano-aggregates was 
studied by dynamic light scattering spectroscopy using Carl Zeiss. The SEM images were recorded with a TESCAN VEGA3 instrument using a SE detector and equipped with an EDAX energy-dispersive X-ray spectroscopy (EDX) detector. HPLC grade THF and double distilled water were employed in all spectral measurements. Freshly prepared sample solutions were used for each measurement.

Frequency-domain fluorescence lifetime measurements were performed using a ChronosFD spectrofluorometer (ISS, Champaign, IL). Samples were excited with a $280 \mathrm{~nm}$ modulated diode, and emission was collected using $305 \mathrm{~nm}$ long-pass filters (Andover, Salem, NH). All measurements were conducted at room temperature in quartz cells. Modulation-phase data were analyzed using GlobalsWE software, and the $\chi^{2}$ parameter was used as goodness-of-fit criterion. The average intensity decay lifetime was obtained by fitting the data to a multiple-exponential decay model.

X-ray diffraction data were collected with Bruker D8 Quest diffractometer. Colorless single crystals of 3.1-3.5 and ligand-PA compounds were obtained by recrystallization from organic solvents such as acetone and/or dichloromethane. A suitable crystal for each compound was selected and mounted on a Mitegen loop using Parabar oil on a Bruker D8 Quest CMOS diffractometer. The crystal was kept at room temperature during data collection. Using APEX3, the structure was solved with the ShelXT ${ }^{35}$ structure solution program, using the intrinsic phasing method. Using Olex $2^{36}$, the model was refined with version $2016 / 6$ of ShelXL ${ }^{37}$ using full matrix least squares on $\mathbf{F}^{2}$ minimization. A multi-scan absorption correction was performed using SADABS-2016/2 (Bruker, 2016/2) was used for absorption correction. All non-hydrogen atoms were refined anisotropically. Hydrogen atom positions were calculated geometrically and refined using the riding model, but some hydrogen atoms were refined freely. Disordered solvent 
electron densities were removed using SQUEEZE routine (PLATON) ${ }^{38}$ or Solvent MASK $(\mathrm{Olex} 2)^{36}$ from compounds [3.5] and [3.3]-PA(1:2).

\subsubsection{Synthesis of Tris-(4-Ph-pz); $\left(\mathrm{C}_{42} \mathrm{H}_{42} \mathrm{~N}_{6}\right)[3.1]$}

A round bottom flask was charged with $\mathrm{NaOH}(250 \mathrm{mg}), 4$-(phenyl)-1H-pyrazole (385 mg; 1.75 mmol) and $15 \mathrm{~mL}$ of dimethylforamide (DMF) and the reaction mixture was stirred for $40 \mathrm{~min}$. 1,3,5-tris(bromoethyl)-2,4,6-triethyl benzene ( $220 \mathrm{mg}$; $0.5 \mathrm{mmol}$ ) was added, the reaction mixture was heated for $36 \mathrm{~h}$ at $70{ }^{\circ} \mathrm{C}$ and the hot contents of the flask were poured into $50 \mathrm{~mL}$ cold water; the white, spongy solid that formed was refrigerated overnight. The white product was filtered out under suction and washed with water, followed by diethylether. Finally, the compound was redissolved in the minimal volume of dichloromethane, crushed out by hexane and dried. Yield: $284 \mathrm{mg}$ (90 \%). Molecular weight: $630.84 \mathrm{~g} / \mathrm{mol} .{ }^{1} \mathrm{H}-\mathrm{NMR}$ (ppm, DMSO-d $\left.{ }^{6}\right): 0.88$ (9H, t, $\mathrm{CH}_{3}$ ); $2.87\left(6 \mathrm{H}, \mathrm{q}, \mathrm{CH}_{2}\right) ; 5.54\left(6 \mathrm{H}, \mathrm{s}, \mathrm{CH}_{2}\right) ; 7.16(3 \mathrm{H}, \mathrm{t}$, phenyl); $7.29(6 \mathrm{H}, \mathrm{t}$, phenyl); $7.51(6 \mathrm{H}, \mathrm{d}$, phenyl); 7.89 (3H, s, pz); 7.96 (3H, s, pz). IR ( $\left.\mathrm{v}_{\max } \mathrm{cm}^{-1}\right)$ : 3060(w), 2976(w), 1658(w), 1608(w), 1564(m), 1491(w), 1456(w), 1554(w), 1367(m), 1336(m), 1298(w), 1228(w), 1176(s), 1068(w), 994(s), 952(s), 752(s), 688(s), 583(w). Elemental analysis; found $(\%) \mathrm{C}=79.79, \mathrm{H}=6.35, \mathrm{~N}=$ 13.31; calculated $(\%) \mathrm{C}=79.97, \mathrm{H}=6.71, \mathrm{~N}=13.32$. $\mathrm{X}$-ray quality single crystals were grown by slow evaporation from acetone or dichloromethane solutions.

\subsubsection{Synthesis of Tris-4-(3-Cl-Ph-pz); $\left(\mathrm{C}_{42} \mathrm{H}_{39} \mathrm{~N}_{6} \mathrm{Cl}_{3}\right)$ [3.3]}

Similarly to the synthesis of 3.1, but, using 4-(3-Cl-Ph)pzH (312 $\mathrm{mg} ; 1.75 \mathrm{mmol})$ as a pyrazole; Yield: $327 \mathrm{mg}$ (89\%). Molecular weight: $734.17 \mathrm{~g} / \mathrm{mol} .{ }^{1} \mathrm{H}-\mathrm{NMR}\left(\mathrm{ppm}, \mathrm{CDCl}_{3}\right)$ : $1.02(9 \mathrm{H}, \mathrm{t}$, $\left.\mathrm{CH}_{3}\right) ; 2.82\left(6 \mathrm{H}, \mathrm{q}, \mathrm{CH}_{2}\right) ; 5.50\left(6 \mathrm{H}, \mathrm{s}, \mathrm{CH}_{2}\right) ; 7.16-7.24$ (9H, m, phenyl), 7.37 (3H, s, phenyl) ; $7.33(3 \mathrm{H}, \mathrm{s}, \mathrm{pz}) 7.81(1 \mathrm{H}, \mathrm{s}, \mathrm{pz}) . \mathrm{IR}\left(\mathrm{v}_{\max } \mathrm{cm}^{-1}\right): 3109(\mathrm{w}), 2979(\mathrm{w}), 1679(\mathrm{w}), 1604(\mathrm{~s}), 1568(\mathrm{~m})$, 1465(m), 1351(m), 1179(s), 1078(m), 1067(s), 993(m), 858(s), 771(s), 666(s), 588(m). Elemental analysis for the Tris $[4-(3-\mathrm{Cl}-\mathrm{Ph})-\mathrm{pz}]$ found $(\%) \mathrm{C}=67.55, \mathrm{H}=5.52, \mathrm{~N}=11.12$; 
Calculated $(\%) \mathrm{C}=67.07, \mathrm{H}=5.49, \mathrm{~N}=11.17$. X-ray quality crystals were grown by slow evaporation from an acetone solution.

\subsubsection{Synthesis of Tris-4-(4- $\mathrm{NO}_{2}$-phenyl-pz); $\left(\mathrm{C}_{42} \mathrm{H}_{39} \mathrm{~N}_{9} \mathrm{O}_{6}\right)$ [3.4]}

Similarly to the synthesis of 3.1, but, 4-(4-NO $2-\mathrm{Ph}) \mathrm{pz}(332 \mathrm{mg} ; 1.75 \mathrm{mmol})$ as a pyrazole; Yield: $325 \mathrm{mg}$ (85\%). Molecular weight: $765.83 \mathrm{~g} / \mathrm{mol} .{ }^{1} \mathrm{H}-\mathrm{NMR}$ (ppm, $\left.\mathrm{CDCl}_{3}\right): 1.05\left(9 \mathrm{H}, \mathrm{t}, \mathrm{CH}_{3}\right) ; 2.84$ $\left(6 \mathrm{H}, \mathrm{q}, \mathrm{CH}_{2}\right) ; 5.53\left(6 \mathrm{H}, \mathrm{s}, \mathrm{CH}_{2}\right) ; 7.51(6 \mathrm{H}, \mathrm{d}$, phenyl); 8.12 (6H, d, phenyl); 7.53 (3H, s, pz); 7.89 (3H, d, pz). IR ( $\left.\mathrm{v}_{\max } \mathrm{cm}^{-1}\right): 3115(\mathrm{w}), 2977(\mathrm{~m}), 1672(\mathrm{w}), 1598(\mathrm{~s}), 1589(\mathrm{~m}), 1500(\mathrm{~s}), 1442(\mathrm{w})$, 1330(s), 1227(m), 1194(m), 1110(s), 1069(m), 994(m), 952(s), 846(s), 753(s), 693(m), 590(m). Elemental analysis for the TPZ [4-(4-NO2- $-\mathrm{Ph})-\mathrm{pz}]\left(\mathrm{C}_{42} \mathrm{H}_{39} \mathrm{~N}_{9} \mathrm{O}_{6}\right)$ was found $(\%) \mathrm{C}=62.50, \mathrm{H}=$ 5.08, $\mathrm{N}=15.51$; Calculated $(\%) \mathrm{C}=62.91, \mathrm{H}=5.41, \mathrm{~N}=15.72 . \mathrm{X}$-ray quality single crystals were grown by slow evaporation from acetone or dichloromethane solution.

\subsubsection{Synthesis of Tris-(4-I-pz) $\left(\mathrm{C}_{24} \mathrm{H}_{27} \mathrm{~N}_{6} \mathrm{I}\right)$ [3.5]}

Similarly, to the synthesis of $\mathbf{3 . 1}$, but, using 4-(iodo)-1H-pyrazole (339 $\mathrm{mg} ; 1.75 \mathrm{mmol}$ ) as a pyrazole; Yield: $351 \mathrm{mg}$ (90\%). Molecular weight: 780.24g/mol. ${ }^{1} \mathrm{H}-\mathrm{NMR}$ (ppm, $\mathrm{CDCl}_{3}$ ): 0.93 $\left(9 \mathrm{H}, \mathrm{t}, \mathrm{CH}_{3}\right) ; 2.71\left(6 \mathrm{H}, \mathrm{q}, \mathrm{CH}_{2}\right) ; 5.43\left(6 \mathrm{H}, \mathrm{s}, \mathrm{CH}_{2}\right) ; 7.07(3 \mathrm{H}, \mathrm{s}, \mathrm{pz}) ; 7.55(3 \mathrm{H}, \mathrm{s}, \mathrm{pz}) . \mathrm{IR}\left(\mathrm{v}_{\max } \mathrm{cm}^{-}\right.$ $\left.{ }^{1}\right):$ 3066(w), 2974(w), 1678(w), 1574(w), 1507(w), 1456(m), 1416(m), 1276(m), 1160(m), 1112(m), 989(s), 938(s), 843(s), 793(s), 762(m), 718(m), 645(m), 604(s), 569(m). Elemental analysis for the tris(4-I-pz) $\left[\mathrm{C}_{24} \mathrm{H}_{27} \mathrm{~N}_{6} \mathrm{I}\right]$ was found $(\%) \mathrm{C}=36.47, \mathrm{H}=3.52, \mathrm{~N}=10.45$; Calculated $(\%) \mathrm{C}=36.95, \mathrm{H}=3.49, \mathrm{~N}=10.77$. X-ray quality single crystals were grown by slow evaporation from dichloromethane solution.

\subsubsection{Synthesis of $[3.1](\mathrm{PA})\left(\mathrm{C}_{48} \mathrm{H}_{43} \mathrm{~N}_{9} \mathrm{O}_{7}\right)$}

$31.5 \mathrm{mg}(0.05 \mathrm{mmol}) \mathrm{T}(4-\mathrm{Ph}) \mathrm{pz}$ and $11.4 \mathrm{mg}(0.05 \mathrm{mmol})$ were dissolved in $7 \mathrm{~mL} \mathrm{CHCl}_{3}$ or acetone and stirred 10 minutes at room temperature. Yield: $30 \mathrm{mg}(70 \%) .{ }^{1} \mathrm{H}-\mathrm{NMR}$ (ppm, $\left.\mathrm{CDCl}_{3}\right): 1.06\left(9 \mathrm{H}, \mathrm{t}, \mathrm{CH}_{3}\right) ; 2.81\left(6 \mathrm{H}, \mathrm{q}, \mathrm{CH}_{2}\right) ; 5.53\left(6 \mathrm{H}, \mathrm{s}, \mathrm{CH}_{2}\right) ; 7.24-7.36$ (18H phenyl+pz); 
$7.30\left(1 \mathrm{H}, \mathrm{s},-\mathrm{OH}_{\mathrm{PA}}\right) ; 9.13\left(2 \mathrm{H}, \mathrm{s},-\mathrm{CH}_{\mathrm{PA}}\right)$ phenyl); $7.85(3 \mathrm{H}, \mathrm{s}, \mathrm{pz}) . \mathrm{X}$-ray quality golden yellow colored single crystals were obtained by slow evaporation of the reaction solution.

\subsubsection{Synthesis of [3.2] $(\mathrm{PA})_{2}\left(\mathrm{C}_{60} \mathrm{H}_{47} \mathrm{Cl}_{3} \mathrm{~N}_{15} \mathrm{O}_{21}\right)$}

$7.8 \mathrm{mg}(0.01 \mathrm{mmol}) \mathrm{T}-4-\left(4-\mathrm{NO}_{2}-\mathrm{Ph}\right) \mathrm{pz}$ and $6.8 \mathrm{mg}(0.03 \mathrm{mmol})$ were dissolved in $7 \mathrm{~mL} \mathrm{CHCl}_{3}$ and stirred 2 minutes at room temperature. Yield: $80 \mathrm{mg}(68 \%) .{ }^{1} \mathrm{H}-\mathrm{NMR}$ (ppm, $\mathrm{CDCl}_{3}$ ): 1.04 $\left(9 \mathrm{H}, \mathrm{t}, \mathrm{CH}_{3}\right) ; 2.82\left(6 \mathrm{H}, \mathrm{q}, \mathrm{CH}_{2}\right) ; 5.52\left(6 \mathrm{H}, \mathrm{s}, \mathrm{CH}_{2}\right) ; 7.23-7.38(15 \mathrm{H}, \mathrm{m}$, phenyl + pz); $7.84(3 \mathrm{H}$, s, pz); $7.36\left(2 \mathrm{H}, \mathrm{s},-\mathrm{OH}_{\mathrm{PA}}\right) ; 9.13\left(4 \mathrm{H}, \mathrm{s},-\mathrm{CH}_{\mathrm{PA}}\right)$. X-ray quality golden yellow colored single crystals were obtained by slow evaporation of the reaction solution.

\subsubsection{Synthesis of $[3.1](\mathrm{PA})_{3}\left(\mathrm{C}_{63} \mathrm{H}_{51.5} \mathrm{~N}_{16.5} \mathrm{O}_{24.5}\right)$}

$31.5 \mathrm{mg}(0.05 \mathrm{mmol}) \mathrm{T}(4-\mathrm{Ph}) \mathrm{pz}$ and $33.4 \mathrm{mg}(0.15 \mathrm{mmol})$ were dissolved in $7 \mathrm{~mL} \mathrm{CHCl}_{3}$ or acetone and stirred 10 minutes at room temperature. Yield: $50 \mathrm{mg}(75 \%) .{ }^{1} \mathrm{H}-\mathrm{NMR}$ (ppm, $\left.\mathrm{CDCl}_{3}\right): 1.07\left(9 \mathrm{H}, \mathrm{t}, \mathrm{CH}_{3}\right) ; 2.81\left(6 \mathrm{H}, \mathrm{q}, \mathrm{CH}_{2}\right) ; 5.57\left(6 \mathrm{H}, \mathrm{s}, \mathrm{CH}_{2}\right) ; 7.23-7.36(18 \mathrm{H}$ phenyl+pz); $7.38\left(3 \mathrm{H}, \mathrm{s},-\mathrm{OH}_{\mathrm{PA}}\right) ; 9.14\left(6 \mathrm{H}, \mathrm{s},-\mathrm{CH}_{\mathrm{PA}}\right)$ phenyl); $7.89(3 \mathrm{H}, \mathrm{s}, \mathrm{pz}) . \mathrm{X}$-ray quality golden yellow colored single crystals were obtained by slow evaporation of the reaction solution.

\subsubsection{Computational Details}

Geometry optimization of the complexes of trispyrazole with one, two and three molecules of picric acid have been performed using a density functional $\omega$ B97XD method developed by HeadGordon's group, ${ }^{39}$ which includes a correction for dispersion, with the $6-31 \mathrm{G}^{*}$ basis set. Next, single point time dependent density functional theory (TD-DFT) ${ }^{40}$ calculations were carried out at the optimized geometries to evaluate electronic excitation energies and oscillator strengths. All electronic structure calculations were carried out using the GAUSSIAN 09 program package. ${ }^{41}$ 


\subsection{Result and discussions}

All five pyrazole derivatives were synthesized in similar ways in an one-pot reaction, modifying a published procedure ${ }^{33 a}$, 33b , resulting in good, $80-90 \%$ yields (Scheme 3.1). The synthesis and Xray crystal structure of compound 3.2 have already been reported elsewhere by some of us ${ }^{33 b}$. Each one of the five compounds has three pyrazole functionalities attached to the 2-, 4- and 6positions of a central 1,3,5-triethylbenzene ring via $\mathrm{N}$-methylene bridges. Compounds 3.1, 3.3 and 3.4 crystallized in monoclinic, whereas 3.5 in orthorhombic crystal systems and compounds 3.1 and 3.3 in $P 2_{1} / n$ space group, while compounds 3.4 and 3.5 in $P 2_{l} / c$ and $P{ }_{1}{ }_{2}{ }_{1}{ }_{2}$ space groups, respectively, with the whole molecule in the asymmetric unit. In the crystal structures of compounds 3.1, 3.3 and 3.4, two pyrazolyl groups are on one side of the benzene ring plane and the third pyrazolyl group along with all three ethyl groups are on the other. In compound $\mathbf{3 . 5}$, however, two pyrazolyl and two ethyl groups lie on one side of the plane and the remaining one pyrazolyl and one ethyl group on the other. All bond distances and angles are unexceptional. Molecular structures of compounds 3.1 - 3.5 are shown in Figure 3.1.

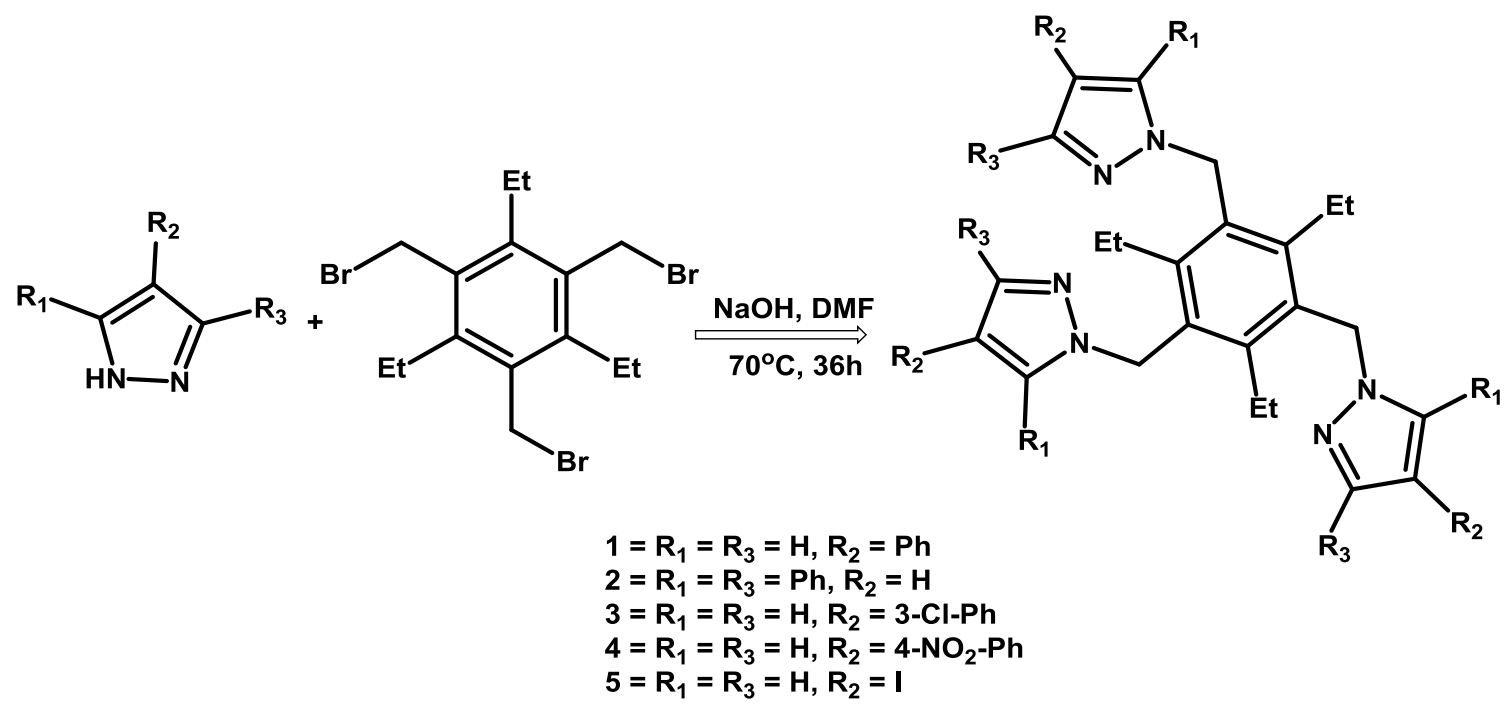

Scheme 3.1. Synthetic scheme of five tripodal pyrazoles (3.1-3.5) 

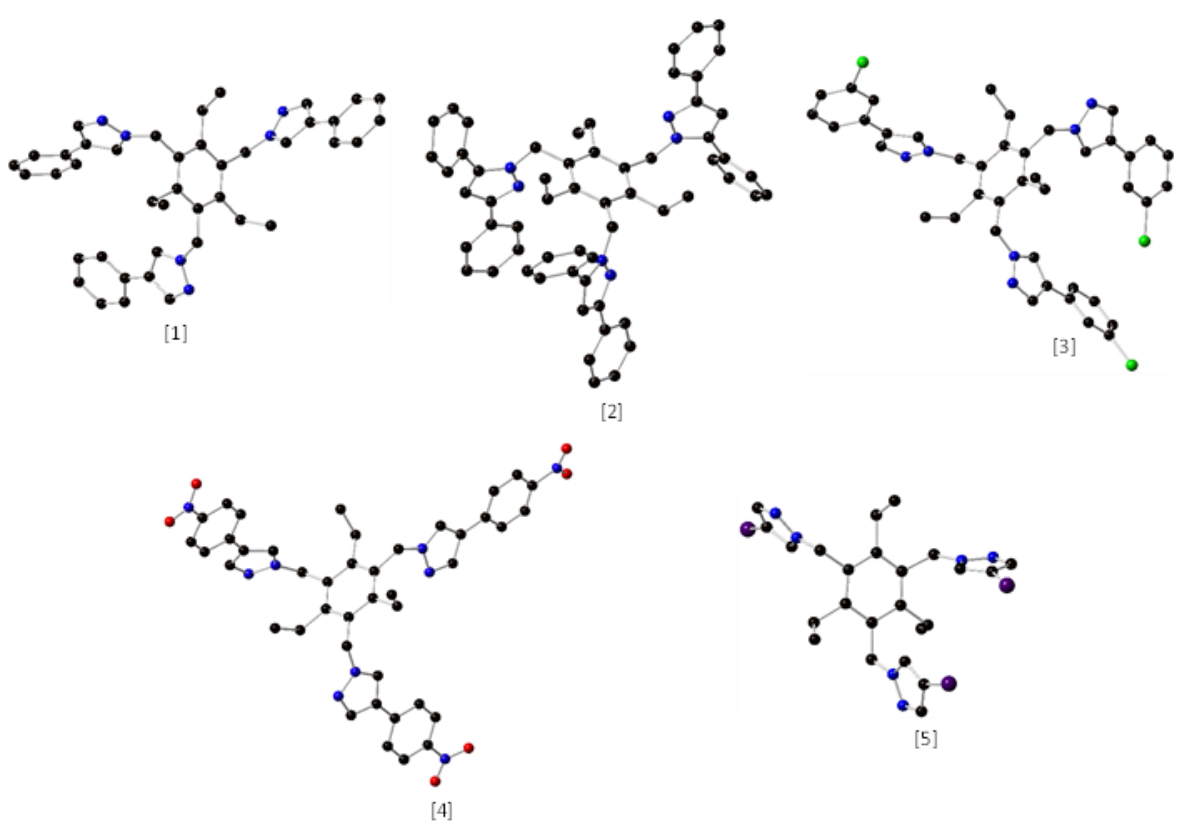

Figure 3.1. Molecular structures of compounds 3.1 - 3.5 (1 to 5 respectively). Color code: black, C; blue, N; red, O; green, $\mathrm{Cl}$; purple, I.

The ${ }^{1} \mathrm{H}-\mathrm{NMR}$ resonances of $\mathbf{3 . 1}, \mathbf{3 . 3}-\mathbf{3 . 5}$ are clearly resolved and consistent with threefold molecular symmetry in solution (Table A3.1 and Figs. A3.1-A3.4). In their IR spectra, the weak $\mathrm{sp}^{2}(\mathrm{C}-\mathrm{H})$ stretching vibration bands for all compounds occur in the $3060-3118 \mathrm{~cm}^{-1}$ range, the weak to medium bands between $2974 \mathrm{~cm}^{-1}$ and $2979 \mathrm{~cm}^{-1}$ correspond to $\mathrm{sp}^{3}(\mathrm{C}-\mathrm{H})$ stretching vibrations, while the aromatic $\mathrm{C}=\mathrm{C}$ and $\mathrm{C}=\mathrm{N}$ bands appear in the $1363-1679 \mathrm{~cm}^{-1}$ region (Figures A3.5-A3.8).

Compounds 3.1 -3.5 are soluble in common organic solvents, such as $\mathrm{CH}_{2} \mathrm{Cl}_{2}$, THF and acetone, but insoluble in water, and are, therefore, convenient candidates to study aggregation in organic solvents upon water addition. 


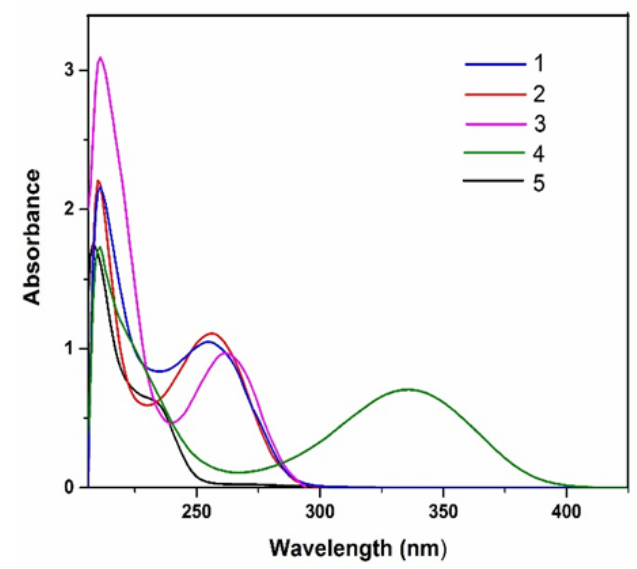

Figure 3.2. UV-vis absorption spectra of 3.1-3.5 in THF

The UV-vis absorption spectra of 3.1 -3.5 in THF (Fig. 3.2) show broad absorbance bands at 230-300 nm, assigned to $\pi-\pi^{*}$ transitions of the aromatic rings, which shifts to lower energy in 3.4. Upon water addition into the THF solution of $\mathbf{3 . 1}-\mathbf{3 . 3}$, the absorbance decreases and $\lambda_{\max }$ redshifts from $255 \mathrm{~nm}$ (in THF) to $265 \mathrm{~nm}$ (in 70\% water) (Figs. 3.3a and A3.9, A3.10). The gradual levelling-off of the absorbance tail in the region of $500 \mathrm{~nm}$ and beyond, attributed to the Mie effect, confirms the formation of nanoparticle aggregates in these solvent mixtures ${ }^{42}$. The formation of nanoaggregates was further confirmed by a DLS study, which determined that particles in the 100-250 nm size range were formed (Figs. A3.11-A3.13).

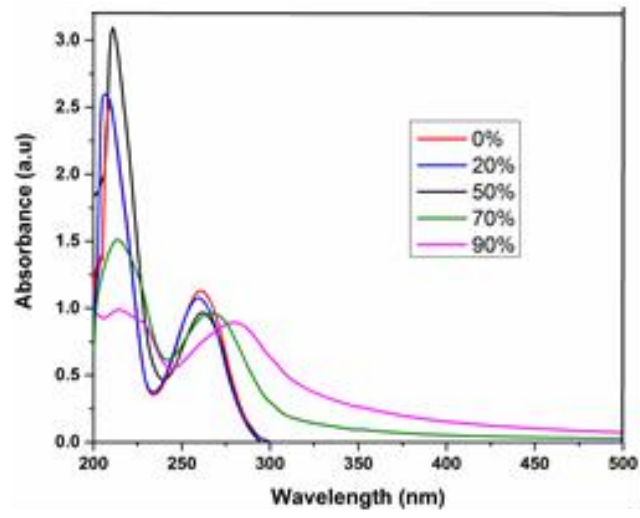

a

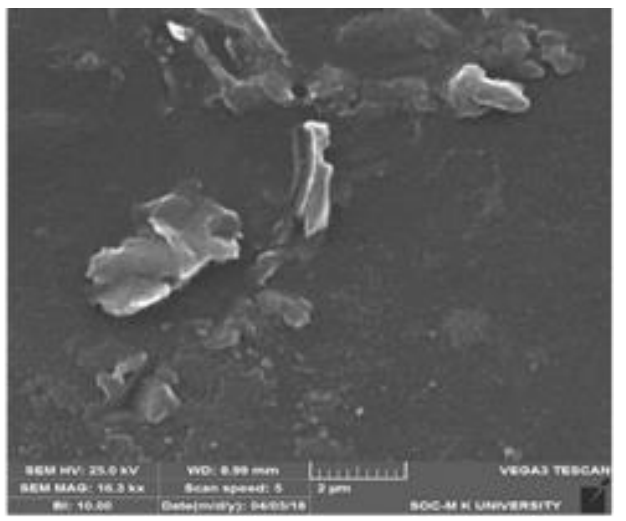

b

Figure 3.3. (a) UV - visible absorption spectral changes of $\mathbf{3 . 3}$ in THF with the addition of water (0 to $90 \%$ ). (b) SEM image of $\mathbf{3 . 3}$ in $\mathrm{THF} / \mathrm{H}_{2} \mathrm{O}$ (30:70) mixture. 
SEM image of compound $\mathbf{3 . 3}$ in a $70 \%$ of aqueous mixture were also consistent with the formation of such aggregates of irregular morphology (Fig. 3.3b). When the water content of the mixture was raised to $>70 \%$, the solution became turbid. Irradiation of the turbid $\mathrm{THF} / \mathrm{H}_{2} \mathrm{O}-$ 80/20 solution of $\mathbf{3 . 3}$ with a $365 \mathrm{~nm}$ lamp causes it to become blue luminescent (Fig. 3.4). Similar observations were made with the other four compounds, 3.1, 3.2, 3.4 and 3.5.
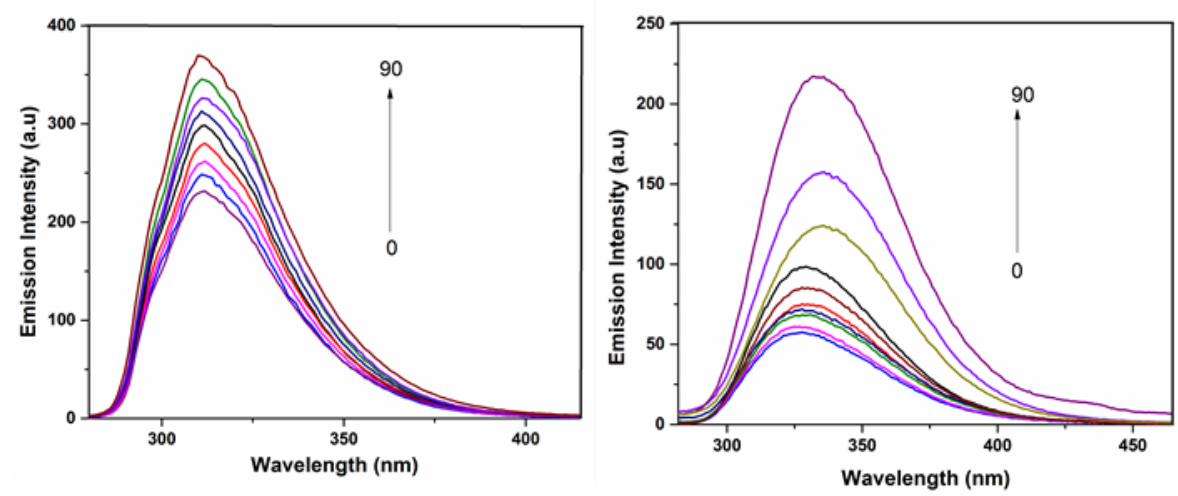

Figure 3.4. Fluorescence spectral changes of $3.1 \& 3.3(15 \mu \mathrm{M})$ with the addition of water from 0 to $90 \%$ into THF.

In pure THF, compounds $\mathbf{3 . 1}-\mathbf{3 . 3}$ are weakly fluorescent with $\lambda_{\max }$ in the $310-330 \mathrm{~nm}$ range. Importantly, their emission intensity is gradually enhanced upon stepwise addition of water, due to the AIEE effect, caused by restriction of intramolecular rotation (RIR) ${ }^{43}$. The fluorescence spectra of $\mathbf{3 . 1}$ and $\mathbf{3 . 3}$ in water-THF mixtures with varying water content are shown in Fig. 3.4 (for 3.2 see Fig. A3.14). In a dilute solution, the free rotation of the peripheral phenyl rings eff ectively deactivates its excited species, hence only a faint emission is observed. However, the formation of aggregates blocks the non-radiative relaxation channel, thereby activating radiative decay $^{44}$. Consequently, the emission intensity increases in the aggregated state. Obviously, a notable AIEE effect was not observed for compound 3.5, which lacks peripheral phenyl rings. Whereas the emission spectra of $\mathbf{3 . 1}$ and $\mathbf{3 . 3}$ were invariant with time, the intensity of the emission of 3.2, monitored at $5 \mathrm{~min}$ intervals, steadily increased over a period of $30 \mathrm{~min}$ 
following the addition of $\mathrm{H}_{2} \mathrm{O}$ (Fig. A3.15). This effect is tentatively attributed to the larger number of rotating phenyl rings of 3.2, compared to other compounds reported here ${ }^{45}$. The emission lifetime of compound 3.2 is $1.2 \mathrm{~ns}$ in THF, but increases to $1.8 \mathrm{~ns}$ in 10:90 $\mathrm{THF} / \mathrm{H}_{2} \mathrm{O}$ mixture (Figs. A3.16 \& A3.17), while the lifetimes of 3.1, 3.3, 3.4, and 3.5 are shorter than $1 \mathrm{~ns}$ and were not determined. Addition of (viscous) ethylene glycol into THF solutions of $\mathbf{3 . 1}-\mathbf{3 . 3}$, caused their emission intensities to increase (Figs A3.18 \& A3.19), consistent with the proposal that the slowing down of rotations is responsible for this effect.

\subsubsection{Sensor for nitroaromatic compounds}

Because of the tripodal arrangement of $\mathrm{N}$-sites available to act as $\mathrm{H}$-bond acceptors, we envisioned that compounds 3.1 $-\mathbf{3 . 5}$ might be good sensors for nitrophenols, picric acid in particular. To study the recognition of nitrophenols and other nitroaromatics, a $3 \times 10^{-6} \mathrm{M}$ solution of PA was added stepwise to the suspension of nanoaggregates ( $\left.\mathrm{THF} / \mathrm{H}_{2} \mathrm{O} 20 / 80 \%\right)$ of 3.1-3.3 (vide supra), causing initially an increase of the UV-vis absorbance (Figs. A3.20 \& A3.21), due to the formation of a ground state charge transfer complex ${ }^{46}$. The fluorescence spectral changes accompanying PA addition to $\mathbf{3 . 1 - 3 . 3}$ were monitored (Figs. 3.5 \& A3.22): Quenching of fluorescence intensity with a blueshift from 315 to $305 \mathrm{~nm}$ was observed, attributed to the photoinduced electron transfer from the electron-rich trispyrazoles to electron-poor $\mathrm{PA}^{47}$. This assignment was also confirmed by computational MO analysis (vide infra).
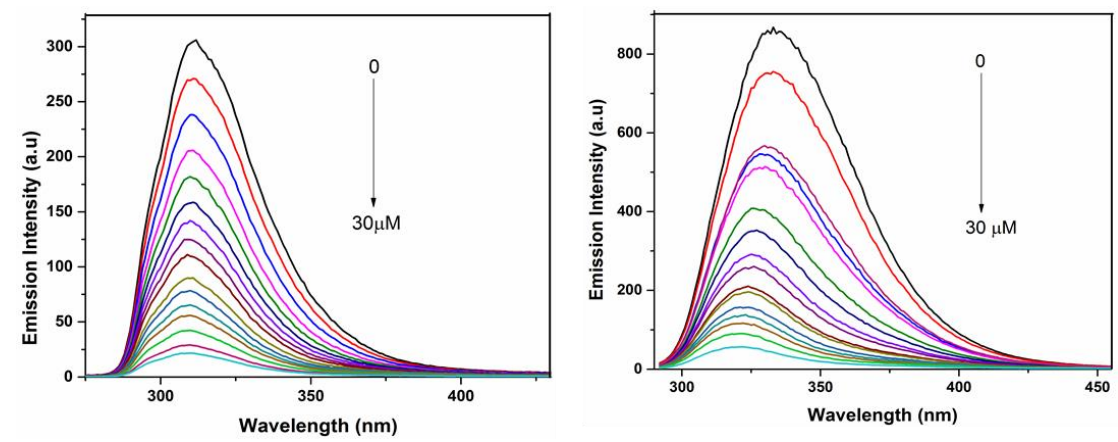

Figure 3.5. Emission spectra of $\mathbf{3 . 1} \& \mathbf{3 . 2}(15 \mu \mathrm{M})$ in $\mathrm{THF} / \mathrm{H}_{2} \mathrm{O}(20: 80)$ upon addition of PA from 0 to $30 \mu \mathrm{M}$. 
The fluorescence quenching was analyzed using the Stern- Volmer $(\mathrm{S}-\mathrm{V})$ relationship ${ }^{48}, \mathrm{I}_{0} / \mathrm{I}=1+$ $K_{\mathrm{SV}}[\mathrm{PA}]$, where, $\mathrm{I}_{0}$ and I are the fluorescence intensities of nanoaggregates before and after the addition of PA, and $K_{\mathrm{SV}}$ is the Stern-Volmer constant. A S-V plot for $\mathbf{3 . 1}$ - $\mathbf{3 . 3}$ (Figs. 3.6, A3.23 \& A3.24) contain a linear ( $\left.\mathrm{I}_{\mathrm{o}} / \mathrm{I}\right) v s$. [PA] section at low PA concentration, corresponding to $K_{\mathrm{sv}}$ values of $9.3 \times 10^{4} \mathrm{M}^{-1}, 1.1 \times 10^{5} \mathrm{M}^{-1}$ and $4.6 \times 10^{4} \mathrm{M}^{-1}$ for 3.1, 3.2 and 3.3, respectively. The higher $K_{\mathrm{sv}}$ value of compound $\mathbf{3 . 2}$ is in line with literature values reported for the detection of PA by Stern-Volmer equation ${ }^{49}$ At higher concentrations of PA, the graph shows an upward curvature, due to the super-amplified quenching eff ect ${ }^{50}$. The AIEE-turned on fluorescence was turned off by the addition of PA, so that the luminescent blue color disappeared after the addition of $3 \times 10^{-6} \mathrm{~mol}$ PA (Figure A3.25).
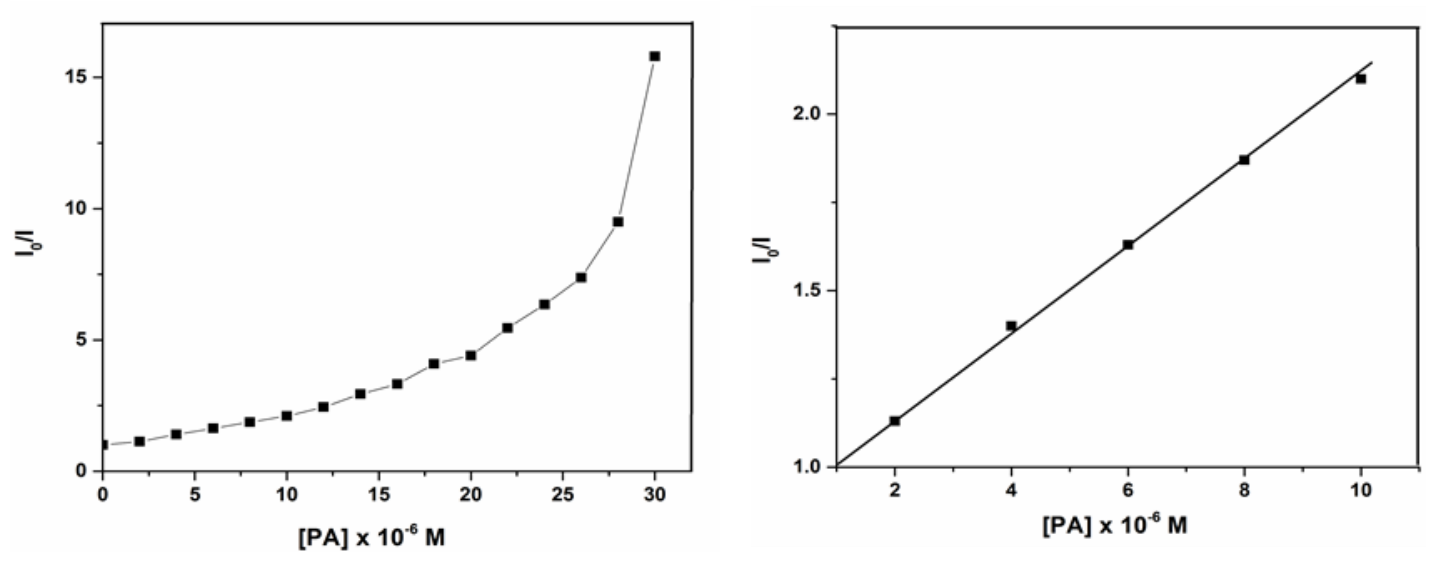

Figure 3.6. (a) Stern-Volmer plot for the complex 3.2 with PA (b) SV plot obtained at lower concentration of PA.

\subsection{2. ${ }^{1} \mathrm{H}$ NMR studies of PA-trispyrazole complexes}

${ }^{1} \mathrm{H}$ NMR spectra were recorded for compounds 3.1 and 3.2 upon stepwise addition of PA to confirm the complexation of PA. (Figs. $3.7 \&$ A3.26). Addition of PA to 3.1 and 3.2 resulted in significant shifts in the resonances of both the host (trispyrazole) and the guest (picric acid) protons. Especially the one corresponding to the -OH (11.97 ppm in free PA vs. $7.30 \mathrm{ppm}$ in 3.1$\mathrm{PA}$ ), and-CH of PA (9.20 in free PA to $9.13 \mathrm{ppm}$ in 3.1-PA), shifts are consistent with 
complexation. The corresponding shifts for - $\mathrm{OH}$ and $-\mathrm{CH}$ protons for 3.2-PA are $11.97 \mathrm{ppm}$ to $8.07 \mathrm{ppm}$ and $9.20 \mathrm{ppm}$ to $9.04 \mathrm{ppm}$, respectively. A complete list of ${ }^{1} \mathrm{H}-\mathrm{NMR}$ chemical shifts of 3.1, 3.2, 3.3 and their PA complexes is in Table A3.2. The ${ }^{1} \mathrm{H}$ NMR of mixtures of $\mathbf{3 . 4}$ and 3.5 with various concentrations of PA do not show shifts in resonances, suggesting that no tripyrazolyl-PA interactions are present.



Figure 3.7. Partial ${ }^{1} \mathrm{H}-\mathrm{NMR}$ spectra of 3.1 and 3.1-PA. (1 in the figure corresponds to 3.1)

\subsubsection{Single crystal $X$-ray diffraction studies of PA-trispyrazole complexes}

Three single-crystal X-ray structures were obtained for PA-trispyrazole compounds as follows: 1:1 (3.1-(PA), (Fig. 3.8) and 1:3.5 (3.1-(PA) 3.5, (Fig. 3.8b), complexes with compound 3.1:PA and a 1:2 complex with compound 3.3:PA $\left.(\text { 3.3-(PA })_{2}\right)$. Single crystals were grown from acetone solutions of PA and 3.1 (or 3.3) in 1:1 and 3:1 ratio. The structures are stabilized by strong $\mathrm{H}-$ bonding between pyrazole $\mathrm{N}$-atoms and phenolic proton from PA, and $\pi-\pi$ interaction between 
the ligand and picric acid. The crystals obtained were thin needles, and hence the diffraction quality was poor. However, the data quality was sufficient to reveal important structural features that enable complexation. The host-guest complex 3.1(PA) crystallizes in the monoclinic $C 2 / c$ space group with the whole complex in the asymmetric unit. The conformation of the ligand is not retained in the complex, with all three pyrazolyl groups on one side of the phenyl plane. The crystal structure is also characterized by numerous $\pi-\pi$ interactions between the phenyl rings of the host. When the crystals were grown from an acetone solution containing 1:3 ratio of $\mathbf{3 . 1}$ to PA, the complex obtained was 3.1(PA) $)_{3.5}$, where three PA molecules are bound to the three pyrazolyl $\mathrm{N}$-atoms and the fourth is wedged between the phenyl rings of the pyrazole and is stabilized purely by $\pi-\pi$ interactions (centroid-centroid distance between the PA ring and one of the phenyl groups is $3.657 \AA$ on either side). The crystal is in monoclinic $P 2 / c$ space group with the whole ligand and 3.5 molecules of the PA present in the asymmetric unit. The three H-bonded N...O distances between pyrazolyl $\mathrm{N}$-atoms and respective phenolic oxygen are 2.614(6) $\AA$, 2.542(6) $\AA$ and 2.601(6) A. Host-guest complex 3(PA) $)_{2}$ crystallizes in monoclinic $P 2_{1} / m$ space group with one half of the complex in the asymmetric unit. All three 4-(3-chloro-phenyl)pyrazolyl groups are arranged on one side of the triethyl benzene ring. One of the two PA molecules is stabilized by a H-bond with a pyrazolyl N-atom (N...O distance: 2.568(5) $\AA$ ), whereas the other PA is stabilized by intermolecular $\pi$ - $\pi$ interactions (centroid-centroid distance: 3.686 А; Fig. 3.9 shows the crystal packing diagram depicting the $\pi-\pi$ interactions). Comparison of the three crystal structures makes evident that both $\mathrm{H}$-bonding and $\pi$ - $\pi$ interactions are crucial for the stabilization of PA guest molecules by tris-pyrazole compounds. 


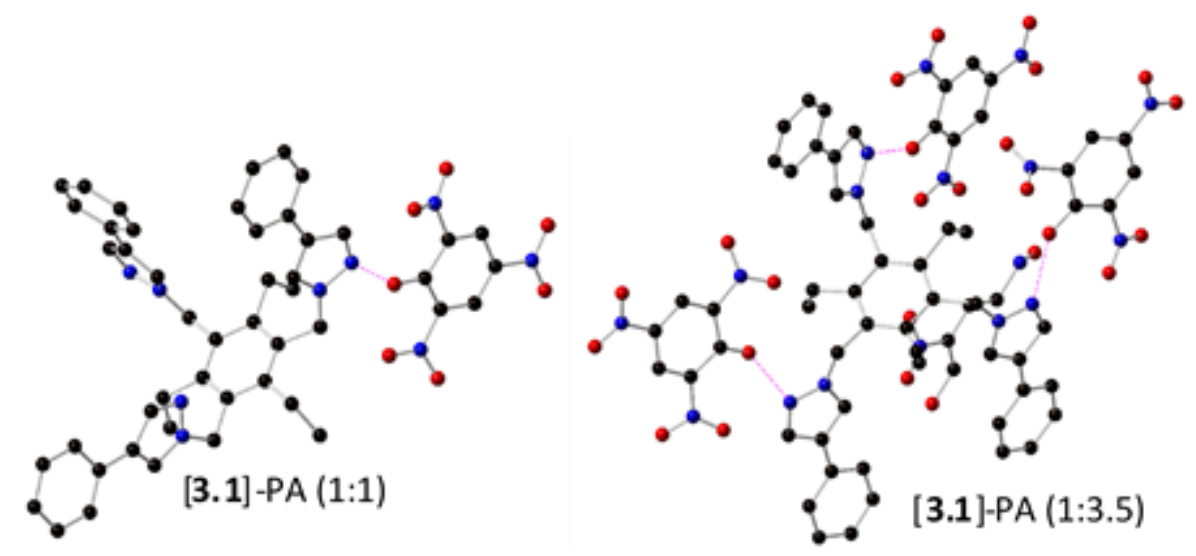

Figure 3.8. Crystal structures of [3.1](PA) (top) and [3.1](PA) 3.5. H-atoms omitted for clarity



Figure 3.9. Crystal packing diagram of $\mathbf{3 . 3}(\mathrm{PA})_{2}$ viewed parallel to a-axis. H-atoms are omitted for clarity

Furthermore, to investigate the sensing preference of $\mathbf{3 . 1}$ and 3.2 aggregates for PA over various nitro compounds, fluorescence titrations with PA, nitromethane (NM), nitrobenzene (NB), 2nitrophenol (2-NP), 4-nitrophenol (4-NP), and other aromatic compounds, such as benzoic acid (BA) and benzoquinone (BQ). The quenching efficiencies of PA towards $\mathbf{3 . 1}$ and $\mathbf{3 . 2}$ were found to be $92 \%$ and $91 \%$, respectively, significantly higher than other compounds (Fig. 3.10). 

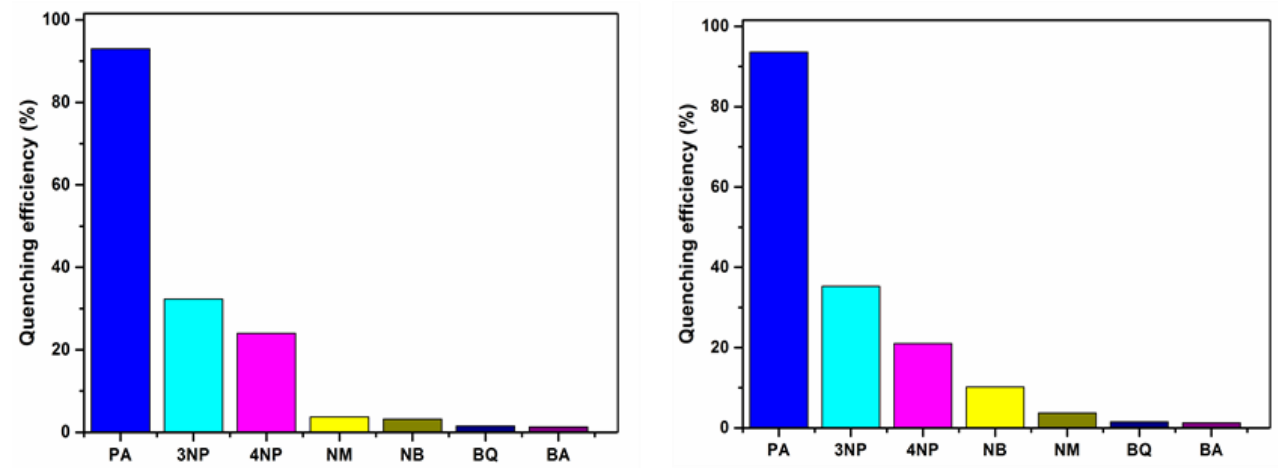

Figure 3.10. Fluorescence quenching efficiency of complexes 3.1 and 3.2 with various nitro aromatic compounds.

For the detection of PA vapors, a Whatman ${ }^{\mathrm{TM}}$ filter paper strip impregnated with $\mathbf{3 . 1}$ or $\mathbf{3 . 2}$ (10 $\mathrm{mM}$ in THF) and was exposed to the PA vapors (Fig. 3.11).
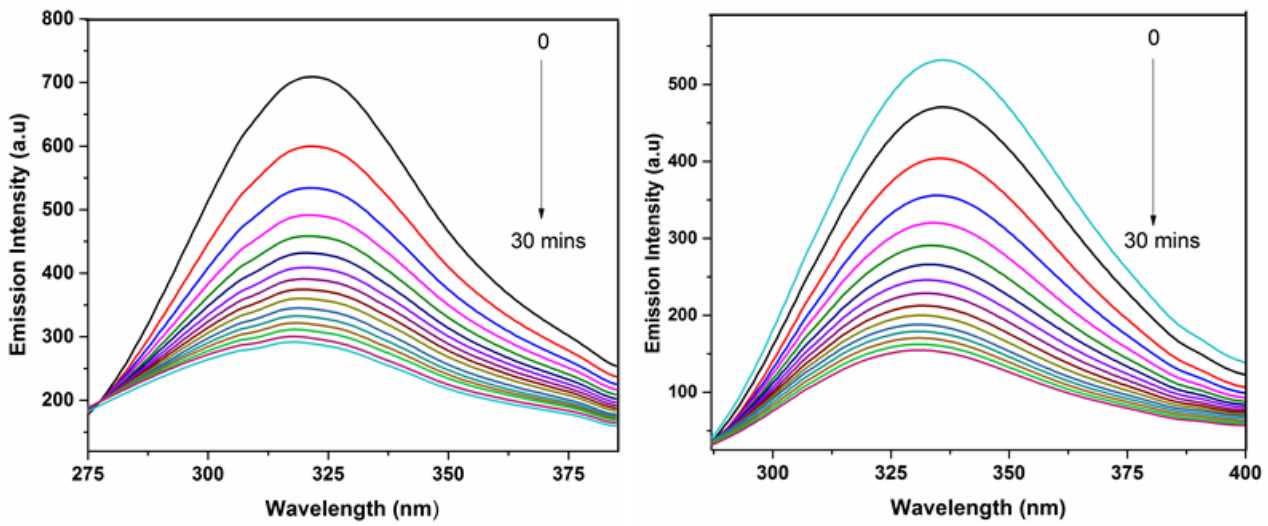

Figure 3.11. Change in emission spectra of 3.1 \& 3.2 $\left(1 \times 10^{-4} \mathrm{M}\right)$ on exposing to the vapors of PA with different time intervals. $(\Delta t=2 \operatorname{mins})\left(\lambda_{\mathrm{ex}}=255 \mathrm{~nm}\right)$.

Monitoring the exposure over a period of $30 \mathrm{~min}$, showed that the fluorescence intensity was quenched by $\sim 60 \%$ and $70 \%$ for 3.1 and 3.2, respectively. A separate chart of comparison of the fluorescence response times of test strips with PA vapors is also presented in Fig. 3.12. After irradiation with a UV lamp, the spots begin to darken after 20 min of strip exposure to PA vapors (Fig. A3.27). These results show the practical applicability of derivatives $\mathbf{3 . 1}$ and $\mathbf{3 . 2}$ towards the instant visualization of traces of PA. Therefore, these compounds are suitable probes for PA in the vapor phase and their efficiency is comparable to other systems reported in the literature ${ }^{51}$. 


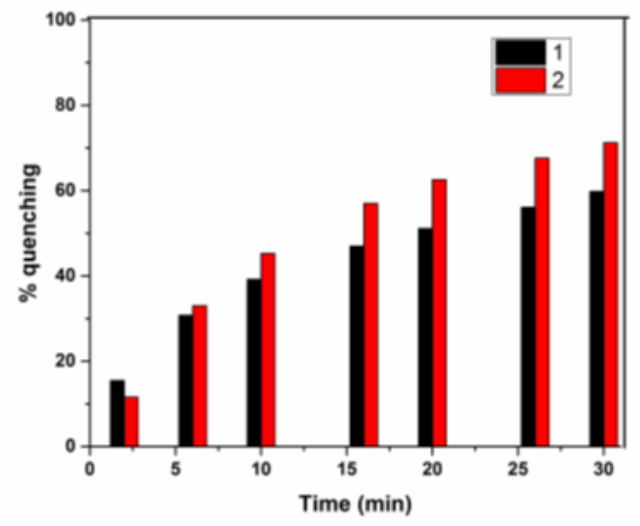

Figure 3.12. Comparison plot of fluorescence quenching performance for compounds $\mathbf{3 . 1}$ and $\mathbf{3 . 2}$ with PA vapors upon different exposure of time (0 to $30 \mathrm{~min}$ ).

Compound 3.2 was also used to detect the PA in contact mode by applying small spots $(10 \mu \mathrm{L})$ of various concentrations of PA solution into compound 3.2 impregnated test strips. The dark color spot was observed not only at higher concentrations $(1 \mathrm{mM})$ of PA, but also in nanomolar concentrations (Fig. 3.13).
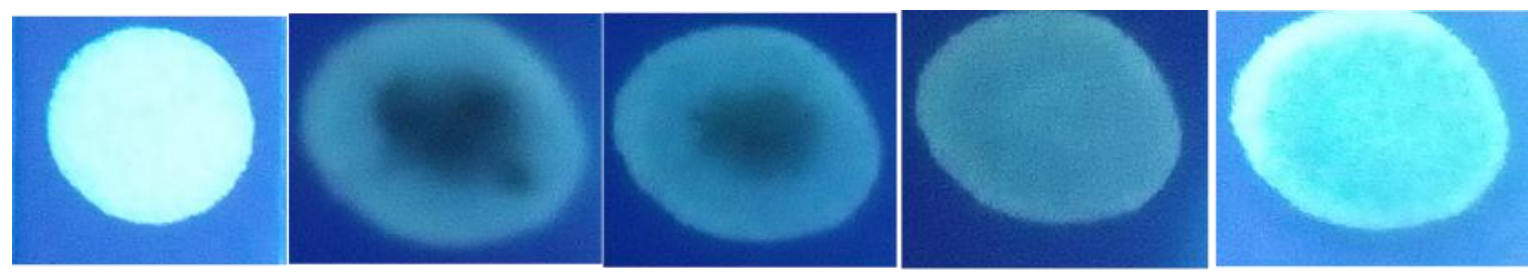

Figure 3.13. Photographs of compound 3.2 impregnated test strips under various concentrations of PA under illumination of $365 \mathrm{~nm}$ UV lamp blank, $1 \times 10^{-3} \mathrm{M}, 1 \times 10^{-4} \mathrm{M}, 1 \times 10^{-6} \mathrm{M}$ and, $1 \times 10^{-}$ ${ }^{9} \mathrm{M}$ respectively (left to right)

These observations confirm that the test strips containing trispyrazole compounds are responsive to even very low concentrations $\mathrm{PA}^{52}$. In addition, a gloved thumbprint of PA when rubbed on compound 3.2 was visualized under illumination by a $365 \mathrm{~nm}$ UV lamp (Fig. 3.14). Therefore, paper strips prepared by dip coating a solution of these compounds provide a simple, portable, sensitive, selective and low-cost method for the detection of PA, which could lead to real time applications such as onsite detection, forensic research, etc. 

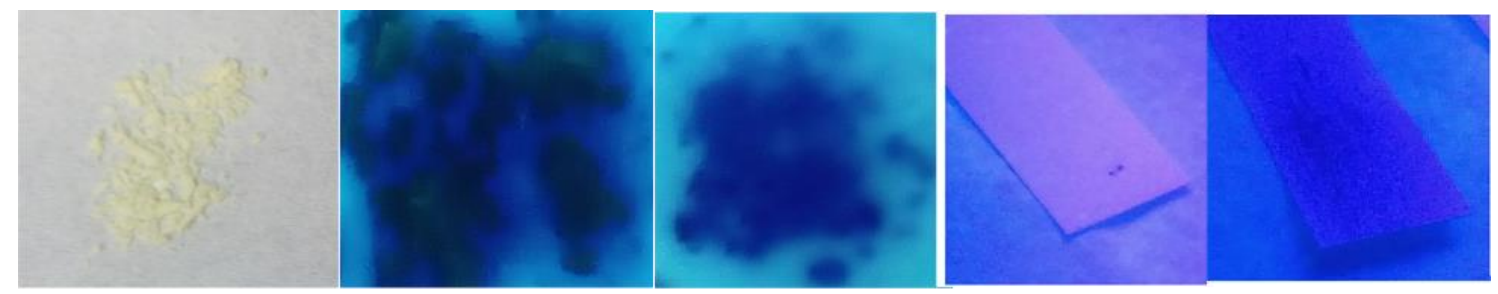

Figure 3.14. Pictures of compound 3.2 impregnated test strips under different experimental conditions under illumination of $365 \mathrm{~nm}$ UV lamp (i) PA under daylight. (ii) PA under UV light. (iii) After removal of the PA (iv) and (v) Thumb impressions before and after rubbing with PA.

\subsubsection{Computational study}

Geometry optimization of the complexes of trispyrazole 3.1 with one, two and three molecules of PA have been performed using a density functional $\omega$ B97XD method developed by HeadGordon's group ${ }^{39}$, which includes a correction for dispersion, with the 6-31G* basis set. The optimized geometries show a clear pattern of H-bond formation between the $\mathrm{OH}$ hydrogen and one of the $\mathrm{N}$ atoms of a pyrazole ring in 3.1-PA, 3.1-(PA) $)_{2}$ and 3.1-(PA) $)_{3}$, with the H-N distance varying in the 1.682-1.916 ̊ range. Interestingly, in 3.1-(PA) 3 , one PA molecule is linked with a pyrazole ring via $\mathrm{H}$-bonding, but the second PA molecule is trapped via $\pi$-stacking interaction. Even after repeated attempts to force a second H-bonding interaction by changing the initial geometry, the optimization still converged to the same structure with $\pi$-stacking interaction The TD-DFT calculations carried out at the $\omega \mathrm{B} 97 \mathrm{XD} / 6-311 \mathrm{G}^{* *}$ level of theory have shown the existence of excited electronic states, which have much higher oscillator strengths than the other states. For instance, for 3.1-PA, the excitation energy for the $9^{\text {th }}$ state was calculated to be 255.8 $\mathrm{nm}$, with the oscillator strength of 0.167 being at least one order of magnitude higher than those for the lower lying states and for consequent higher lying states up to $230 \mathrm{~nm}$. For 3.1-(PA) , a similar bright state is found at $256.1 \mathrm{~nm}$, with the oscillator strength of 0.173 . For 3.1-(PA) ${ }_{3}$, two bright states have been found in the same wavelength range, at $258.3 \mathrm{~nm}(f=0.178)$ and 254.4 $\mathrm{nm}(f=0.155)$. Figure 15 illustrates molecular orbitals (MOs) involved in the transition to the bright state in 3.1-PA. Clearly, the unoccupied MOs, accepting an electron, are localized on PA, 
whereas the occupied MOs, from which an electron is removed during the transition, have a significant contribution from the pyrazole ring forming a hydrogen bond with the picric acid. Thus, the calculations confirm the hypothesis that the bright absorption/emission observed experimentally is due to a charge transfer state, with an electron being excited from pyrazole to picric acid.

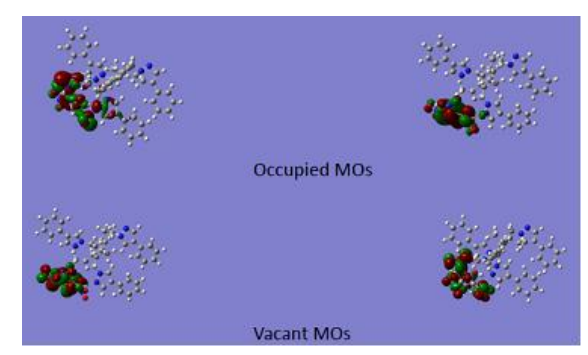

Figure 3.15. Occupied and vacant MOs involved in the bright transition in the complex of trispyrazole with one picric acid molecule.

\subsection{Conclusions}

In summary, we have designed and prepared five tripodal pyrazole compounds and studied their AIEE characteristics owing to their intramolecular rotation of phenyl rings, which were blocked by increasing the ratio of water in THF solution. These nanoaggregates serve as sensitive sensors for picric acid as confirmed by absorption, emission and NMR spectral techniques and corroborated by single-crystal X-ray crystallography and DFT calculations. These compounds show a good quenching constant with a low detection limit. In addition, test strips made of filter paper impregnated with these compounds detect PA vapors efficiently leading to practical field applications. Compounds 3.1 - 3.3 are selective and sensitive detectors towards picric acid in the vapor phase, a challenging task, due to its much lower vapor pressure compared to other nitro explosives. Compounds $\mathbf{3 . 1}$ and $\mathbf{3 . 3}$ have detection limits of 458 and 325 ppb for PA, comparable to the sensors reported by Roy et $\mathrm{al}^{47}$. As these chemosensors are characterized by sensitivity, fast 
response, simplicity, portability, and a low-cost, they can play kernel role in real time detection of explosives, opening new vistas for the development of simple, new fluorescent AIEE probes.

\subsection{References}

1. Tang, B. Z.; Qin, A., Aggregation-induced emission: Applications. John Wiley \& Sons: 2013.

2. Kumar, S.; Singh, P.; Mahajan, A.; Kumar, S., Aggregation induced emission enhancement in ionic self-assembled aggregates of benzimidazolium based cyclophane and sodium dodecylbenzenesulfonate. Organic letters 2013, 15 (13), 3400-3403.

3. Lo, D.; Chang, C.-H.; Krucaite, G.; Volyniuk, D.; Grazulevicius, J. V.; Grigalevicius, S., Sky-blue aggregation-induced emission molecules for non-doped organic light-emitting diodes. Journal of Materials Chemistry C 2017, 5 (24), 6054-6060.

4. Kitai, A., Luminescent materials and applications. John Wiley \& Sons: 2008; Vol. 25.

5. (a) Ding, D.; Li, K.; Liu, B.; Tang, B. Z., Bioprobes based on AIE fluorogens. Accounts of chemical research 2013, 46 (11), 2441-2453; (b) Kwok, R. T.; Leung, C. W.; Lam, J. W.; Tang, B. Z., Biosensing by luminogens with aggregation-induced emission characteristics. Chemical Society Reviews 2015, 44 (13), 4228-4238.

6. (a) Ma, X.; Sun, R.; Cheng, J.; Liu, J.; Gou, F.; Xiang, H.; Zhou, X., Fluorescence aggregation-caused quenching versus aggregation-induced emission: A visual teaching technology for undergraduate chemistry students. Journal of Chemical Education 2015, 93 (2), 345-350; (b) v. Bünau, G., JB Birks: Photophysics of Aromatic Molecules. WileyInterscience, London 1970. 704 Seiten. Preis: 210s. Berichte der Bunsengesellschaft für physikalische Chemie 1970, 74 (12), 1294-1295.

7. (a) Luo, J.; Xie, Z.; Lam, J. W.; Cheng, L.; Chen, H.; Qiu, C.; Kwok, H. S.; Zhan, X.; Liu, Y.; Zhu, D., Aggregation-induced emission of 1-methyl-1, 2, 3, 4, 5-pentaphenylsilole. Chemical communications 2001, (18), 1740-1741; (b) An, B.-K.; Kwon, S.-K.; Jung, S.-D.; Park, S. Y., Enhanced emission and its switching in fluorescent organic nanoparticles. Journal of the American Chemical Society 2002, 124 (48), 14410-14415; (c) Hong, Y.; Lam, J. W.; Tang, B. Z., Aggregation-induced emission. Chemical Society Reviews 2011, 40 (11), 5361-5388; (d) Hu, R.; Leung, N. L.; Tang, B. Z., AIE macromolecules: syntheses, structures and functionalities. Chemical Society Reviews 2014, 43 (13), 4494-4562; (e) Mei, J.; Leung, N. L.; Kwok, R. T.; Lam, J. W.; Tang, B. Z., Aggregation-induced emission: together we shine, united we soar! Chemical reviews 2015, 115 (21), 11718-11940.

8. Zhao, Z.; He, B.; Tang, B. Z., Aggregation-induced emission of siloles. Chemical science 2015, 6 (10), 5347-5365.

9. Yang, Z.; Qin, W.; Leung, N. L.; Arseneault, M.; Lam, J. W.; Liang, G.; Sung, H. H.; Williams, I. D.; Tang, B. Z., A mechanistic study of AIE processes of TPE luminogens: intramolecular rotation vs. configurational isomerization. Journal of Materials Chemistry $C$ 2016, 4 (1), 99-107. 
10. Meher, N.; Chowdhury, S. R.; Iyer, P. K., Aggregation induced emission enhancement and growth of naphthalimide nanoribbons via J-aggregation: insight into disaggregation induced unfolding and detection of ferritin at the nanomolar level. Journal of Materials Chemistry $B$ 2016, 4 (36), 6023-6031.

11. Sharma, S.; Virk, T. S.; Pradeep, C. P.; Dhir, A., ESIPT- Induced Carbazole- Based AIEE Material for Nanomolar Detection of $\mathrm{Cu} 2+$ and CN-Ions: A Molecular Keypad Security Device. European Journal of Inorganic Chemistry 2017, 2017 (18), 2457-2463.

12. Lin, L.; Lin, X.; Guo, H.; Yang, F., Diphenylacrylonitrile-connected BODIPY dyes: fluorescence enhancement based on dark and AIE resonance energy transfer. Organic \& biomolecular chemistry 2017, 15 (28), 6006-6013.

13. Kathiravan, A.; Sundaravel, K.; Jaccob, M.; Dhinagaran, G.; Rameshkumar, A.; Arul Ananth, D.; Sivasudha, T., Pyrene Schiff base: photophysics, aggregation induced emission, and antimicrobial properties. The Journal of Physical Chemistry B 2014, 118 (47), 1357313581.

14. Alam, P.; Kachwal, V.; Laskar, I. R., A multi-stimuli responsive "AIE" active salicylaldehyde-based Schiff base for sensitive detection of fluoride. Sensors and Actuators B: Chemical 2016, 228, 539-550.

15. Yang, M.; Xu, D.; Xi, W.; Wang, L.; Zheng, J.; Huang, J.; Zhang, J.; Zhou, H.; Wu, J.; Tian, Y., Aggregation-induced fluorescence behavior of triphenylamine-based Schiff bases: the combined effect of multiple forces. The Journal of organic chemistry 2013, 78 (20), 1034410359.

16. Zhang, G.-F.; Chen, Z.-Q.; Aldred, M. P.; Hu, Z.; Chen, T.; Huang, Z.; Meng, X.; Zhu, M.Q., Direct validation of the restriction of intramolecular rotation hypothesis via the synthesis of novel ortho-methyl substituted tetraphenylethenes and their application in cell imaging. Chemical Communications 2014, 50 (81), 12058-12060.

17. Han, F.; Zhang, R.; Zhang, Z.; Su, J.; Ni, Z., A new TICT and AIE-active tetraphenylethenebased Schiff base with reversible piezofluorochromism. RSC Advances 2016, 6 (72), 6817868184.

18. Mati, S. S.; Chall, S.; Bhattacharya, S. C., Aggregation-induced fabrication of fluorescent organic nanorings: selective biosensing of cysteine and application to molecular logic gate. Langmuir 2015, 31 (18), 5025-5032.

19. Singh, P.; Singh, H.; Sharma, R.; Bhargava, G.; Kumar, S., Diphenylpyrimidinonesalicylideneamine-new ESIPT based AIEgens with applications in latent fingerprinting. Journal of Materials Chemistry C 2016, 4 (47), 11180-11189.

20. Chen, B.; Sun, X.; Evans, R. E.; Zhou, R.; Demas, J. N.; Trindle, C. O.; Zhang, G., Aggregation-Induced Emission from Fluorophore-Quencher Dyads with Long-Lived Luminescence. The Journal of Physical Chemistry A 2015, 119 (33), 8854-8859.

21. Namitharan, K.; Pitchumani, K., Cascade synthesis of bis-N-sulfonylcyclobutenes via $\mathrm{Cu}$ (i)/Lewis acid-catalyzed $(3+2) /(2+2)$ cycloadditions: observation of aggregation-induced 
emission enhancement from restricted $\mathrm{C}$ [double bond, length as m-dash] $\mathrm{N}$ photoisomerization. Organic \& biomolecular chemistry 2012, 10 (15), 2937-2941.

22. Salinas, Y.; Martínez-Máñez, R.; Marcos, M. D.; Sancenón, F.; Costero, A. M.; Parra, M.; Gil, S., Optical chemosensors and reagents to detect explosives. Chemical Society Reviews 2012, 41 (3), 1261-1296.

23. Singh, S., Sensors-An effective approach for the detection of explosives. Journal of hazardous materials 2007, 144 (1-2), 15-28.

24. Snellinx, Z.; Nepovím, A.; Taghavi, S.; Vangronsveld, J.; Vanek, T.; Van Der Lelie, D., Biological remediation of explosives and related nitroaromatic compounds. Environmental Science and Pollution Research 2002, 9 (1), 48-61.

25. Sun, X.; Wang, Y.; Lei, Y., Fluorescence based explosive detection: from mechanisms to sensory materials. Chemical Society Reviews 2015, 44 (22), 8019-8061.

26. Sensors, F., Biosensors, ed. RB Thompson. CRC Press, LLC, Boca Raton, FL: 2006.

27. (a) Kaur, S.; Gupta, A.; Bhalla, V.; Kumar, M., Pentacenequinone derivatives: aggregationinduced emission enhancement, mechanism and fluorescent aggregates for superamplified detection of nitroaromatic explosives. Journal of Materials Chemistry C 2014, 2 (35), 73567363; (b) Mukundam, V.; Kumar, A.; Dhanunjayarao, K.; Ravi, A.; Peruncheralathan, S.; Venkatasubbaiah, K., Tetraaryl pyrazole polymers: versatile synthesis, aggregation induced emission enhancement and detection of explosives. Polymer Chemistry 2015, 6 (44), 77647770 .

28. Sathish, V.; Ramdass, A.; Velayudham, M.; Lu, K.-L.; Thanasekaran, P.; Rajagopal, S., Development of luminescent sensors based on transition metal complexes for the detection of nitroexplosives. Dalton Transactions 2017, 46 (48), 16738-16769.

29. (a) Ansari, A.; Ali, A.; Asif, M., biologically active pyrazole derivatives. New Journal of Chemistry 2017, 41 (1), 16-41; (b) Burschka, J.; Kessler, F.; Nazeeruddin, M. K.; Grätzel, M., Co (III) complexes as p-dopants in solid-state dye-sensitized solar cells. Chemistry of Materials 2013, 25 (15), 2986-2990.

30. (a) González, C. M.; Oton, F.; Espinosa, A.; Tarraga, A.; Molina, P., Tris (triazole) tripodal receptors as selective probes for citrate anion recognition and multichannel transition and heavy metal cation sensing. Organic \& biomolecular chemistry 2015, 13 (5), 1429-1438; (b) Kuswandi, B.; Verboom, W.; Reinhoudt, D., Tripodal receptors for cation and anion sensors. Sensors 2006, 6 (8), 978-1017.

31. Koch, N.; Seichter, W.; Mazik, M., Hexapodal pyrazole-based receptors: complexes with ammonium ions and solvent molecules in the solid state. Tetrahedron 2015, 71 (47), 89658974.

32. Sohn, H.; Calhoun, R. M.; Sailor, M. J.; Trogler, W. C., Detection of TNT and picric acid on surfaces and in seawater by using photoluminescent polysiloles. Angewandte Chemie International Edition 2001, 40 (11), 2104-2105. 
33. (a) Koch, N.; Mazik, M., Synthesis of Tripodal and Hexapodal Pyrazole-and BenzimidazoleBearing Compounds. Synthesis 2013, 45 (24), 3341-3348; (b) Jonah, T. M.; Mathivathanan, L.; Morozov, A. N.; Mebel, A. M.; Raptis, R. G.; Kavallieratos, K., Remarkably selective $\mathrm{NH} 4+$ binding and fluorescence sensing by tripodal tris (pyrazolyl) receptors derived from 1, 3, 5-triethylbenzene: structural and theoretical insights on the role of ion pairing. New Journal of Chemistry 2017, 41 (24), 14835-14838; (c) Vacca, A.; Nativi, C.; Cacciarini, M.; Pergoli, R.; Roelens, S., A new tripodal receptor for molecular recognition of monosaccharides. A paradigm for assessing glycoside binding affinities and selectivities by 1H NMR spectroscopy. Journal of the American Chemical Society 2004, 126 (50), 1645616465 .

34. Olguín, J.; Brooker, S., Synthesis of 3-and 5-formyl-4-phenyl-1 H-pyrazoles: promising head units for the generation of asymmetric imine ligands and mixed metal polynuclear complexes. New Journal of Chemistry 2011, 35 (6), 1242-1253.

35. Sheldrick, G. M., SHELXT-Integrated space-group and crystal-structure determination. Acta Crystallographica Section A: Foundations and Advances 2015, 71 (1), 3-8.

36. Dolomanov, O. V.; Bourhis, L. J.; Gildea, R. J.; Howard, J. A.; Puschmann, H., OLEX2: a complete structure solution, refinement and analysis program. Journal of Applied Crystallography 2009, 42 (2), 339-341.

37. Sheldrick, G. M., Crystal structure refinement with SHELXL. Acta Crystallographica Section C: Structural Chemistry 2015, 71 (1), 3-8.

38. Spek, A. L., PLATON SQUEEZE: a tool for the calculation of the disordered solvent contribution to the calculated structure factors. Acta Crystallographica Section C: Structural Chemistry 2015, 71 (1), 9-18.

39. Chai, J.-D.; Head-Gordon, M., Long-range corrected hybrid density functionals with damped atom-atom dispersion corrections. Physical Chemistry Chemical Physics 2008, 10 (44), 6615-6620.

40. (a) Casida, M. E.; Jamorski, C.; Casida, K. C.; Salahub, D. R., Molecular excitation energies to high-lying bound states from time-dependent density-functional response theory: Characterization and correction of the time-dependent local density approximation ionization threshold. The Journal of chemical physics 1998, 108 (11), 4439-4449; (b) Stratmann, R. E.; Scuseria, G. E.; Frisch, M. J., An efficient implementation of timedependent density-functional theory for the calculation of excitation energies of large molecules. The Journal of Chemical Physics 1998, 109 (19), 8218-8224.

41. Gaussian09, R. A., 1, MJ Frisch, GW Trucks, HB Schlegel, GE Scuseria, MA Robb, JR Cheeseman, G. Scalmani, V. Barone, B. Mennucci, GA Petersson et al., Gaussian. Inc., Wallingford CT 2009, 121, 150-166.

42. (a) Scaiano, J.; Turro, N.; Ramamurthy, G., Modern Molecular Photochemistry of Organic Molecules. University Science Books: New York: 2010; (b) Boominathan, M.; Sathish, V.; Nagaraj, M.; Bhuvanesh, N.; Muthusubramanian, S.; Rajagopal, S., Aggregation induced emission characteristics of maleimide derivatives. RSC Advances 2013, 3 (44), 2224622252; (c) Tang, B. Z.; Geng, Y.; Lam, J. W. Y.; Li, B.; Jing, X.; Wang, X.; Wang, F.; 
Pakhomov, A. B.; Zhang, X., Processible nanostructured materials with electrical conductivity and magnetic susceptibility: preparation and properties of maghemite/polyaniline nanocomposite films. Chemistry of materials 1999, 11 (6), 15811589.

43. Hong, Y.; Lam, J. W.; Tang, B. Z., Aggregation-induced emission: phenomenon, mechanism and applications. Chemical communications 2009, (29), 4332-4353.

44. Virgili, T.; Forni, A.; Cariati, E.; Pasini, D.; Botta, C., Direct evidence of torsional motion in an aggregation-induced emissive chromophore. The Journal of Physical Chemistry C 2013, 117 (51), 27161-27166.

45. Sathish, V.; Ramdass, A.; Lu, Z.-Z.; Velayudham, M.; Thanasekaran, P.; Lu, K.-L.; Rajagopal, S., Aggregation-Induced Emission Enhancement in Alkoxy-Bridged Binuclear Rhenium (I) Complexes: Application as Sensor for Explosives and Interaction with Microheterogeneous Media. The Journal of Physical Chemistry B 2013, 117 (46), 1435814366.

46. Shanmugaraju, S.; Joshi, S. A.; Mukherjee, P. S., Self-assembly of metallamacrocycles using a dinuclear organometallic acceptor: synthesis, characterization, and sensing study. Inorganic chemistry 2011, 50 (22), 11736-11745.

47. Roy, B.; Bar, A. K.; Gole, B.; Mukherjee, P. S., Fluorescent tris-imidazolium sensors for picric acid explosive. The Journal of organic chemistry 2013, 78 (3), 1306-1310.

48. Lakowicz, J. R., Mechanisms and dynamics of fluorescence quenching. Principles of fluorescence spectroscopy 2006, 3, 331-351.

49. Mahendran, V.; Pasumpon, K.; Thimmarayaperumal, S.; Thilagar, P.; Shanmugam, S., Tetraphenylethene-2-pyrone conjugate: aggregation-induced emission study and explosives sensor. The Journal of organic chemistry 2016, 81 (9), 3597-3602.

50. Wang, J.; Mei, J.; Yuan, W.; Lu, P.; Qin, A.; Sun, J.; Ma, Y.; Tang, B. Z., Hyperbranched polytriazoles with high molecular compressibility: aggregation-induced emission and superamplified explosive detection. Journal of Materials Chemistry 2011, 21 (12), 40564059.

51. (a) Kumar, M.; Vij, V.; Bhalla, V., Vapor-phase detection of trinitrotoluene by AIEE-active hetero-oligophenylene-based carbazole derivatives. Langmuir 2012, 28 (33), 12417-12421;

(b) Vij, V.; Bhalla, V.; Kumar, M., Attogram detection of picric acid by hexa-perihexabenzocoronene-based chemosensors by controlled aggregation-induced emission enhancement. ACS applied materials \& interfaces 2013, 5 (11), 5373-5380.

52. Bejoymohandas, K.; George, T.; Bhattacharya, S.; Natarajan, S.; Reddy, M., AIPE-active green phosphorescent iridium (III) complex impregnated test strips for the vapor-phase detection of 2, 4, 6-trinitrotoluene (TNT). Journal of Materials Chemistry C 2014, 2 (3), 515-523. 


\section{CHAPTER 4}

Chemistry of mercury(II)-pyrazolyl complexes; characterization and extraction studies

\subsection{Abstract}

This project is designed to focus on the removal of both organic and inorganic mercury from lowlevel nuclear waste (LLW) present in the Savannah River nuclear waste site (SRS). We have designed several pyrazole-based ligands, including tripodal trispyrazoles. Pyrazoles are versatile soft-donor ligands with a high affinity for mercury(II). Herein we describe seven new compounds incorporating differently substituted pyrazoles, namely, $\left[\mathrm{Hg}\left(\mathrm{CH}_{2} \mathrm{COCH}_{3}\right)\left(4-\mathrm{NO}_{2}\right.\right.$-bis $(2,4-$ dinitrophenyl)pz)] [4.1], $\left(\mathrm{Et}_{3} \mathrm{NH}\right)\left[\mathrm{Hg}_{2} \mathrm{Cl}_{2}\left(\mu-3,5-\mathrm{Me}_{2}-4-\mathrm{NO}_{2}-\mathrm{pz}\right)_{3}\right] \quad[4.2], \quad\left[\mathrm{Hg}_{2}\left(\mathrm{CH}_{3} \mathrm{COO}\right) \mathrm{Cl}_{2}(3-\right.$ $\left.\left.\mathrm{NO}_{2}-\mathrm{pz}\right)\right][4.3],\left[\mathrm{HgCl}\left(\mu-4-\mathrm{NO}_{2}-3,5-\mathrm{Me}_{2}-\mathrm{pz}\right)\right]_{\mathrm{n}}[4.4],[\mathrm{Hg}(\mu-\mathrm{Cl}) \mathrm{Cl}(4-\mathrm{I}-\mathrm{pzH})]_{\mathrm{n}}[4.5],\left[\mathrm{Hg}(\mu-\mathrm{Cl})_{2}(4-\right.$ $\left.\mathrm{I}-\mathrm{pzH})_{2}\right]_{\mathrm{n}} \quad[4.6]$ and $\left[\mathrm{HgCl}\left(2,4,6-\mathrm{Et}_{3}-1,3,5-\operatorname{tris}(4 \mathrm{Ph}-\mathrm{pz})\right]_{\mathrm{n}} \quad[4.7]\right.$. These complexes were characterized by single crystal X-ray diffraction, ${ }^{1} \mathrm{H}$ NMR and IR spectroscopic techniques and elemental analyses, showing a variety of nuclearities and coordination numbers. Preliminary results of the selective extraction of $\mathrm{Hg}(\mathrm{II})$ from $\mathrm{Ln}(\mathrm{III})$-containing solutions are also reported.

\subsection{Introduction}

The Savannah River low nuclear waste site contains about 60 metric tons of mercury, which was used as a catalyst to dissolve the aluminum cladding of reactor fuel (canyon processing). Even though mercury is present in various forms, i.e. $\operatorname{Hg}(0, \mathrm{I}, \mathrm{II})$, organomercury (methylmercury(II)) is its most abundant. ${ }^{1}$ Existing methods for the removal of mercury from this site is not effective enough, and several chemists/engineers are working on it to overcome the challenges. ${ }^{2}$

Pyrazoles can be good candidates to extract mercury from both acidic and alkaline waste. The tunability of the pyrazoles is one of the good reasons for its use. Physical and chemical properties, such as acidity/basicity, steric and electronic environment, and solubility can be tuned easily by 
varying the substituents on the 3-, 4- and 5-positions of the ring. ${ }^{2}{ }^{4}$ Pyrazoles can also be easily incorporated in monopodal to the polypodal molecular platforms. Lipophilic ligands are desired to extract mercury from the aqueous radioactive waste. ${ }^{5}$ Extraction of mercury, lead, and other toxic metals from the environment is another challenging issue, since they exist in water soluble salt form. Among the available methodologies, the use of lipophilic ligands to extract the toxic metals out of aqueous solution can be an effective way for their removal from the environment. ${ }^{6}$

Besides the nuclear waste, it is found everywhere in the Earth's lithosphere. From the lithosphere, it is emitted in the atmosphere as elemental gaseous $\mathrm{Hg}^{0}$ form. ${ }^{7}$ From the atmosphere, it goes back to water and soil and gets buried in terrestrial reservoirs (lithosphere) and the cycle continues. While approximately $500 \mathrm{mg} / \mathrm{year}$ are emitted back naturally, human activities, such as mining, fossil fuel combustion, and industrial production, have augmented the emission of mercury from lithosphere to atmosphere $2000 \mathrm{mg} / \mathrm{year}^{8}$

Regardless of the source and form of mercury, its extraction and removal have gained considerable research interest, because of its toxicity to human as well as other living creatures and its wide distribution. ${ }^{9}$ Mercury is toxic in its all forms and exposure to them can be detrimental to the kidney, brains, and lungs, resulting in hepatotoxicity, neurotoxicity, nephrotoxicity, or pulmonary toxicity. ${ }^{10}$ Thiol compounds, such as dimercaptopropanesulfonic acid (DMPS), dimercaptosuccinic acid (DMPA), are being used currently in clinical chelation therapy of mercury poisoning. ${ }^{11}$ However, they are not well optimized, nor effective enough. ${ }^{12}$ Also, catabolism of Cys in the gastrointestinal tract and blood plasma limits their use in chelation therapy. ${ }^{13} \mathrm{~N}$-acetylcysteine (NAC) is another ligand used in chelation therapy; it has been found that post-exposure treatment with NAC has increased the concentration of mercury in the brain, because mercury-NAC complex acts as a structural and functional homolog of cysteine and is transported to the brain. ${ }^{14}$ Moreover, although S-donor ligands have a higher binding constant 
with $\mathrm{Hg}(\mathrm{II})$, they may also replace the $\mathrm{Cl}$ atom present in most of the organic and inorganic compounds of mercury, leaving the concentration of chloride. Therefore, it is useful to study other options for the therapeutic chelation of mercury. Pyrazoles may be suitable ligands to overcome the limitation, because they have been used in vivo for other treatments and proved to be biologically compatible. ${ }^{15}$ Also, as a result of the structural flexibility of the mercury, pyrazole $\mathrm{N}$-atoms selectively bind $\mathrm{Hg}$-compounds without replacing $\mathrm{Cl}^{-}$ions. ${ }^{16}$

The "soft acid" nature of the $\mathrm{Hg}(\mathrm{II})$ acceptor ion favors strong binding to "soft base" donor atoms, such as nitrogen, sulfur, selenium, and phosphorus. ${ }^{17} \mathrm{Hg}(\mathrm{II})$ has $\mathrm{d}^{10}$ electronic configuration and it prefers the formation of low-coordinate linear, trigonal planar, or tetrahedral complexes. ${ }^{16}$ Tripodal ligands are better over the monopodal ligands, because the chelate effect. ${ }^{13}$ Pyrazoles and benzimidazole having heterocyclic recognition sites have been reported to be more effective than acyclic ones. ${ }^{18}$

The primary objective of our study is to explore the pyrazole/pyrazolate chemistry and use the ligands as mercury getters to extract mercury from Savannah River nuclear waste. Herein, we report the synthesis and structural characterization of seven new mercury pyrazole/pyrazolate complexes varying from mononuclear to polynuclear and linear to octahedral coordination, namely, [PNDP-pzHgCH $\mathrm{COCH}_{3}$ ] [4.1] (a mononuclear, linear coordination compound), $\left[\left(\mathrm{Hg}_{2} \mathrm{Cl}_{2}\left(\mu-3,5-\mathrm{Me}_{2}-4-\mathrm{NO}_{2} \mathrm{pz}\right)_{3}\right)\left(\mathrm{Et}_{3} \mathrm{NH}\right)\right]$ [4.2] (a dinuclear capped, tetrahedral coordination compound with completely novel motif), $\left[\mathrm{Hg}_{2}\left(\mathrm{CH}_{3} \mathrm{COO}\right) \mathrm{Cl}_{2}\left(3-\mathrm{NO}_{2}-\mathrm{pz}\right)\right]$ [4.3] (a pentanuclear, linear and trigonal planar coordination compound), $\left[\mathrm{Hg}(\mu-\mathrm{Cl})\left(\mu-3,5-\mathrm{Me}_{2}-4-\mathrm{NO}_{2} \mathrm{pz}\right)\right]_{\mathrm{n}}[4.4]$ (a polymeric, tetrahedral coordination compound), $[\mathrm{HgCl}(\mu-\mathrm{Cl})(4-\mathrm{I}-\mathrm{pzH})]_{\mathrm{n}}[4.5]$ (a polymeric, tetrahedral coordination compound), $\left[\mathrm{Hg}(\mu-\mathrm{Cl})_{2}(4-\mathrm{I}-\mathrm{pzH})_{2}\right]_{\mathrm{n}}[$ 4.6] (a polymeric, octahedral coordination compound), and $\left[\mathrm{HgCl}\left(2,4,6-\mathrm{Et}_{3}-1,3,5-\operatorname{tris}(4 \mathrm{Ph}-\mathrm{pz})\right]_{\mathrm{n}}[4.7]\right.$ (a polymeric, tetrahedral 
coordination compound). Selective extraction of $\mathrm{Hg}^{2+}$ from an aqueous solution of $\mathrm{Hg}^{2+}$ and $\mathrm{Ln}^{3+}$ was carried out in organic media and was found promising.

\subsection{Experimental}

\subsubsection{Materials and methods}

Reagent grade chemicals were purchased from Aldrich Chemical Co, Alfa Aesar, Fisher scientific or ACROS Organics. Further purification was carried out for solvents for Shlenk line syntheses. 1,3,5-tris(bromomethyl)-2,4,6-triethylbenzene was synthesized using the literature. ${ }^{9}$ A new tripodal ligand; $\mathrm{T}(4 \mathrm{Ph}) \mathrm{pzH}$ was synthesized by slight modification of the literature. ${ }^{19} \mathrm{PNDPpzH}^{20}$ and 3,5 dimethyl 4nitropyrazole ${ }^{21}$ were synthesized by using the literature methods. X-ray structures were obtained from 'Bruker D8 CMOS' diffractometer. ${ }^{1} \mathrm{H}-\mathrm{NMR}$ spectra were recorded on a $400 \mathrm{MHz}$ BrukerAvance spectrometer and were referenced using the residual solvent proton resonances. FT-IR spectra were recorded with an ATR-IR, diamond Spectrometer. Elemental analyses were recorded from GALBRAITH Laboratories. Inc., Knoxville, TN, USA.

\subsubsection{Synthesis of [PNDP-pzHgCH $\left.\mathrm{COCH}_{3}\right][4.1]$}

$50.3 \mathrm{mg}(0.1 \mathrm{mmol})$ PNDPpzH was added to the suspension $31.8 \mathrm{mg}(0.1 \mathrm{mmol})$ of $\mathrm{Hg}\left(\mathrm{CH}_{3} \mathrm{COO}\right)_{2}$ in $6 \mathrm{~mL}$ acetone and stirred for 4 days. The compound was crushed out adding 20 $\mathrm{mL}$ of water and the byproduct $\left(\mathrm{CH}_{3} \mathrm{COOH}\right)$ in the solution was filtered off. The precipitate was washed with water followed by diethyl ether. The solid was dried under vacuum. Molecular weight: $701.9 \mathrm{~g} / \mathrm{mol}$. Yield, $50 \mathrm{mg}(71 \%)$. Light yellow colored crystals of X-ray quality were obtained by the slow evaporation of the compound solution in acetone. Anal. Calcd: C, 30.80; H, 1.58; N, 13.97. Found C, 30.08; H, 1.17; N, 14.84. IR ( $\left.\mathrm{v}_{\max }, \mathrm{cm}^{-1}\right): 3095(\mathrm{w}), 1600(\mathrm{w}), 1531(\mathrm{~s})$, 1344(s), 1211(w), 1068(w), 914(m), 833(s), 738(m) ${ }^{1} \mathrm{H}$ NMR (acetone- $\mathrm{D}_{6}, 298 \mathrm{~K}, \delta$ in ppm, 400MHz): $1.20(\mathrm{~s})\left(3 \mathrm{H},-\mathrm{CH}_{3}\right), 2.14(\mathrm{~s})\left(1 \mathrm{H},-\mathrm{CH}_{2}\right), 2.61(\mathrm{~s})\left(1 \mathrm{H},-\mathrm{CH}_{2}\right), 8.20(\mathrm{~d})(2 \mathrm{H},-\mathrm{CH} / \mathrm{pz})$, 8.76(d) $(1 \mathrm{H},-\mathrm{CH} / \mathrm{pz}), 8.79(\mathrm{~d})(1 \mathrm{H},-\mathrm{CH} / \mathrm{pz}), 9.04(\mathrm{~d})(2 \mathrm{H},-\mathrm{CH} / \mathrm{pz})$. 


\subsubsection{Synthesis of $\left(\mathrm{Et}_{3} \mathrm{NH}\right)\left[\left(\mathrm{Hg}_{2} \mathrm{Cl}_{2}\left(\mu-3,5-\mathrm{Me}_{2}-4-\mathrm{NO}_{2} \mathrm{pz}\right)_{3}\right)\right][4.2]$}

$27.1 \mathrm{mg}(0.1 \mathrm{mmol}) \mathrm{HgCl}_{2}$ and $21.1 \mathrm{mg}(0.15 \mathrm{mmol}) 3,5-\left(\mathrm{CH}_{3}\right)_{2}-4-\mathrm{NO}_{2}-\mathrm{pzH}$ in $8 \mathrm{~mL} \mathrm{CH}_{2} \mathrm{Cl}_{2}$ or acetone was stirred for 20 minutes. Addition of $20.85 \mu \mathrm{L}\left(0.15 \mathrm{mmol}^{2} \mathrm{Et}_{3} \mathrm{~N}\right.$ to the suspension resulted clear solution. Colorless crystals of X-ray quality were obtained by slow evaporation of the solution. Molecular weight: $994.65 \mathrm{~g} / \mathrm{mol}$. Yield, $37 \mathrm{mg}$ (74\%). Anal. Calcd: C, 25.36; H, 3.45; N, 14.08. Found C, 24.70; H, 3.12; N, 14.29. IR ( $\left.v_{\max }, \mathrm{cm}^{-1}\right): 3202(w), 3129(w), 2885(w)$, 1587(w), 1544(m), 1465(w), 1411(w), 1355(s), 1172(s), 1029(w), 991(w), 831(s), 767(m). ${ }^{1} \mathrm{H}$ NMR $\left(\mathrm{CDCl}_{3}, 298 \mathrm{~K}, \delta\right.$ in ppm, $\left.400 \mathrm{MHz}\right): 1.42(\mathrm{t})\left(9 \mathrm{H},-\mathrm{CH}_{3} / \mathrm{Et}_{3} \mathrm{NH}\right), 2.61(\mathrm{~s})\left(18 \mathrm{H},-\mathrm{CH}_{3} / \mathrm{pz}\right)$, $3.27(\mathrm{q})\left(6 \mathrm{H},-\mathrm{CH}_{2} / \mathrm{Et}_{3} \mathrm{NH}\right)$.

\subsubsection{Synthesis of $\left[\mathrm{Hg}_{2}\left(\mathrm{CH}_{3} \mathrm{COO}\right) \mathrm{Cl}_{2}\left(3-\mathrm{NO}_{2}-\mathrm{pz}\right)\right][4.3]$}

$27.1 \mathrm{mg}(0.1 \mathrm{mmol}) \mathrm{HgCl}_{2}, 31.8 \mathrm{mg}(0.1 \mathrm{mmol}) \mathrm{Hg}\left(\mathrm{CH}_{3} \mathrm{COO}\right)_{2}, 11.3 \mathrm{mg}(0.1 \mathrm{mmol}) 3-\mathrm{NO}_{2}-\mathrm{pzH}$ and $13.9 \mu \mathrm{L}(0.1 \mathrm{mmol}) \mathrm{Et}_{3} \mathrm{~N}$ in $8 \mathrm{~mL} \mathrm{MeOH}$ was stirred for $24 \mathrm{~h}$. The resulting precipitate was dried under vacuum. Colorless crystals of X-ray quality were obtained by slow evaporation of the acetone solution of the precipitate.

\subsubsection{Synthesis of $\left[\mathrm{Hg}(\mu-\mathrm{Cl})\left(\mu-3,5-\mathrm{Me}_{2}-4-\mathrm{NO}_{2} \mathrm{pz}\right)\right]_{\mathrm{n}}[4.4]$}

$27.1 \mathrm{mg}(0.1 \mathrm{mmol}) \mathrm{HgCl}_{2}$ and $14.1 \mathrm{mg}(0.1 \mathrm{mmol}) 3,5\left(\mathrm{CH}_{3}\right)_{2} 4 \mathrm{NO}_{2} \mathrm{pzH}$ in $8 \mathrm{~mL} \mathrm{MeOH}$ was stirred for 20 minutes. Addition of $13.9 \mu \mathrm{L}(0.1 \mathrm{mmol}) \mathrm{Et}_{3} \mathrm{~N}$ to the suspension resulted clear solution. Colorless crystals of X-ray quality were obtained by the slow evaporation of the solution. Molecular weight: $752.32 \mathrm{~g} / \mathrm{mol}$ (for a monomeric unit). Yield, $67 \mathrm{mg}$ (89\%). Anal.

Calcd: C, 15.97; H, 1.61; N, 11.17. Found C, 16.87; H, 1.85; N, 11.01. IR ( $\left.\mathrm{U}_{\max }, \mathrm{cm}^{-1}\right): 2923(\mathrm{w})$, 1546(s), 1475(s), 1413(s), 1380(s), 1357(s), 1174(s), 995(m), 883(s), 763(m). ${ }^{1} \mathrm{H}$ NMR (DMSO$\mathrm{D}_{6}, 298 \mathrm{~K}, \delta$ in ppm, $\left.400 \mathrm{MHz}\right): 2.54(\mathrm{~s})\left(\mathrm{CH}_{3} / \mathrm{pz}\right)$. 


\subsubsection{Synthesis of $[\mathrm{HgCl}(\mu-\mathrm{Cl})(4-\mathrm{I}-\mathrm{pzH})]_{\mathrm{n}}[4.5]$}

Mixture of $27.1 \mathrm{mg}(0.1 \mathrm{mmol}) \mathrm{HgCl}_{2}, 19.4 \mathrm{mg}(0.1 \mathrm{mmol})$ 4-I-pzH, and $13.9 \mu \mathrm{L}(0.1 \mathrm{mmol})$ $\mathrm{Et}_{3} \mathrm{~N}$ were stirred in $8 \mathrm{~mL}$ for $24 \mathrm{~h}$. The suspension was filtered. Colorless crystals of X-ray quality were obtained by slow evaporation of the filtrate. Molecular weight: $465.54 \mathrm{~g} / \mathrm{mol}$ (for a monomeric unit). Yield, $29 \mathrm{mg}(62 \%)$. Addition of excess $\mathrm{Et}_{3} \mathrm{~N}$ did not deprotonate the pyrazole. Similar procedure without using the $\mathrm{Et}_{3} \mathrm{~N}$ also gave the same result. IR $\left(\mathrm{v}_{\max }, \mathrm{cm}^{-1}\right): 3228(\mathrm{w})$, 1627(m), 1452(m), 1369(s), 1311(s), 1207(m), 1162(w), 1062(s), 948(m), 836(s), 671(m). ${ }^{1} \mathrm{H}$ NMR (THF-D ${ }_{8}, 298 \mathrm{~K}, \delta$ in ppm, 400MHz): 7.57(s) (-CH/pz), 10.83(-NH/pz). $\left(\mathrm{CDCl}_{3}, 298 \mathrm{~K}, \delta\right.$ in ppm, 400MHz): 7.65(s) (-CH/pz).

\subsubsection{Synthesis of $\left[\mathrm{Hg}(\mu-\mathrm{Cl})_{2}(4-\mathrm{I}-\mathrm{pzH})_{2}\right]_{\mathrm{n}}[4.6]$}

Mixture of $27.1 \mathrm{mg}(0.1 \mathrm{mmol}) \mathrm{HgCl}_{2}, 38.8 \mathrm{mg}(0.2 \mathrm{mmol})$ 4-I-pzH and $27.8 \mu \mathrm{L}(0.2 \mathrm{mmol})$ $\mathrm{Et}_{3} \mathrm{~N}$ were stirred in $8 \mathrm{~mL}$ for $24 \mathrm{~h}$. The suspension was filtered. Colorless crystals of X-ray quality were obtained by the slow evaporation of the filtrate. Molecular weight: $659.44 \mathrm{~g} / \mathrm{mol}$ (for a monomeric unit). Yield, 44mg (67\%). Addition of excess $\mathrm{Et}_{3} \mathrm{~N}$ did not deprotonate the pyrazole. Similar procedure without using the $\mathrm{Et}_{3} \mathrm{~N}$ also gave the same result. IR ( $\left.\mathrm{v}_{\max }, \mathrm{cm}^{-1}\right): 3214(\mathrm{w})$, 3085(s), 1710(w), 1461(s), 1373(s), 1193(m), 1132(s), 1062(s), 939(s), 856(s), 690(s). ${ }^{1} \mathrm{H}$ NMR $\left(\mathrm{CDCl}_{3}, 298 \mathrm{~K}, \delta\right.$ in ppm, 400MHz): 7.67(s) (-CH/pz).

\subsubsection{Synthesis of $\left[\mathrm{HgCl}\left(2,4,6-\mathrm{Et}_{3}-1,3,5-\operatorname{tris}(4 \mathrm{Ph}-\mathrm{pz})\right]_{\mathrm{n}}\right.$}

$27.1 \mathrm{mg}(0.1 \mathrm{mmol}) \mathrm{HgCl}_{2}$ and $63 \mathrm{mg}(0.1 \mathrm{mmol})\left[2,4,6-\mathrm{Et}_{3}-1,3,5\right.$-tris$\left.(4 \mathrm{Ph}-\mathrm{pz})\right]$ were stirred in acetone for $24 \mathrm{~h}$. Colorless crystals of X-ray quality were obtained by slow evaporation of the solution. Molecular weight: $902.33 \mathrm{~g} / \mathrm{mol}$ (for a monomeric unit). Yield, $75 \mathrm{mg}$ (83\%). Anal. Calcd: C, 56.61; H, 5.34; N, 9.25. Found C, 56.73; H, 5.03; N, 9.12. IR ( $\left.\mathrm{v}_{\max }, \mathrm{cm}^{-1}\right): 3104(\mathrm{w})$, 2960(w), 1706(w), 1671(w), 1604(w), 1562(w), 1446(w), 1363(w), 1361(w), 1280(w), 1220(w), 1176(s), 1068(w), 1008(w), 952(m), 867(w), 755(s), 692(s), 655(w). ${ }^{1} \mathrm{H}$ NMR $\left(\mathrm{CD}_{2} \mathrm{Cl}_{2}, 298 \mathrm{~K}, \delta\right.$ 
in ppm, 400MHz): 1.03(t) $\left(9 \mathrm{H},-\mathrm{CH}_{3}, \mathrm{Et} / \mathrm{Tpz}\right), 2.12(\mathrm{~s})\left(6 \mathrm{H},-\mathrm{CH}_{3} /\right.$ acetone $), 2.82(\mathrm{q})\left(6 \mathrm{H},-\mathrm{CH}_{2}\right.$, Et/Tpz), 5.51(s) (6H, -CH2, Tpz), 7.18-7.38(m) (18H, -Ph +pz(C5), 7.81(s) (3H, pz(C3))

\subsubsection{Extraction study}

Solvent extraction experiment was carried out to study the selective extraction of mercury from the mixture of mercury $\left(\mathrm{Hg}^{2+}\right)$ and lanthanide salts $\left(\mathrm{Ln}^{3+}\right)$ in aqueous solution using two ligands (ligands of complexes 4.4 and 4.7). Employing 3,5-( $\left(\mathrm{CH}_{3}\right)_{2}-4-\mathrm{NO}_{2} \mathrm{pzH} ; \mathrm{ErCl}_{3}+\mathrm{Sm}\left(\mathrm{NO}_{3}\right)_{3}+$ $\mathrm{HgCl}_{2}$ (in an equimolar amount) was dissolved in a vial and 3,5-( $\left(\mathrm{CH}_{3}\right)_{2}-4-\mathrm{NO}_{2} \mathrm{pzH}$ (extractant) and $\mathrm{Et}_{3} \mathrm{~N}$ in an equimolar amount with that of each salt was dissolved in $\mathrm{CHCl}_{3}$. Both solutions were kept in a separatory funnel and shaken for a few minutes. Slow evaporation of the organic layer gave 4.4, confirming that this ligand selectively extracts $\mathrm{Hg}$ out of aqueous solution. Employing $\mathrm{T}(4 \mathrm{Ph}) \mathrm{pz} ; \mathrm{Sm}\left(\mathrm{NO}_{3}\right)_{3}+\mathrm{HgCl}_{2}$ (equimolar amounts) were dissolved in a vial and $\mathrm{T}(4 \mathrm{Ph}) \mathrm{pz}$ (extractant) in an equimolar amount with that of each salt was dissolved in $\mathrm{CHCl}_{3}$. Both solutions were kept into a separatory funnel and shaken for a few minutes. Slow evaporation of the organic layer gave 4.7, confirming that this ligand selectively extracts $\mathrm{Hg}$ out of aqueous solution. Several reactions with many lanthanide salts and using various solvents were carried out with all the pyrazoles employed in this work and several spectroscopic techniques were employed to see if the ligand binds lanthanides but, the result was always negative.

\subsection{Results and discussions}

\subsubsection{Synthesis and crystal structures of complexes}

Water-soluble mercury salts, either $\mathrm{HgCl}_{2}$ or $\mathrm{Hg}\left(\mathrm{CH}_{3} \mathrm{COO}\right)_{2}$ or both, were used to synthesize the compounds. Five different types of pyrazolyl ligands with a wide range of chemical/electronic/steric properties were used. Six out of seven pyrazoles used are monopodal $1 \mathrm{H}$ pyrazoles and the last one is a tripodal pyrazole. Compounds 4.4-4.7 are polynuclear. All the compounds are organosoluble (soluble in $\mathrm{CH}_{2} \mathrm{Cl}_{2}, \mathrm{CHCl}_{3}$, and acetone) and none of them are 
water soluble. Compound 4.4, however, is barely soluble in any organic solvents other than DMSO, although crystals were grown from $\mathrm{MeOH}$ or $\mathrm{CH}_{2} \mathrm{Cl}_{2} .{ }^{1} \mathrm{H}-\mathrm{NMR}$ of in situ reaction corresponds to dimeric form and the peaks are highly shifted from the pyrazole, confirming that it polymerizes via dimerization. ${ }^{1} \mathrm{H}$ NMR of the compounds are shown in Figures 4.8, 4.9 and A4.1A4.5. Compounds 4.1 and 4.3 have a long range of intermolecular (H-bonding) interaction forming a supramolecular structure. All compounds except 4.2 are neutral whereas, 4.2 has $\mathrm{Et}_{3} \mathrm{NH}^{+}$counter cation. Regardless of the stoichiometry, compound 4.5 and 4.6 always cocrystallize but, stoichiometry determines the major and minor products. Addition of excess base in 4.5 and 4.6 does not deprotonate the pyrazole, hence the compounds are stable over a wide $\mathrm{pH}$ range (acidic to alkaline).

Although $\mathrm{Hg}$ prefers low coordination numbers (usually 2 and 3), we synthesized seven compounds ranging from linear to octahedral (2-6) coordination numbers. [4.1] is a mononuclear $\mathrm{Hg}$ compound with linear coordination geometry around $\mathrm{Hg}(\mathrm{II})$. [4.2] is a dinuclear triclipped compound with each $\mathrm{Hg}(\mathrm{II})$ center coordinated with one N-donor atom from each pyrazole and one terminal chlorine, giving tetrahedral geometry. This is an unprecedented motif for $\mathrm{Hg}$ compounds. A pentanuclear $\mathrm{Hg}$ compound [4.3], has two $\mathrm{Hg}$ atoms in T-shaped coordination geometry and the remaining three $\mathrm{Hg}$ atoms are in linear coordination geometry. The polymeric compounds [4.4], [4.5] and [4.7] compounds have tetrahedral geometry on Hg center, whereas [4.6] has octahedral geometry. X-ray structures of 4.1-4.7 are given in Figures 4.1-4.7 respectively. The crystallographic details are given in the appendices Tables A4.1 and A4.2. 


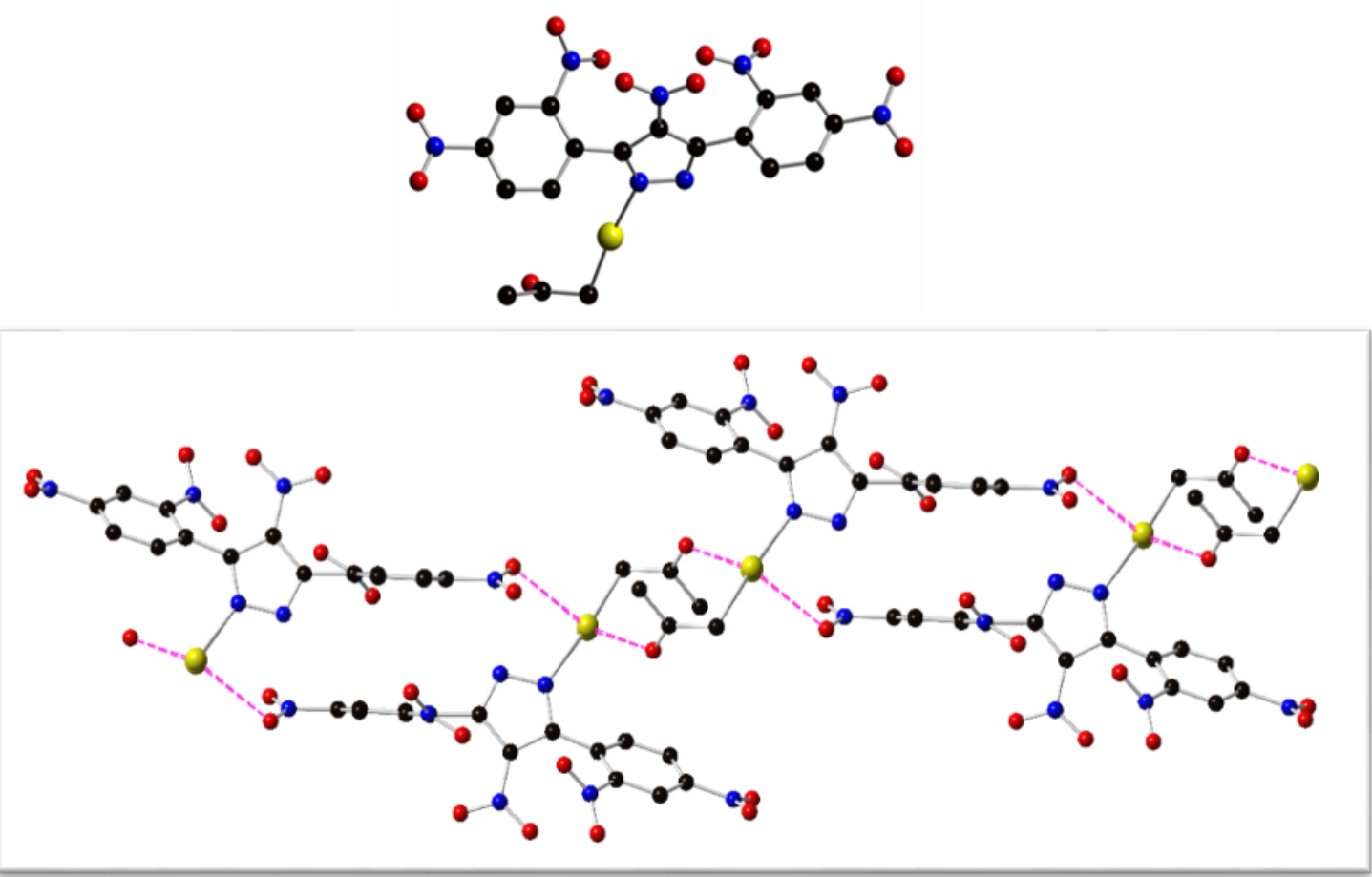

Figure 4.1. The molecular structure of $\mathbf{4 . 1}$ (top), long-range $\mathrm{Hg} \ldots \mathrm{O}$ interaction forming supramolecular structure (bottom); $\mathrm{H}$-atoms are omitted for clarity. Color code: Yellow, $\mathrm{Hg}$; black, C; blue, N; red, O.

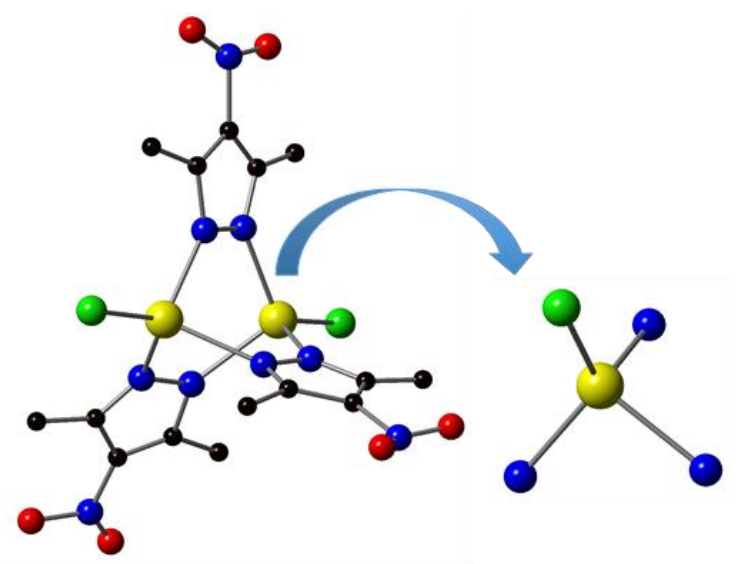

Figure 4.2. The molecular structure of 4.2, showing tetrahedral geometry around $\mathrm{Hg}$ center; $\mathrm{H}$ atoms are omitted for clarity. Color code: Yellow, $\mathrm{Hg}$; black, C; blue, N; red, O; green, $\mathrm{Cl}$. 


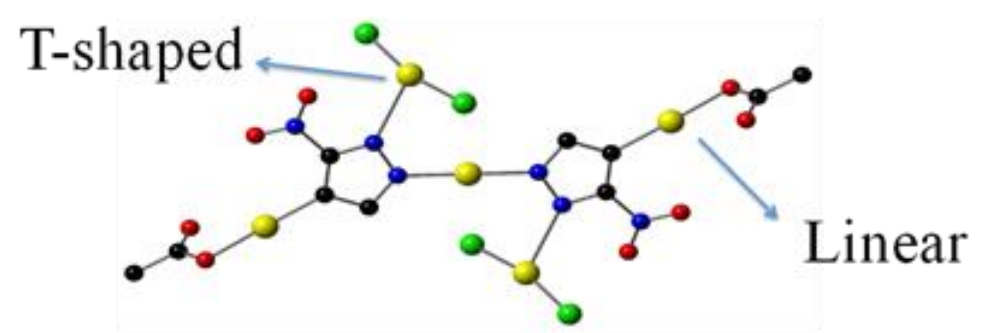

Figure 4.3. The molecular structure of 4.3; H-atoms are omitted for clarity. Color code: Yellow, $\mathrm{Hg}$; black, C; blue, N; red, O; green, $\mathrm{Cl}$.
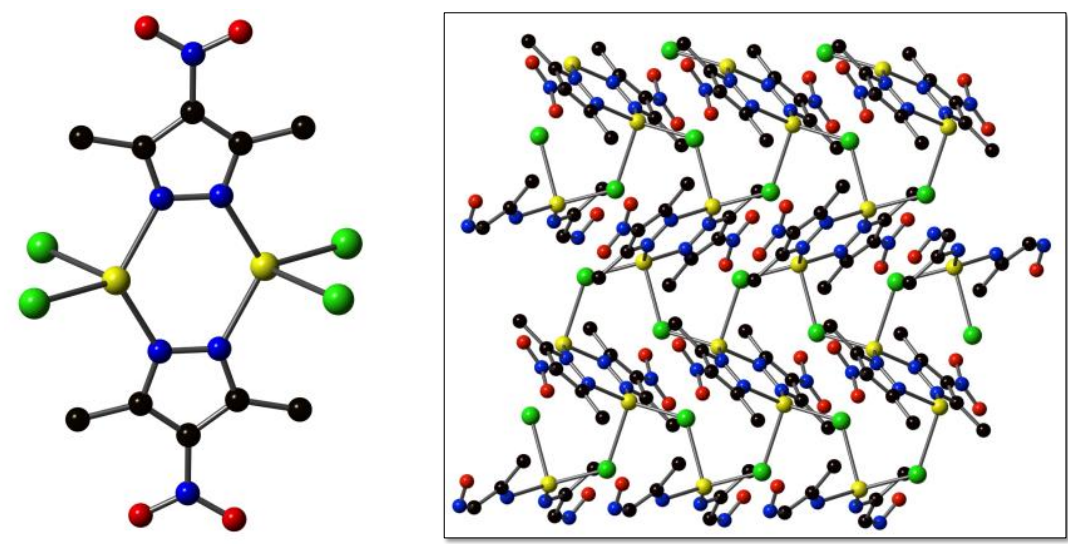

Figure 4.4. The molecular structure of $\mathbf{4 . 4}$ (right) and monomeric unit (left); H-atoms are omitted for clarity. Color code: Yellow, $\mathrm{Hg}$; black, C; blue, N; red, O; green, $\mathrm{Cl}$.

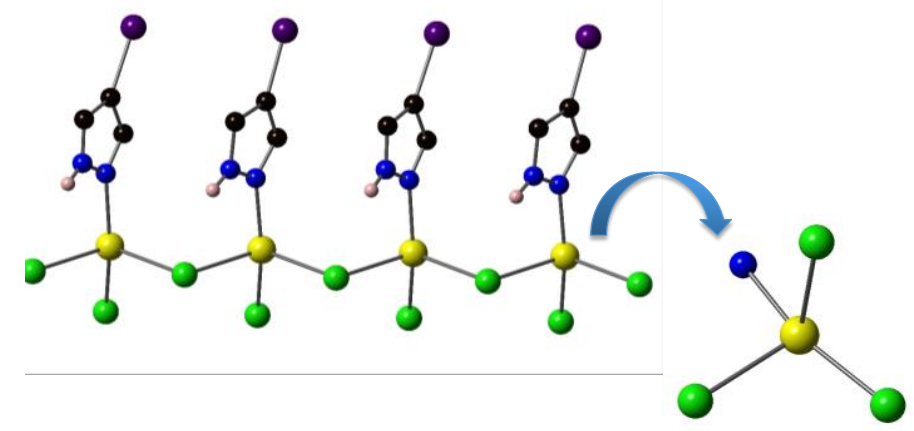

Figure 4.5. The molecular structure of $\mathbf{4 . 5}$ showing tetrahedral geometry around $\mathrm{Hg}$-center; $\mathrm{H}$ atoms [other than pz $(\mathrm{N}-\mathrm{H})$ ] are omitted for clarity. Color code: Yellow, Hg; black, C; blue, N; red, O; green, $\mathrm{Cl}$; violet, I. 


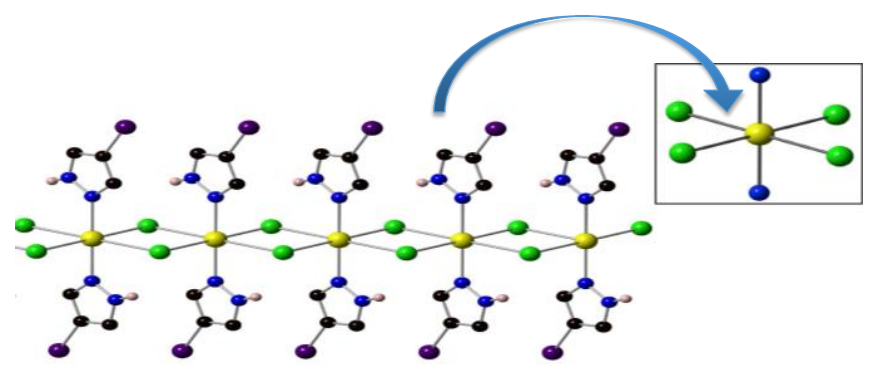

Figure 4.6. The molecular structure of $\mathbf{4 . 6}$ showing octahedral geometry around $\mathrm{Hg}$-center; $\mathrm{H}$ atoms [other than pz $(\mathrm{N}-\mathrm{H})$ ] are omitted for clarity. Color code: Yellow, Hg; black, C; blue, N; red, O; green, $\mathrm{Cl}$; violet, I.

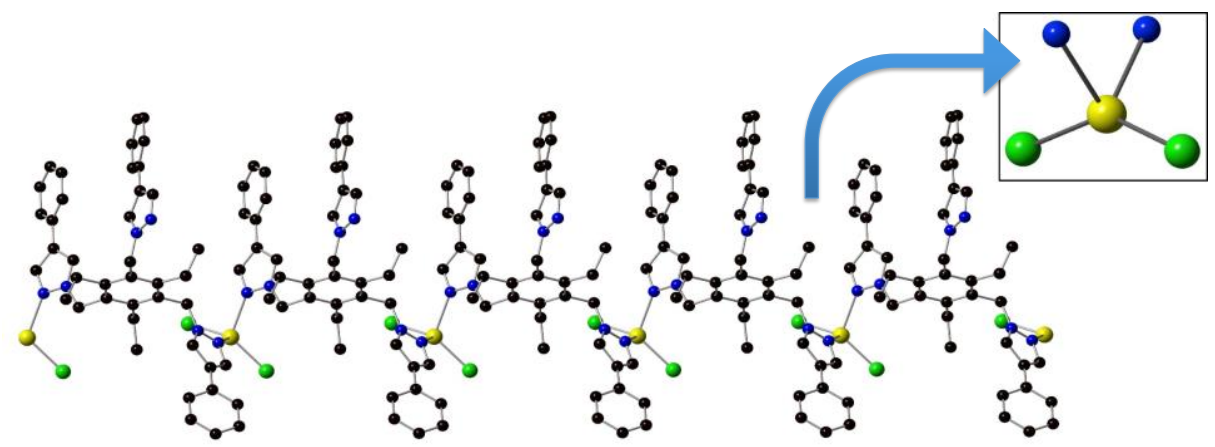

Figure 4.7. The molecular structure of $\mathbf{4 . 7}$ showing tetrahedral geometry around Hg-center.; Hatoms are omitted for clarity. Color code: Yellow, $\mathrm{Hg}$; black, C; blue, N; red, O; green, $\mathrm{Cl}$.



Figure 4.8. ${ }^{1} \mathrm{H}$ NMR of dinuclear unit of 4.4. in MeOD. 


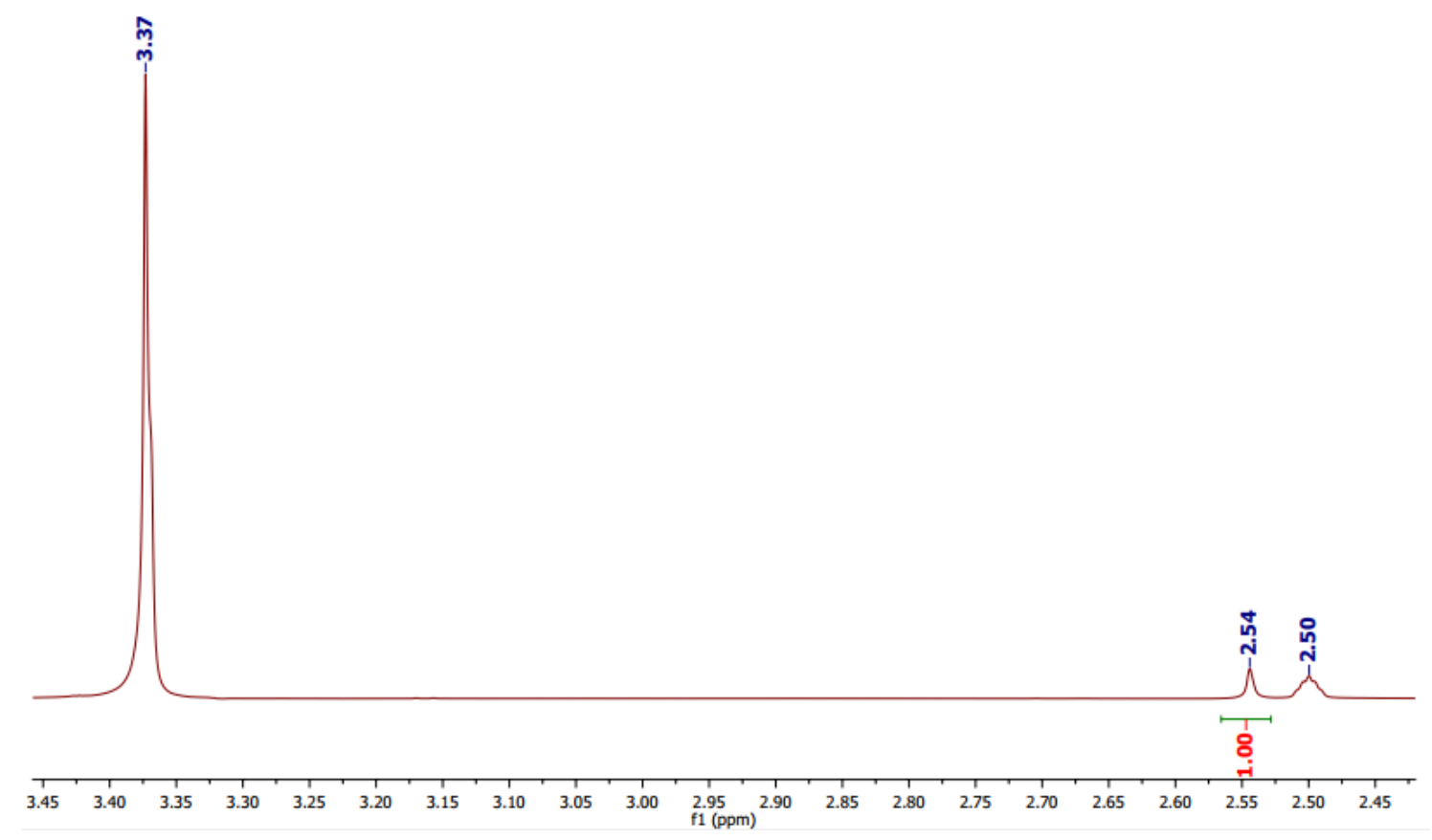

Figure 4.9. ${ }^{1} \mathrm{H}$ NMR of 4.4. in DMSO- $\mathrm{d}_{6}$.

\subsubsection{Extraction study}

As described before (in 4.3.2), two ligands; 3,5-( $\left(\mathrm{CH}_{3}\right)_{2}-4-\mathrm{NO}_{2} \mathrm{pzH}$ and $\mathrm{T}(4 \mathrm{Ph}) \mathrm{pz}$ successfully extracted $\mathrm{HgCl}_{2}$ in organic media $\left(\mathrm{CHCl}_{3}\right)$ from the aqueous mixture of lanthanide salts. $\mathrm{N}$-donor ligands are considered promising ligands for binding mercury. ${ }^{22}$

\subsection{Conclusion}

Seven new $\mathrm{Hg}(\mathrm{II})$ complexes with unprecedented motifs and diverse nuclearities -- ranging from mononuclear to polynuclear -- and diverse geometry -- ranging from linear to octahedral -- were synthesized and characterized with SCXRD, NMR, IR, and elemental analyses. Two of the ligands were used to extracting $\mathrm{Hg}$ from an aqueous mixture of $\mathrm{Hg}^{2+}$ and $\mathrm{Ln}^{3+}$. 


\subsection{References}

1. Jain, V.; Shah, H.; Occhipinti, J. E.; Wilmarth, W. R.; Edwards, R. E. Evaluation of Mercury in Liquid Waste Processing Facilities; SRR-CES-2015-00012 Rev. 1. Savannah River Remediation, Aiken, SC 29808: 2015.

2. Halcrow, M. A., Pyrazoles and pyrazolides-flexible synthons in self-assembly. Dalton Transactions 2009, (12), 2059-2073.

3. Pérez, J.; Riera, L., Stable metal-organic complexes as anion hosts. Chemical Society Reviews 2008, 37 (12), 2658-2667.

4. Burini, A.; Mohamed, A. A.; Fackler, J. P., CYCLIC TRINUCLEAR GOLD (I) COMPOUNDS: SYNTHESIS, STRUCTURES AND SUPRAMOLECULAR ACID-BASE $\pi$-STACKS. Comments on Inorganic Chemistry 2003, 24 (5-6), 253-280.

5. Panak, P. J.; Geist, A., Complexation and extraction of trivalent actinides and lanthanides by triazinylpyridine N-donor ligands. Chemical reviews 2013, 113 (2), 1199-1236.

6. Kersch, C.; Van Roosmalen, M.; Woerlee, G.; Witkamp, G., Extraction of heavy metals from fly ash and sand with ligands and supercritical carbon dioxide. Industrial \& engineering chemistry research 2000, 39 (12), 4670-4672.

7. Streets, D. G.; Devane, M. K.; Lu, Z.; Bond, T. C.; Sunderland, E. M.; Jacob, D. J., All-time releases of mercury to the atmosphere from human activities. Environmental science \& technology 2011, 45 (24), 10485-10491.

8. (a) Pirrone, N.; Cinnirella, S.; Feng, X.; Finkelman, R. B.; Friedli, H. R.; Leaner, J.; Mason, R.; Mukherjee, A. B.; Stracher, G.; Streets, D. G., Global mercury emissions to the atmosphere from natural and anthropogenic sources. In Mercury fate and transport in the global atmosphere, Springer: 2009; pp 1-47; (b) Pirrone, N.; Cinnirella, S.; Feng, X.; Finkelman, R.; Friedli, H.; Leaner, J.; Mason, R.; Mukherjee, A.; Stracher, G.; Streets, D., Global mercury emissions to the atmosphere from anthropogenic and natural sources. Atmospheric Chemistry and Physics 2010, 10 (13), 5951-5964; (c) Streets, D. G.; Zhang, Q.; $\mathrm{Wu}, \mathrm{Y}$., Projections of global mercury emissions in 2050. Environmental science \& technology 2009, 43 (8), 2983-2988.

9. Zhao, Q.; Cao, T.; Li, F.; Li, X.; Jing, H.; Yi, T.; Huang, C., A Highly Selective and Multisignaling Optical- Electrochemical Sensor for $\mathrm{Hg} 2+$ Based on a Phosphorescent Iridium (III) Complex. Organometallics 2007, 26 (8), 2077-2081.

10. Organization, W. H., Exposure to Mercury: A Major Public Health Concern-Preventing Disease Through Healthy Environment. World Health Organization, Geneva 2007.

11. Andersen, O., Principles and recent developments in chelation treatment of metal intoxication. Chemical Reviews 1999, 99 (9), 2683-2710. 
12. Rooney, J. P., The role of thiols, dithiols, nutritional factors and interacting ligands in the toxicology of mercury. Toxicology 2007, 234 (3), 145-156.

13. Ngu-Schwemlein, M.; Merle, J. K.; Healy, P.; Schwemlein, S.; Rhodes, S., Thermodynamics of the complexation of $\mathrm{Hg}$ (II) by cysteinyl peptide ligands using isothermal titration calorimetry. Thermochimica Acta 2009, 496 (1), 129-135.

14. Bridges, C. C.; Zalups, R. K., Molecular and ionic mimicry and the transport of toxic metals. Toxicology and applied pharmacology 2005, 204 (3), 274-308.

15. Goldberg, L.; Rydberg, U., Inhibition of ethanol metabolism in vivo by administration of pyrazole. Biochemical pharmacology 1969, 18 (7), 1749-1762.

16. Huheey, J.; Keitler, E.; Keitler, R., Inorganic Chemistry, Principles of Structure and Bonding. Harper Collins College Publishers, New York: 1993.

17. Pearson, R., Hard and soft acids and bases. Chemistry in Britain 1967, 3 (3), 103-\&.

18. (a) Gale, P. A., Anion receptor chemistry: highlights from 2008 and 2009. Chemical Society Reviews 2010, 39 (10), 3746-3771; (b) Hartshorn, C. M.; Steel, P. J., Poly (pyrazol-1ylmethyl) benzenes: New multidentate ligands. Australian journal of chemistry 1995, 48 (9), 1587-1599.

19. Koch, N.; Mazik, M., Synthesis of Tripodal and Hexapodal Pyrazole-and BenzimidazoleBearing Compounds. Synthesis 2013, 45 (24), 3341-3348.

20. Mathivathanan, L., 3, 5-Bis (2, 4-dinitrophenyl)-4-nitro-1H-pyrazole acetone monosolvate. Acta Crystallographica Section E: Structure Reports Online 2012, 68 (2), o411-o411.

21. Ardizzoia, G. A.; Cenini, S.; La Monica, G.; Masciocchi, N.; Maspero, A.; Moret, M., Syntheses, structures, and reactivity of polynuclear pyrazolato copper (I) complexes, including an ab-initio XRPD study of [Cu (dmnpz)] 3 (Hdmnpz= 3, 5-Dimethyl-4nitropyrazole). Inorganic chemistry 1998, 37 (17), 4284-4292.

22. Mahmoudi, G.; Morsali, A.; Zeller, M., Mercury (II) acetate/thiocyanate coordination polymers with n-donor ligands, spectroscopic, thermal and structural studies. Inorganica Chimica Acta 2009, 362 (1), 217-225. 


\section{CHAPTER 5}

Synthesis and characterization of palladium pyrazolates and their use as a catalyst

\subsection{Abstract}

Nine new Pd-pyrazolyl complexes $\left[\mathrm{PdCl}_{2}\left(4-\left(\mathrm{CH}_{2}\right)_{3}-\mathrm{pzH}\right)_{2}\right]\left[\right.$ 5.1], $\left[\left(\mathrm{Et}_{3} \mathrm{NH}\right)_{2} \mathrm{Pd}_{2} \mathrm{Cl}_{4}\left(\mu-3-\mathrm{NO}_{2}-\mathrm{pz}\right)_{2}\right]$

[5.2], [( $\left.\left.\mathrm{Et}_{3} \mathrm{NH}\right)_{2} \mathrm{Pd}_{2} \mathrm{Cl}_{4}\left(\mu-3,5-\left(\mathrm{CH}_{3}\right)_{2}-4-\mathrm{NO}_{2}-\mathrm{pz}\right)_{2}\right]$ [5.3], [( $\left.\left.\mathrm{Et}_{3} \mathrm{NH}\right)_{2} \mathrm{Pd}_{2} \mathrm{Cl}_{4}\left(\mu-4-\mathrm{NO}_{2}-\mathrm{pz}\right)_{2}\right]$ [5.4],

$\left[\left(\mathrm{Et}_{3} \mathrm{NH}\right)_{2} \mathrm{Pd}_{2} \mathrm{Cl}_{4}\left(\mu-4-\left(\mathrm{CH}_{2}\right)_{2} \mathrm{OH}-\mathrm{pz}\right)_{2}\right] \quad$ [5.5], $\quad\left[\left(\mathrm{Et}_{3} \mathrm{NH}\right)_{2} \mathrm{Pd}_{3} \mathrm{Cl}_{4}\left(\mu-3,5-\left(\mathrm{CH}_{3}\right)_{2}-4-\mathrm{NO}_{2}-\mathrm{pz}\right)_{4}\right] \quad$ [5.6],

$\left[\left(\mathrm{Et}_{3} \mathrm{NH}\right)_{2} \mathrm{Pd}_{3} \mathrm{Cl}_{4}\left(\mu-4-\mathrm{NO}_{2}-\mathrm{pz}\right)_{4}\right] \quad\left[\right.$ 5.7], $\quad\left[\left(\mathrm{Et}_{3} \mathrm{NH}\right)_{2} \mathrm{Pd}_{3} \mathrm{Cl}_{4}(\mu-4-\mathrm{OH}-\mathrm{pz})_{4}\right] \quad[$ 5.8 $] \quad$ and

$\left[\left(\mathrm{Et}_{3} \mathrm{NH}\right)_{1.5} \mathrm{Pd}_{3} \mathrm{Cl}_{3}\left(\mu_{3}-\mathrm{OH}_{0.5}\right)\left(\mu-4-\mathrm{NO}_{2}-\mathrm{pz}\right)_{3}\right]_{2}[5.9]$ were synthesized and characterized by single

crystal X-ray crystallography, ${ }^{1} \mathrm{H}-\mathrm{NMR}$, IR and elemental analyses $(\mathrm{C}, \mathrm{H}, \mathrm{N}) \mathbf{. 5 . 1}, \mathbf{5 . 5}$, and $\mathbf{5 . 8}$ are water-soluble complexes. Compound 5.1 is mononuclear, compounds 5.2, 5.3, 5.4 and 5.5 are dinuclear, compounds 5.6, 5.7 and 5.8 are linear trinuclear and 5.9 is hexanuclear (dimer of cyclic trimers). The latter is an unprecedented motif in palladium coordination chemistry. $\mathbf{5 . 2}$ and $\mathbf{5 . 3}$ were studied as catalysts for Sonogashira coupling reactions and found promising, opening up catalytic prospects for Pd-pyrazolates. A range of seven arylated alkynes $(\mathbf{4 a}-\mathbf{4 h})$ were synthesized from terminal alkynes and corresponding aryl halides through Sonogashira crosscoupling reactions of $\mathrm{C}(\operatorname{aryl})-\mathrm{C}$ bond formation using the palladium pyrazolate dimer catalysts 5.2 or 5.3. Compounds $4 b$ and $4 \mathbf{e}$ are same, but prepared from different starting materials. All reactions were carried in open air, in the absence of $\mathrm{Cu}(\mathrm{I})$ co-catalyst, and under mild conditions. Reaction conditions were optimized for a reaction and the optimized conditions were used for the other reactions. The metathetical ligand reactivity of $\mathbf{5 . 9}$ was probed with silver cyanide and IR confirmed the substitution of terminal chlorides by cyanides.

\subsection{Introduction}

Despite several demerits associated with phosphines, such as toxicity, instability (ligands are added separately to produce Pd-catalyst in situ because of stability problem) and air and moisture 
sensitivity, ${ }^{1}$ phosphine based Pd-compounds are the most used catalysts for the C-C crosscoupling reactions. In addition, phosphines are toxic and also produce unwanted toxic side products. ${ }^{1}$ The aforementioned reasons make them difficult in handling. ${ }^{2}$ Due to lack of development of more convenient ligands, Pd catalysis system with the externally added ligands, mostly phosphines, is the most popular catalytic system for the reactions to date. ${ }^{3} \mathrm{NHC}$ ligands are being investigated as an alternative of phosphine ligands but, they are handicapped by the lack of coordinative flexibility. ${ }^{2 a}$

Many of the reported Sonogashira coupling reactions use $\mathrm{Cu}^{+}$as a co-catalyst, which has the serious disadvantage of forming homocoupled products of terminal alkynes (Glasser-Hay coupling). ${ }^{4}$ Separation of cleaner products is always a challenge for the $\mathrm{Cu}^{+}$-cocatalyzed reactions. ${ }^{4-5}$ Moreover, $\mathrm{Cu}^{+}$inhibits the activation of $\mathrm{Pd}$-catalysts and promotes oxidation of $\mathrm{Pd}(0)$ to $\mathrm{Pd}(\mathrm{I})$ promoting alkyne polymerization, which again reduces the yield of products and makes purification difficult. ${ }^{6}$ Besides the disadvantages associated with using $\mathrm{Cu}$ as a cocatalyst, it is the most prevalent way for Sonogashira reactions in industries and academia. ${ }^{5 \mathrm{a}, 7}$

The commonly used solvents in the Sonogashira reactions are $\mathrm{DMF}^{2 \mathrm{a}, 8}, \mathrm{NMP}^{8 \mathrm{~b}}$ and toluene. ${ }^{9}$ Separation of the products is difficult from the DMF, which requires additional work up. A greener and safer solvent is always desirable.

Although investigations are rapidly advancing in the field, choosing a right solvent, ligand, base, optimization of temperature and whether to use (or not to use) $\mathrm{Cu}$ as a cocatalyst have become a big challenge. ${ }^{7 \mathrm{~b}}$ Comparing to Suzuki and Heck coupling, limited studies have been carried out on Sonogashira coupling and optimization studies have become cutting edge research. ${ }^{\text {tb }}$

Use of bulky ligands is always desired to favor oxidative addition and reductive elimination steps. ${ }^{10}$ To our best knowledge, no palladium(II) pyrazolate dimer as a catalyst for Sonogashira coupling reactions has been reported yet. Although many natural multinuclear catalysts are 
known, synthetic catalysts are dominated by monomers, because of the limited understanding of underlying synergism and reactivity of multimetallic assemblies. ${ }^{11}$

A weaker $\sigma$-donor, stronger $\pi$-acceptor, and more labile $N$-donor pyrazole ligands are expected to have higher catalytic benefits and N-N donor ligands favor the oxidative addition over P-P donor ligands. ${ }^{12}$ The catalytic advantages of N-donor ligated Pd-compounds over non-ligated Pd-salts and phosphine based ligands have been investigated. ${ }^{13}$ They also proved the catalytic superiority of the dimers compared to monomers, and among the dimers, the one with shorter Pd---Pd distance was found superior over other dimers. Pd complexes with N-based ligands have proven to be versatile and efficient for catalyzing a broad range of cross-coupling reactions under aerobic conditions. $^{2 \mathrm{a}}$

Chemical nature of alkyl/aryl halide (R-X) is crucial for the Sonogashira catalysis. Electron withdrawing groups reduce the electron density of $\mathrm{C}-\mathrm{X}$ bond, weakening the bond and making a reaction easier. ${ }^{14}$ Although $\mathrm{PdCl}_{2}$ and $\mathrm{Pd}(\mathrm{OAc})_{2}$ have been tested for some of the Sonogashira coupling reactions, ${ }^{15}$ they suffer of several drawbacks, such as high amount of catalyst is required, ${ }^{14 \mathrm{~b}, 15}$ a longer reaction time is required. ${ }^{16}$

In this work, we synthesized nine new palladium pyrazolate compounds including three water soluble ones. Compounds $\mathbf{5 . 2}$ and $\mathbf{5 . 3}$ have been employed as a catalyst for a Sonogashira coupling reaction producing 1,2-diphenylacetylene and rest of the cross coupled compounds were synthesized using 5.3. Seven compounds (eight different reactions) were synthesized for the study and the synthesized compounds are shown in Scheme 5.1. They have excellent and catalytic activity with a slight superiority of $\mathbf{5 . 3}$ over $\mathbf{5 . 2}$ for the optimization reaction. Terminal $\mathrm{Cl}^{-}$the substitution of 5.9 with $\mathrm{CN}^{-}$was initially accessed by color change and further confirmed by FTIR spectroscopy. 

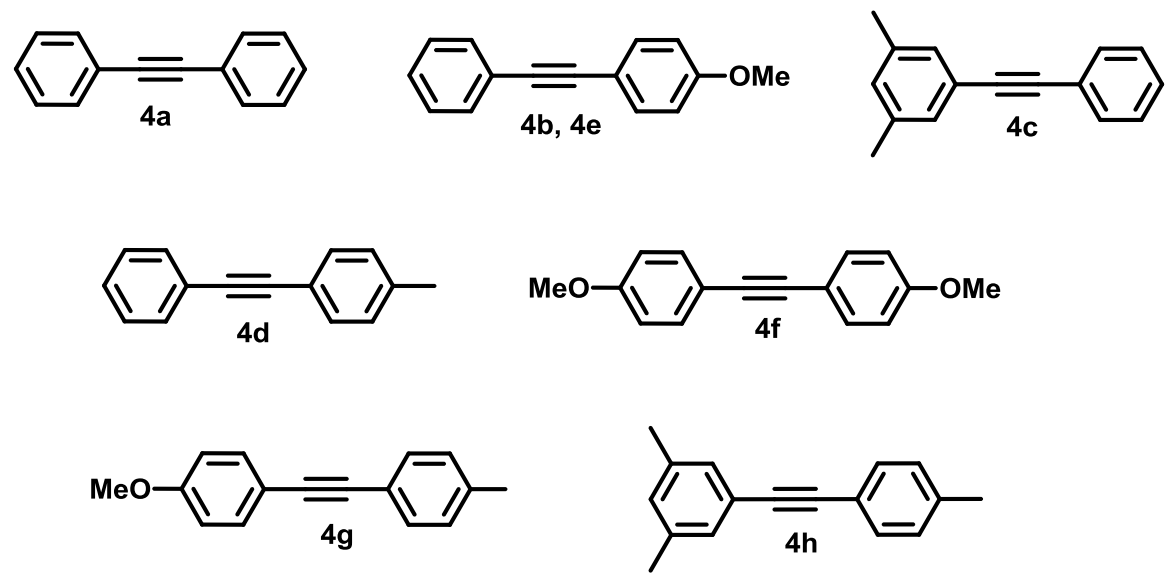

Scheme 5.1. Sonogashira cross-coupling compounds synthesized in this study.

\subsection{Experimental}

\subsubsection{Materials and Methods}

Reagent grade chemicals were purchased from Aldrich Chemical Co, Alfa Aesar, Fisher scientific or ACROS Organics and used as received. THF was distilled over $\mathrm{Na} /$ benzophenone, $\mathrm{CH}_{2} \mathrm{Cl}_{2}$ was distilled over $\mathrm{CaCl}_{2} / \mathrm{CaH}_{2}$ and $\mathrm{MeCN}$ was distilled over $\mathrm{CaH}_{2}$ before use. Literature procedure was followed for the synthesis of 4-nitro-pyrazole. ${ }^{17}{ }^{1} \mathrm{H}-\mathrm{NMR}$ and ${ }^{13} \mathrm{C}-\mathrm{NMR}$ spectra were recorded on a $400 \mathrm{MHz}$ or $500 \mathrm{MHz}$ Bruker Avance spectrometer and were referenced using the residual solvent proton resonance. FT-IR spectra were recorded with a Perkin Elmer Spectrum 100 FT-IR Spectrometer. The crystal structure was determined with a Bruker single crystal X-ray diffractometer. Elemental analysis (CHN) was performed using an Elemental VarionEL CHN elemental analyzer in Galbraith Lab. Sonogashira coupling reactions were monitored with analytical thin layer chromatography (EMD Millipore ${ }^{\mathrm{TM}}$ Silica Gel $60 \mathrm{~F}_{254}$ Coated AluminumBacked TLC Sheets), visualized with a UV lamp. Purification of the Sonogashira products was performed by column chromatography using Silica gel 60, 230-400 mesh. 


\subsubsection{Synthesis of $\left.\left[\operatorname{PdCl}_{2}\left\{4-\left(\mathrm{CH}_{2}\right)_{3}-\mathrm{pzH}\right)_{2}\right\}\right][5.1]$}

$0.1 \mathrm{mmol}(25.9 \mathrm{mg}) \mathrm{PdCl}_{2}\left(\mathrm{CH}_{3} \mathrm{CN}\right)_{2}$ and $0.2 \mathrm{mmol}(25.2 \mathrm{mg})$ 4- $\mathrm{OH}\left(\mathrm{CH}_{2}\right)_{3}-\mathrm{pzH}$ in 1:2 ratio was stirred in $5 \mathrm{~mL}$ acetonitrile for 3 days. The reaction mixture was clear. X-ray quality single crystals were obtained from slow evaporation of the reaction solution. (90\% yield). The compound was characterized by SCXRD.

\subsubsection{Synthesis of $\left(\mathrm{Et}_{3} \mathrm{NH}\right)_{2}\left[\mathrm{Pd}_{2} \mathrm{Cl}_{4}\left(\mu-3-\mathrm{NO}_{2}-\mathrm{pz}\right)_{2}\right][5.2]$}

$0.1 \mathrm{mmol}(25.9 \mathrm{mg}) \mathrm{PdCl}_{2}\left(\mathrm{CH}_{3} \mathrm{CN}\right)_{2}$ and $0.1 \mathrm{mmol}(11.3 \mathrm{mg}) 3-\mathrm{NO}_{2}-\mathrm{pzH}$ were dissolved in $5 \mathrm{~mL}$ tetrahydrofuran and stirred for $20 \mathrm{~min}$ in room temperature. To the clear reaction solution, an equimolar amount of trimethylamine $(0.1 \mathrm{mmol}, 13.9 \mathrm{~mL})$ was added and stopped stirring immediately while color change was observed. Golden (yellow) colored X-ray quality crystals of 5.2 were obtained by the diffusion of diethyl ether into the reaction solution. Yield: $75 \mathrm{mg}$ (96 \%). Anal. Calcd for $\mathrm{C}_{18} \mathrm{H}_{36} \mathrm{~N}_{8} \mathrm{Cl}_{4} \mathrm{O}_{4} \mathrm{Pd}_{2}\left(783.18 \mathrm{~g} \mathrm{~mol}^{-1}\right)$ : $\mathrm{C}, 27.61 ; \mathrm{H}, 4.63 ; \mathrm{N}, 14.31$. Found: $\mathrm{C}$, 28.01; H, 4.73; N, 14.61. IR (vmax, cm-1): 3282 (s), 3143 (w), 2977 (w), 1601 (w), 2493 (w), 1531 (s) 1484 (s), 1392 (s), 1353 (s), 1216 (w), 1128 (m), 1058 (m), 1031 (w), 970 (m), 821 (s), $781(\mathrm{~m}), 744(\mathrm{~s}), 671(\mathrm{w}) .{ }^{1} \mathrm{H}$ NMR (CD3OD, 298K, $\delta$ in ppm, 400MHz): 1.33(t) $(18 \mathrm{H},-$ $\left.\mathrm{CH}_{3} / \mathrm{Et}_{3} \mathrm{NH}\right), 3.25(\mathrm{q})\left(12 \mathrm{H},-\mathrm{CH}_{2} / \mathrm{Et}_{3} \mathrm{NH}\right), 6.71-7.66(4 \mathrm{H},-\mathrm{CHpz})[6.71(\mathrm{~d})(1.33 \mathrm{H}), 6.85(\mathrm{~d})$ $(0.66 \mathrm{H}), 7.60(\mathrm{~d})(1.33 \mathrm{H}), 7.66(\mathrm{~d})(0.66 \mathrm{H})]$.

\subsubsection{Synthesis of $\left(\mathrm{Et}_{3} \mathrm{NH}\right)_{2}\left[\mathrm{Pd}_{2} \mathrm{Cl}_{4}\left(\mu-3,5-\left(\mathrm{CH}_{3}\right)_{2}-4-\mathrm{NO}_{2}-\mathrm{pz}\right)_{2}\right][5.3]$}

$0.1 \mathrm{mmol}(25.9 \mathrm{mg}) \mathrm{PdCl}_{2}\left(\mathrm{CH}_{3} \mathrm{CN}\right)_{2}$ and $0.1 \mathrm{mmol}(14.1 \mathrm{mg}) 3,5 \mathrm{Me}_{2} 4-\mathrm{NO}_{2}-\mathrm{pzH}$ were dissolved in $6 \mathrm{ml} \mathrm{CH}_{2} \mathrm{Cl}_{2}$ and stirred for $20 \mathrm{~min}$ in room temperature. To the clear reaction solution, an equimolar amount of trimethylamine $(0.1 \mathrm{mmol}, 13.9 \mathrm{~mL})$ was added and continued stirring for 20 minutes while color change as well of a lot of precipitate observed. Resulting reaction mixture was stirred to $12 \mathrm{~h}$ until all the precipitate disappeared. Golden (yellow) colored X-ray quality crystals of $\mathbf{5 . 3}$ were obtained by the diffusion of diethyl ether into the reaction solution. Yield: 79 
mg $(95 \%)$. The compound was characterized by SCXRD, ${ }^{1} \mathrm{H}-\mathrm{NMR}$ and elemental analysis. Anal. Calcd. for $\mathrm{C}_{22} \mathrm{H}_{44} \mathrm{~N}_{8} \mathrm{Cl}_{4} \mathrm{O}_{4} \mathrm{Pd}_{2}\left(839.29 \mathrm{~g} \mathrm{~mol}^{-1}\right)$ : C, 31.48; H, 5.28; N, 13.35. Found: C, 31.18; H, 5.19; N, 13.50. IR (vmax, cm-1): 3029 (w), 2977 (w), 2599 (w), 2495 (w), 1606 (w), 1546 (s), 1471 (s), 1409 (s), 1351 (s), 1180 (s), 1035 (w), 995 (w), 835 (s), 763 (m), 694 (w). ${ }^{1} \mathrm{H}-\mathrm{NMR}$ (CD3OD, 298K, $\delta$ in ppm, 400MHz): 1.45(t) $\left(18 \mathrm{H},-\mathrm{CH}_{3} / \mathrm{Et}_{3} \mathrm{NH}\right), 3.58(\mathrm{q})\left(12 \mathrm{H},-\mathrm{CH}_{2} / \mathrm{Et}_{3} \mathrm{NH}\right)$, $2.76(\mathrm{~s})\left(12 \mathrm{H},-\mathrm{CH}_{3} \mathrm{pz}\right)$

\subsubsection{Synthesis of $\left(\mathrm{Et}_{3} \mathrm{NH}\right)_{2}\left[\mathrm{Pd}_{2} \mathrm{Cl}_{4}\left(\mu-4-\mathrm{NO}_{2}-\mathrm{pz}\right)_{2}\right][5.4]$}

$\left(\mathrm{NH}_{4}\right)_{2} \mathrm{PdCl}_{4} 0.1 \mathrm{mmol}(28.4 \mathrm{mg})$ and $0.1 \mathrm{mmol}(11.3 \mathrm{mg}) 4-\mathrm{NO}_{2}-\mathrm{pzH}$ was dissolved in $6 \mathrm{~mL}$ methanol and stirred for $20 \mathrm{~min}$. To the clear reaction solution equimolar amount of trimethylamine $(0.1 \mathrm{mmol})$ was added and continued stirring for $20 \mathrm{~min}$. Gold (yellow) colored crystals of X-ray quality were grown by diffusion of diethyl ether into the reaction solution (80\% yield). The compound was characterized by SCXRD, ${ }^{1} \mathrm{HNMR}$ and elemental analysis. $\mathrm{C}_{18} \mathrm{H}_{36} \mathrm{~N}_{8} \mathrm{Cl}_{4} \mathrm{O}_{4} \mathrm{Pd}_{2}\left(783.18 \mathrm{~g} \mathrm{~mol}^{-1}\right)$ : C. 27.61; H, 4.63; N, 4.63. Found: C, 27.91; H,4.70; N, 14.55. IR ( $\left.\mathrm{U}_{\max } \mathrm{cm}^{-1}\right): 3110(\mathrm{w}), 3050(\mathrm{w}), 1498$ (m), 1400 (s), 1282 (s), $1184(\mathrm{w}), 1041$ (w), 1004 (w), $871(\mathrm{w}), 852(\mathrm{w}), 817(\mathrm{~m}), 750(\mathrm{~m}) .{ }^{1} \mathrm{H}-\mathrm{NMR}\left(\mathrm{CD}_{3} \mathrm{ODCD}_{3}{ }^{\prime} 298 \mathrm{~K}, \delta\right.$ in ppm, 400MHz): 1.48 (t) $\left(18 \mathrm{H},-\mathrm{CH}_{3} / \mathrm{Et}_{3} \mathrm{NH}\right) ; 3.56$ (q) $\left(12 \mathrm{H},-\mathrm{CH}_{2} / \mathrm{Et}_{3} \mathrm{NH}\right) ; 8.11$ (s) (4H, -CHpz).

\subsubsection{Synthesis of $\left(\mathrm{Et}_{3} \mathrm{NH}\right)_{2}\left[\mathrm{Pd}_{2} \mathrm{Cl}_{4}\left(\mu-4-\left(\mathrm{CH}_{2}\right)_{2} \mathrm{OH}-\mathrm{pz}\right)_{2}\right][5.5]$}

$0.1 \mathrm{mmol}(25.9 \mathrm{mg}) \mathrm{PdCl}_{2}\left(\mathrm{CH}_{3} \mathrm{CN}\right)_{2}$ in $3 \mathrm{~mL} \mathrm{CH}_{2} \mathrm{Cl}_{2}$ and $0.1 \mathrm{mmol}(11.2 \mathrm{mg}) 4-\mathrm{OHCH}_{2} \mathrm{CH}_{2}-\mathrm{pzH}$ in $4 \mathrm{~mL} \mathrm{MeOH}$ was mixed together and stirred for $5 \mathrm{~min} .2 \mathrm{~mL} \mathrm{MeOH}$ was added to the reaction solution. To the clear reaction solution equimolar amount of trimethylamine $(0.1 \mathrm{mmol})$ was added and continued stirring for $20 \mathrm{~min}$. Gold (yellow) colored crystals of X-ray quality were grown by the slow evaporation of the solution (20\% yield). The compound was characterized by SCXRD. 


\subsubsection{Synthesis of $\left(\mathrm{Et}_{3} \mathrm{NH}\right)_{2}\left[\mathrm{Pd}_{3} \mathrm{Cl}_{4}\left(\mu-3,5-\left(\mathrm{CH}_{3}\right)_{2}-4-\mathrm{NO}_{2}-\mathrm{pz}\right)_{4}\right][5.6]$}

$0.1 \mathrm{mmol}(25.9 \mathrm{mg})\left(\mathrm{CH}_{3} \mathrm{CN}\right)_{2} \mathrm{PdCl}_{2}$ and $0.1 \mathrm{mmol}(14.1 \mathrm{mg}) 3,5-\mathrm{Me}_{2}-4-\mathrm{NO}_{2}-\mathrm{pzH}$ were dissolved in $6 \mathrm{~mL} \mathrm{CH}_{2} \mathrm{Cl}_{2}$ and stirred for $15 \mathrm{~min}$. To the clear solution equimolar amount of trimethylamine was added and stirred for $20 \mathrm{~min}$. X-ray quality single crystal were obtained by slow evaporation of the reaction solution. Using the $\left(\mathrm{NH}_{4}\right)_{2} \mathrm{PdCl}_{4}$ salt also gave the same compound (82\% yield). The compound was characterized by SCXRD, ${ }^{1} \mathrm{HNMR}$ and IR. IR( $\left.\mathrm{v}_{\max }, \mathrm{cm}^{-1}\right): 2994(\mathrm{~m}$, broad), $1544(\mathrm{~m}), 1465$ (m), 1407 (m), 1351 (s), 1180 (m), $1118(\mathrm{w}), 1024(\mathrm{w}), 995(\mathrm{w}), 835$ (m), 765 (w). ${ }^{1} \mathrm{H}-\mathrm{NMR}\left(\mathrm{CD}_{3} \mathrm{ODCD}_{3}, 298 \mathrm{~K}, \delta\right.$ in ppm, 400MHz): 1.43 (t) $\left(18 \mathrm{H},-\mathrm{CH}_{3} / \mathrm{Et}_{3} \mathrm{NH}\right) ; 3.40$ (q) $\left(12 \mathrm{H},-\mathrm{CH}_{2} / \mathrm{Et}_{3} \mathrm{NH}\right) ; 2.71(\mathrm{~s})\left(12 \mathrm{H},-\mathrm{CH}_{3} \mathrm{pz}\right), 2.88(\mathrm{~s})\left(12 \mathrm{H},-\mathrm{CH}_{3} \mathrm{pz}\right)$.

\subsubsection{Synthesis of $\left(\mathrm{Et}_{3} \mathrm{NH}\right)_{2}\left[\mathrm{Pd}_{3} \mathrm{Cl}_{4}\left(\mu-4-\mathrm{NO}_{2}-\mathrm{pz}\right)_{4}\right][5.7]$}

$0.1 \mathrm{mmol}(28.4 \mathrm{mg})\left(\mathrm{NH}_{4}\right)_{2} \mathrm{PdCl}_{4}$ and $0.1 \mathrm{mmol}(11.3 \mathrm{mg}) 4-\mathrm{NO}_{2}-\mathrm{pzH}$ were dissolved in $6 \mathrm{~mL}$ $\mathrm{MeOH}$ and stirred for $15 \mathrm{~min}$. To the clear solution, an equimolar amount of triethylamine was added and stirred for $20 \mathrm{~min}$. The reaction solution was allowed for the air concentration. Two different colored crystals were obtained from the reaction solution and they were manually separated under the microscope. One with lighter yellow colored crystal was the compound 5.9 and the other with the intense yellow colored crystal turned out to be compound 5.7. (20\% yield). The compound was characterized by SCXRD, IR, ${ }^{1} \mathrm{H}-\mathrm{NMR}$ and elemental analysis. Anal. Calcd for [5.7]: C, 25.88; H, 3.62; N, 17.61. Found: C, 25.66; H, 3.54; N, 17.32. IR( $\left(v_{\max }, \mathrm{cm}^{-1}\right): 3143$ (w), 2983 (w), 2622 (w), 2495 (w), 1531 (m), $1484(\mathrm{~m}), 1392$ (m), 1351 (s), 1207 (w), 1128 (m), 1058 w), 1031 (w), 970 (w), 823 (s), 781 (m), 744 (s), 669 (w). ${ }^{1} \mathrm{H}-\mathrm{NMR}\left(\mathrm{CD}_{3} \mathrm{OD}, 298 \mathrm{~K}, \delta\right.$ in ppm, $400 \mathrm{MHz}): 1.31$ (t) $\left(18 \mathrm{H},-\mathrm{CH}_{3} / \mathrm{Et}_{3} \mathrm{NH}\right) ; 3.21$ (q) $\left(12 \mathrm{H},-\mathrm{CH}_{2} / \mathrm{Et}_{3} \mathrm{NH}\right) ; 8.02$ (s) $(4 \mathrm{H}$, CHpz), 8.26 (s) (4H, -CHpz). 


\subsubsection{Synthesis of $\left(\mathrm{Et}_{3} \mathrm{NH}\right)_{2}\left[\mathrm{Pd}_{3} \mathrm{Cl}_{4}(\mu-4-\mathrm{OH}-\mathrm{pz})_{4}\right][5.8]$}

$0.1 \mathrm{mmol}(28.4 \mathrm{mg})(\mathrm{NH} 4) 2 \mathrm{PdCl} 4$ and $0.2 \mathrm{mmol}(16.8 \mathrm{mg})$ 4-OH-pzH was dissolved in $5 \mathrm{~mL}$ $\mathrm{MeOH}$ and stirred for $10 \mathrm{~min}$. To the clear solution, $0.2 \mathrm{mmol} \mathrm{Et}_{3} \mathrm{~N}$ was added and stirred for 20 minutes. X-ray quality single crystals were obtained by the slow evaporation of the reaction solution. Yield: undetermined. The compound was characterized by SCXRD.

\subsubsection{Synthesis of $\left(\mathrm{Et}_{3} \mathrm{NH}\right)_{1.5}\left[\mathrm{Pd}_{3} \mathrm{Cl}_{3}\left(\mu_{3}-\mathrm{OH}_{0.5}\right)\left(\mu-4-\mathrm{NO}_{2}-\mathrm{pz}\right)_{3}\right]_{2}[5.9]$}

$0.1 \mathrm{mmol}(28.4 \mathrm{mg})\left(\mathrm{NH}_{4}\right)_{2} \mathrm{PdCl}_{4}$ and $0.1 \mathrm{mmol}(11.3 \mathrm{mg})$ 4- $\mathrm{NO}_{2}-\mathrm{pzH}$ was dissolved in $6 \mathrm{~mL}$ $\mathrm{MeOH}$ and stirred for $15 \mathrm{~min}$. To the clear solution, an equimolar amount of triethylamine was added and stirred for $20 \mathrm{~min}$. The reaction solution was allowed for the air concentration. After 4 days, golden yellow crystals were obtained before the precipitation of $\mathrm{Et}_{3} \mathrm{NHCl}$ in about $80 \%$ yield. Instead of $\left(\mathrm{NH}_{4}\right)_{2} \mathrm{PdCl}_{4}, \mathrm{PdCl}_{2}\left(\mathrm{CH}_{3} \mathrm{CN}\right)_{2}$ on the equimolar amount of ligand and base in $\mathrm{CH}_{2} \mathrm{Cl}_{2} / \mathrm{MeOH}$ also gave the same compound, but due to the solubility issue more precipitate and less crystal were obtained and yield was about $40 \%$. The compound was characterized by SCXRD, IR, ${ }^{1} \mathrm{H}-\mathrm{NMR}$ and elemental analysis. ${ }^{1} \mathrm{H}-\mathrm{NMR}$ (ppm, $\left.\mathrm{CD}_{3} \mathrm{COCD}_{3}\right): 1.41\left(27 \mathrm{H}, \mathrm{t}, \mathrm{CH}_{3}\right)$; $3.41\left(18 \mathrm{H}, \mathrm{q}, \mathrm{CH}_{2}\right) ; 8.18\left(12 \mathrm{H}, \mathrm{s}, \mathrm{CH}_{\mathrm{pz}}\right)$. IR ( $\left.\mathrm{U}_{\max } \mathrm{cm}^{-1}\right): 3097(\mathrm{~s}), 2977$ (w), $1500(\mathrm{~s}), 1407$ (s), 1286 (s), 1170 (m) 1029 (m), 997 (m), 869 (w), 840 (w), 815 (s), 752 (s). Elemental analysis; found $(\%) \mathrm{C}=22.89, \mathrm{H}=3.66, \mathrm{~N}=16.05$; calculated $(\%) \mathrm{C}=22.55, \mathrm{H}=3.52, \mathrm{~N}=15.34$.

\subsubsection{General procedure for the Sonogashira reactions}

To the distilled/degassed $\mathrm{MeCN}(4 \mathrm{~mL})$ were added $1.00 \mathrm{mmol}$ of aryl iodide, $1.00 \mathrm{mmol}$ of terminal alkynes, $1.20 \mathrm{mmol}$ of $\mathrm{Et}_{3} \mathrm{~N}$ and $0.009 \mathrm{mmol}$ of catalyst $(\mathbf{5 . 2}$ or $\mathbf{5 . 3})$. The reactions were stirred at room temperature in open air about 4-6 h. The cprogress of reactions was monitored by TLC until completion. The products obtained were concentrated in a rotary evaporator and purified by column chromatography. 


\subsubsection{Synthesis of diphenylacetylene (1, 1'(1,2-ethynediyl)bis-benzene) (4a)}

Purification by column chromatography (100\% hexane). ${ }^{1} \mathrm{H}-\mathrm{NMR}(400 \mathrm{MHz}, 298 \mathrm{~K}, \delta$ in ppm, $\left.\mathrm{CDCl}_{3}\right)$ 7.55-7.53 $(4 \mathrm{H}, \mathrm{m}), 7.38-7.33(6 \mathrm{H}, \mathrm{m}) ;{ }^{13} \mathrm{C} \mathrm{NMR}\left(400 \mathrm{MHz}, 298 \mathrm{~K}, \delta\right.$ in ppm, $\left.\mathrm{CDCl}_{3}\right)$ 131.61, 128.33, 128.24, 123.31, 89.37. Yield: $170 \mathrm{mg}(0.97 \mathrm{mmol}, 97 \%)$.

\subsubsection{Synthesis of (1-methoxy-4-(2-phenylacetynyl) benzene) $(4 \mathrm{~b}, 4 \mathrm{e})$}

Purification by column chromatography (100\% hexane). ${ }^{1} \mathrm{H}-\mathrm{NMR}(400 \mathrm{MHz}, 298 \mathrm{~K}, \delta$ in ppm, $\left.\mathrm{CDCl}_{3}\right)$ 7.53-7.47 (4H, m), 7.34-7.32 (3H, m), 6.89-6.87 (2H, m), $3.83(3 \mathrm{H}, \mathrm{s}) ;{ }^{13} \mathrm{C}$ NMR $\left(400 \mathrm{MHz}, 298 \mathrm{~K}, \delta\right.$ in ppm, $\left.\mathrm{CDCl}_{3}\right) 159.64,133.05,131.45,128.29,127.91,123.63,115.43$, 114.01, 89.37, 88.07, 55.64. Yield (1a): 197 mg (0.95 mmol, 95\%), (1d): 190 mg (0.9 mmol, 90 $\%)$.

\subsubsection{Synthesis of (1,3-dimethyl-5-(2-phenylethynylbenzene)) (4c)}

Purification by column chromatography (100\% hexane). ${ }^{1} \mathrm{H}-\mathrm{NMR}(400 \mathrm{MHz}, 298 \mathrm{~K}, \delta$ in ppm, $\left.\mathrm{CDCl}_{3}\right) 7.52(2 \mathrm{H}, \mathrm{m}), 7.36-7.34(3 \mathrm{H}, \mathrm{m}), 7.18(2 \mathrm{H}, \mathrm{s}), 2.32(6 \mathrm{H}, \mathrm{s}) ;{ }^{13} \mathrm{C}-\mathrm{NMR}(400 \mathrm{MHz}, 298 \mathrm{~K}$, $\delta$ in ppm, $\left.\mathrm{CDCl}_{3}\right) 137.88,131.58,130.19,129.30,128.30,128.07,123.50,122.89,89.73,88.69$, 21.10. Yield: $204 \mathrm{mg}(>99 \%,>0.99 \mathrm{mmol})$.

\subsubsection{Synthesis of 1-methyl-4-(2-phenylethynyl)-benzene (4d)}

Purification by column chromatography (100\% hexane). Yield: $197 \mathrm{mg}(97 \%, 0.97 \mathrm{mmol}) .{ }^{1} \mathrm{H}$ $\operatorname{NMR}\left(400 \mathrm{MHz}, 298 \mathrm{~K}, \delta\right.$ in ppm, $\left.\mathrm{CDCl}_{3}\right) 7.53(2 \mathrm{H}, \mathrm{m}), 7.43(2 \mathrm{H}, \mathrm{d}), 7.36-7.32(3 \mathrm{H}, \mathrm{m}), 7.16$ $(2 \mathrm{H}, \mathrm{d}), 2.37(3 \mathrm{H}, \mathrm{s})$.

\subsubsection{Synthesis of $(1,1$ '(1,2-ethynediyl)bis(4-methoxybenzene) (4f)}

Purification by column chromatography (hexane + ethyl acetate (98:2)). ${ }^{1} \mathrm{H}$ NMR (400 MHz, 298 $\mathrm{K}, \delta$ in ppm, $\left.\mathrm{CDCl}_{3}\right) 7.44(4 \mathrm{H}, \mathrm{d}), 6.88(4 \mathrm{H}, \mathrm{d}) ;{ }^{13} \mathrm{C} \mathrm{NMR}\left(400 \mathrm{MHz}, 298 \mathrm{~K}, \delta\right.$ in ppm, $\left.\mathrm{CDCl}_{3}\right)$ 159.41, 132.87, 115.76, 113.97, 87.94, 55.18. Yield: 220mg (92\%, $0.92 \mathrm{mmol})$. 


\subsubsection{Synthesis of 1-methoxy-4-[2-(4methylphenyl)ethynyl]-benzene (4g)}

Purification by column chromatography (100\% hexane). Yield: $212 \mathrm{mg}(95 \%, 0.95 \mathrm{mmol}) .{ }^{1} \mathrm{H}-$ NMR (400 MHz, $298 \mathrm{~K}, \delta$ in ppm, $\left.\mathrm{CDCl}_{3}\right) 7.46(2 \mathrm{H}, \mathrm{d}), 7.40(2 \mathrm{H}, \mathrm{d}), 7.14(2 \mathrm{H}, \mathrm{d}), 6.87(2 \mathrm{H}, \mathrm{d})$, $3.83(3 \mathrm{H}, \mathrm{s}), 2.36(3 \mathrm{H}, \mathrm{s})$.

\subsubsection{Synthesis of 1,3-dimethyl-5-[2-(4-methylphenyl)ethynyl]- Benzene (4h)}

Purification by column chromatography (100\% hexane). Yield: $210 \mathrm{mg}(95 \%, 0.95 \mathrm{mmol}) .{ }^{1} \mathrm{H}-$ NMR (400 MHz, $298 \mathrm{~K}, \delta$ in ppm, $\left.\mathrm{CDCl}_{3}\right) 7.41(2 \mathrm{H}, \mathrm{d}), 7.16-7.14(4 \mathrm{H}, \mathrm{m}), 6.96(1 \mathrm{H}, \mathrm{s}), 2.36$ $(3 \mathrm{H}, \mathrm{s}), 2.31(6 \mathrm{H}, \mathrm{s})$.

\subsection{Results and discussions}

\subsubsection{X-ray data and structure refinement}

Block-shaped crystals of the complexes (5.1-5.9) were obtained by recrystallization through slow evaporation of the reaction solution and/or diffusion of hexanes into their dichloromethane $\left(\mathrm{CH}_{2} \mathrm{Cl}_{2}\right)$ solutions. Crystal for each complex was selected and mounted on a Bruker D8 Quest diffractometer equipped with PHOTON 100 detector operating at T = $298 \mathrm{~K}$. Data were collected with $\omega$ shutter-less scan technique using graphite monochromated Mo-K $\alpha$ radiation $(\lambda=0.71073$ $\AA$ ). Resolution of $\theta>25^{\circ}$ was achieved in all cases. Cell parameters were retrieved using the SAINT (Bruker) software and refined using SAINT (Bruker). Data reduction was performed using the SAINT (Bruker) software, which corrects for Lorentz and polarization effects. Multi-scan absorption corrections were performed on all data sets using SADABS 2016/2. The structures for complexes 5.1 and 5.2 were solved by intrinsic phasing using the ShelXT (Sheldrick, 2015) structure solution program and refined by full-matrix least square procedure on $\mathrm{F}^{2}$ using version 2016/6 of ShelXL. The non-hydrogen atoms were refined anisotropically in all cases. Hydrogen atom positions were calculated geometrically and refined using the riding model. All calculations and molecular graphics were performed using either SHELXTL 2014 or Olex2 programs. 
The relatively large thermal ellipsoids (associated with large thermal motion) of certain $\mathrm{C}$ atoms of the counter cations are restrained with Enhanced Rigid Bond Restrain. ${ }^{18}$ The application of this restrain enabled to achieve similar displacement parameters $\left(\mathrm{U}_{\mathrm{ij}}\right)$ to emulate rigid body motion. In few cases, two adjacent atoms were also constrained to have an equivalent atomic displacement parameter. Certain C-C distances are restrained with DFIX card. The crystal data and structure refinement parameters for the complexes $\mathbf{5 . 2}$ and $\mathbf{5 . 3}$ are given in Table 5.1, for complex 5.9 is given in Table 5.2 and the remaining compounds are listed in Table A5.1 and Table A5.2. The molecular structure of $\mathbf{5 . 2}$ and $\mathbf{5 . 3}$ is given in Figure 5.1 and the molecular structure of 5.9 is given in Figure 5.2. Crystal structures of 5.1, 5.4, and $\mathbf{5 . 5}$ are given in Figure A5.1. Crystal structures of 5.6, 5.7 and 5.8 are given in Figure A5.2.

Table 5.1. Crystal data and structure refinement parameters for the complexes

\begin{tabular}{|c|c|c|}
\hline Formula & $\mathrm{C}_{18} \mathrm{H}_{20} \mathrm{Cl}_{4} \mathrm{~N}_{8} \mathrm{O}_{4} \mathrm{Pd}_{2}(\mathbf{5 . 2})$ & $\mathrm{C}_{30} \mathrm{H}_{60} \mathrm{Cl}_{8} \mathrm{~N}_{16} \mathrm{O}_{8} \mathrm{Pd}_{4}(\mathbf{5 . 3})$ \\
\hline$D_{\text {calc. }} / \mathrm{g} \mathrm{cm}^{-3}$ & 1.699 & 1.794 \\
\hline$\mu / \mathrm{mm}^{-1}$ & 1.56 & 1.74 \\
\hline Formula Weight & 783.15 & 1482.14 \\
\hline Color & gold & gold \\
\hline Shape & Block & Block \\
\hline$T / \mathrm{K}^{1}$ & $298(2)$ & $298(2)$ \\
\hline Crystal System & Triclinic & Triclinic \\
\hline Space Group & $P-1$ & $P-1$ \\
\hline$a / \AA$ & $9.7734(5)$ & $11.909(1)$ \\
\hline$b / \AA$ & $11.2516(6)$ & $12.824(1)$ \\
\hline$c / \AA$ & $15.4811(8)$ & $19.497(2)$ \\
\hline$\alpha l^{\circ}$ & $101.824(1)$ & $87.477(2)$ \\
\hline$\beta /^{\circ}$ & $92.325(1)$ & $80.449(2)$ \\
\hline$y^{\circ}$ & $11.692(1)$ & $69.196(2)$ \\
\hline $\mathrm{V} / \AA^{3}$ & $1530.6(1)$ & $2744.4(4)$ \\
\hline$Z$ & 2 & 2 \\
\hline Wavelength/A & 0.71073 & 0.71073 \\
\hline Radiation type & Mo-K $\alpha$ & Mo-K $\alpha$ \\
\hline $2 \theta_{\min } /^{\circ}$ & 5.60 & 5.80 \\
\hline $2 \theta_{\max } x^{\circ}$ & 53.40 & 53.00 \\
\hline Measured Refl. & 26574 & 48492 \\
\hline Independent Refl. & 6395 & 11241 \\
\hline Reflections Used & 5343 & 9159 \\
\hline$R_{i n t}$ & 0.021 & 0.036 \\
\hline
\end{tabular}


Table 5.1. Crystal data and structure refinement parameters for the complexes (Continued)

\begin{tabular}{lll}
\hline Formula & $\mathrm{C}_{18} \mathrm{H}_{20} \mathrm{Cl}_{4} \mathrm{~N}_{8} \mathrm{O}_{4} \mathrm{Pd}_{2}$ (5.2) & $\mathrm{C}_{30} \mathrm{H}_{60} \mathrm{Cl}_{8} \mathrm{~N}_{16} \mathrm{O}_{8} \mathrm{Pd}_{4}(\mathbf{5 . 3})$ \\
\hline Parameters & 353 & 606 \\
${ }^{\mathrm{a}} \mathrm{GooF}$ & 1.040 & 1.030 \\
${ }^{c} w R_{2}$ & 0.109 & 0.101 \\
${ }^{b} R_{1}$ & 0.039 & 0.037 \\
\hline
\end{tabular}

${ }^{\mathrm{a}} \mathrm{GOF}=\left[\Sigma\left[\omega\left(\mathrm{F}_{\mathrm{o}}{ }^{2}-\mathrm{F}_{\mathrm{c}}{ }^{2}\right)^{2}\right] /\left(\mathrm{N}_{\mathrm{o}}-\mathrm{N}_{\mathrm{v}}\right)\right]^{1 / 2}\left(\mathrm{~N}_{\mathrm{o}}=\right.$ number of observations, $\mathrm{N}_{\mathrm{v}}=$ number of variables $)$.

${ }^{\mathrm{b}} \mathrm{R}_{1}=\Sigma|| \mathrm{F}_{\mathrm{o}}|-| \mathrm{F}_{\mathrm{c}}|| / \Sigma\left|\mathrm{F}_{\mathrm{o}}\right| \cdot{ }^{\mathrm{c}} \mathrm{WR}_{2}=\left[\left(\Sigma \omega\left(\mathrm{F}_{\mathrm{o}}{ }^{2}-\mathrm{F}_{\mathrm{c}}{ }^{2}\right)^{2} / \Sigma\left|\mathrm{F}_{\mathrm{o}}\right|^{2}\right)\right]^{1 /}$

Table 5.2. Crystal data and structure refinement parameters for [5.9].

\begin{tabular}{|c|c|}
\hline Empirical formula & $\mathrm{C}_{30} \mathrm{H}_{40} \mathrm{Cl}_{6} \mathrm{~N}_{20} \mathrm{O}_{14} \mathrm{Pd}_{6}$ \\
\hline Formula weight & 1755.92 \\
\hline Temperature/K & 273.15 \\
\hline Crystal system & Monoclinic \\
\hline Space group & $C 2 / c$ \\
\hline $\mathrm{a} / \AA ̊ \AA$ & $26.657(1)$ \\
\hline $\mathrm{b} / \AA$ & $17.0681(8)$ \\
\hline $\mathrm{c} / \AA$ & $15.9050(7)$ \\
\hline$\alpha /{ }^{\circ}$ & 90 \\
\hline$\beta /{ }^{\circ}$ & $117.100(1)$ \\
\hline$\gamma /{ }^{\circ}$ & 90 \\
\hline Volume $/ \AA^{3}$ & $6442.0(5)$ \\
\hline $\mathrm{Z}$ & 4 \\
\hline$\rho_{\text {calc }} \mathrm{g} / \mathrm{cm}^{3}$ & 1.810 \\
\hline$\mu / \mathrm{mm}^{-1}$ & 1.952 \\
\hline $\mathrm{F}(000)$ & 3400.0 \\
\hline Crystal size $/ \mathrm{mm}^{3}$ & $0.146 \times 0.067 \times 0.027$ \\
\hline Radiation & $\operatorname{MoK} \alpha(\lambda=0.71073)$ \\
\hline $2 \theta$ range for data collection $/^{\circ}$ & 5.574 to 54.98 \\
\hline Index ranges & $-33 \leq \mathrm{h} \leq 33,-21 \leq \mathrm{k} \leq 21,-20 \leq 1 \leq 20$ \\
\hline Reflections collected & 68251 \\
\hline Independent reflections & $6763\left[\mathrm{R}_{\mathrm{int}}=0.0481, \mathrm{R}_{\mathrm{sigma}}=0.0524\right]$ \\
\hline Data/restraints/parameters & $6763 / 0 / 350$ \\
\hline Goodness-of-fit on $\mathrm{F}^{2}$ & 1.055 \\
\hline Final $R$ indexes $[\mathrm{I}>=2 \sigma(\mathrm{I})]$ & $\mathrm{R}_{1}=0.0584, \mathrm{wR}_{2}=0.1502$ \\
\hline Final $\mathrm{R}$ indexes [all data] & $\mathrm{R}_{1}=0.1001, \mathrm{wR}_{2}=0.1699$ \\
\hline Largest diff. peak/hole / e $\AA^{-3}$ & $1.81 /-0.98$ \\
\hline
\end{tabular}




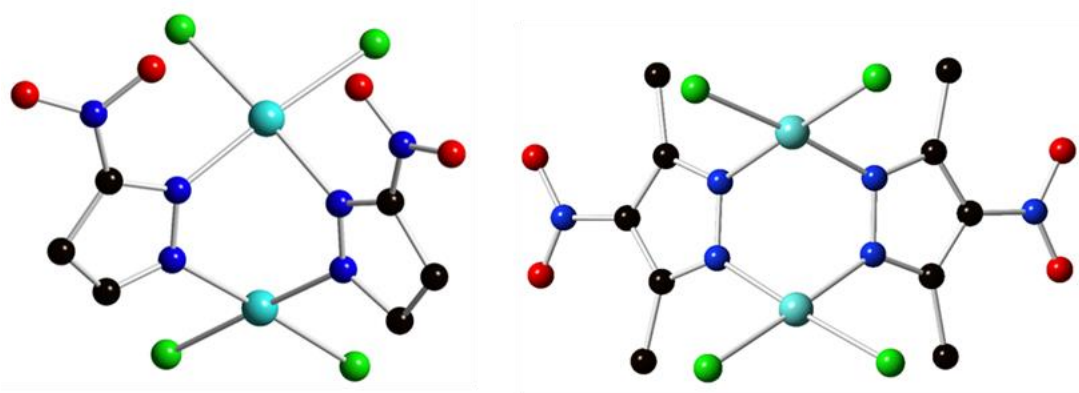

Figure 5.1. Molecular structure of $\mathbf{5 . 2}$ (left) and $\mathbf{5 . 3}$ (right). Color code: $\mathrm{C}$, black; $\mathrm{N}$, blue; $\mathbf{C l}$, green; O, red; Pd, cyan; H-atoms are omitted for clarity.
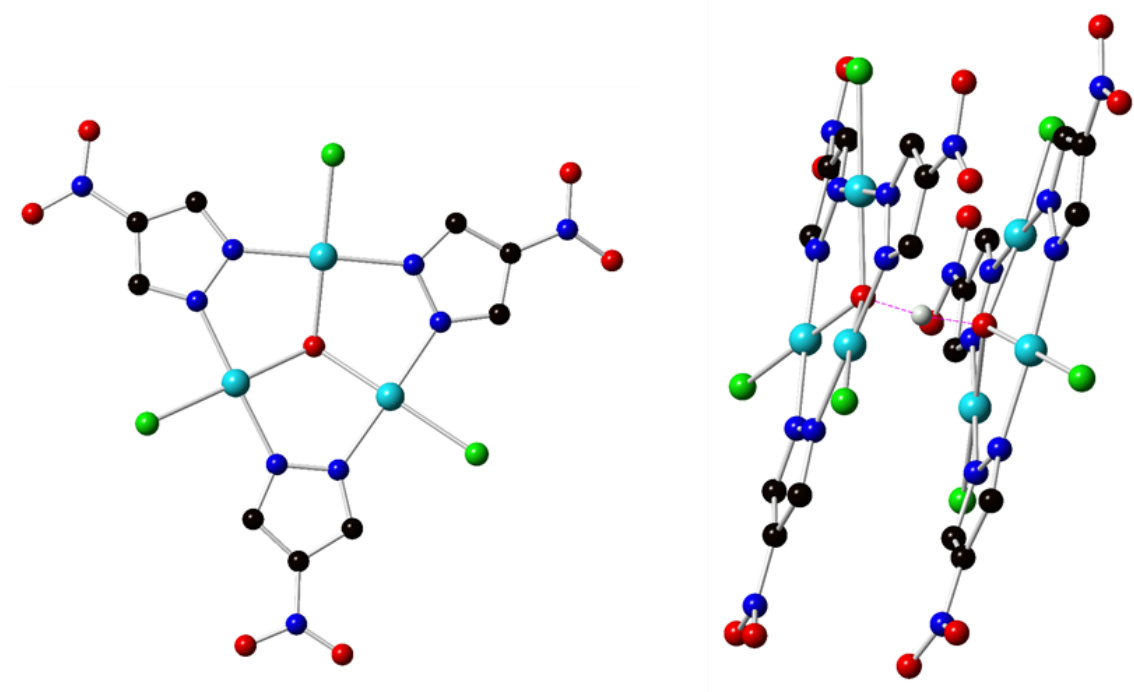

Figure 5.2. The molecular structure of $\mathbf{5 . 9}$ (single trimeric unit, left) and (whole hexamer, right). Color code: $\mathrm{C}$, black; $\mathrm{H}$, white; $\mathrm{N}$, blue; $\mathrm{Cl}$, green; $\mathrm{O}$, red; $\mathrm{Pd}$, cyan;H-atoms, except H-bonding, are omitted for clarity.

\subsubsection{NMR analysis}

The ${ }^{1} \mathrm{H}-\mathrm{NMR}$ spectra of the compounds are unexceptional. For all the compounds, acetone- $\mathrm{d}_{6}$ was used as a NMR solvent. 5.9 has three $\mathrm{Et}_{3} \mathrm{~N}$ counter ions, consistent with the H-bonded dimer-oftrimer formulation. Although two doublets were expected for compound 5.2, it has three doublets in the aromatic regions. This might be because the compound exists in two different isomeric forms $\left(C_{2}\right.$ and $\left.C_{s}\right)$ in the solution. Attempts to crystallize both isomers failed and, in all cases, only the $C_{s}$ isomer was obtained. ${ }^{1} \mathrm{H}-\mathrm{NMR}$ data are of the compounds are given in the 
experimental section. NMR spectra of $\mathbf{5 . 2}$ and $\mathbf{5 . 9}$ are given in Figures 5.3 and 5.4. NMR spectra of other compounds are given in appendices, Figures A5.3 - A5.6.
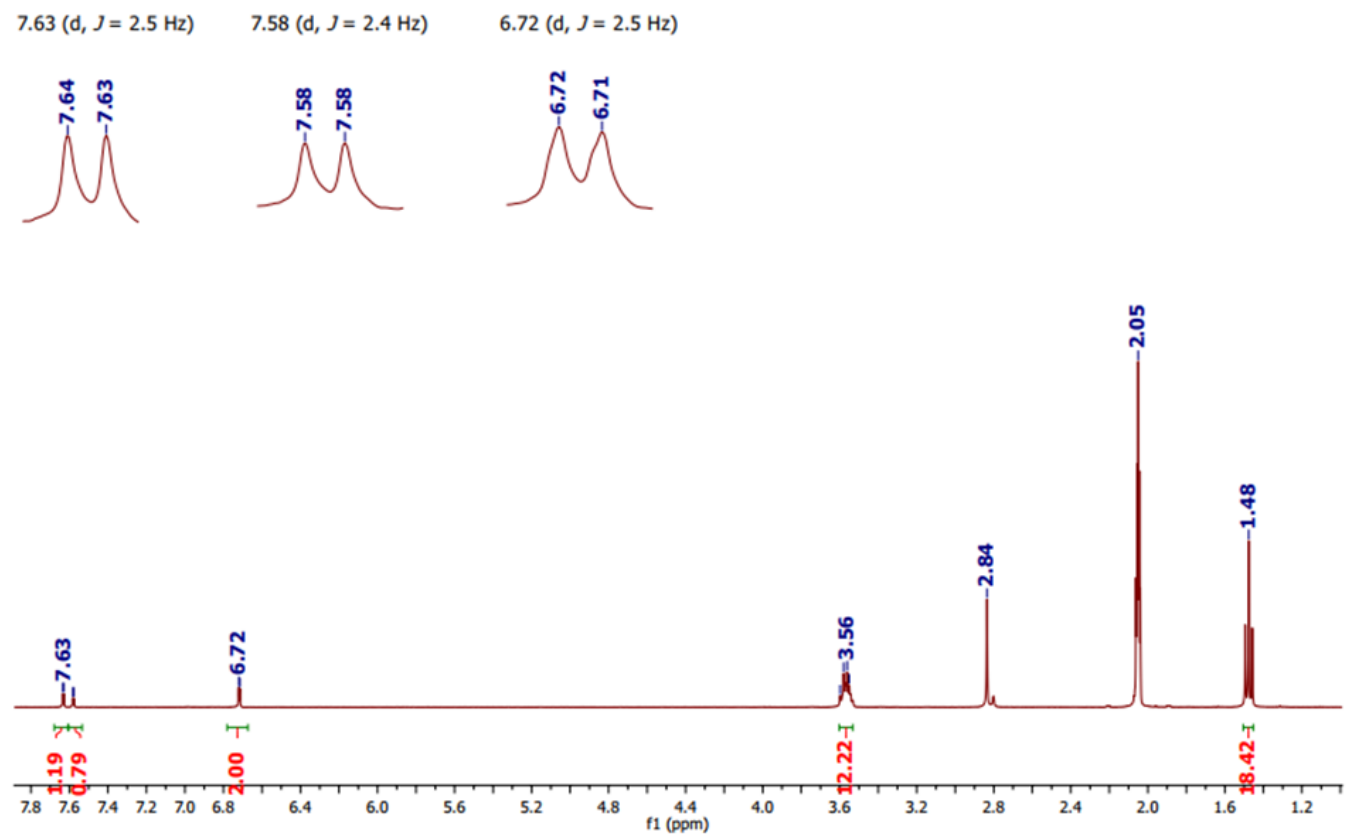

Figure 5.3. ${ }^{1} \mathrm{H}-\mathrm{NMR}$ of $\mathbf{5 . 2}$ (in acetone)



Figure 5.4. ${ }^{1} \mathrm{H}-\mathrm{NMR}$ of $\mathbf{5 . 9}$ (in acetone) 


\subsubsection{Catalytic study}

The reaction conditions, such as the most commonly used solvents and bases, were optimized for one reaction and applied for the rest of the reactions. The palladium precursors $\mathrm{PdCl}_{2}$ and $\mathrm{PdCl}_{2}\left(\mathrm{CH}_{3} \mathrm{CN}\right)_{2}$ were also used as a catalyst but resulted in yield significantly lower than $\mathbf{5 . 2}$ or 5.3. Presence or absence of $\mathrm{CuI}$ was also studied for the reaction and concluded that $\mathrm{CuI}$ is the main culprit for homocoupling reactions. Optimization conditions are listed in Table 5.3. Low catalytic loading $(0.9 \mathrm{~mol} \%)$ was sufficient to proceed with the reaction to completion. Turnover number (TON) of the catalysts are at least 103 to 108 . The chemical nature of alkyl/aryl halide $(\mathrm{R}-\mathrm{X})$ is crucial for the Sonogashira catalysis. Although electron withdrawing groups reduce the electron density of $\mathrm{C}-\mathrm{X}$ bond, weakening the bond and making reaction easier, ${ }^{14}$ no significant effect was observed in our study; this might be because for all the cases the yield is very high (92 - $99 \%)$. However, for the same product $\mathbf{4 b}(\mathbf{4 e})$, use of 4-methoxyiodobenzene and 4iodobenzene gave $95 \%$ and $92 \%$ yields, respectively, consistent with the C-I weakening effect of methoxy substituent and accelerating the reaction. Catalyst $\mathbf{5 . 3}$ was found to be slightly superior to $\mathbf{5 . 2}$ (Table 5.3), because the methyl substituents in $\mathbf{5 . 3}$, make the catalyst bulkier, favoring oxidative addition and reductive elimination steps. ${ }^{10}$ All other reactions were carried out by using catalyst 5.3. For all reactions the isolated yield achieved was $92 \%$ or higher. The reactions are listed in Table 5.4.

\subsubsection{Terminal $-\mathrm{Cl}$ substitution of 5.9 by $-\mathrm{CN}$}

Compound 5.9 is a hexanuclear compound (dimer of trimer) containing six terminal chloride $(\mathrm{Cl})$ atoms. Addition of equimolar $\mathrm{AgCN}$ on the $\mathrm{MeCN}$ solution of $\mathbf{5 . 9}$ tarnishes the original yellow color of the solution with the formation of a white precipitate. Further addition of AgCN results more white ppt and color further tarnishes. However, six equivalent or more $\mathrm{AgCN}$ is required to completely remove the yellow color. The color change is the preliminary confirmation of the $-\mathrm{Cl}$ substitution by $-\mathrm{CN}$. The original color of the [5.9] and after complete addition of $\mathrm{AgCN}$ is 
shown in Figure 5.5. This was further confirmed by FT-IR. After complete addition of AgCN, an additional $-\mathrm{CN}$ peak in $2136 \mathrm{~cm}^{-1}$ appears along with all the other peaks that are very slightly shifted (Figure 5.6). The $-\mathrm{CN}$ peaks of $\mathrm{AgCN}$ appears in $2162 \mathrm{~cm}^{-1}$. The comparison of IR of 5.9 and after substitution is shown in Figure 5.6.

Table 5.3. Optimization of Reaction Conditions ${ }^{\mathrm{a}}$

\begin{tabular}{|c|c|c|c|c|c|c|}
\hline $2 a$ & $3 a$ & & & $4 a$ & & 5 \\
\hline Entry & $\begin{array}{l}\text { Catalyst } \\
0.9 \mathrm{~mol} \%\end{array}$ & Base & $\begin{array}{l}\text { Cocatalyst } \\
5 \mathrm{~mol} \%\end{array}$ & Solvent & $\%$ Yield (4a) & $\%$ Yield (5) \\
\hline 1. & 5.2 & TEA & Cul & $\mathrm{CH}_{3} \mathrm{CN}$ & 32 & 33 \\
\hline 2. & 5.2 & TEA & - & $\mathrm{CH}_{3} \mathrm{CN}$ & 96 & - \\
\hline 3. & 5.3 & TEA & Cul & $\mathrm{CH}_{3} \mathrm{CN}$ & 32 & 34 \\
\hline 4. & 5.3 & TEA & - & $\mathrm{CH}_{3} \mathrm{CN}$ & 97 & - \\
\hline 5. & $\mathrm{PdCl}_{2}$ & TEA & - & $\mathrm{CH}_{3} \mathrm{CN}$ & 20 & - \\
\hline 6. & $\mathrm{PdCl}_{2}\left(\mathrm{CH}_{3} \mathrm{CN}\right)_{2}$ & TEA & - & $\mathrm{CH}_{3} \mathrm{CN}$ & 25 & - \\
\hline 7. & 5.3 & $\mathrm{Cs}_{2} \mathrm{CO}_{3}$ & - & $\mathrm{CH}_{3} \mathrm{CN}$ & 90 & 3 \\
\hline 8. & 5.3 & TEA & - & DMF & 92 & - \\
\hline 9. & 5.3 & TEA & - & THF & 93 & - \\
\hline
\end{tabular}


Table 5.4. Sonogashira coupling reactions carried out for this work

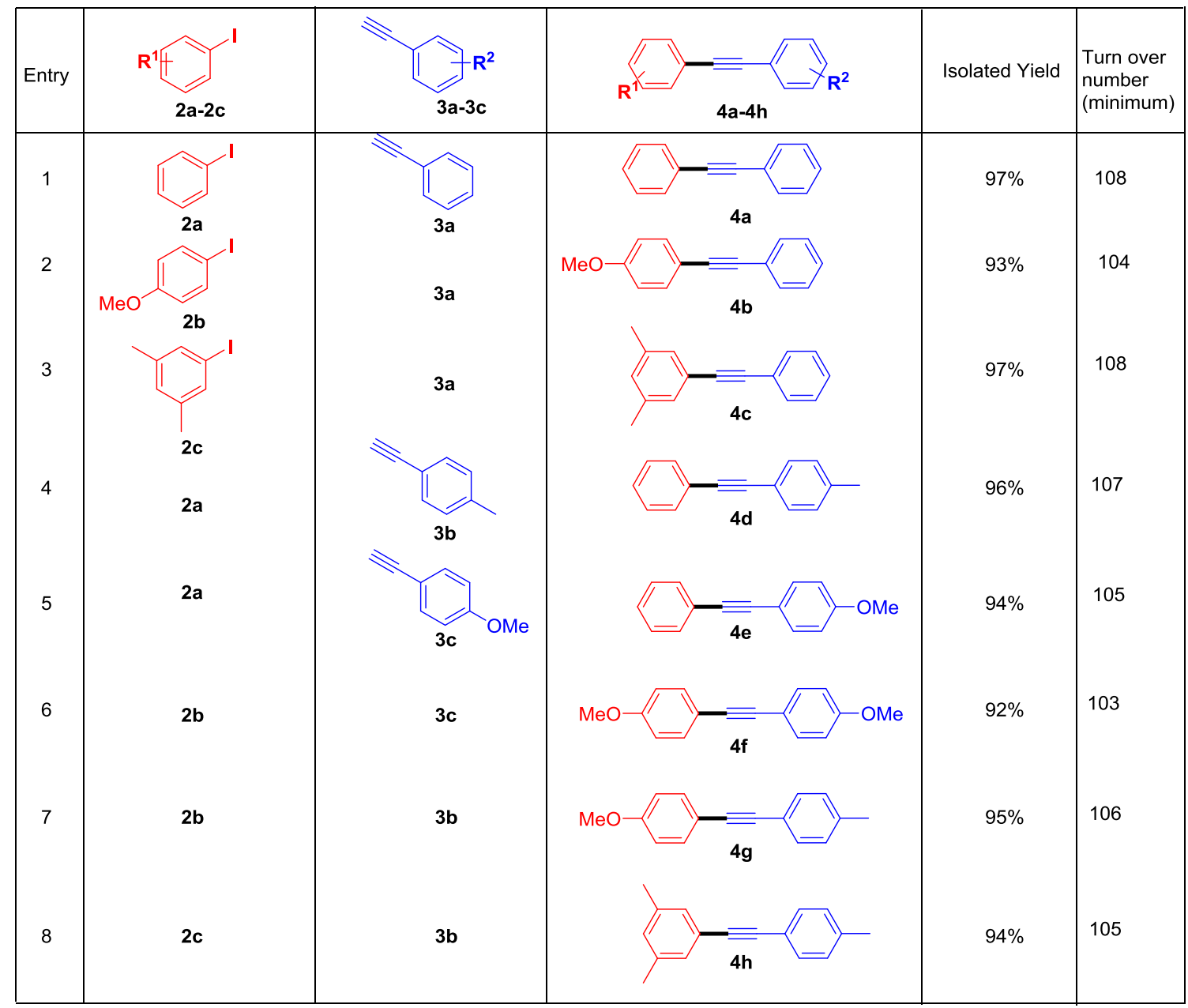

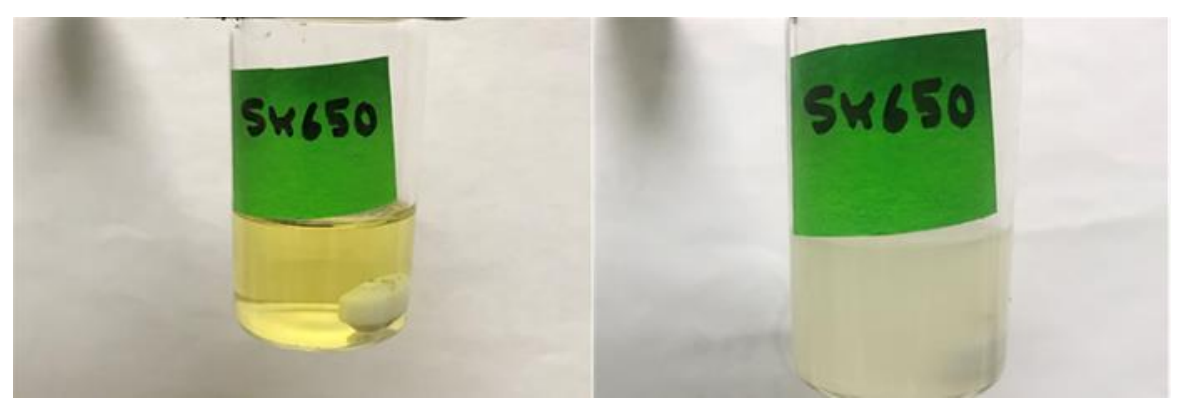

Figure 5.5. [5.9] before adding $\mathrm{AgCN}$ (left) and after adding $\mathrm{AgCN}$ (right) 


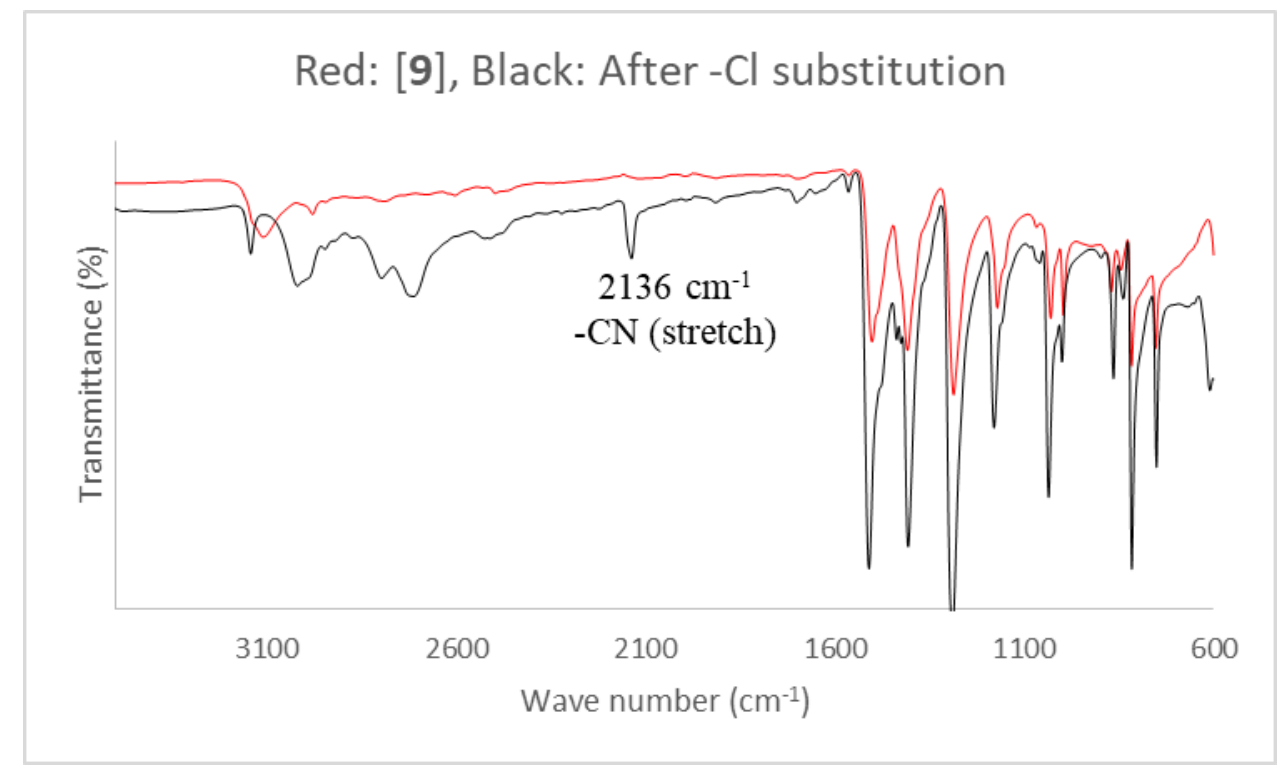

Figure 5.6. IR comparison of $\mathbf{5 . 9}$ and after $-\mathrm{Cl}$ substitution by $-\mathrm{CN}$.

\subsection{Conclusions}

In summary, nine new palladium pyrazolyl complexes $(\mathbf{5 . 1 - 5 . 9})$ were synthesized ranging from mononuclear to hexanuclear ones. Three of them are water soluble and they are potential candidates for green catalysis applications These compounds are characterized by SCXRD, ${ }^{1} \mathrm{H}$ NMR, FT-IR, and elemental analyses. Compound 5.2 exist in isomeric forms in the solution, as determined by ${ }^{1} \mathrm{H}$ NMR. The hexanuclear compound $\mathbf{5 . 9}$ (dimer-of-trimer) has an unprecedented motif, which prompted us to further explore its chemistry. Terminal $-\mathrm{Cl}$ atoms were replaced by $-\mathrm{CN}$. The color change was the preliminary indication of the reaction and which was further confirmed by FT-IR. Two dimers, $\mathbf{5 . 2}$ and 5.3, were used as catalysts to synthesize the Sonogashira products $\mathbf{4 a}$ and $\mathbf{5 . 3}$, the latter having a slightly higher yield. Compound $\mathbf{5 . 3}$ was slightly superior to $\mathbf{5 . 2}$, which might be caused by the steric effect of $-\mathrm{CH}_{3}$ groups in the 3-and 5-position of the pyrazole. All other reactions were catalyzed by 5.3. These types of pyrazolyl dimer complexes have not been ported previously, at least for the cross-coupling reactions. The catalysis reactions were carried out in an open air atmosphere, without $\mathrm{Cu}(\mathrm{I})$, relatively short 
reaction times and mild conditions. This might open up a new horizons for a catalytic system for

the cross-coupling reactions to overcome limitations of the existing catalytic system.

\subsection{References}

1. Yang, D.; Li, B.; Yang, H.; Fu, H.; Hu, L., Efficient copper-catalyzed Sonogashira couplings of aryl halides with terminal alkynes in water. Synlett 2011, 2011 (05), 702-706.

2. (a) Li, F.; Hor, T. A., Benzimidazolium- Pyrazole- Palladium (II) Complexes: New and Efficient Catalysts for Suzuki, Heck and Sonogashira Reactions. Advanced Synthesis \& Catalysis 2008, 350 (14- 15), 2391-2400; (b) Hill, L. L.; Smith, J. M.; Brown, W. S.; Moore, L. R.; Guevera, P.; Pair, E. S.; Porter, J.; Chou, J.; Wolterman, C. J.; Craciun, R., Neopentylphosphines as effective ligands in palladium-catalyzed cross-couplings of aryl bromides and chlorides. Tetrahedron 2008, 64 (29), 6920-6934; (c) Hill, L. L.; Moore, L. R.; Huang, R.; Craciun, R.; Vincent, A. J.; Dixon, D. A.; Chou, J.; Woltermann, C. J.; Shaughnessy, K. H., Bulky alkylphosphines with neopentyl substituents as ligands in the amination of aryl bromides and chlorides. The Journal of organic chemistry 2006, 71 (14), 5117-5125; (d) Littke, A. F.; Schwarz, L.; Fu, G. C., Pd/P (t-Bu) 3: a mild and general catalyst for Stille reactions of aryl chlorides and aryl bromides. Journal of the American Chemical Society 2002, 124 (22), 6343-6348.

3. (a) Komáromi, A.; Novák, Z., Efficient copper-free Sonogashira coupling of aryl chlorides with palladium on charcoal. Chemical Communications 2008, (40), 4968-4970; (b) Rizkin, B. A.; Hartman, R. L., Catalytic activity of Pd/hydrophilic phosphine ligand in the interface of an aqueous-phase $\mathrm{Cu}$-free Sonogashira coupling. Reaction Chemistry \& Engineering 2018, 3 (3), 251-257.

4. Jover, J.; Spuhler, P.; Zhao, L.; McArdle, C.; Maseras, F., Toward a mechanistic understanding of oxidative homocoupling: the Glaser-Hay reaction. Catalysis Science \& Technology 2014, 4 (12), 4200-4209.

5. (a) Siemsen, P.; Livingston, R. C.; Diederich, F., Acetylenic coupling: a powerful tool in molecular construction. Angewandte Chemie International Edition 2000, 39 (15), 26322657; (b) Wang, X.; Song, Y.; Qu, J.; Luo, Y., Mechanistic Insights into the CopperCocatalyzed Sonogashira Cross-Coupling Reaction: Key Role of an Anion. Organometallics 2017, 36 (5), 1042-1048; (c) Gholinejad, M.; Dasvarz, N.; Nájera, C., Novel oximepalladacycle supported on clay composite as an efficient heterogeneous catalyst for Sonogashira reaction. Inorganica Chimica Acta 2018, 483, 262-270.

6. Bandini, M.; Luque, R.; Budarin, V.; Macquarrie, D. J., Aryl alkynylation versus alkyne homocoupling: unprecedented selectivity switch in $\mathrm{Cu}$, phosphine and solvent-free heterogeneous Pd-catalysed couplings. Tetrahedron 2005, 61 (41), 9860-9868.

7. (a) Chinchilla, R.; Nájera, C., Recent advances in Sonogashira reactions. Chemical Society Reviews 2011, 40 (10), 5084-5121; (b) Biffis, A.; Centomo, P.; Del Zotto, A.; Zecca, M., Pd metal catalysts for cross-couplings and related reactions in the 21st century: a critical review. Chemical reviews 2018, 118 (4), 2249-2295. 
8. (a) Batey, R. A.; Shen, M.; Lough, A. J., Carbamoyl-substituted N-heterocyclic carbene complexes of palladium (II): Application to Sonogashira cross-coupling reactions. Organic letters 2002, 4 (9), 1411-1414; (b) Ma, Y.; Song, C.; Jiang, W.; Wu, Q.; Wang, Y.; Liu, X.; Andrus, M. B., Sonogashira coupling using bulky palladium-phenanthryl imidazolium carbene catalysis. Organic letters 2003, 5 (18), 3317-3319; (c) Soheili, A.; AlbanezeWalker, J.; Murry, J. A.; Dormer, P. G.; Hughes, D. L., Efficient and general protocol for the copper-free Sonogashira coupling of aryl bromides at room temperature. Organic letters 2003, 5 (22), 4191-4194.

9. Son, S. U.; Jang, Y.; Park, J.; Na, H. B.; Park, H. M.; Yun, H. J.; Lee, J.; Hyeon, T., Designed synthesis of atom-economical $\mathrm{Pd} / \mathrm{Ni}$ bimetallic nanoparticle-based catalysts for sonogashira coupling reactions. Journal of the American Chemical Society 2004, 126 (16), 5026-5027.

10. Balcells, D.; Nova, A., Designing Pd and Ni Catalysts for Cross-Coupling Reactions by Minimizing Off-Cycle Species. ACS Catalysis 2018, 8 (4), 3499-3515.

11. (a) Dürr, A. B.; Fisher, H. C.; Kalvet, I.; Truong, K. N.; Schoenebeck, F., Divergent reactivity of a dinuclear (NHC) Nickel (I) catalyst versus nickel (0) enables chemoselective trifluoromethylselenolation. Angewandte Chemie International Edition 2017, 56 (43), 13431-13435; (b) Helms, B.; Frechet, J. M., The dendrimer effect in homogeneous catalysis. Advanced Synthesis \& Catalysis 2006, 348 (10- 11), 1125-1148.

12. (a) Li, P. H.; Wang, L., An Amine- , Copper- and Phosphine- Free Sonogashira Coupling Reaction Catalyzed by Immobilization of Palladium in Organic-Inorganic Hybrid Materials. Advanced synthesis \& catalysis 2006, 348 (6), 681-685; (b) Trilla, M.; Pleixats, R.; Man, M. W. C.; Bied, C.; Moreau, J. J., Hybrid Organic- Inorganic Materials from Di- (2- pyridyl) methylamine- Palladium Dichloride Complex as Recoverable Catalysts for Suzuki, Heck and Sonogashira Reactions. Advanced synthesis \& catalysis 2008, 350 (4), 577-590; (c) Kandel, S.; Stenger-Smith, J.; Chakraborty, I.; Raptis, R. G., Syntheses and X-ray crystal structures of a family of dinuclear silver (I) pyrazolates: Assessment of their antibacterial efficacy against P. aeruginosa with a soft tissue and skin infection model. Polyhedron 2018, $154,390-397$.

13. Dehury, N.; Maity, N.; Tripathy, S. K.; Basset, J.-M.; Patra, S., Dinuclear Tetrapyrazolyl Palladium Complexes Exhibiting Facile Tandem Transfer Hydrogenation/Suzuki Coupling Reaction of Fluoroarylketone. ACS Catalysis 2016, 6 (8), 5535-5540.

14. (a) Negishi, E.-i.; de Meijere, A., Handbook of organopalladium chemistry for organic synthesis. Wiley-Interscience: 2002; Vol. 2; (b) Chinchilla, R.; Nájera, C., The Sonogashira reaction: a booming methodology in synthetic organic chemistry. Chemical reviews 2007, 107 (3), 874-922.

15. Urgaonkar, S.; Verkade, J. G., Ligand-, copper-, and amine-free Sonogashira reaction of aryl iodides and bromides with terminal alkynes. The Journal of organic chemistry 2004, 69 (17), 5752-5755.

16. Li, J.-H.; Zhang, X.-D.; Xie, Y.-X., Efficient and copper-free Pd (OAc) 2/DABCOcatalyzed Sonogashira cross-coupling reaction. Synthesis 2005, 2005 (05), 804-808. 
17. Maresca, K. P.; Rose, D. J.; Zubieta, J., Synthesis and characterization of a binuclear rhenium nitropyrazole complex [Re $2 \mathrm{O} 3 \mathrm{Cl} 2$ ( $\mathrm{PPh} 3) 2(\mathrm{C} 3 \mathrm{H} 2 \mathrm{~N} 3 \mathrm{O}$ 2) 2]. Inorganica chimica acta 1997, 260 (1), 83-88.

18. Lebedev, A. A.; Young, P.; Isupov, M. N.; Moroz, O. V.; Vagin, A. A.; Murshudov, G. N., JLigand: a graphical tool for the CCP4 template-restraint library. Acta Crystallographica Section D: Biological Crystallography 2012, 68 (4), 431-440. 


\section{CHAPTER 6}

\subsection{Overall conclusions}

In summary, the dissertation work contains six chapters including the general introduction and the general conclusions in chapters 1 and 6 respectively. The first project (second chapter) contains the synthesis and characterization the water-soluble, biocompatible silver pyrazolates complexes for bio-medicinal applications and one of the water-soluble compounds proved to be highly effective compared to $\mathrm{AgNO}_{3}$ for inhibiting/killing the gram negative bacteria. The ligands and co-ligands chosen for this project are biocompatible. To the best of our knowledge, it is the first report of an antibacterial/medicinal application using silver pyrazolates. Although several silver pyrazolate complexes are found in the literature with the study of their chemical and physical properties, no medicinal applications have been reported previously. We also proved that watersoluble silver pyrazolates are better over water-insoluble ones with regard to their antibacterial properties. The need for the slow delivery of $\mathrm{Ag}^{+}$ions to the target has been accomplished.

Exploiting the versatility of pyrazolyl ligands, we explored their applications in luminescent sensors. In this work (third chapter) we designed tripodal pyrazolyl ligands and probed their nitroaromatic sensing behaviors. To our best knowledge, we used the new tripodal pyrazolyl ligands for the first time for the application with fascinating results. Although relatively newer, the cutting edge research area of sensing using AIEE property was well introduced. The selective sensing of picric acid over other nitroaromatics has been experimentally demonstrated.

The literature for the mercury pyrazolate lacks examples for the higher coordination number modes. According to the Cambridge structural database (CSD), mercury pyrazolates with only coordination numbers 2, 3 and 4 are reported. Also, most of the pyrazolates isolated were polymers, which limits their solubility and prevents the growth of single crystals; Most of the structures had been elucidated by powder diffraction technique. All the hitherto reported work 
involves mercury pyrazolates of only four pyrazoles: $\mathrm{Hpz}, \mathrm{dmpzH}, \mathrm{dPhpzH}$, and diisopropylpzH. Also, no literature was found reporting pyrazole-based ligands for selective extraction purposes. We have synthesized a variety of mercury pyrazolates with a great range of nuclearity, solubility, and coordination number. Some of the polymers we synthesized are highly soluble in organic media. We have synthesized a C-mercuriated complex. Only one C-mercuriated Hg-pyrazolate exists in the literature. We have synthesized an $\mathrm{Hg}$-pyrazolate with a tripodal ligand. No literature was found reporting a pyrazolyl mercury complex with a tripodal pyrazole. The tripodal ligand was used to extract mercury and found promising. We have tuned the solvents and stoichiometry for the same reactants and synthesized various compounds. All five ligands employed are structurally highly different from one another. We have synthesized the mercury pyrazolates having all the geometry reported previously as well as a new octahedral geometry for the mercury pyrazolates. The work has been reported in chapter four. The literature reported deals with the synthesis and characterization of mercury pyrazolates aiming to explore the chemistry. Our primary objective is to design the ligands which are good to extract mercury from the mixture of lanthanides and actinides in an aqueous alkaline solution. Added toxicological effect to the worker in Savannah River nuclear waste site prompted us to design the project. Preliminary result for the extraction study is successful and the ligands we design are stable in acidic to alkaline conditions. Some of the work on liquid-liquid extraction of mercury have been reported already. They have found that lipophilicity is an important parameter for the extraction to the organic phase. Although much work has been reported for the extraction of mercury, most of them are limited to extraction in acidic media and use of sulfur donor extractants. No pyrazolate ligands for the extraction of mercury have been reported yet.

Nine new palladium pyrazolyl complexes with a broad range of solubility have been synthesized and characterized with SCXRD, standard spectroscopic techniques, and elemental analyses. Two 
of them were used as a catalyst for Sonogashira coupling reactions and found promising. The catalytic products were characterized by NMR.

\subsection{Future work}

In the future, we will be pursing antimicrobial activity of water-soluble silver pyrazolate complexes in wider scope. Optimization of synthetic routes of water-soluble palladium pyrazolates and use them as a catalyst for green catalysis will be our another project in future. Moreover, further investigation of mercury pyrazolate chemistry will also be pursued.

\section{APPENDICES}

\section{Figures}

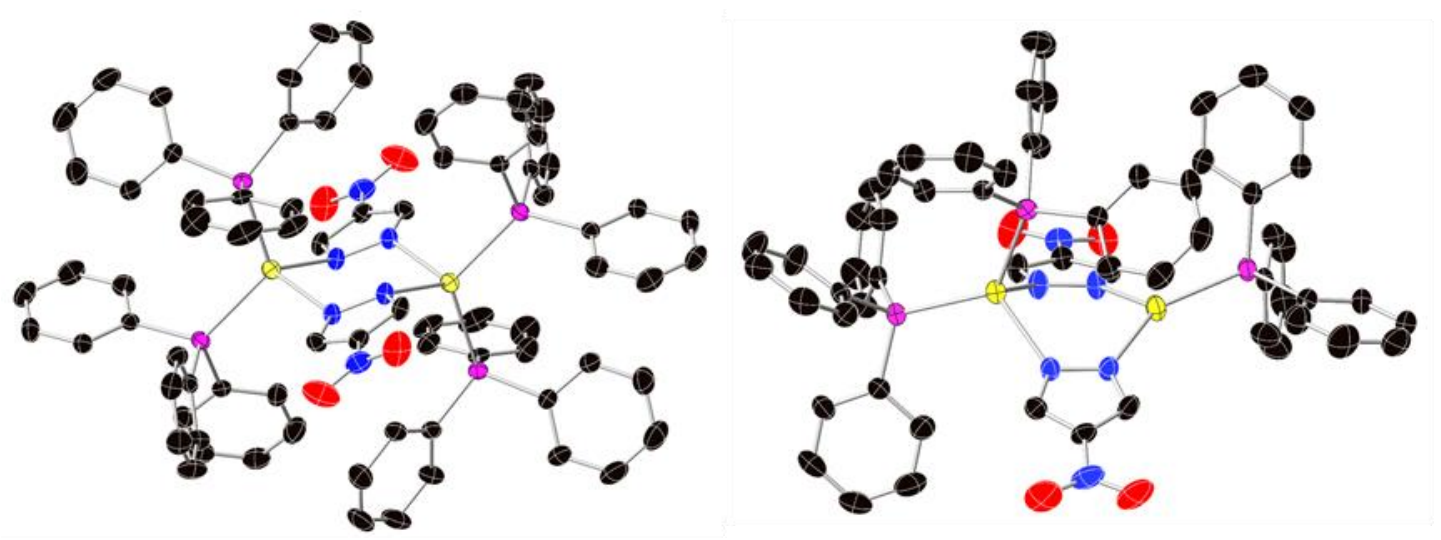

Figure A2.1. Perspective view of the molecular structure of complexes 2.3 (left) and 2.4 (right). The thermal ellipsoids are shown at 35\% probability level ( $\mathrm{H}$ atoms are omitted, and the labeling scheme are shown only for the hetero atom for the sake of clarity). Color code: C, black; N, blue; $\mathrm{O}$, red; P, pink and Ag, yellow. 


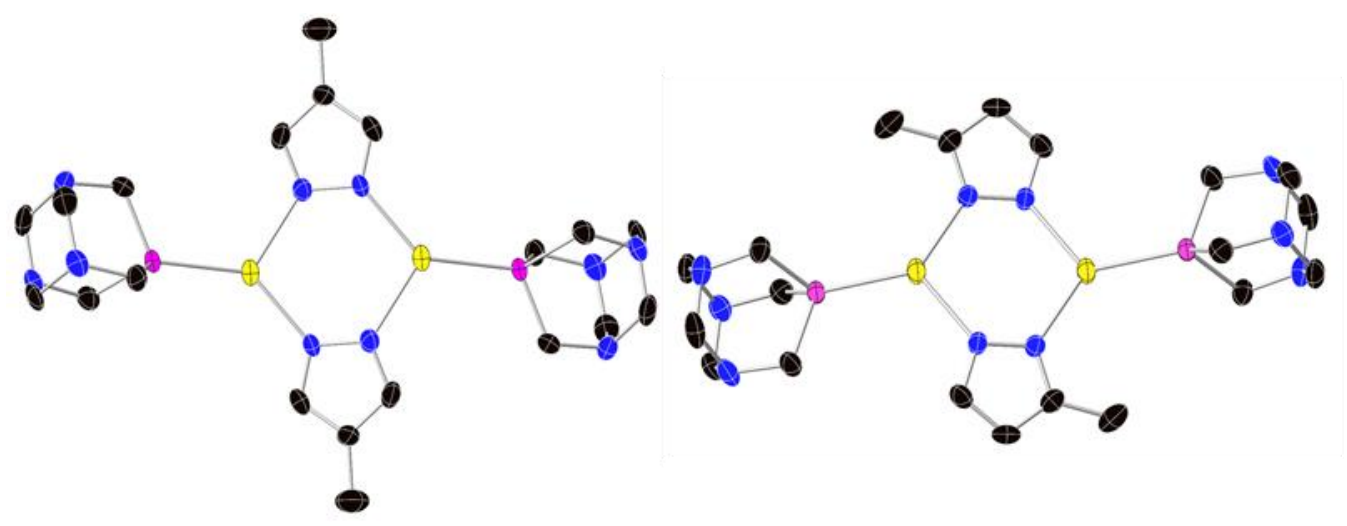

Figure A2.2. Perspective view of the molecular structure of complexes $\mathbf{2 . 7}$ (left) and $\mathbf{2 . 8}$ (right). The thermal ellipsoids are shown at 35\% probability level ( $\mathrm{H}$ atoms are omitted and the labeling scheme are shown only for the hetero atom for the sake of clarity). Color code: $\mathrm{C}$, black; N, blue; $\mathrm{P}$, pink and Ag, yellow.
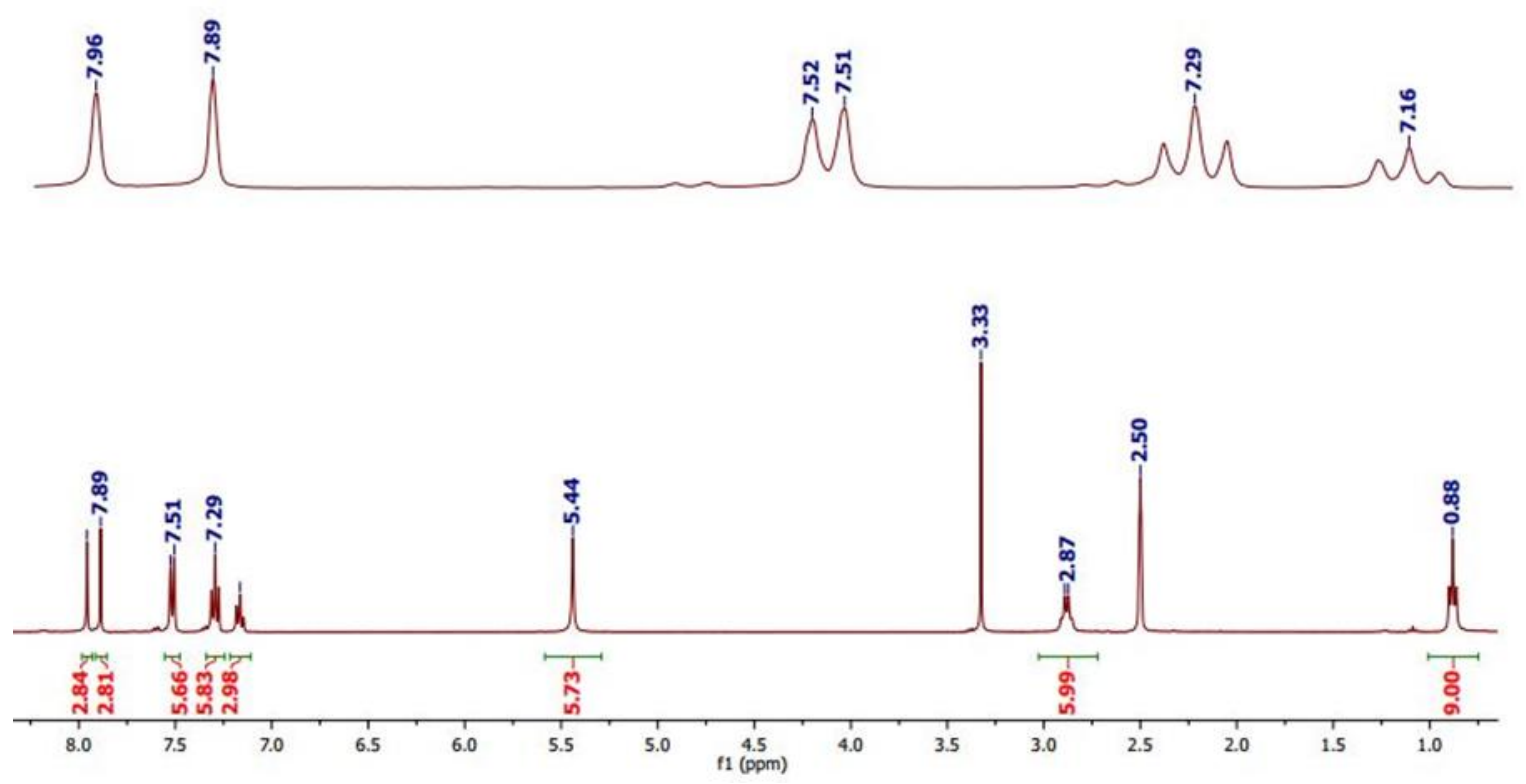

Figure A3.1. ${ }^{1} \mathrm{H}$ NMR spectrum of compound 3.1, DMSO-d 6 . (Top: Expanded aromatic region) 

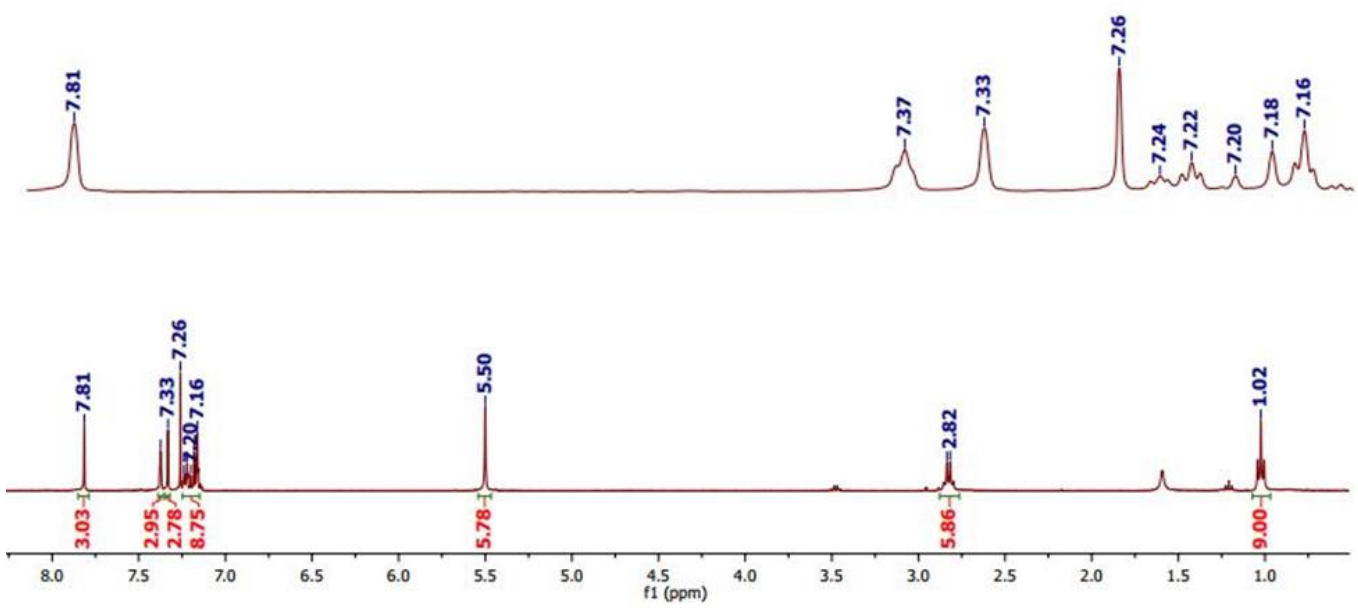

Figure A3.2. ${ }^{1} \mathrm{H}-\mathrm{NMR}$ spectrum of compound 3.3, $\mathrm{CDCl}_{3}$. (Top: Expanded aromatic region)
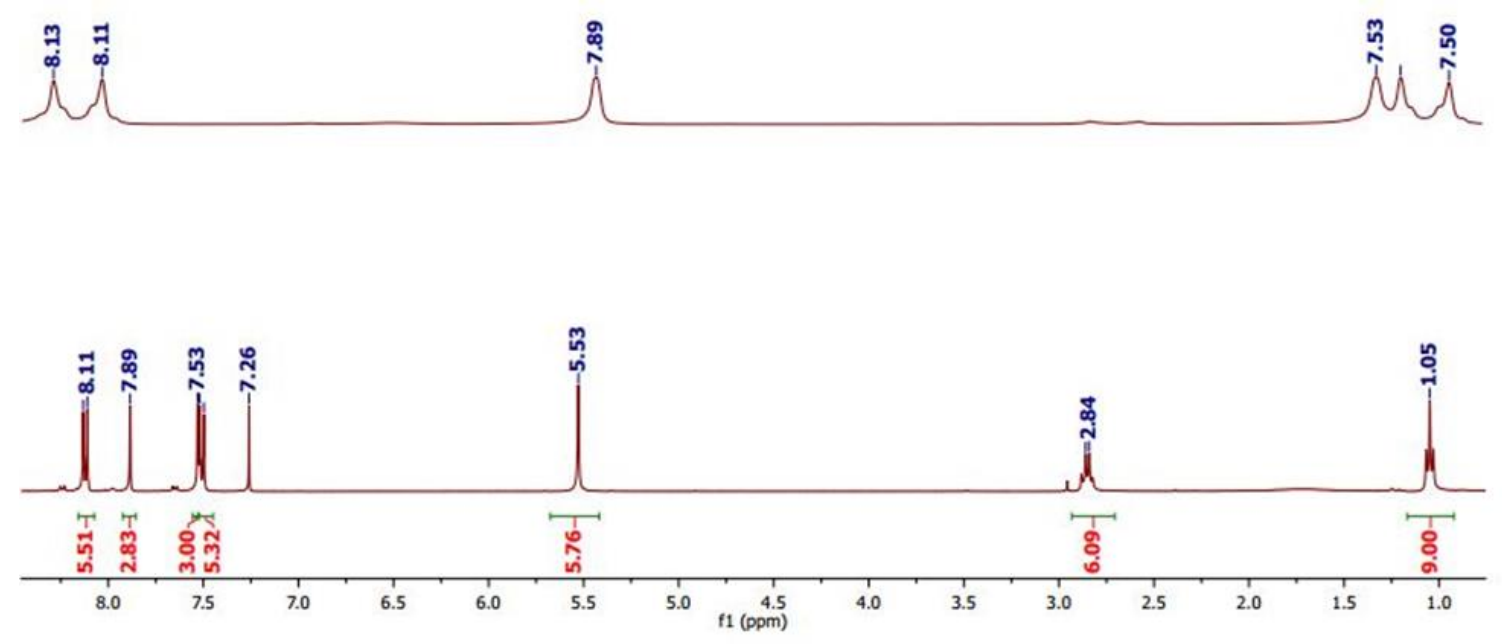

Figure A3.3. ${ }^{1} \mathrm{H}-\mathrm{NMR}$ spectrum of compound 3.4, $\mathrm{CDCl} 3$. (Top: Expanded aromatic region) 


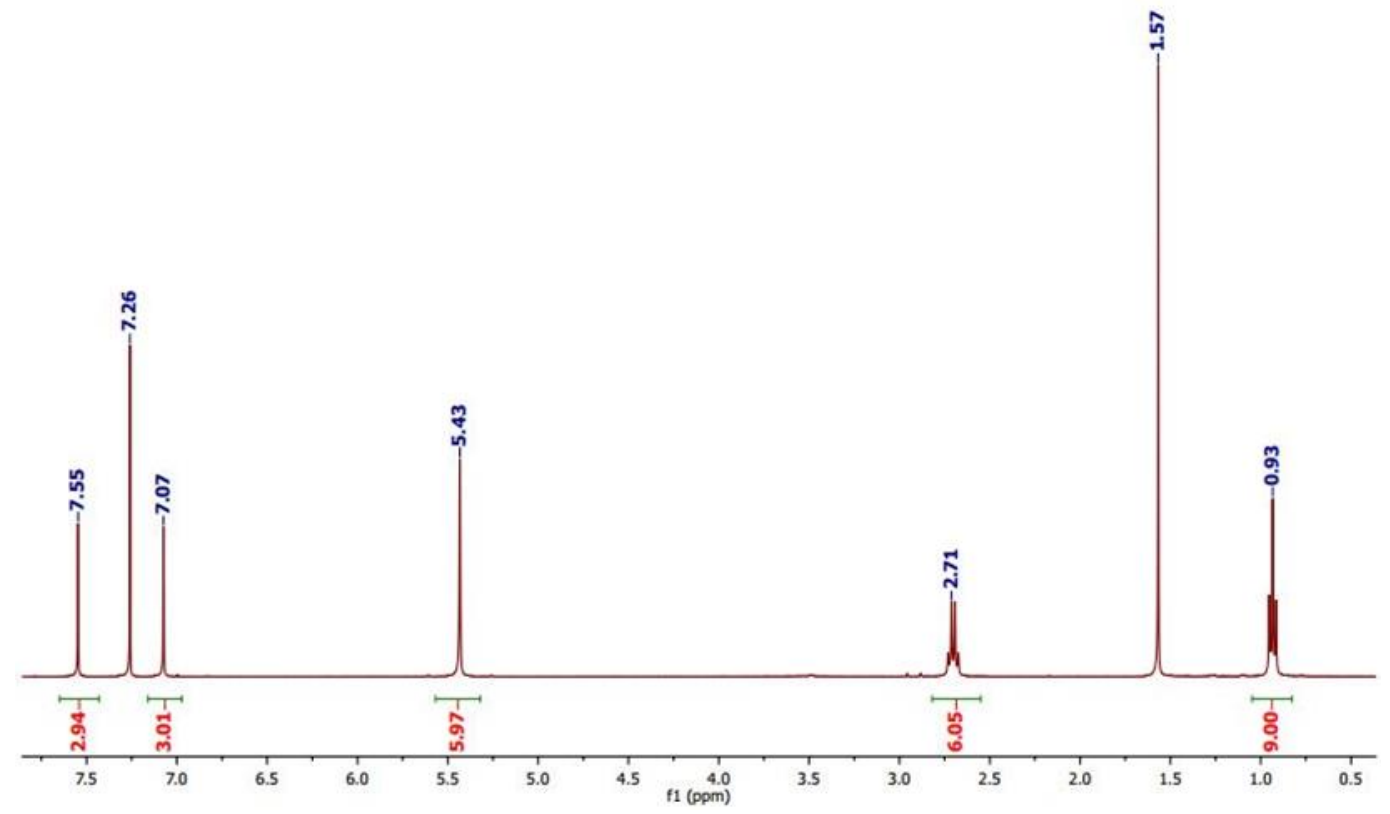

Figure A3.4. ${ }^{1} \mathrm{H}-\mathrm{NMR}$ spectrum of compound 3.5, $\mathrm{CDCl}_{3}$.

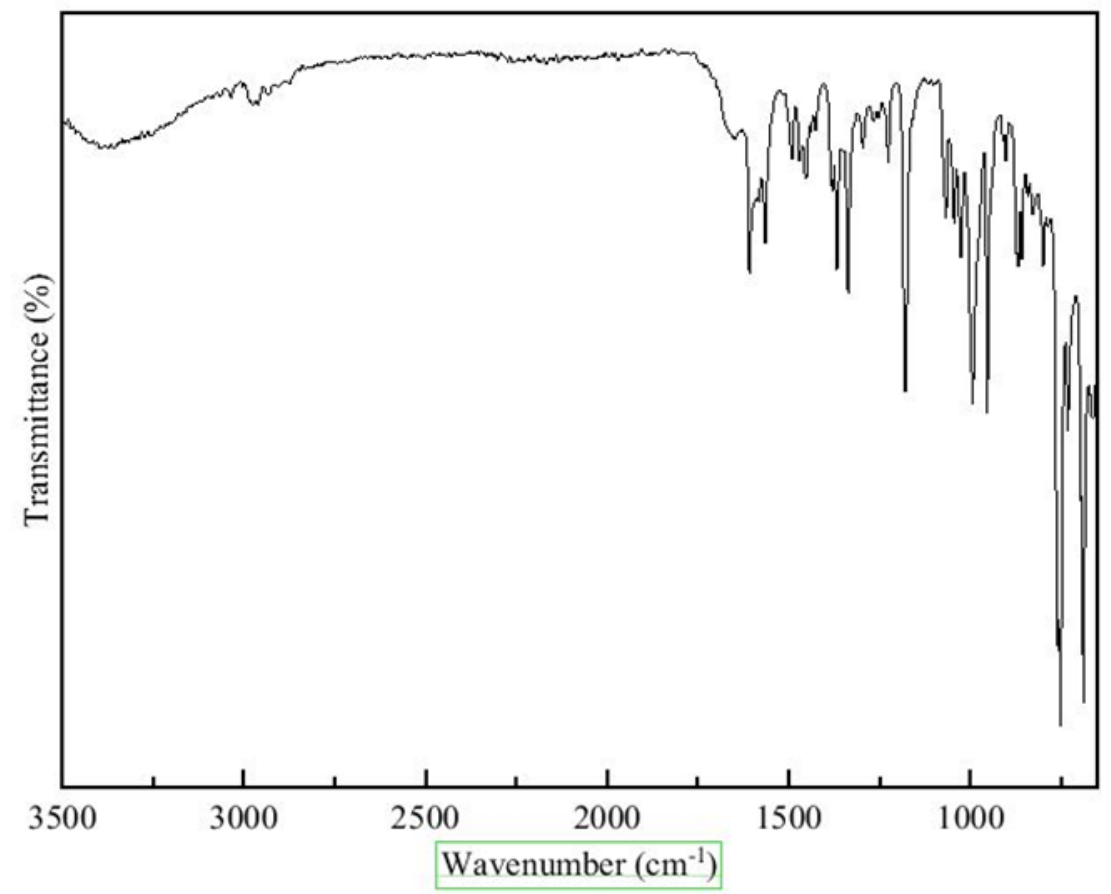

Figure A3.5. IR spectrum of compound 3.1. 




Figure A3.6. IR spectrum of compound 3.3.




Figure A3.7. IR spectrum of compound 3.4.

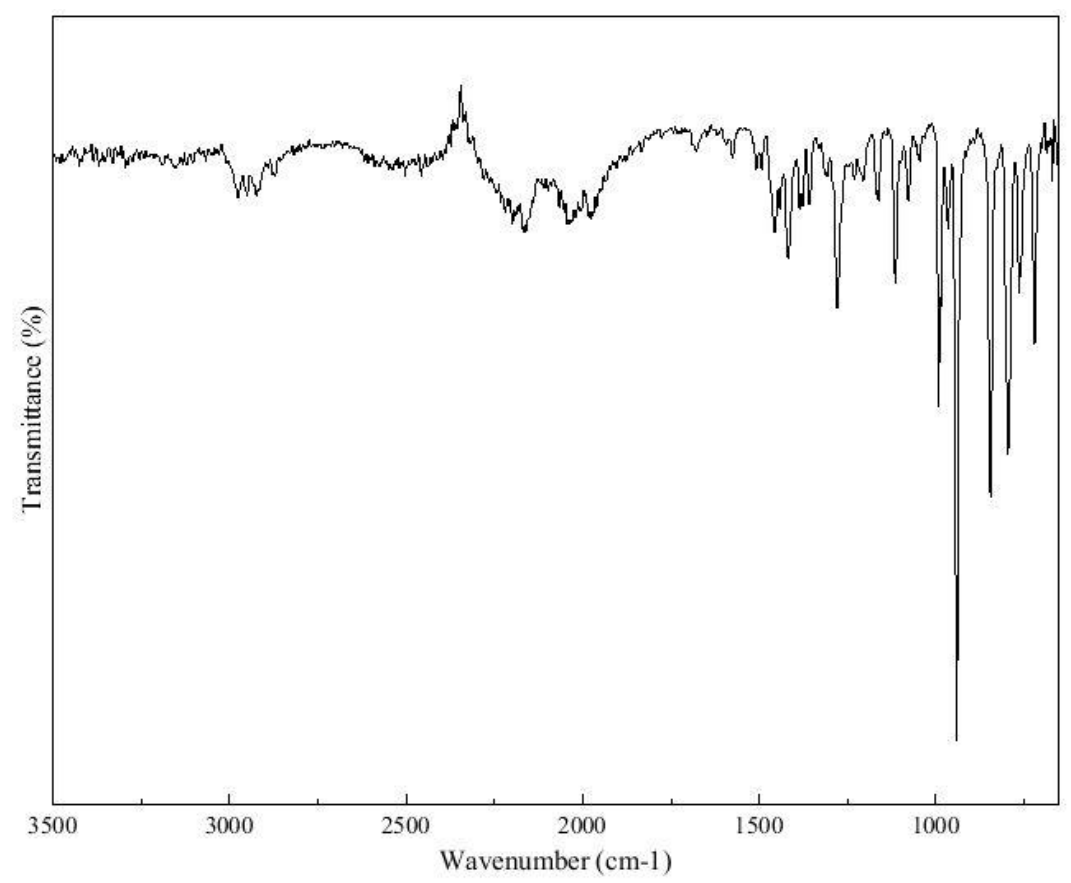

Figure A3.8. IR spectrum of compound 3.5.
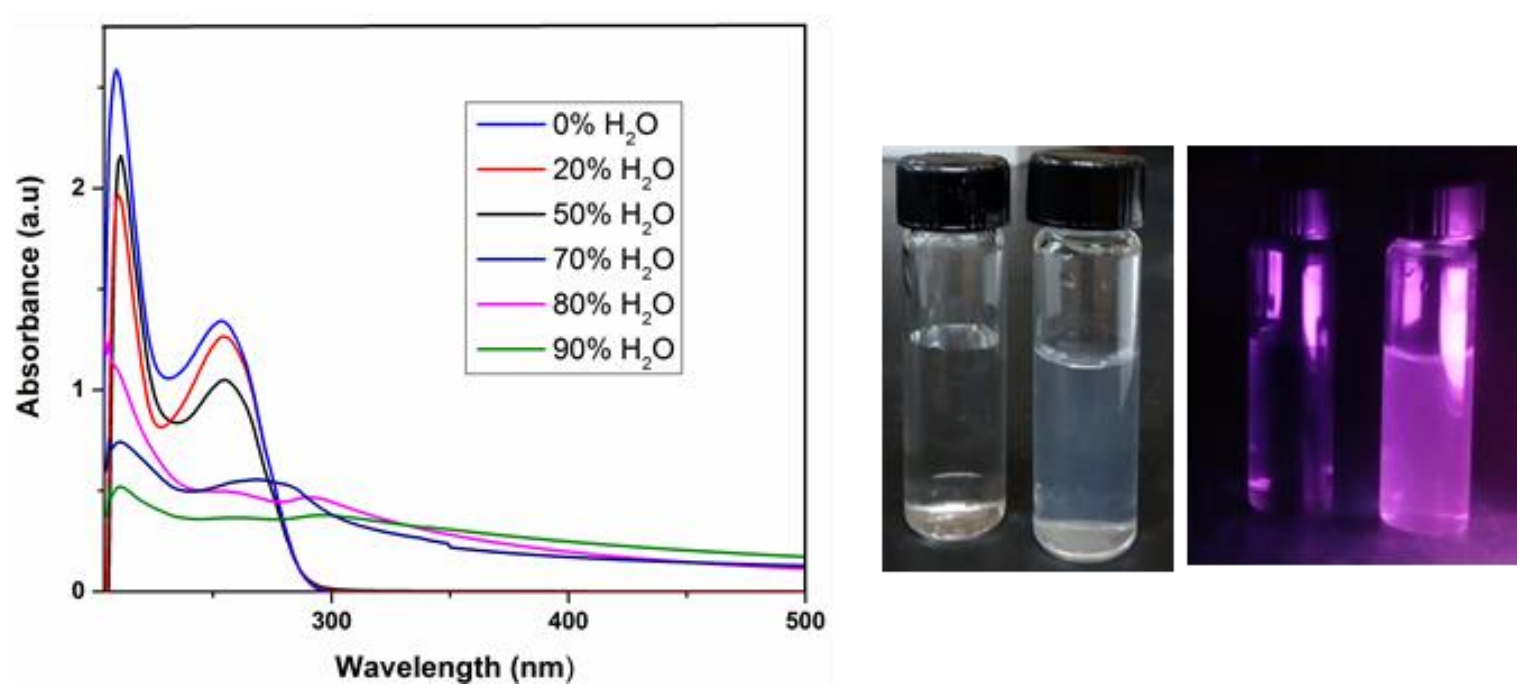

Figure A3.9. (a) UV - visible spectra of $\mathbf{3 . 2}$ in THF with the addition of water (0 to $90 \%$ ). (b) Photographs of 3.3 before (a) and after (b) in THF and $\mathrm{THF} / \mathrm{H}_{2} \mathrm{O}(20: 80)$ mixture. 


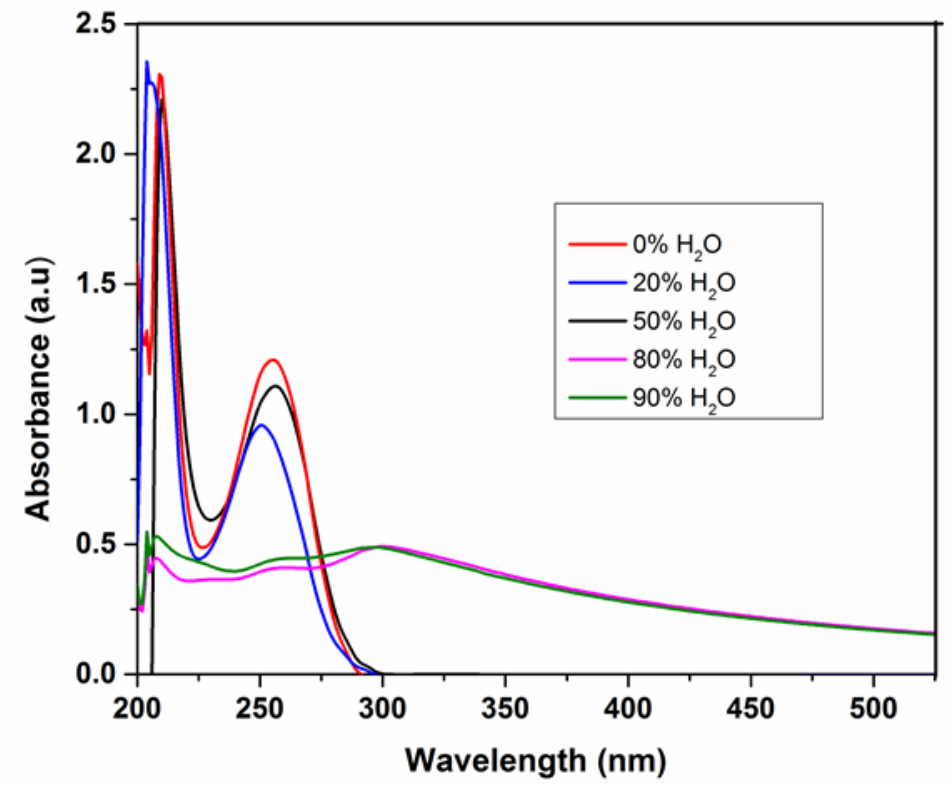

Figure A3.10. UV - visible spectra for 3.1 in THF with the gradual addition of water from 0 to $90 \%$.

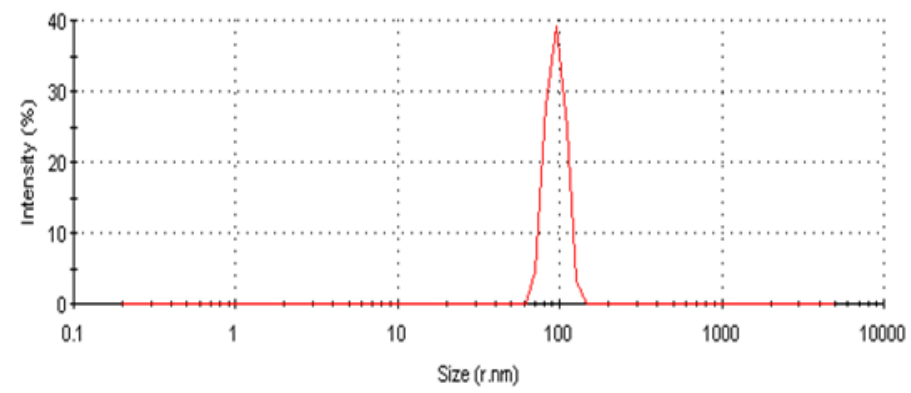

Figure A3.11. DLS data for the aggregates of $\mathbf{3 . 1}(15 \mu \mathrm{M})$ in $\mathrm{THF} / \mathrm{H}_{2} \mathrm{O}(20: 80)$ mixture. 


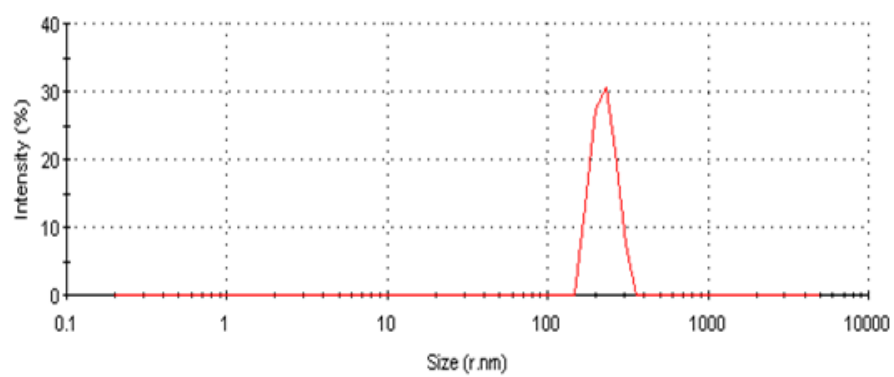

Figure A3.12. DLS data for the aggregates of $\mathbf{3 . 2}(15 \mu \mathrm{M})$ in $\mathrm{THF} / \mathrm{H}_{2} \mathrm{O}(20: 80)$ mixture.

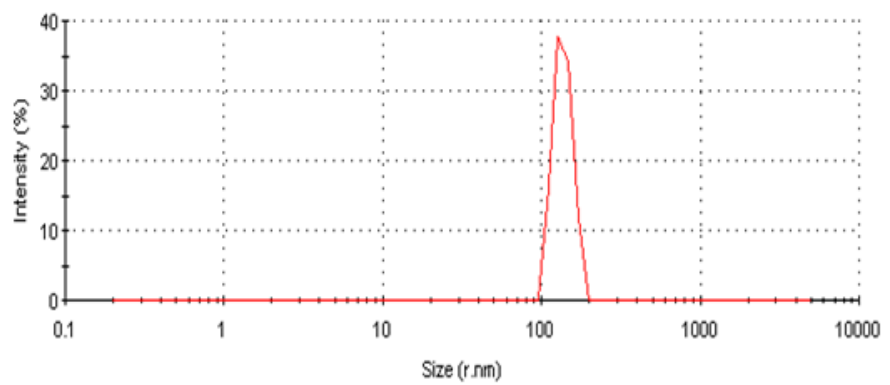

Figure A3.13. DLS data for the aggregates of $\mathbf{3 . 3}(15 \mu \mathrm{M})$ in $\mathrm{THF} / \mathrm{H}_{2} \mathrm{O}(20: 80)$ mixture.

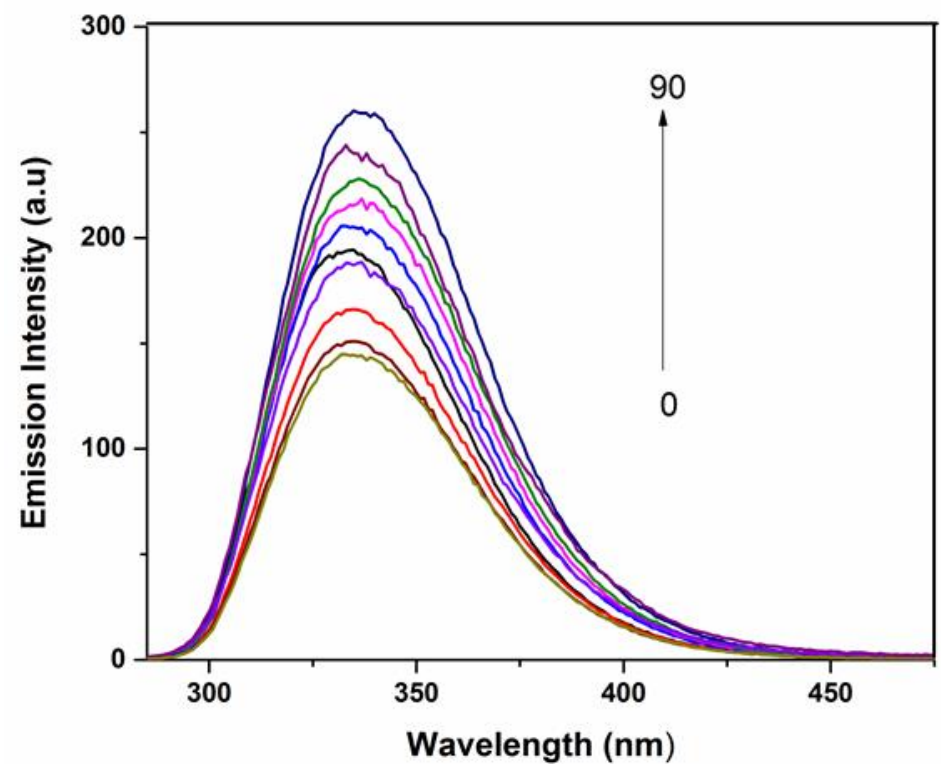

Figure A3.14. Fluorescence spectra of $\mathbf{3 . 2}(15 \mu \mathrm{M})$ with the addition of water from 0 to $90 \%$ into THF. 


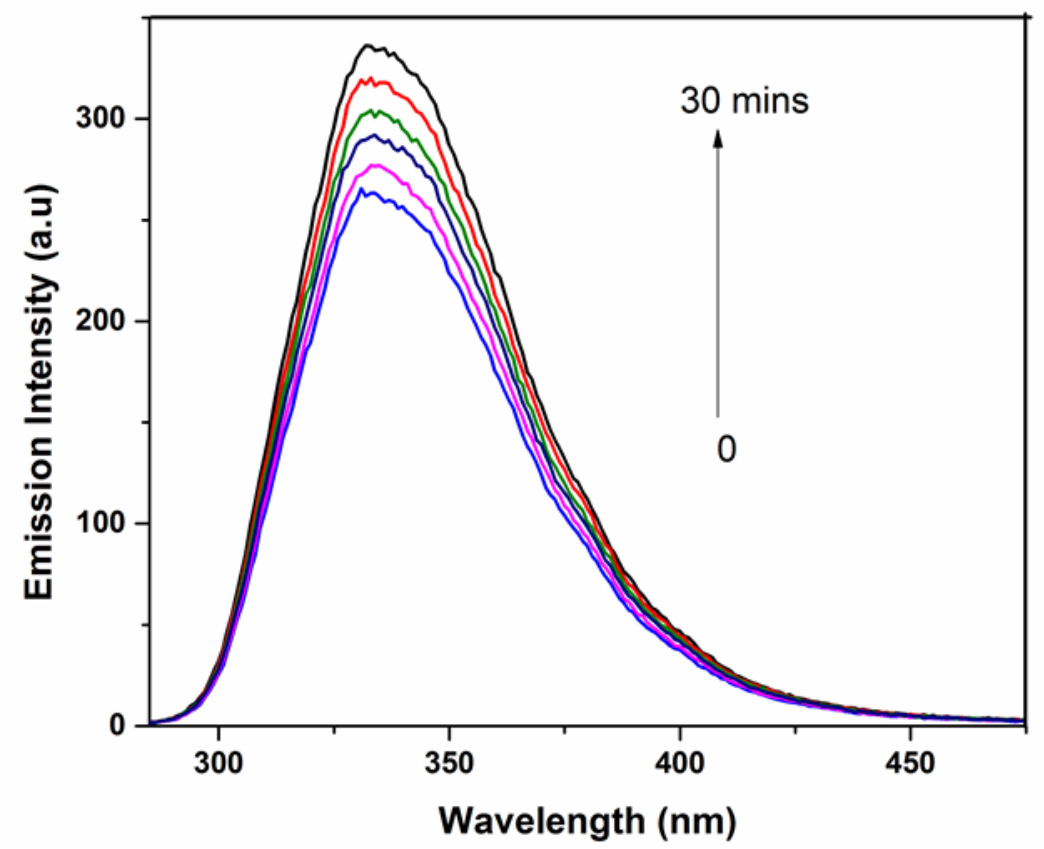

Figure A3.15. Fluorescence spectra of $3.2(15 \mu \mathrm{M})$ in a $\mathrm{THF} / \mathrm{H}_{2} \mathrm{O}$ mixture $(10: 90 \mathrm{v} / \mathrm{v})$ at different aging times. $(\Delta t=5$ mins $)$

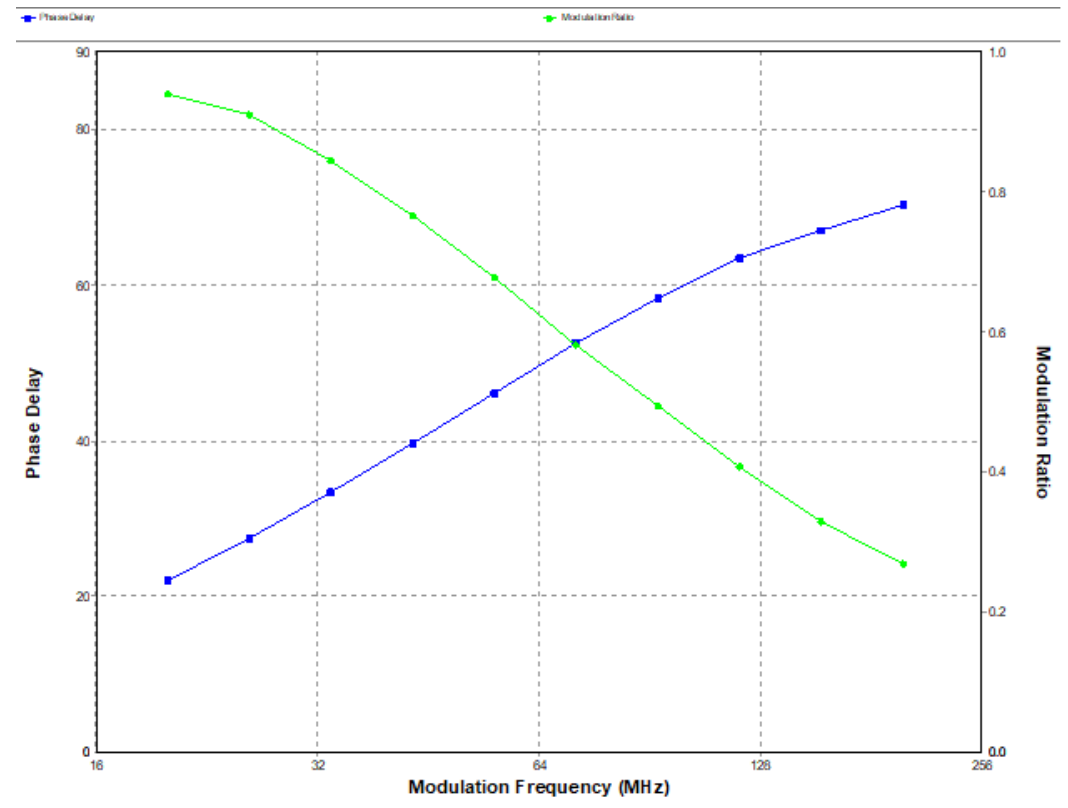

Figure A3.16. Frequency modulation data for 3.2 in THF. $(\tau=1.2 \mathrm{~ns})$ 


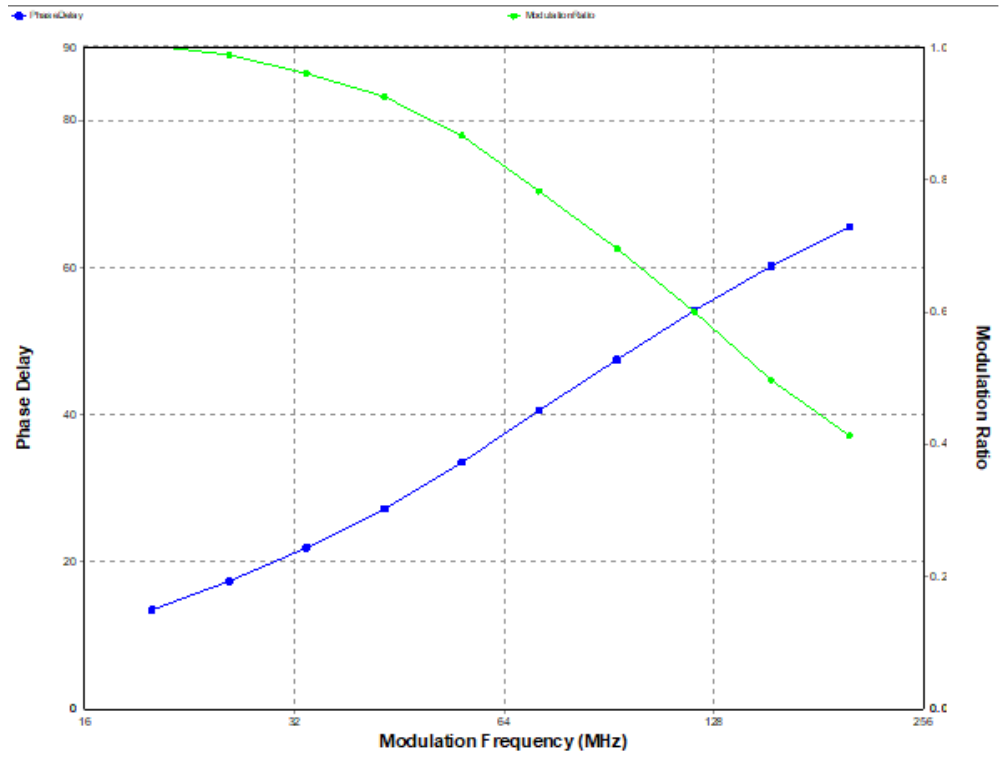

Figure A3.17. Frequency modulation data for 3.2 in $\mathrm{THF} / \mathrm{H}_{2} \mathrm{O}(10: 90)$ mixture. $(\tau=1.8 \mathrm{~ns})$


Figure A3.18. Variation of fluorescence intensity of compound 3.1 \& $3.2(15 \mu \mathrm{M})$ in THF/ethylene glycol (EG) mixture. $(0,20,40,60,80 \& 90$ volume fraction of EG in THF) 




Figure A3.19. Variation of fluorescence intensity of compound $3.3(15 \mu \mathrm{M})$ in THF/ethylene glycol (EG) mixture. $(0,20,40,60,80 \& 90$ volume fraction of $\mathrm{EG}$ in THF)
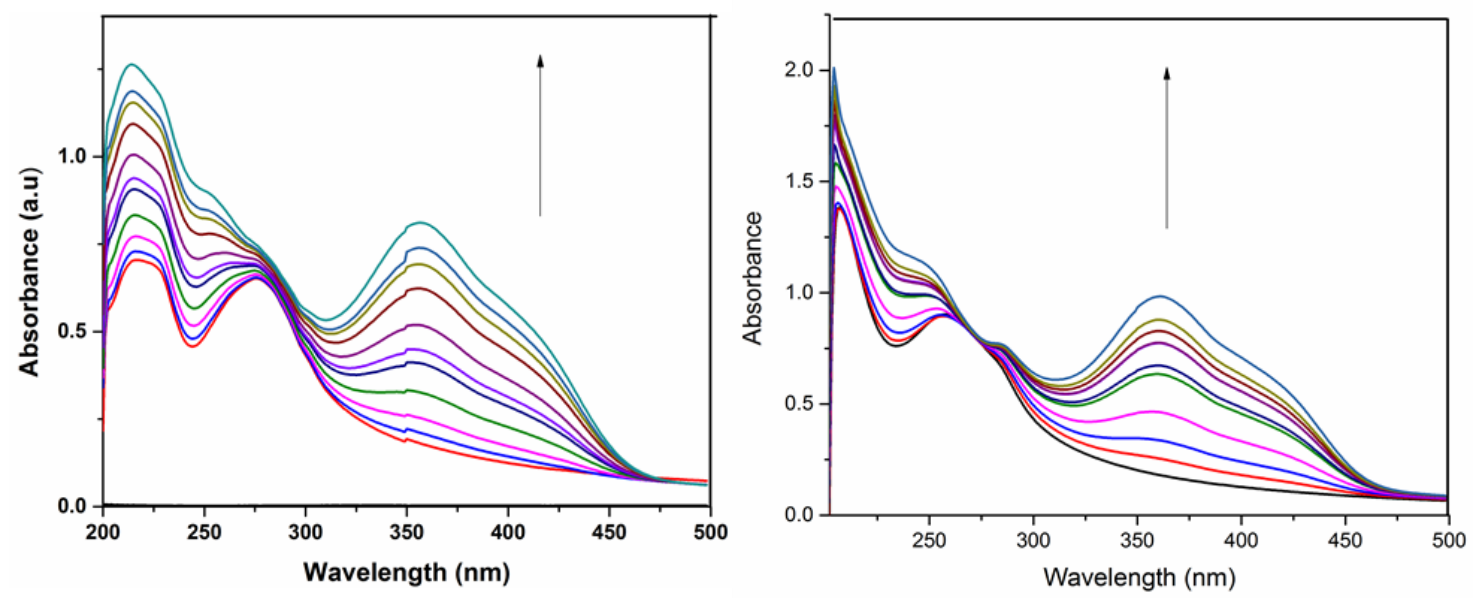

Figure A3.20. Absorption spectral changes of 3.1 \& $3.2(15 \mu \mathrm{M})$ in $\mathrm{THF} / \mathrm{H}_{2} \mathrm{O}(20: 80)$ with the addition of PA (0 to $20 \mu \mathrm{M})$ 


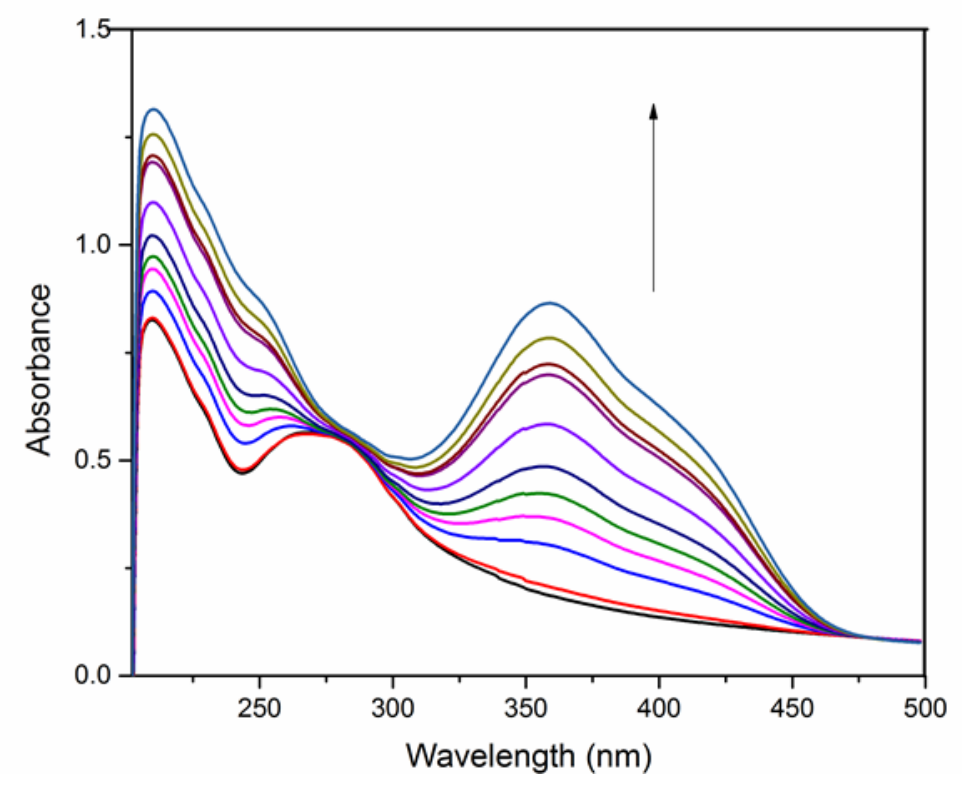

Figure A3.21. Absorption spectral changes of $3.3(15 \mu \mathrm{M})$ in $\mathrm{THF} / \mathrm{H}_{2} \mathrm{O}(20: 80)$ with the addition of PA (0 to $20 \mu \mathrm{M})$

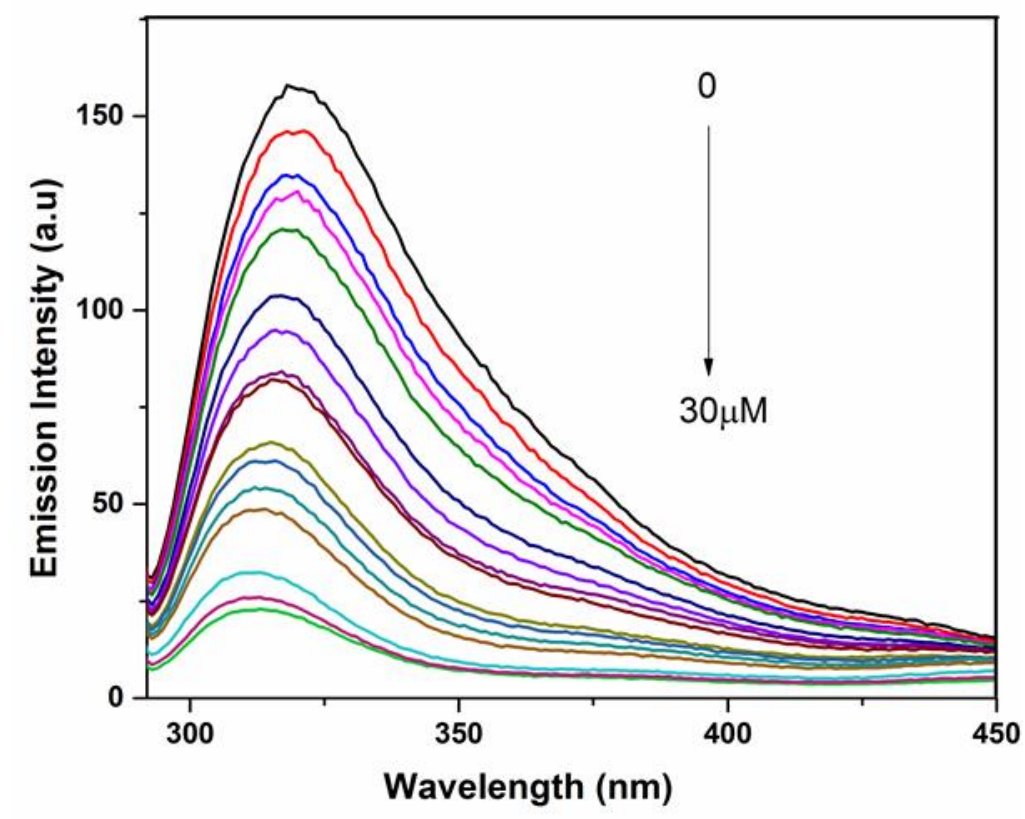

Figure A3.22. Emission spectra of $\mathbf{3 . 3}(15 \mu \mathrm{M})$ in $\mathrm{THF} / \mathrm{H}_{2} \mathrm{O}(20: 80)$ upon addition of PA from 0 to $30 \mu \mathrm{M}$. 



Figure A3.23. (a) Stern-Volmer plot for the complex 3.1 with PA (b) SV plot obtain at lower concentration of PA.
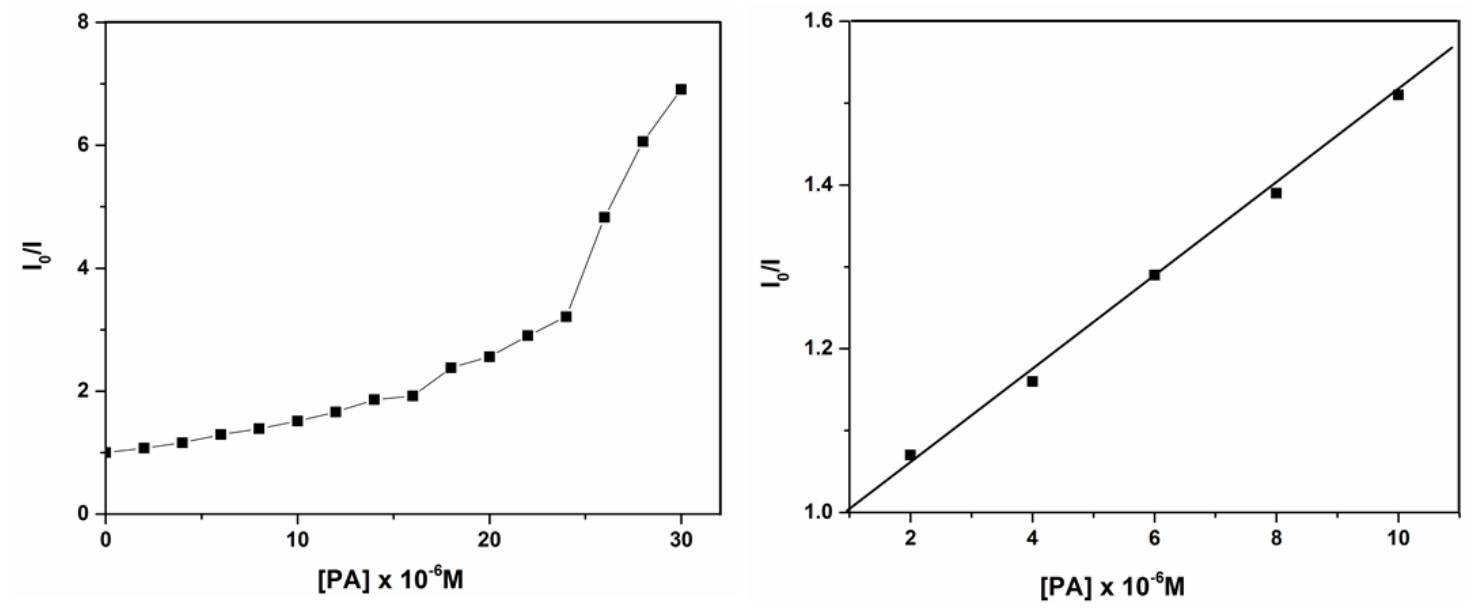

Figure A3.24. (a) Stern-Volmer plot for the complex 3.3 with PA (b) SV plot obtain at lower concentration of PA. 


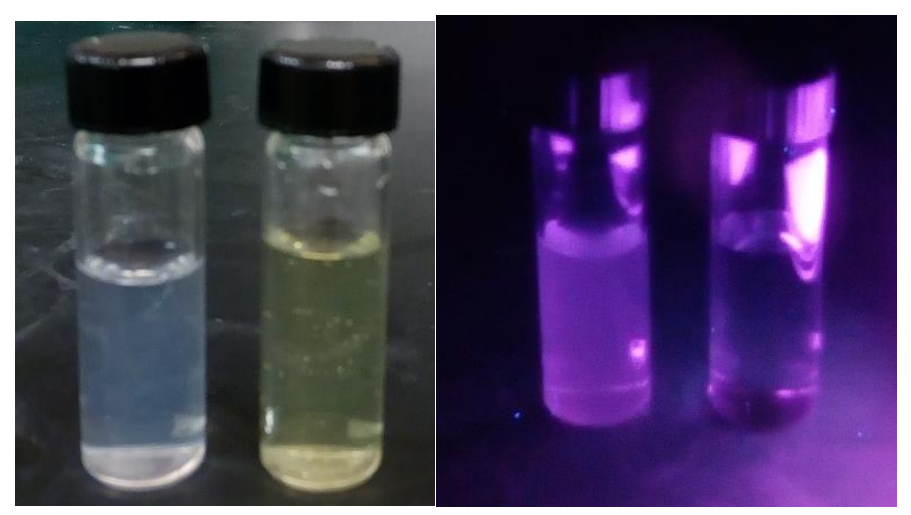

Figure A3.25. Photographs taken before (A) Complex 3.2 and 3.2+PA after (B) Compound 3.2 and 3.2+ PA.

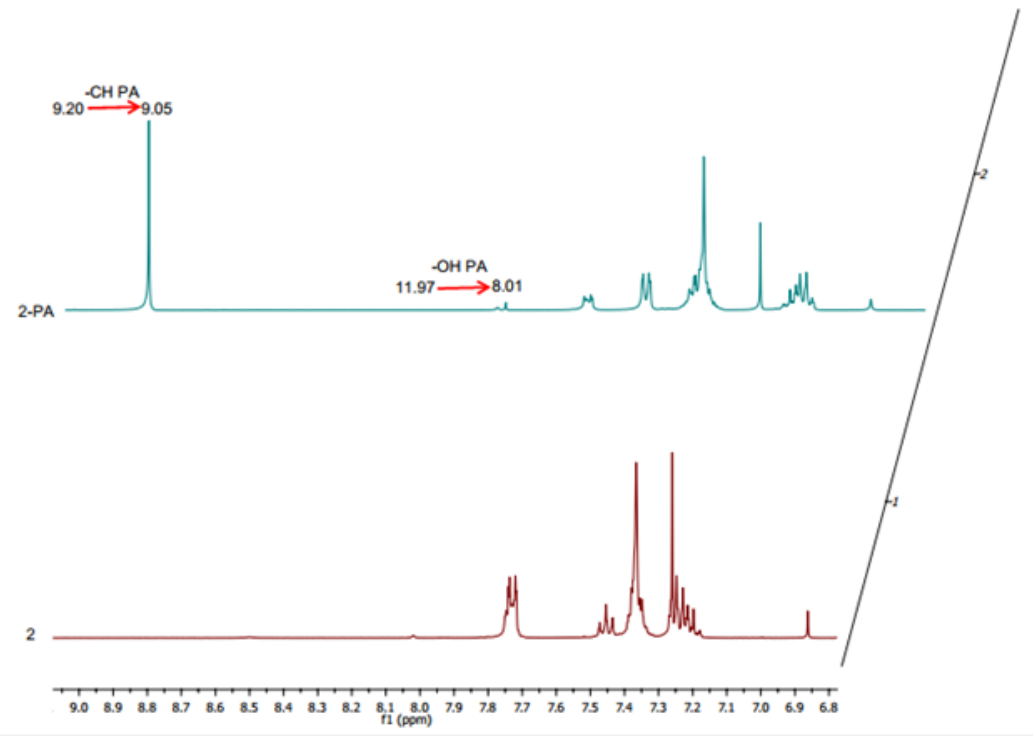

Figure A3.26. Partial ${ }^{1} \mathrm{H}-\mathrm{NMR}$ spectra of 3.2 and 3.2-PA.
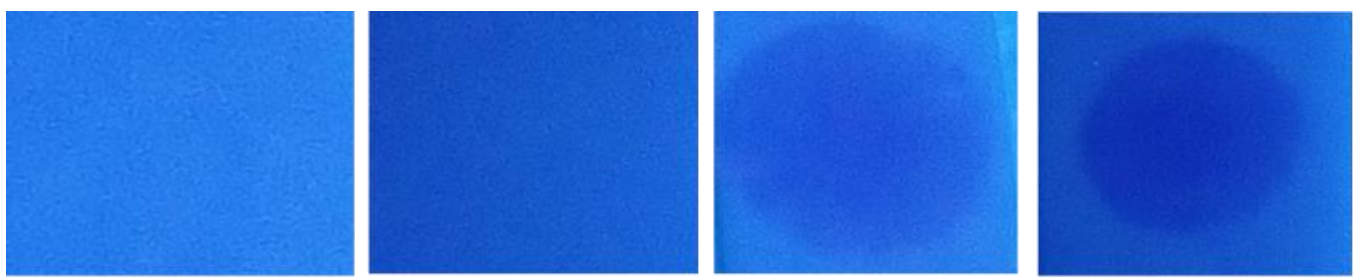
Figure A3.27. Photographs of compound 3.2 impregnated test paper strips upon exposure to the vapors of PA. (0 min, $5 \mathrm{~min}, 10 \mathrm{~min}$ and $20 \mathrm{~min}$ from left to right respectively.
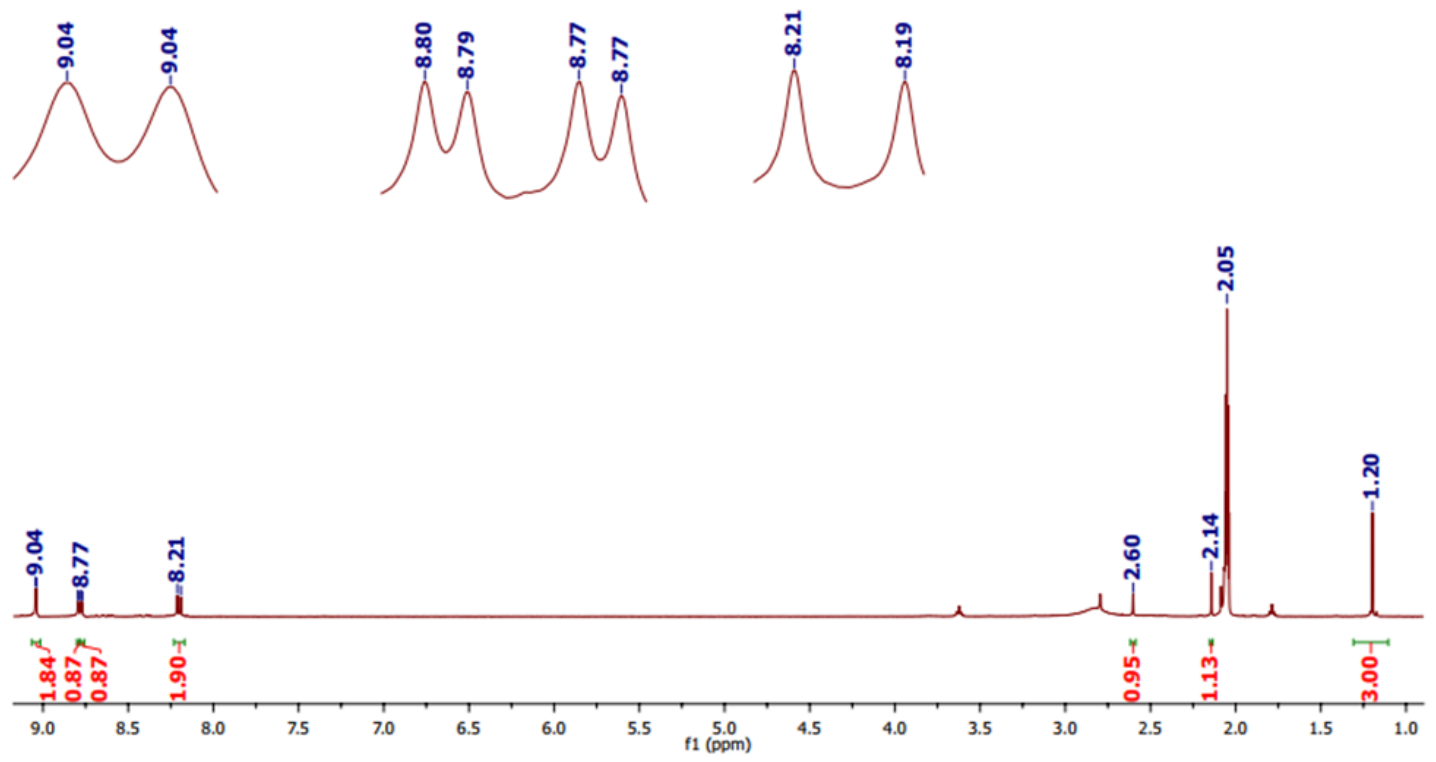

Figure A4.1. ${ }^{1} \mathrm{H}-\mathrm{NMR}$ of 4.1., $\mathrm{CD}_{3} \mathrm{COCD}_{3}$ 


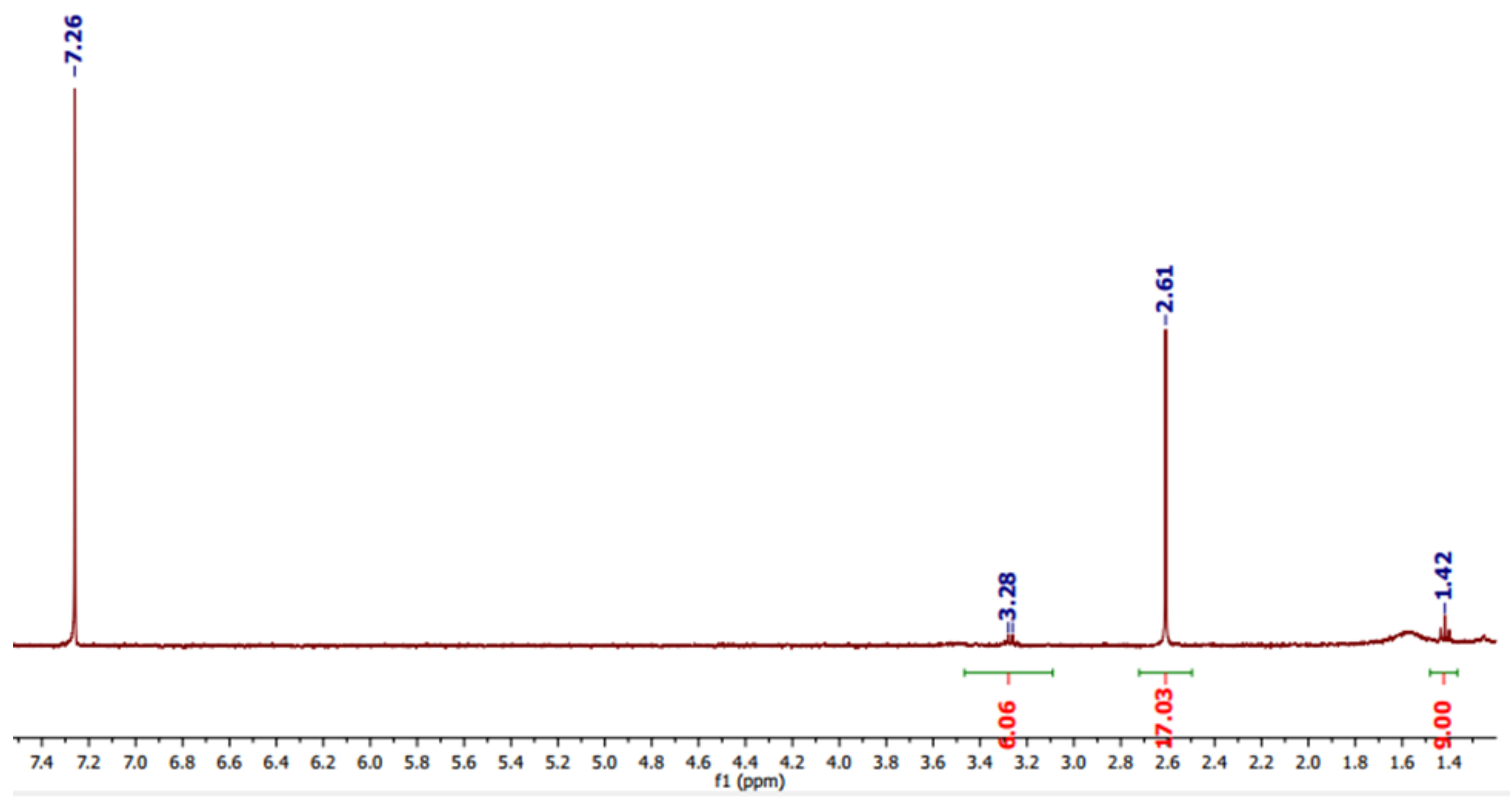

Figure A4.2. ${ }^{1} \mathrm{H}-\mathrm{NMR}$ of 4.2., $\mathrm{CDCl}_{3}$

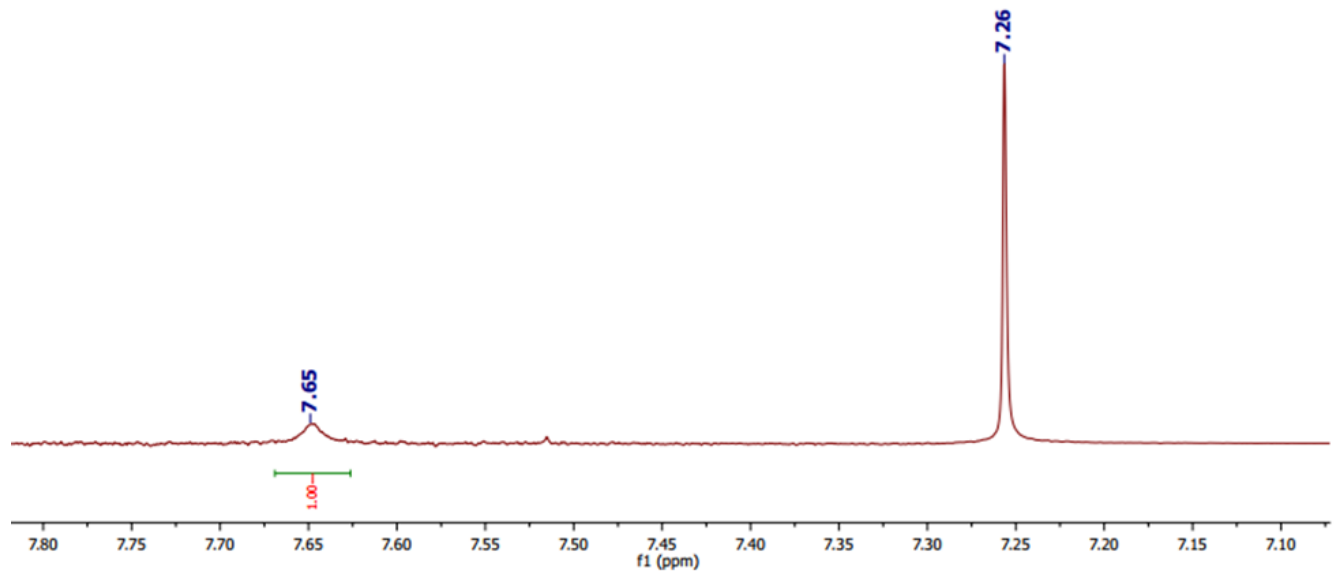

Figure A4.3. ${ }^{1} \mathrm{H}-\mathrm{NMR}$ of 4.5., $\mathrm{CDCl}_{3}$ 


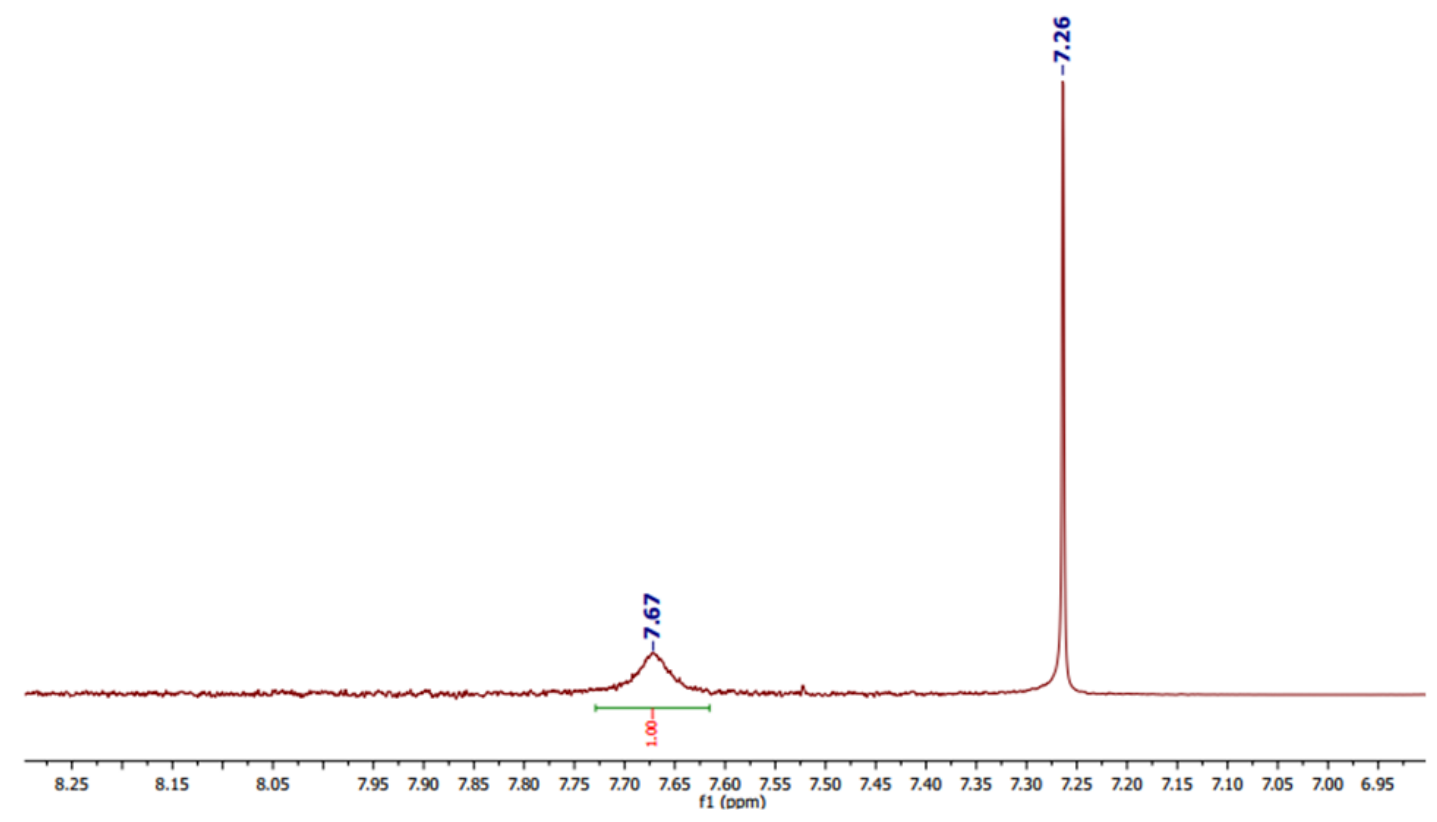

Figure A4.4. ${ }^{1} \mathrm{H}-\mathrm{NMR}$ of 4.6., $\mathrm{CDCl}_{3}$

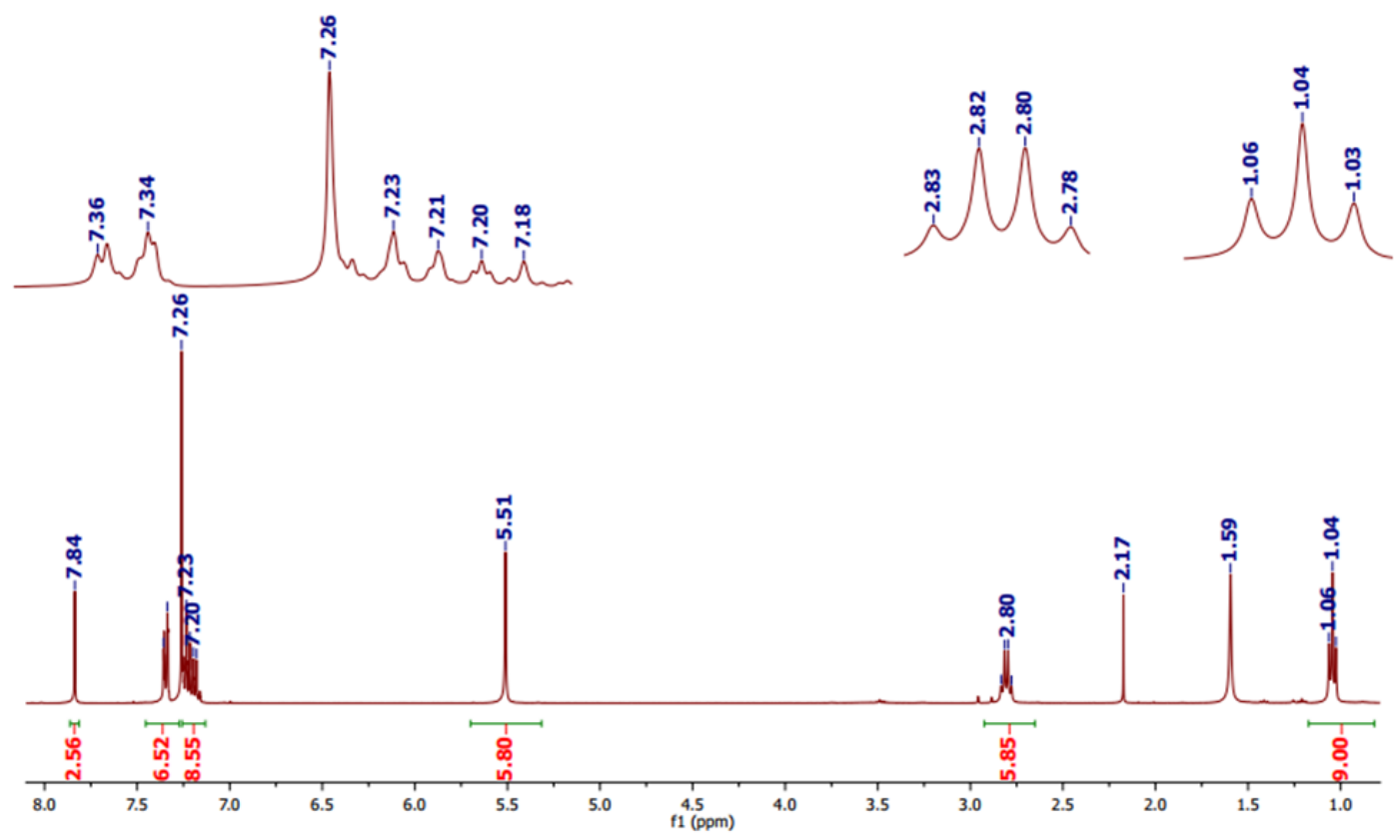

Figure A4.5. ${ }^{1} \mathrm{H}-\mathrm{NMR}$ of 4.7., $\mathrm{CDCl}_{3}$ 



Figure A5.1. Molecular structures of $\mathbf{5 . 1}$ (bottom), $\mathbf{5 . 4}$ (top right) and $\mathbf{5 . 5}$ (top left). Color code: $\mathrm{C}$, black; $\mathrm{H}$, white; $\mathrm{N}$, blue; $\mathrm{Cl}$, green; $\mathrm{O}$, red; $\mathrm{Pd}$, cyan. (H-atoms are omitted for clarity, except for $\mathrm{N}-\mathrm{H}$ in 5.1)
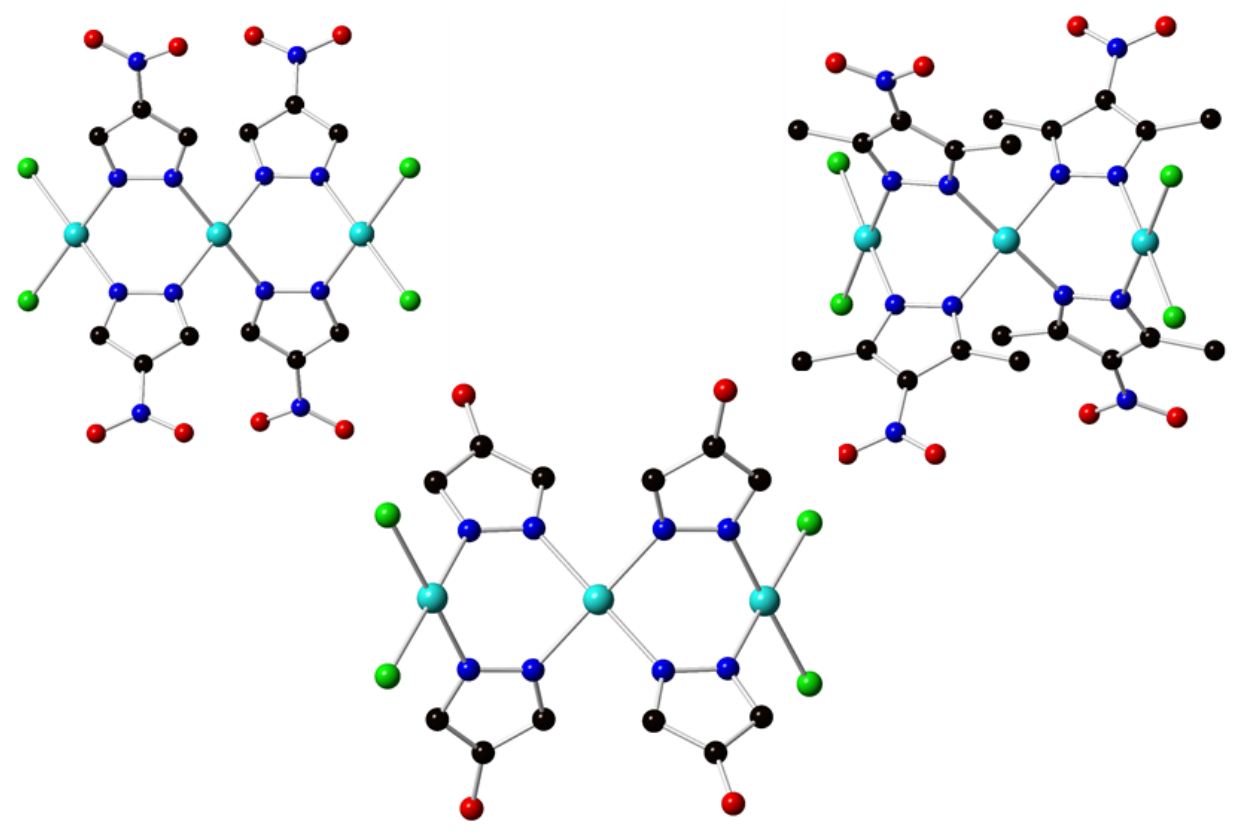

Figure A5.2. Molecular structures of $\mathbf{5 . 6}$ (top right), 5.7 (top left) and $\mathbf{5 . 8}$ (bottom). Color code: $\mathrm{C}$, black; $\mathrm{H}$, white; $\mathrm{N}$, blue; $\mathrm{Cl}$, green; $\mathrm{O}$, red; $\mathrm{Pd}$, cyan. (H-atoms are omitted for clarity) 

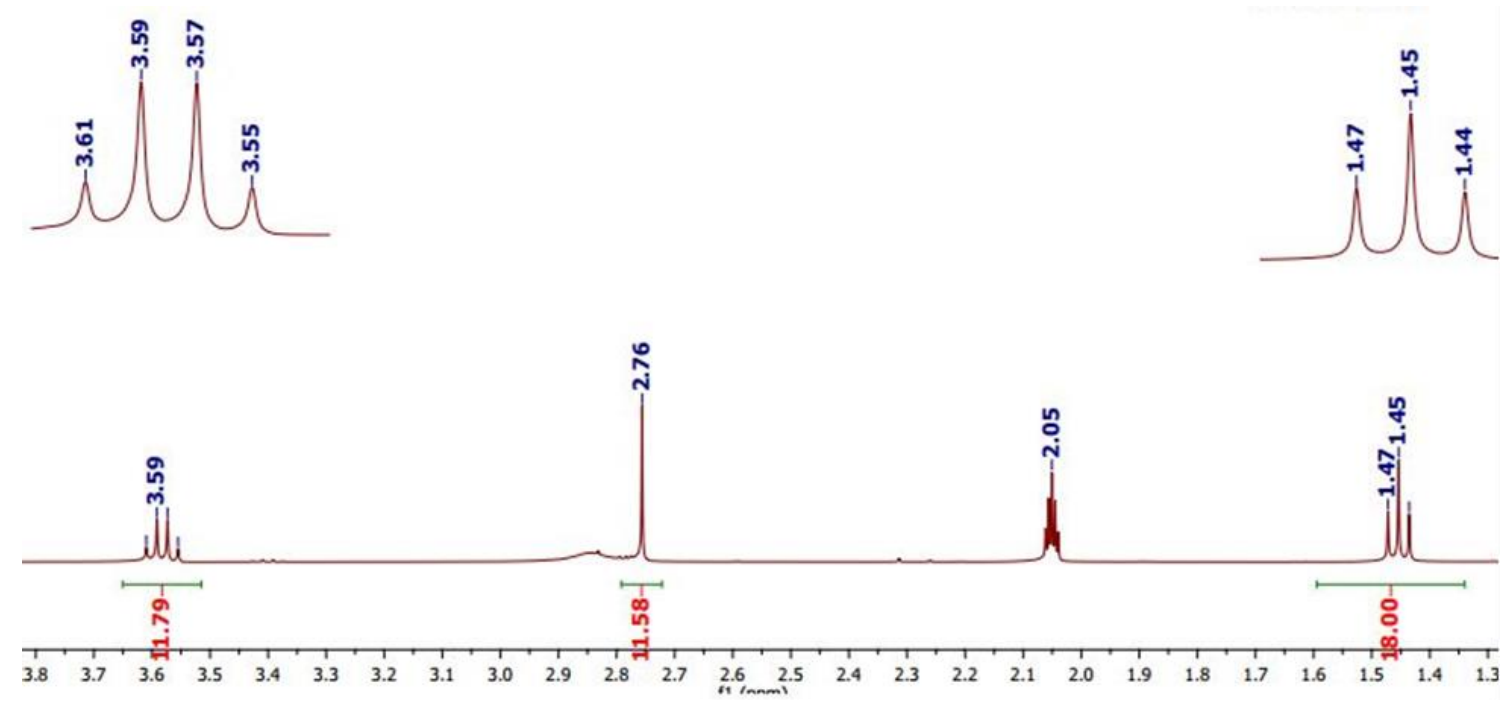

Figure A5.3. ${ }^{1} \mathrm{H}-\mathrm{NMR}$ of 5.3., $\mathrm{CD}_{3} \mathrm{COCD}_{3}$

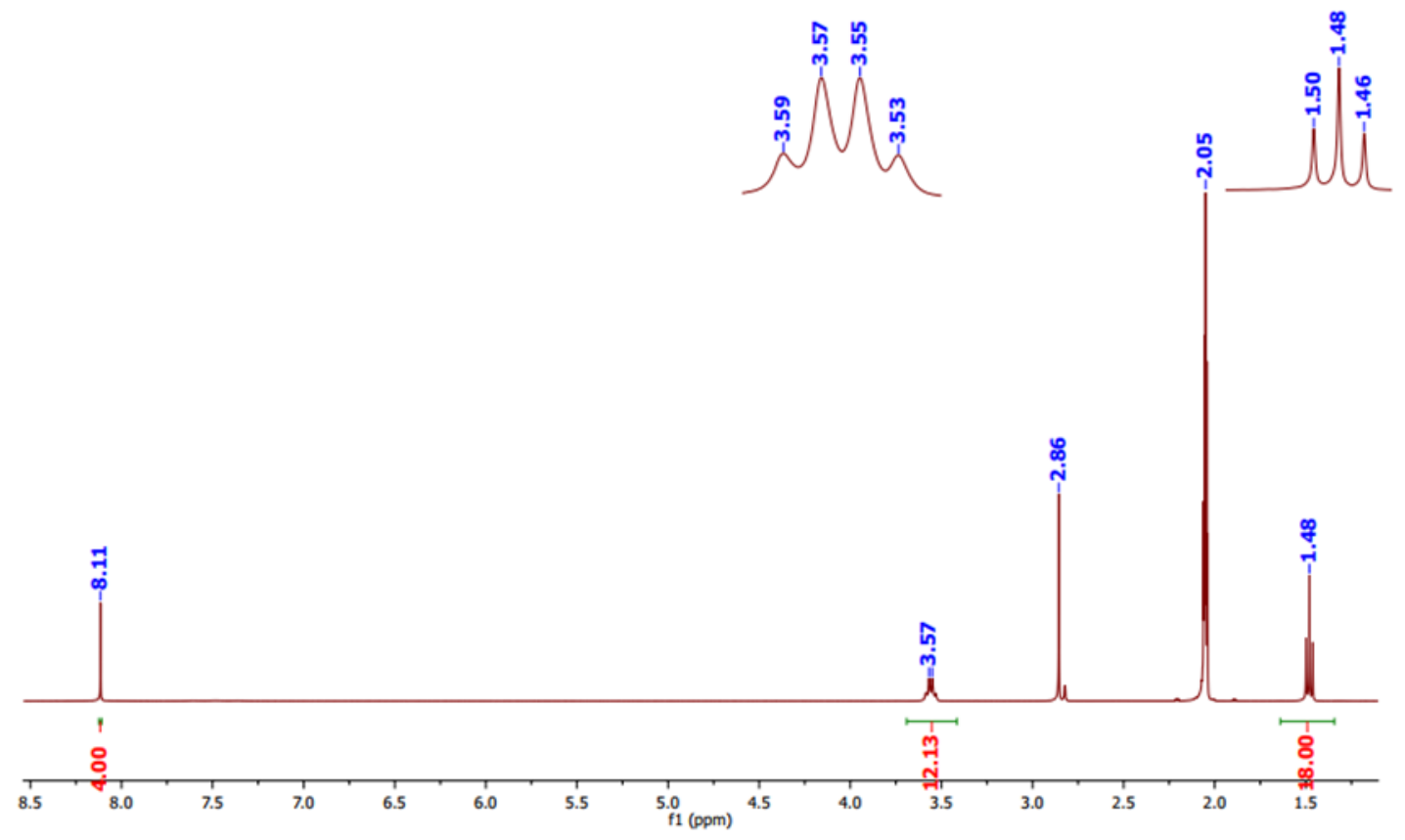

Figure A5.4. ${ }^{1} \mathrm{H}-\mathrm{NMR}$ of 5.4., $\mathrm{CD}_{3} \mathrm{COCD}_{3}$ 

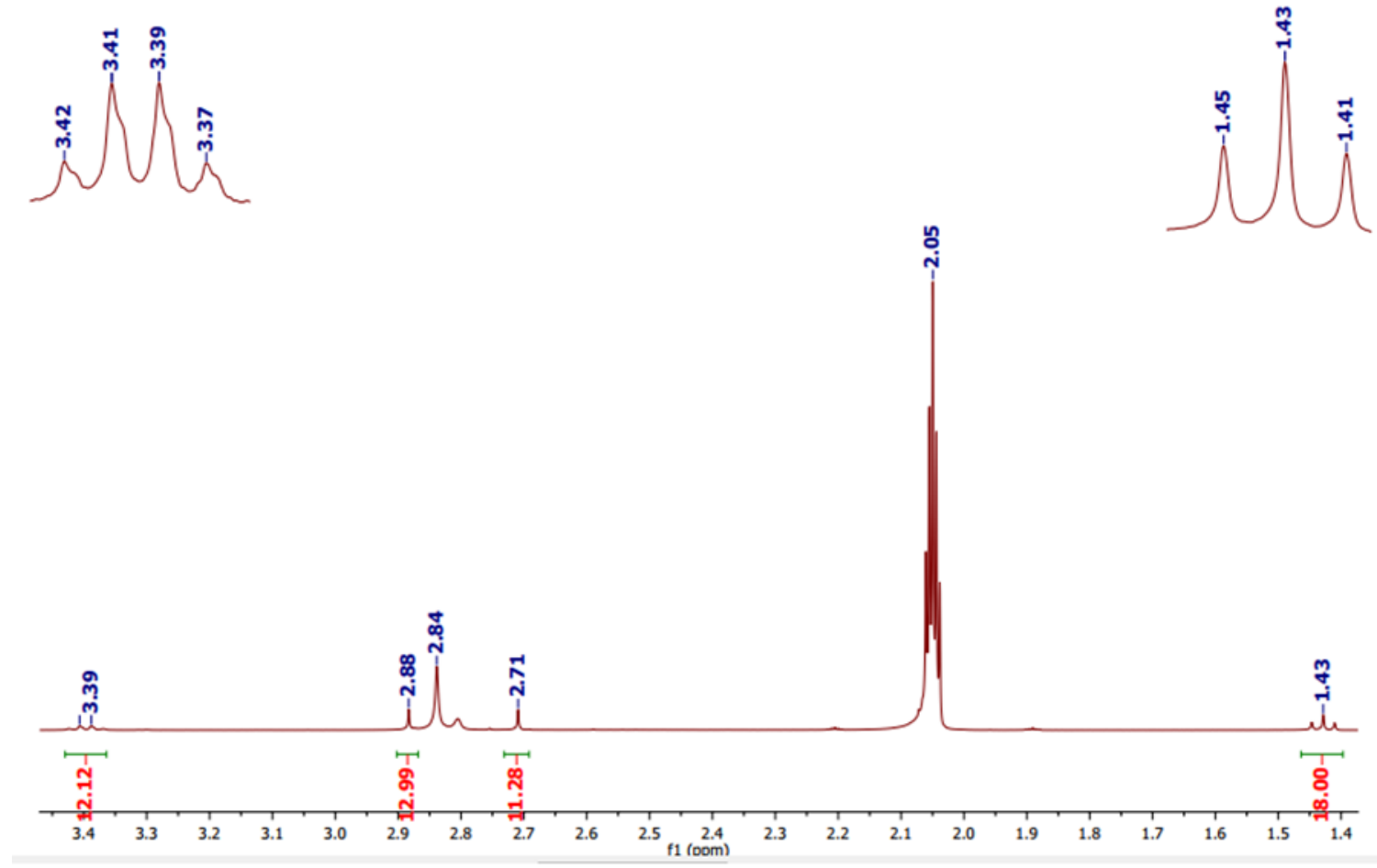

Figure A5.5. ${ }^{1} \mathrm{H}-\mathrm{NMR}$ of 5.6., $\mathrm{CD}_{3} \mathrm{COCD}_{3}$

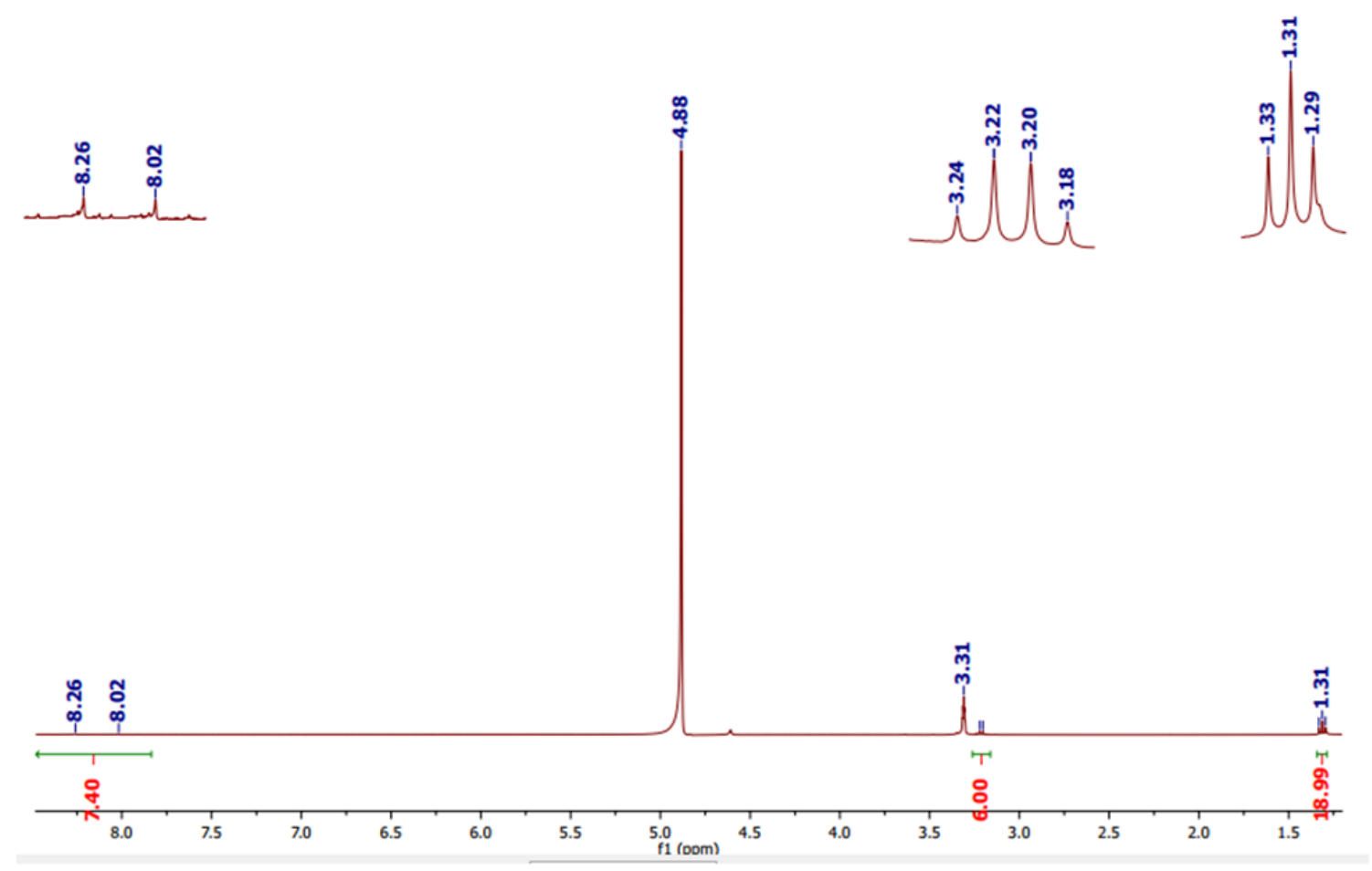

Figure A5.6. ${ }^{1} \mathrm{H}-\mathrm{NMR}$ of 5.6., $\mathrm{CD}_{3} \mathrm{OD}$ 


\section{Tables}

Table A2.1. Crystal data and structure refinement parameters for complexes 2.6-2.8

\begin{tabular}{|c|c|c|c|}
\hline & $\mathrm{C}_{18} \mathrm{H}_{28} \mathrm{Ag}_{2} \mathrm{Cl}_{2} \mathrm{~N}_{10} \mathrm{P}_{2}$ & $\mathrm{C}_{60} \mathrm{H}_{49} \mathrm{Ag}_{2} \mathrm{~N}_{4} \mathrm{Cl}_{2} \mathrm{P}_{3}$ & $\mathrm{C}_{22} \mathrm{H}_{38} \mathrm{Ag}_{2} \mathrm{Cl}_{4} \mathrm{~N}_{10} \mathbf{P}_{2}$ \\
\hline$D_{\text {calc. }} / \mathrm{g} \mathrm{cm}^{-3}$ & 1.610 & 1.722 & 1.747 \\
\hline$\mu / \mathrm{mm}^{-1}$ & 1.602 & 1.627 & 1.605 \\
\hline Formula Weight & 733.08 & 862.10 & 862.10 \\
\hline Color & Colorless & Colorless & Colorless \\
\hline Shape & Block & Block & Block \\
\hline$T / \mathrm{K}$ & $298(2)$ & $298(2)$ & $298(2)$ \\
\hline Crystal System & Monoclinic & Monoclinic & Monoclinic \\
\hline Space Group & $\mathrm{C} 2 / \mathrm{c}$ & $P 21 / n$ & $P 21 / n$ \\
\hline$a / \AA$ & $24.956(7)$ & $6.1657(7)$ & $6.571(3)$ \\
\hline$b / \AA$ & $6.1178(17)$ & $21.732(2)$ & $19.140(9)$ \\
\hline$c / \AA$ & $19.893(6)$ & $12.4739(13)$ & $13.116(6)$ \\
\hline$\alpha l^{\circ}$ & 90 & 90 & 90 \\
\hline$\beta l^{\circ}$ & $95.248(7)$ & $95.841(3)$ & $96.390(9)$ \\
\hline$y^{\circ}$ & 90 & 90 & 90 \\
\hline $\mathrm{V} / \AA^{3}$ & $3024.6(15)$ & $1662.8(3)$ & $1639.3(13)$ \\
\hline$Z$ & 4 & 2 & 2 \\
\hline Wavelength/A & 0.71073 & 0.71073 & 0.71073 \\
\hline Radiation type & Mo-K $\alpha$ & Mo-K $\alpha$ & Mo-K $\alpha$ \\
\hline $2 \theta_{\min } 1^{\circ}$ & 5.49 & 6.51 & 6.25 \\
\hline$\left.2 \theta_{\max }\right|^{\circ}$ & 53 & 52.86 & 53.80 \\
\hline Measured Refl. & 21517 & 28168 & 27783 \\
\hline Independent Refl. & 3127 & 3412 & 3523 \\
\hline Reflections Used & 2442 & 1868 & 2560 \\
\hline$R_{\text {int }}$ & 0.069 & 0.15 & 0.069 \\
\hline Parameters & 154 & 182 & 182 \\
\hline${ }^{\mathrm{a}} \mathrm{GooF}$ & 1.087 & 1.070 & 1.116 \\
\hline${ }^{c} w R_{2}$ & 0.0944 & 0.11 & 0.0843 \\
\hline${ }^{b} R_{1}$ & 0.0453 & 0.074 & 0.0461 \\
\hline
\end{tabular}

${ }^{\mathrm{a}} \mathrm{GOF}=\left[\Sigma\left[\omega\left(\mathrm{F}_{\mathrm{o}}^{2}-\mathrm{F}_{\mathrm{c}}{ }^{2}\right)^{2}\right] /\left(\mathrm{N}_{\mathrm{o}}-\mathrm{N}_{\mathrm{v}}\right)\right]^{1 / 2}\left(\mathrm{~N}_{\mathrm{o}}=\right.$ number of observations, $\mathrm{N}_{\mathrm{v}}=$ number of variables $)$. ${ }^{\mathrm{b}} \mathrm{R}_{1}=\Sigma|| \mathrm{F}_{\mathrm{o}}|-| \mathrm{F}_{\mathrm{c}}|| / \Sigma\left|\mathrm{F}_{\mathrm{o}}\right| \cdot{ }^{\mathrm{c}} \mathrm{WR}_{2}=\left[\left(\Sigma \omega\left(\mathrm{F}_{\mathrm{o}}{ }^{2}-\mathrm{F}_{\mathrm{c}}{ }^{2}\right)^{2} / \Sigma\left|\mathrm{F}_{\mathrm{o}}\right|{ }^{2}\right)\right]^{1 / 2}$ 
Table A2.2. Selected bond distances $(\AA)$ and angles $\left(^{\circ}\right)$ for $\mathbf{2 . 3}$

\begin{tabular}{|c|c|c|c|}
\hline & \multicolumn{2}{|r|}{ Complex 2.3} & \\
\hline Ag1-P1 & \multicolumn{2}{|r|}{$2.5017(12)$} & \\
\hline Ag1-P2 & \multicolumn{2}{|r|}{$2.4868(12)$} & \\
\hline Ag1-N1 & \multicolumn{2}{|r|}{$2.307(4)$} & \\
\hline $\mathrm{Ag} 1-\mathrm{N} 2 \mathrm{a}$ & \multicolumn{2}{|r|}{$2.378(4)$} & \\
\hline P2-Ag1-P1 & \multicolumn{2}{|r|}{$120.75(4)$} & \\
\hline $\mathrm{N} 1-\mathrm{Ag} 1-\mathrm{P} 2$ & \multicolumn{2}{|r|}{$110.74(11)$} & \\
\hline $\mathrm{N} 1-\mathrm{Ag} 1-\mathrm{P} 1$ & \multicolumn{2}{|r|}{$114.88(11)$} & \\
\hline $\mathrm{N} 1-\mathrm{Ag} 1-\mathrm{N} 2 \mathrm{a}$ & \multicolumn{2}{|r|}{$96.10(14)$} & \\
\hline $\mathrm{N} 2 \mathrm{a}-\mathrm{Ag} 1-\mathrm{P} 2$ & \multicolumn{2}{|r|}{$105.86(11)$} & \\
\hline $\mathrm{N} 2-\mathrm{Ag} 1-\mathrm{P} 1$ & \multicolumn{2}{|r|}{$104.75(10)$} & \\
\hline \multicolumn{4}{|c|}{ The a-labeled atoms are generated by the $-x+1,-y+2,-z+1$ symmetry operation } \\
\hline \multicolumn{4}{|c|}{ Table A2.3. Selected bond distances $(\AA)$ and angles $\left({ }^{\circ}\right)$ for $\mathbf{2 . 4}$} \\
\hline & \multicolumn{3}{|c|}{ Complex 2.4} \\
\hline Ag1-P1 & $2.4694(8)$ & Ag2-P3 & $2.3789(8)$ \\
\hline Ag1-P2 & $2.4948(8)$ & Ag2-N5 & $2.187(3)$ \\
\hline Ag1-N1 & $2.373(3)$ & $\mathrm{Ag} 2-\mathrm{N} 2$ & $2.278(3)$ \\
\hline Ag1-N4 & $2.355(3)$ & & \\
\hline P1-Ag1-P2 & $124.62(3)$ & N5-Ag2-P3 & $144.74(8)$ \\
\hline N4-Ag1-P2 & $105.26(8)$ & $\mathrm{N} 5-\mathrm{Ag} 2-\mathrm{N} 2$ & $105.06(11)$ \\
\hline N4-Ag1-P1 & $115.20(7)$ & $\mathrm{N} 2-\mathrm{Ag} 2-\mathrm{P} 3$ & $109.14(8)$ \\
\hline N4-Ag1-N1 & $97.24(11)$ & & \\
\hline N1-Ag1-P2 & $108.56(8)$ & & \\
\hline N1-Ag1-P1 & $102.28(8)$ & & \\
\hline
\end{tabular}


Table A2.4. Selected bond distances $(\AA)$ and angles $\left(^{\circ}\right)$ for $\mathbf{2 . 6 - 2 . 8}$

\begin{tabular}{llll}
\hline & $\mathbf{2 . 6}$ & $\mathbf{2 . 7}$ & $\mathbf{2 . 8}$ \\
\hline Ag1-P1 & $2.3630(12)$ & $2.3618(19)$ & $2.3654(13)$ \\
Ag1-N1 & $2.224(4)$ & $2.169(6)$ & $2.186(3)$ \\
Ag1-N2 & $2.238(4)$ & $2.263(6)$ & $2.251(4)$ \\
N1-Ag1-P1 & $126.73(10)$ & $132.66(17)$ & $133.31(10)$ \\
N1-Ag1-N2 & $107.47(13)$ & $108.3(2)$ & $108.48(12)$ \\
N21-Ag1-P1 & $125.67(10)$ & $116.53(17)$ & $117.72(10)$ \\
\hline
\end{tabular}

Table A3.1. ${ }^{1} \mathrm{H}$ NMR shifts (ppm) 3.1, 3.3-3.5

\begin{tabular}{|c|c|c|c|c|c|}
\hline Compound & $\mathrm{A}(9 \mathrm{H}, \mathrm{t})$ & $\mathrm{B}(6 \mathrm{H}, \mathrm{q})$ & $\mathrm{C}(6 \mathrm{H}, \mathrm{s})$ & Phenyl protons & $\begin{array}{l}\text { Pyrazolyl } \\
\text { Protons }\end{array}$ \\
\hline $\begin{array}{l}{[3.1](\mathrm{ppm},} \\
\left.\left(\mathrm{CD}_{3}\right)_{2} \mathrm{SO}\right)\end{array}$ & 0.88 & 2.87 & 5.44 & $\begin{array}{l}7.16(3 \mathrm{H}, \mathrm{t}) \\
7.29(6 \mathrm{H}, \mathrm{t}) \\
7.51(6 \mathrm{H}, \mathrm{d})\end{array}$ & $\begin{array}{l}7.89(3 \mathrm{H}, \mathrm{s}) \\
7.96(3 \mathrm{H}, \mathrm{s})\end{array}$ \\
\hline$[3.3]\left(\mathrm{ppm}, \mathrm{CDCl}_{3}\right)$ & 1.02 & 2.82 & 5.50 & $\begin{array}{l}7.16-7.24(9 \mathrm{H}) \\
7.37(3 \mathrm{H}, \mathrm{S})\end{array}$ & $\begin{array}{l}7.33(3 \mathrm{H}, \mathrm{s}) \\
7.81(3 \mathrm{H}, \mathrm{s})\end{array}$ \\
\hline$[3.4]\left(\mathrm{ppm}, \mathrm{CDCl}_{3}\right)$ & 1.05 & 2.84 & 5.53 & $\begin{array}{l}7.51(6 \mathrm{H}, \mathrm{d}) \\
8.12(6 \mathrm{H}, \mathrm{d})\end{array}$ & $\begin{array}{l}7.53(3 \mathrm{H}, \mathrm{s}) \\
7.89(3 \mathrm{H}, \mathrm{s})\end{array}$ \\
\hline$[3.5]\left(\mathrm{ppm}, \mathrm{CDCl}_{3}\right)$ & 0.93 & 2.71 & 5.43 & & $\begin{array}{l}7.07(3 \mathrm{H}, \mathrm{s}) \\
7.55(3 \mathrm{H}, \mathrm{s})\end{array}$ \\
\hline A: $-\mathrm{CH}_{3}$ (ethyl) & & $\mathrm{CH}_{2}$ (ethyl) & $\mathrm{C}:-$ & $\left.-\mathrm{CH}_{2}-\mathrm{pz}^{*}\right)$ & \\
\hline
\end{tabular}


Table A3.2. ${ }^{1} \mathrm{H}$ NMR spectra of ligands (3.1-3.3) and ligands + picric acid in $\mathrm{CDCl}_{3}$.

\begin{tabular}{|c|c|c|c|c|c|c|c|}
\hline Compounds & $\begin{array}{l}\text { A } \\
(9 H, t)\end{array}$ & $\begin{array}{l}\mathrm{B} \\
(6 \mathrm{H}, \mathrm{q})\end{array}$ & $\begin{array}{l}\mathrm{C} \\
(6 \mathrm{H}, \mathrm{s})\end{array}$ & $\begin{array}{l}\mathrm{D} \\
{[3 \mathrm{H}, \mathrm{s}, \mathrm{Pz}-} \\
\mathrm{C}(3)]\end{array}$ & $\begin{array}{l}{[18 \mathrm{H}, \text { benzene ring }+} \\
\mathrm{Pz}-\mathrm{C}(5)]\end{array}$ & $\begin{array}{l}\mathrm{PA}(\mathrm{s}, \\
-\mathrm{CH})\end{array}$ & $\begin{array}{l}\mathrm{PA}(\mathrm{s},- \\
\mathrm{OH})\end{array}$ \\
\hline $\begin{array}{l}\mathrm{PA} \\
{[3.1]}\end{array}$ & 1.05 & 2.82 & 5.50 & 7.82 & $\begin{array}{l}7.25(9 \mathrm{H}), 7.34+7.36 \\
(9 \mathrm{H})\end{array}$ & 9.20 & 11.97 \\
\hline $\begin{array}{l}{[3.1-\mathrm{PA}]} \\
(1: 1)\end{array}$ & 1.06 & 2.81 & 5.53 & 7.85 & $\begin{array}{l}7.24(9 \mathrm{H}), 7.30(3 \mathrm{H}) \\
7.34+7.36(6 \mathrm{H})\end{array}$ & 9.13 & 7.30 \\
\hline $\begin{array}{l}{[3.1-\mathrm{PA}]} \\
(1: 2)\end{array}$ & 1.06 & 2.81 & 5.54 & 7.86 & $7.24(9 \mathrm{H}), 7.34(9 \mathrm{H})$ & 9.15 & 7.32 \\
\hline $\begin{array}{l}{[3.1-\mathrm{PA}]} \\
(1: 3)\end{array}$ & 1.07 & 2.81 & 5.57 & 7.89 & $\begin{array}{l}7.23(6 \mathrm{H}), 7.27(3 \mathrm{H}), \\
7.36(9 \mathrm{H})\end{array}$ & 9.14 & 7.38 \\
\hline Compounds & $\begin{array}{l}\text { A } \\
(9 \mathrm{H}, \mathrm{t})\end{array}$ & $\begin{array}{l}\text { B } \\
(6 \mathrm{H}, \mathrm{q})\end{array}$ & $\begin{array}{l}\text { C } \\
(6 \mathrm{H}, \mathrm{s})\end{array}$ & $\begin{array}{l}\mathrm{D} \\
{[3 \mathrm{H}, \mathrm{s}, \mathrm{Pz}-} \\
\mathrm{C}(4)]\end{array}$ & Benzene ring $(30 \mathrm{H})$ & $\begin{array}{l}\text { PA (s, } \\
-\mathrm{CH})\end{array}$ & $\begin{array}{l}\mathrm{PA}(\mathrm{s},- \\
\mathrm{OH})\end{array}$ \\
\hline$[3.2]$ & 0.65 & 2.56 & 5.25 & 6.56 & $\begin{array}{l}7.18-7.24(6 \mathrm{H}), 7.36 \\
(15 \mathrm{H}), 7.43-7.47 \\
(3 \mathrm{H}), 7.73(6 \mathrm{H})\end{array}$ & & \\
\hline $\begin{array}{l}{[3.2-\mathrm{PA}]} \\
(1: 1)\end{array}$ & 0.73 & 2.59 & 5.29 & 6.57 & $\begin{array}{l}7.11-7.17(9 \mathrm{H}), 7.43 \\
(12 \mathrm{H}), 7.59(6 \mathrm{H}), 7.77 \\
(3 \mathrm{H})\end{array}$ & 9.05 & 8.01 \\
\hline Compounds & $\begin{array}{l}\text { A } \\
(9 \mathrm{H}, \mathrm{t})\end{array}$ & $\begin{array}{l}\mathrm{B} \\
(6 \mathrm{H}, \mathrm{q})\end{array}$ & $\begin{array}{l}\mathrm{C} \\
(6 \mathrm{H}, \mathrm{s})\end{array}$ & $\begin{array}{l}\text { D } \\
{[3 \mathrm{H}, \mathrm{s}, \mathrm{Pz}-} \\
\mathrm{C}(3)]\end{array}$ & $\begin{array}{l}{[15 \mathrm{H}, \text { benzene ring }+} \\
\mathrm{Pz}-\mathrm{C}(5)]\end{array}$ & $\begin{array}{l}\mathrm{PA}(\mathrm{s}, \\
-\mathrm{CH})\end{array}$ & $\begin{array}{l}\mathrm{PA}(\mathrm{s},- \\
\mathrm{OH})\end{array}$ \\
\hline [3.3] & 1.02 & 2.82 & 5.50 & 7.81 & $\begin{array}{l}7.16-7.24(9 \mathrm{H}), 7.37 \\
(3 \mathrm{H}) \\
7.33(3 \mathrm{H})\end{array}$ & & \\
\hline $\begin{array}{l}{[3.3-\mathrm{PA}]} \\
(1: 1)\end{array}$ & 1.04 & 2.82 & 5.52 & 7.84 & $\begin{array}{l}7.15-7.23(9 \mathrm{H}), 7.36- \\
7.38(6 \mathrm{H})\end{array}$ & 9.16 & 7.36 \\
\hline
\end{tabular}


Table A4.1. Crystallographic table of Hg complexes [4.1-4.3]

\begin{tabular}{|c|c|c|c|}
\hline Empirical formula & $\mathrm{C}_{6} \mathrm{H}_{4} \mathrm{Cl}_{4} \mathrm{Hg}_{2} \mathrm{I}_{2} \mathrm{~N}_{4}[\mathbf{4 . 1}]$ & $\mathrm{C}_{42} \mathrm{H}_{58} \mathrm{Cl}_{4} \mathrm{Hg}_{4} \mathrm{~N}_{20} \mathrm{O}_{12}[$ [4.2] & $\mathrm{C}_{5} \mathrm{H}_{3} \mathrm{Cl}_{2} \mathrm{Hg}_{2.5} \mathrm{~N}_{3} \mathrm{O}_{4}[4.3]$ \\
\hline Formula weight & 928.91 & 1979.24 & 741.48 \\
\hline Temperature/K & $298(2)$ & $298(2)$ & $298(2)$ \\
\hline Crystal system & Triclinic & orthorhombic & Monoclinic \\
\hline Space group & $\mathrm{P}-1$ & $\mathrm{P} 2{ }_{1} 2_{1} 2_{1}$ & $\mathrm{P} 2{ }_{1} / \mathrm{c}$ \\
\hline $\mathrm{a} / \AA$ & $8.379(6)$ & $15.6614(16)$ & $8.6198(7)$ \\
\hline $\mathrm{b} / \AA$ & $9.977(6)$ & $19.778(2)$ & $18.7637(15)$ \\
\hline $\mathrm{c} / \AA$ & $10.808(6)$ & $21.694(2)$ & $8.1631(7)$ \\
\hline$\alpha /^{\circ}$ & $75.757(15)$ & 90 & 90 \\
\hline$\beta /{ }^{\circ}$ & $80.29(2)$ & 90 & $115.656(2)$ \\
\hline$\gamma /{ }^{\circ}$ & $74.81(2)$ & 90 & 90 \\
\hline Volume $/ \AA^{3}$ & $839.9(9)$ & $6719.6(12)$ & $1190.13(17)$ \\
\hline $\mathrm{Z}$ & 2 & 4 & 4 \\
\hline$\rho_{\text {calc }} \mathrm{g} / \mathrm{cm}^{3}$ & 3.673 & 1.956 & 4.138 \\
\hline$\mu / \mathrm{mm}^{-1}$ & 22.556 & 9.335 & 32.637 \\
\hline $\mathrm{F}(000)$ & 804.0 & 3736.0 & 1280.0 \\
\hline Radiation & $\operatorname{MoK} \alpha(\lambda=0.71073)$ & $\operatorname{MoK} \alpha(\lambda=0.71076)$ & $\operatorname{MoK} \alpha(\lambda=0.71076)$ \\
\hline $2 \Theta$ range for data collection $/^{\circ}$ & 5.858 to 52.86 & 5.902 to 48.36 & 5.948 to 52.916 \\
\hline Index ranges & $\begin{array}{l}-10 \leq \mathrm{h} \leq 10,-12 \leq \mathrm{k} \leq 12,- \\
13 \leq 1 \leq 13\end{array}$ & $\begin{array}{l}-17 \leq \mathrm{h} \leq 18,-22 \leq \mathrm{k} \leq 22,- \\
24 \leq 1 \leq 24\end{array}$ & $\begin{array}{l}-10 \leq \mathrm{h} \leq 10,-23 \leq \mathrm{k} \leq 23,- \\
10 \leq 1 \leq 10\end{array}$ \\
\hline Reflections collected & 8083 & 113981 & 21737 \\
\hline Independent reflections & $\begin{array}{l}3337\left[\mathrm{R}_{\text {int }}=0.0441, \mathrm{R}_{\text {sigma }}=\right. \\
0.0549]\end{array}$ & $\begin{array}{l}10707\left[\mathrm{R}_{\text {int }}=0.0548, \mathrm{R}_{\text {sigma }}=\right. \\
0.0398]\end{array}$ & $\begin{array}{l}2451\left[\mathrm{R}_{\text {int }}=0.0334, \mathrm{R}_{\text {sigma }}=\right. \\
0.0188]\end{array}$ \\
\hline Data/restraints/parameters & $3337 / 0 / 163$ & $10707 / 961 / 747$ & $2451 / 0 / 152$ \\
\hline Goodness-of-fit on $\mathrm{F}^{2}$ & 1.144 & 1.005 & 1.115 \\
\hline Final $R$ indexes $[I>=2 \sigma(I)]$ & $\mathrm{R}_{1}=0.0558, \mathrm{wR}_{2}=0.1578$ & $\mathrm{R}_{1}=0.0537, \mathrm{wR}_{2}=0.0981$ & $\mathrm{R}_{1}=0.0311, \mathrm{wR}_{2}=0.0815$ \\
\hline Final $\mathrm{R}$ indexes [all data] & $\mathrm{R}_{1}=0.0930, \mathrm{wR}_{2}=0.1721$ & $\mathrm{R}_{1}=0.1186, \mathrm{wR}_{2}=0.1232$ & $\mathrm{R}_{1}=0.0373, \mathrm{wR}_{2}=0.0842$ \\
\hline Largest diff. peak/hole / e $\AA^{-3}$ & $2.70 /-3.73$ & $0.99 /-1.09$ & $2.50 /-2.11$ \\
\hline
\end{tabular}


Table A4.2. Crystallographic table of $\mathrm{Hg}$ complexes [4.4-4.6]

\begin{tabular}{|c|c|c|c|}
\hline Empirical formula & $\begin{array}{l}\mathrm{C}_{5} \mathrm{H}_{6} \mathrm{ClHgN}_{3} \mathrm{O}_{2} \\
{[\mathbf{4 . 4}]}\end{array}$ & $\begin{array}{l}\mathrm{C}_{6} \mathrm{H}_{6} \mathrm{Cl}_{4} \mathrm{Hg}_{2} \mathrm{I}_{2} \mathrm{~N}_{4} \\
\text { [4.5] }\end{array}$ & $\begin{array}{l}\mathrm{C}_{6} \mathrm{H}_{6} \mathrm{Cl}_{2} \mathrm{HgI}_{2} \mathrm{~N}_{4} \\
{[\text { 4.6] }}\end{array}$ \\
\hline Formula weight & 376.17 & 930.93 & 659.44 \\
\hline Temperature/K & $298(2)$ & $298(2)$ & $298(2)$ \\
\hline Crystal system & orthorhombic & Triclinic & monoclinic \\
\hline Space group & Cmce & $\mathrm{P}-1$ & $\mathrm{P} 2{ }_{1} / \mathrm{c}$ \\
\hline $\mathrm{a} / \AA$ & $23.8871(10)$ & $8.379(6)$ & $4.1895(7)$ \\
\hline $\mathrm{b} / \AA$ & $6.5063(3)$ & $9.977(6)$ & $15.189(2)$ \\
\hline $\mathrm{c} / \AA$ & $10.8561(4)$ & $10.808(6)$ & $10.1794(14)$ \\
\hline$\alpha /{ }^{\circ}$ & 90 & $75.757(15)$ & 90 \\
\hline$\beta /{ }^{\circ}$ & 90 & $80.29(2)$ & $94.619(4)$ \\
\hline$\gamma /{ }^{\circ}$ & 90 & $74.81(2)$ & 90 \\
\hline Volume $/ \AA^{3}$ & $1687.22(12)$ & $839.9(9)$ & $645.66(16)$ \\
\hline Z & 8 & 2 & 2 \\
\hline$\rho_{\text {calc }} \mathrm{g} / \mathrm{cm}^{3}$ & 2.962 & 3.681 & 3.392 \\
\hline$\mu / \mathrm{mm}^{-1}$ & 18.522 & 22.555 & 17.089 \\
\hline $\mathrm{F}(000)$ & 1360.0 & 808.0 & 580.0 \\
\hline Crystal size $/ \mathrm{mm}^{3}$ & $\begin{array}{l}0.055 \times 0.048 \times \\
0.045\end{array}$ & $\begin{array}{l}0.273 \times 0.19 \times \\
0.075\end{array}$ & $\begin{array}{l}0.13 \times 0.12 \times \\
0.075\end{array}$ \\
\hline Radiation & $\begin{array}{l}\operatorname{MoK} \alpha(\lambda= \\
0.71076)\end{array}$ & $\begin{array}{l}\operatorname{MoK} \alpha(\lambda= \\
0.71073)\end{array}$ & $\begin{array}{l}\operatorname{MoK} \alpha(\lambda= \\
0.71076)\end{array}$ \\
\hline $\begin{array}{l}2 \Theta \text { range for data } \\
\text { collection }^{\circ}\end{array}$ & 6.824 to 52.752 & 6.424 to 52.86 & 6.702 to 52.66 \\
\hline Index ranges & $\begin{array}{l}-29 \leq \mathrm{h} \leq 29,-8 \\
\leq \mathrm{k} \leq 8,-13 \leq 1 \leq \\
13\end{array}$ & $\begin{array}{l}-10 \leq \mathrm{h} \leq 10,-12 \\
\leq \mathrm{k} \leq 12,-13 \leq 1 \\
\leq 13\end{array}$ & $\begin{array}{l}-5 \leq \mathrm{h} \leq 5,-18 \leq \\
\mathrm{k} \leq 18,-12 \leq 1 \leq \\
12\end{array}$ \\
\hline Reflections collected & 10810 & 8018 & 8603 \\
\hline Independent reflections & $\begin{array}{l}887\left[\mathrm{R}_{\text {int }}=\right. \\
0.0313, \mathrm{R}_{\text {sigma }}= \\
0.0160]\end{array}$ & $\begin{array}{l}3314\left[\mathrm{R}_{\text {int }}=\right. \\
0.0441, \mathrm{R}_{\text {sigma }}= \\
0.0549]\end{array}$ & $\begin{array}{l}1314\left[\mathrm{R}_{\text {int }}=\right. \\
0.0231, \mathrm{R}_{\text {sigma }}= \\
0.0155]\end{array}$ \\
\hline Data/restraints/parameters & $887 / 0 / 60$ & $3314 / 0 / 157$ & $1314 / 0 / 70$ \\
\hline Goodness-of-fit on $\mathrm{F}^{2}$ & 1.068 & 1.144 & 1.216 \\
\hline Final $R$ indexes $[\mathrm{I}>=2 \sigma(\mathrm{I})]$ & $\begin{array}{l}\mathrm{R}_{1}=0.0238 \\
\mathrm{wR}_{2}=0.0559\end{array}$ & $\begin{array}{l}\mathrm{R}_{1}=0.0551 \\
\mathrm{wR}_{2}=0.1530\end{array}$ & $\begin{array}{l}\mathrm{R}_{1}=0.0189 \\
\mathrm{wR}_{2}=0.0420\end{array}$ \\
\hline Final $\mathrm{R}$ indexes [all data] & $\begin{array}{l}\mathrm{R}_{1}=0.0303 \\
\mathrm{wR}_{2}=0.0582\end{array}$ & $\begin{array}{l}\mathrm{R}_{1}=0.0916 \\
\mathrm{wR}_{2}=0.1688\end{array}$ & $\begin{array}{l}\mathrm{R}_{1}=0.0216 \\
\mathrm{wR}_{2}=0.0427\end{array}$ \\
\hline $\begin{array}{l}\text { Largest diff. peak/hole / e } \\
\AA^{-3}\end{array}$ & $2.50 /-1.28$ & $2.67 /-3.86$ & $0.45 /-1.22$ \\
\hline
\end{tabular}


Table A5.1. Crystallographic table of 5.1, 5.4, 5.5.

\begin{tabular}{|c|c|c|c|}
\hline Empirical formula & $\mathrm{C}_{12} \mathrm{H}_{20} \mathrm{Cl}_{2} \mathrm{~N}_{4} \mathrm{O}_{2} \mathrm{Pd}[5.1]$ & $\mathrm{C}_{30} \mathrm{H}_{53} \mathrm{Cl}_{8} \mathrm{~N}_{16} \mathrm{O}_{8} \mathrm{Pd}_{4}[5.4]$ & $\mathrm{C}_{11} \mathrm{H}_{22.5} \mathrm{Cl}_{2} \mathrm{~N}_{3} \mathrm{OPd}$ [5.5] \\
\hline Formula weight & 429.62 & 1475.08 & 390.12 \\
\hline Temperature/K & $298(2)$ & $298(2)$ & $298(2)$ \\
\hline Crystal system & Triclinic & Triclinic & Triclinic \\
\hline Space group & $\mathrm{P}-1$ & $\mathrm{P}-1$ & $\mathrm{P}-1$ \\
\hline $\mathrm{a} / \AA ̊ \AA$ & $7.2002(9)$ & $11.9582(9)$ & $9.3256(6)$ \\
\hline $\mathrm{b} / \AA$ & $8.0525(10)$ & $12.7550(10)$ & $12.4381(8)$ \\
\hline $\mathrm{c} / \AA ̊ \AA$ & $8.2801(11)$ & $19.2701(15)$ & $14.5995(10)$ \\
\hline$\alpha /^{\circ}$ & $112.642(3)$ & $86.753(2)$ & $87.859(2)$ \\
\hline$\beta /{ }^{\circ}$ & $111.018(3)$ & $79.580(2)$ & $71.663(2)$ \\
\hline$\gamma /{ }^{\circ}$ & $92.970(3)$ & $69.696(2)$ & $85.740(2)$ \\
\hline Volume $/ \AA^{3}$ & $403.43(9)$ & 2711.1(4) & $1602.83(18)$ \\
\hline $\mathrm{Z}$ & 1 & 2 & 4 \\
\hline$\rho_{\text {calc }} \mathrm{g} / \mathrm{cm}^{3}$ & 1.768 & 1.807 & 1.617 \\
\hline$\mu / \mathrm{mm}^{-1}$ & 1.490 & 1.757 & 1.484 \\
\hline $\mathrm{F}(000)$ & 216.0 & 1458.0 & 790.0 \\
\hline Crystal size $/ \mathrm{mm}^{3}$ & $0.224 \times 0.104 \times 0.084$ & $0.169 \times 0.102 \times 0.098$ & $0.300 \times 0.200 \times 0.100$ \\
\hline Radiation & $\operatorname{MoK} \alpha(\lambda=0.71073)$ & $\operatorname{MoK} \alpha(\lambda=0.71073)$ & $\operatorname{MoK} \alpha(\lambda=0.71073)$ \\
\hline $2 \Theta$ range for data collection $/{ }^{\circ}$ & 5.848 to 52.896 & 5.968 to 56.696 & 5.836 to 53.782 \\
\hline Index ranges & $\begin{array}{l}-9 \leq \mathrm{h} \leq 9,-10 \leq \mathrm{k} \leq 10,-10 \\
\leq 1 \leq 10\end{array}$ & $\begin{array}{l}-15 \leq \mathrm{h} \leq 15,-17 \leq \mathrm{k} \leq 17,-25 \\
\leq 1 \leq 25\end{array}$ & $\begin{array}{l}-11 \leq \mathrm{h} \leq 11,-15 \leq \mathrm{k} \leq 15,- \\
18 \leq 1 \leq 18\end{array}$ \\
\hline Reflections collected & 4807 & 66397 & 20929 \\
\hline Independent reflections & $\begin{array}{l}1654\left[R_{\text {int }}=0.0249, R_{\text {sigma }}=\right. \\
0.0285]\end{array}$ & $\begin{array}{l}13191\left[R_{\text {int }}=0.0500, R_{\text {sigma }}=\right. \\
0.0564]\end{array}$ & $\begin{array}{l}6734\left[R_{\text {int }}=0.0220, R_{\text {sigma }}=\right. \\
0.0270]\end{array}$ \\
\hline Data/restraints/parameters & $1654 / 0 / 98$ & $13191 / 0 / 604$ & $6734 / 0 / 342$ \\
\hline Goodness-of-fit on $\mathrm{F}^{2}$ & 1.147 & 1.351 & 0.999 \\
\hline Final $R$ indexes $[\mathrm{I}>=2 \sigma(\mathrm{I})]$ & $\mathrm{R}_{1}=0.0335, \mathrm{wR}_{2}=0.0845$ & $\mathrm{R}_{1}=0.0960, \mathrm{wR}_{2}=0.1376$ & $\mathrm{R}_{1}=0.0315, \mathrm{wR}_{2}=0.0804$ \\
\hline Final $\mathrm{R}$ indexes [all data] & $\mathrm{R}_{1}=0.0361, \mathrm{wR}_{2}=0.0861$ & $\mathrm{R}_{1}=0.1233, \mathrm{wR}_{2}=0.1462$ & $\mathrm{R}_{1}=0.0400, \mathrm{wR}_{2}=0.0863$ \\
\hline Largest diff. peak/hole / e $\AA^{-3}$ & $1.37 /-0.56$ & $1.63 /-1.19$ & $1.32 /-0.55$ \\
\hline
\end{tabular}


Table A5.2. Crystallographic table of 5.6-5.8

\begin{tabular}{|c|c|c|c|}
\hline Empirical formula & $\mathrm{C}_{32} \mathrm{H}_{54} \mathrm{Cl}_{4} \mathrm{~N}_{14} \mathrm{O}_{8} \mathrm{Pd}_{3}[5.6]$ & $\mathrm{C}_{24} \mathrm{H}_{40} \mathrm{Cl}_{4} \mathrm{~N}_{14} \mathrm{O}_{8} \mathrm{Pd}_{3}[5.7]$ & $\mathrm{C}_{24} \mathrm{H}_{44} \mathrm{Cl}_{4} \mathrm{~N}_{10} \mathrm{O}_{4} \mathrm{Pd}_{3}[5.8]$ \\
\hline Formula weight & 1223.89 & 1113.70 & 997.69 \\
\hline Temperature/K & $298(2)$ & $298(2)$ & $298(2)$ \\
\hline Crystal system & Triclinic & Triclinic & Monoclinic \\
\hline Space group & $\mathrm{P}-1$ & $\mathrm{P}-1$ & $\mathrm{P} 2{ }_{1} / \mathrm{n}$ \\
\hline $\mathrm{a} / \AA ̊ \AA$ & $10.0414(8)$ & $9.3076(15)$ & $10.2480(5)$ \\
\hline $\mathrm{b} / \AA$ & $11.0767(9)$ & $9.5228(15)$ & $16.2671(7)$ \\
\hline $\mathrm{c} / \AA ̊$ & $11.3946(9)$ & $12.1185(19)$ & $10.4861(5)$ \\
\hline$\alpha /^{\circ}$ & $84.703(2)$ & $84.440(5)$ & 90 \\
\hline$\beta /{ }^{\circ}$ & $89.201(2)$ & $76.779(5)$ & $93.432(2)$ \\
\hline$\gamma /{ }^{\circ}$ & $73.399(2)$ & $74.232(5)$ & 90 \\
\hline Volume $/ \AA^{3}$ & $1209.25(17)$ & $1005.6(3)$ & $1744.95(14)$ \\
\hline $\mathrm{Z}$ & 1 & 1 & 2 \\
\hline$\rho_{\text {calc }} \mathrm{g} / \mathrm{cm}^{3}$ & 1.681 & 1.839 & 1.899 \\
\hline$\mu / \mathrm{mm}^{-1}$ & 1.383 & 1.653 & 1.882 \\
\hline $\mathrm{F}(000)$ & 614.0 & 552.0 & 992.0 \\
\hline Crystal size $/ \mathrm{mm}^{3}$ & $0.224 \times 0.104 \times 0.084$ & $0.092 \times 0.067 \times 0.054$ & $0.123 \times 0.089 \times 0.084$ \\
\hline Radiation & $\operatorname{MoK} \alpha(\lambda=0.71073)$ & $\operatorname{MoK} \alpha(\lambda=0.71073)$ & $\operatorname{MoK} \alpha(\lambda=0.71073)$ \\
\hline $2 \Theta$ range for data collection $/{ }^{\circ}$ & 5.848 to 52.944 & 5.53 to 53.49 & 5.732 to 52.836 \\
\hline Index ranges & $\begin{array}{l}-12 \leq \mathrm{h} \leq 12,-13 \leq \mathrm{k} \leq 13,- \\
14 \leq 1 \leq 14\end{array}$ & $\begin{array}{l}-11 \leq \mathrm{h} \leq 11,-12 \leq \mathrm{k} \leq 12 \\
15 \leq 1 \leq 15\end{array}$ & $\begin{array}{l}-11 \leq \mathrm{h} \leq 11,-12 \leq \mathrm{k} \leq 12,- \\
14 \leq 1 \leq 14\end{array}$ \\
\hline Reflections collected & 15602 & 11672 & 3569 \\
\hline Independent reflections & $\begin{array}{l}4731\left[R_{\text {int }}=0.0413, R_{\text {sigma }}=\right. \\
0.0532]\end{array}$ & $\begin{array}{l}4203\left[R_{\text {int }}=0.0668, R_{\text {sigma }}=\right. \\
0.0944]\end{array}$ & $\begin{array}{l}3569\left[R_{\text {int }}=0.0668, R_{\text {sigma }}=\right. \\
0.1002]\end{array}$ \\
\hline Data/restraints/parameters & $4731 / 0 / 283$ & $4203 / 0 / 248$ & $3569 / 0 / 210$ \\
\hline Goodness-of-fit on $\mathrm{F}^{2}$ & 1.267 & 1.037 & 1.172 \\
\hline Final $R$ indexes $[\mathrm{I}>=2 \sigma(\mathrm{I})]$ & $\mathrm{R}_{1}=0.1036, \mathrm{wR}_{2}=0.1869$ & $\mathrm{R}_{1}=0.0501, \mathrm{wR}_{2}=0.0883$ & $\mathrm{R}_{1}=0.1064, \mathrm{wR}_{2}=0.1857$ \\
\hline Final $\mathrm{R}$ indexes [all data] & $\mathrm{R}_{1}=0.1344, \mathrm{wR}_{2}=0.2064$ & $\mathrm{R}_{1}=0.0994, \mathrm{wR}_{2}=0.1013$ & $\mathrm{R}_{1}=0.1644, \mathrm{w} \mathrm{R}_{2}=0.2050$ \\
\hline Largest diff. peak/hole / e $\AA^{-3}$ & $2.53 /-1.46$ & $0.72 /-0.64$ & $1.32 /-1.37$ \\
\hline
\end{tabular}


VITA

SHAMBHU KANDEL

Born Baglung, Nepal

$2009-2011$

M.S. in Chemistry

Tribhuvan University, Kathmandu, Nepal

Dissertation title: Physico-chemical study of

pollutants in the Bagmati river water

Advisor: Shiva R. Vaidya, Ph.D.

$2013-2019$

$\mathrm{PhD}$ Candidate (expected graduation April 2019)

Florida International University, Miami, FL, USA

Dissertation title: Tuning the coordination properties

of pyrazoles towards specific applications via judicial choice of peripheral substitution

Advisor: Raphael G. Raptis, Ph.D.

2004-2013

Lecturer

High school to university level students

Kathmandu, Nepal

2013-2019

Research and teaching assistant

Florida International University, Miami, FL

\section{PUBLICATIONS AND PRESENTATIONS}

KANDEL S., Vaidya S. "Physico-chemical study of pollutants in Bagmati River water" NAST (Nepal academy of science and technology) national conference on science and technology, Kathmandu, NP (Sept, 2012)

KANDEL S., Raptis R. "Mercury-pyrazolate chemistry for removal of mercury from nuclear waste" ACS national meeting New Orleans, LA (Mar, 2018)

KANDEL S., Raptis R. "Mercury-pyrazolate chemistry for removal of mercury from nuclear waste" SoFL-ACS awards banquet, Miami, FL (Apr, 2018) 
KANDEL S., Chakraborty I., Raptis R."Structural diversity and applications of mercury (II) complexes derived from substituted pyrazoles" ACS regional meeting (SERMACS), Augusta, GA (Nov, 2018)

KANDEL S., Stenger-Smith J., Chakraborty I., Raptis R Synthesis and X-ray crystal structures of a family of dinuclear silver (I)pyrazolates: Assessment of their antibacterial efficacy against P. aeruginosa with a soft tissue and skin infection model; Polyhedron 154 (2018) 390

KANDEL S., Chakraborty I., Raptis R. Synthesis and antimicrobial uses of dinuclear silver pyrazolates; USPTO 62/722,664 (August 24, 2018)

KANDEL S., Veerasamy S., Mathivathanan L., Morozov., Mebel A., Raptis R. Aggregation Induced Emission Enhancement (AIEE) of Tripodal Pyrazole Derivatives for Sensing for Nitroaromatics; Vapor Phase Detection of Picric Acid; New Journal of Chemistry (submitted in 1/10/2019) 